\title{
Bipolar disorder and cognitive functioning : a two-year naturalistic study
}

Citation for published version (APA):

Arts, B. (2012). Bipolar disorder and cognitive functioning : a two-year naturalistic study. [Doctoral Thesis, Maastricht University]. Datawyse / Universitaire Pers Maastricht. https://doi.org/10.26481/dis.20120511ba

Document status and date:

Published: 01/01/2012

DOI:

10.26481/dis.20120511ba

Document Version:

Publisher's PDF, also known as Version of record

\section{Please check the document version of this publication:}

- A submitted manuscript is the version of the article upon submission and before peer-review. There can be important differences between the submitted version and the official published version of record.

People interested in the research are advised to contact the author for the final version of the publication, or visit the DOI to the publisher's website.

- The final author version and the galley proof are versions of the publication after peer review.

- The final published version features the final layout of the paper including the volume, issue and page numbers.

Link to publication

\footnotetext{
General rights rights.

- You may freely distribute the URL identifying the publication in the public portal. please follow below link for the End User Agreement:

www.umlib.nl/taverne-license

Take down policy

If you believe that this document breaches copyright please contact us at:

repository@maastrichtuniversity.nl

providing details and we will investigate your claim.
}

Copyright and moral rights for the publications made accessible in the public portal are retained by the authors and/or other copyright owners and it is a condition of accessing publications that users recognise and abide by the legal requirements associated with these

- Users may download and print one copy of any publication from the public portal for the purpose of private study or research.

- You may not further distribute the material or use it for any profit-making activity or commercial gain

If the publication is distributed under the terms of Article $25 \mathrm{fa}$ of the Dutch Copyright Act, indicated by the "Taverne" license above, 


\section{Bipolar disorder and cognitive functioning:}

A two-year naturalistic study 
This study was supported in part by unrestricted grants from Astra Zeneca, The Netherlands, and Eli Lilly, The Netherlands

(c) Copyright Baer Arts, Wijnandsrade 2012

Cover Image / painting by Henk van der Heijden / photo by Alex Retz

ISBN 9789461591333

Production: Datawyse | Universitaire Pers Maastricht 


\title{
Bipolar disorder and cognitive functioning: A two-year naturalistic study
}

\author{
Proefschrift \\ ter verkrijging van de graad van doctor aan de Universiteit Maastricht \\ op gezag van de Rector Magnificus, Prof. Mr. G.P.M.F. Mols \\ volgens het besluit van het College van Decanen, \\ in het openbaar te verdedigen op vrijdag 11 mei 2012 om 12.00 uur \\ door \\ Bernardus Maria Gerardus Arts \\ Geboren op 25 oktober 1960 te Helmond
}

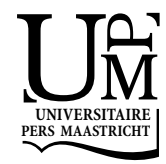




\section{Promotor}

Prof. dr. J. van Os

\section{Copromotor}

Prof. dr. L. Krabbendam (VU, Amsterdam)

\section{Beoordelingscommissie}

Prof. dr. I.Y.R. Myin-Germeys (voorzitter)

Prof. dr. R.W. Kupka (VU Medisch Centrum, Amsterdam)

Prof. dr. W.A. Nolen (Universitair Medisch Centrum Groningen)

Dr. F.P.M.L. Peeters

Prof. dr. R.W.H.M. Ponds 


\section{Contents}

$\begin{array}{lll}\text { Chapter } 1 & \text { Introduction } & 7\end{array}$

Chapter 2 Cognitive functioning in patients with schizophrenia and 21 bipolar disorder: a quantitative review

Chapter 3 Meta-analyses of cognitive functioning in euthymic bipolar patients and their first-degree relatives

Chapter 4 Investigating the association between neurocognition and psychosis in bipolar disorder: further evidence for the overlap with schizophrenia

Chapter 5 A 2-year naturalistic study on cognitive functioning in bipolar disorder

Chapter 6 Evidence for impact of CACNA1C risk allele rs1006737 on two-year cognitive functioning in bipolar disorder

Chapter 7 Antipsychotic medications and two-year cognitive functioning in bipolar disorder: evidence for moderating effects of COMT Val ${ }^{108 / 158}$ Met genotype

Chapter 8 Summary and Discussion

Samenvatting

Dankwoord 

Chapter 1

Introduction 
Manic-depressive illness, or bipolar disorder, is generally an episodic, lifelong mood disorder with a variable course and heterogeneous phenotype, including mania, hypomania, depression, mixed states and subclinical mood episodes.

In the Introduction of the second edition of their textbook on Manic-Depressive Illness, Goodwin and Jamison describe this illness as a medical condition that: '...magnifies common human experiences to larger-than-life proportions. Among its symptoms are exaggerations of normal sadness and joy, profoundly altered thinking, irritability and rage, psychosis and violence, and deeply disrupted patterns of energy and sleep. In its diverse forms, manic-depressive illness afflicts a large number of people...' and: '... genetics is central to the pathophysiology of the disease; and [that] manic-depressive illness is a spectrum of conditions and related temperaments.' (p.xix). ${ }^{1}$

Bipolar disorder, bipolar I disorder together with bipolar II disorder according to DSM-IV criteria, ${ }^{2}$ has a lifetime prevalence of $1-2 \%,{ }^{3-5}$ whereas the lifetime prevalence of the broader bipolar spectrum, including cyclothymia and subtreshold bipolar disorder, is about $4-5 \% .{ }^{5,6}$ The societal costs of this bipolar spectrum are high, ${ }^{7}$ because of unrecognized and inadequately treated bipolar patients, ${ }^{8,9}$ high rates of utilization of healthcare resources, ${ }^{10,11}$ and, most of all, high indirect costs because of absence from work. ${ }^{12-14}$ Furthermore, the disease burden is high, ${ }^{15,16}$ bipolar disorder being one of the world's 10 most disabling conditions ${ }^{17}$ with high comorbidity ${ }^{18-21}$ and mortality. ${ }^{22,23}$

Functional outcome in bipolar disorder is impaired in more than $60 \%$ of patients, mostly due to (subclinical) depressive symptoms occurring 30-50\% of time..$^{24,25}$ Obviously, this has an impact on the (subjective) quality of life of bipolar patients, ${ }^{26,27}$ which is markedly reduced and related to frequently reported subjective depressive symptoms. ${ }^{28,29}$

\section{Bipolar disorder and cognitive functioning}

Cognitive symptoms are included in the DSM-IV criteria for major depressive and manic episodes, highlighting the importance of cognition in bipolar disorder. ${ }^{2}$ Bipolar patients often have subjective cognitive complaints, ${ }^{30}$ which may ${ }^{31}$ or may be not $^{32}$ related to objective cognitive dysfunctioning, possibly depending on insight and awareness of subtreshold affective symptoms. Insight is impaired in bipolar patients in $40-60 \%$ of cases ${ }^{33,34}$ and related to mood symptoms, ${ }^{33,35}$ psychosis, ${ }^{36}$ disease characteristics ${ }^{34}$ and cognitive functioning. ${ }^{34-36}$ Lack of insight, as well as motivational problems, ${ }^{37}$ may play a mediating role between neurocognition and functional outcome leading to non-compliance. ${ }^{38,39}$ The latter is common in the management of bipolar disorder (40-60\%); ${ }^{40-42}$ and, amongst other factors, associated with cognitive side effects of medication ${ }^{43}$ and neurocognitive impairment. ${ }^{44}$ Neurocognitive impairment can play a role in suicide ${ }^{45,46}$ and interferes with treatment and rehabilitation of bipolar patients. ${ }^{47}$ Finally, functional outcome is negatively influ- 
enced by cognitive dysfunctions and subsyndromal depressive symptoms in bipolar patients, ${ }^{25,48}$ possibly explaining up to $40 \%$ of variance. ${ }^{49,50}$ Various cognitive functions may be related to functional outcome and social functioning, ${ }^{51}$ like verbal memory, ${ }^{52-54}$ attention, ${ }^{55,56}$ processing speed ${ }^{57,58}$ and executive functions. ${ }^{54,56}$ Particularly impairment of social cognition is of great importance in this respect, as is illustrated by deficits in theory of mind in bipolar patients, ${ }^{59}$ which may be related to cognitive dysfunctions and deficits in basic emotion recognition..$^{60,61}$

\section{Cognition in mania and depression}

Neurocognitive performance can be disrupted during acute episodes of both depression and mania. ${ }^{62-65}$ Cognitive impairment during acute mania is not well addressed, because of the practical difficulties of using standard neuropsychological tests. ${ }^{62}$ Mania is associated with distractibility and impulsivity ${ }^{66,67}$ and deficits in most of the cognitive domains, like attention, ${ }^{66,68,69}$ memory ${ }^{66,70,71}$ and executive functioning. ${ }^{71-74}$ In general, similar findings have been reported in bipolar depression for attention $^{68,75,76}$ and memory. ${ }^{71,77,78}$ Furthermore, depression may be associated with psychomotor slowing and deficits in effortful processing. ${ }^{76}$

More specific deficits are impaired facial affect recognition during manic states, ${ }^{79,80}$ with possibly a mood congruent negative bias for sad faces, ${ }^{81}$ and attention and response biases, in mania to positive stimuli and in depression towards negative stimuli. ${ }^{82-84}$ Mania may be associated with inability to focus attention and inhibit responses and depression with problems in shifting attention and exaggerated sensitivity to negative feedback. ${ }^{82,85}$ In this respect, specific mood challenging tests are required regarding decision making, problem solving and reward processing. ${ }^{67,85,86}$ This is illustrated by a recent study by Roiser and co-workers (2009), finding only differences between unmedicated depressed bipolar patients and controls on 'hot' tasks regarding reward processing and sensitivity to negative feedback, and no differences on conventional, 'cold' neuropsychological tests. ${ }^{85}$

Furthermore, beside the effect of the specific test and/or cognitive domain, ${ }^{87}$ other factors may influence the cognitive deficits observed during mood episodes. Number of episodes, ${ }^{71,77,88,89}$ psychosis $^{90-92}$ and medication ${ }^{52,93-95}$ are possible candidates in this respect.

Finally, a severe limitation of studies on cognitive functioning during mood episodes is that most findings are cross-sectional, making it difficult to control for clinical characteristics and to conclude whether deficits exist premorbidly, only during episodes, or reflect general cognitive decline. ${ }^{62}$ However, the literature on the longitudinal course of cognitive functioning in bipolar disorder is still sparse. ${ }^{96-98}$ 


\section{Cognition as an endophenotype}

More relevant than cognitive dysfunctions during the acute phases of bipolar illness, are persisting cognitive deficits in euthymic patients, occurring in approximately one third of remitted patients. ${ }^{65,89,99-102}$ The importance of residual and subclinical affective symptoms as a possible confounder in so called 'euthymic' patients, is illustrated in the study by Clark and co-workers. ${ }^{103}$ These authors reported persistent deficits in spatial working memory, set shifting and sustained attention in their cohort of euthymic patients. However, only the deficits in sustaining attention remained when residual affective symptoms were controlled for. ${ }^{103}$ In their review of the literature until 2002, Ferrier et al. ${ }^{101}$ concluded that only five studies adequately controlled for residual symptoms in euthymic bipolar patients. ${ }^{88,103-106}$ This can play a role, amongst other factors, in explaining the heterogeneous findings in the literature on cognitive functioning in bipolar disorder. ${ }^{87,107}$

Thus, cognitive dysfunction in patients with bipolar disorder could be a core and enduring deficit of the illness and in part reflect the expression of genetic risk for this disorder as an intermediate phenotype or endophenotype. ${ }^{108-111}$ Bipolar disorder is strongly influenced by (multiple) genetic factors, with high heritability between $60-90 \%,{ }^{112-114}$ aggregation in families with an eight times increased risk in firstdegree relatives ${ }^{115}$ and a much higher concordance rate in monozygotic twins compared to dizygotic twins (concordance $40-70 \%$ vs $4-9 \%$ ). ${ }^{116}$ An endophenotype is conceptualized as an indicator of biological processes mediating between genotype and (heterogeneous) phenotype; a trait or marker that 1) is associated with the illness in the population; 2) is heritable; 3) is primarily state-independent; 4) cosegregates with the illness in families; and 5) is found in nonaffected family members at a higher rate than in the general population. ${ }^{117}$ Neuropsychological functions are significantly influenced by genetic factors with variable heritability for distinct domains, as illustrated for general intelligence (50-80\%), processing speed (25-80\%) and working memory (30-60\%). ${ }^{109,110}$ Evidence for an association between cognitive dysfunction and genetic liability in healthy twins discordant for bipolar disorder, ${ }^{118}$ presence of premorbid cognitive alterations in at risk populations, ${ }^{119-121}$ cognitive alterations in bipolar children, independent of mood and medication ${ }^{122}$ and impaired neurocognitive functioning in first-degree relatives ${ }^{123,124}$ further support this hypothesis. The issue of co-segregation of cognitive performance and the illness in families (point 4) is unresolved, because cognitive dysfunction may only be present in a particular subtype of the illness. ${ }^{110}$ The latter is illustrated by the study of Thompson et al. (2005) demonstrating that the proportion of bipolar patients with cognitive impairment varied from approximately 15 to $25 \%$ depending on the neuropsychological task involved. ${ }^{87}$

Nevertheless, executive functions, declarative memory and processing speed may be candidate neurocognitive intermediate phenotypes for bipolar disorder. ${ }^{109,110,125}$ 


\section{Overlap with schizophrenia}

Cognitive dysfunction is a core feature of schizophrenia and may be an intermediate phenotype for the genetic risk of this disorder. ${ }^{126,127}$ This is illustrated by stable cognitive deficits in schizophrenic patients ${ }^{128-130}$ and first-episode psychotic patients, ${ }^{131-133}$ like in people at risk for the disorder ${ }^{134,135}$ and in unaffected first-degree relatives. ${ }^{126,136,137}$

There is no consensus whether cognitive deficits in bipolar disorder are qualitatively different from deficits in schizophrenic patients ${ }^{138}$ or if there exist only quantitative differences in cognitive functioning between these disorders. ${ }^{139-143}$ Overlap in cognitive impairment would be in line with the idea of a continuum from bipolar disorder to schizoaffective psychosis up to schizophrenia; a dimensional view considering symptoms as non-specific to disease categories. ${ }^{144}$ Murray et al. (2004) suggest that bipolar disorder and schizophrenia share, amongst other factors, susceptibility genes that give rise to overlapping psychotic, mood and cognitive symptoms in both diseases. ${ }^{145}$ Furthermore, familial co-aggregation of schizophrenia and bipolar disorder ${ }^{146,147}$ and increasing evidence supporting overlap in genetic susceptibility $^{148-150}$ support this hypothesis.

\section{Aims and outline of this thesis}

The two main goals of this thesis are 1) to explore the endophenotype concept of cognitive functioning in bipolar disorder by comparing bipolar patients with firstdegree relatives and schizophrenic patients, and 2) to investigate which environmental and genetic factors may play a role in cognitive function in bipolar disorder.

In the first part, the possible role of cognitive functioning as a genetic vulnerability marker for both schizophrenia and bipolar disorder is evaluated in a metaanalysis of studies comparing cognitive functioning in schizophrenic and bipolar patients (Chapter 2). Our hypothesis is that there exist only quantitative differences in cognitive functioning between these disorders.

In Chapter 3, a meta-analysis of studies investigating neurocognition in euthymic bipolar patients and their first-degree relatives is presented. Further, the role of psychosis in neurocognition is explored in bipolar patients and their unaffected relatives in Chapter 4, testing the hypothesis that there exists overlap with schizophrenia.

In the second part of this thesis, the results of a longitudinal, 2-year naturalistic study on cognitive functioning in a cohort of bipolar patients are described. The differential effects of mood and medication, amongst other factors, are explored in Chapter 5. In Chapter 6, the association between cognitive functioning and the CACNA1C risk allele (rs10067370) is described in bipolar patients. Finally, Chapter 7 presents data on the effects of the interaction between the COMT Val ${ }^{108 / 158} \mathrm{Met}$ 
polymorphism and use of antipsychotic drugs on cognitive functioning, indicating the importance of gene-environment interactions. 


\section{References}

1. Goodwin FK, Jamison, K.R. Manic-Depressive Illness. Second edition edn. Oxford University Press: Oxford, 2007.

2. APA. Diagnostic and Statistical Manual of Mental Disorders, Fourth Edition: Washington, DC, 1994.

3. Bijl RV, Ravelli A, van Zessen G. Prevalence of psychiatric disorder in the general population: results of The Netherlands Mental Health Survey and Incidence Study (NEMESIS). Soc Psychiatry Psychiatr Epidemiol 1998; 33(12): 587-595.

4. ten Have M, Vollebergh W, Bijl R, Nolen WA. Bipolar disorder in the general population in The Netherlands (prevalence, consequences and care utilisation): results from The Netherlands Mental Health Survey and Incidence Study (NEMESIS). J Affect Disord 2002; 68(2-3): 203-213.

5. Regeer EJ, Ten Have M, Rosso ML, Hakkaart-Van Roijen L, Vollebergh W, Nolen WA. Prevalence of bipolar disorder in the general population: a Reappraisal Study of the Netherlands Mental Health Survey and Incidence Study. Acta Psychiatr Scand 2004; 110(5): 374-382.

6. Merikangas KR, Akiskal HS, Angst J, Greenberg PE, Hirschfeld RM, Petukhova M et al. Lifetime and 12-month prevalence of bipolar spectrum disorder in the national comorbidity survey replication. Arch Gen Psychiatry 2007; 64(5): 543-552.

7. Kleinman L, Lowin A, Flood E, Gandhi G, Edgell E, Revicki D. Costs of bipolar disorder. PharmacoEconomics 2003; 21(9): 601-622.

8. Keck PE, Jr., Kessler RC, Ross R. Clinical and economic effects of unrecognized or inadequately treated bipolar disorder. J Psychiatr Pract 2008; 14 Suppl 2: 31-38.

9. Birnbaum HG, Shi L, Dial E, Oster EF, Greenberg PE, Mallett DA. Economic consequences of not recognizing bipolar disorder patients: a cross-sectional descriptive analysis. J Clin Psychiatry 2003; 64(10): 1201-1209.

10. Hirschfeld RM, Vornik LA. Bipolar disorder--costs and comorbidity. The American journal of managed care 2005; 11 (3 Suppl): S85-90.

11. Gonzalez-Pinto AM, Dardennes R, de Zelicourt M, Lopez P, Oliveros RG, Vieta E et al. In-patient care costs of patients with bipolar I disorder: a comparison between two European centers. J Affect Disord 2010; 121(1-2): 152-155.

12. Hakkaart-Van Roijen L, Hoeijenbos MB, Regeer EJ, Ten Have M, Nolen WA, Veraart CP et al. The societal costs and quality of life of patients suffering from bipolar disorder in the Netherlands. Acta Psychiatr Scand 2004; 110(5): 383-392.

13. Gardner HH, Kleinman NL, Brook RA, Rajagopalan K, Brizee TJ, Smeeding JE. The economic impact of bipolar disorder in an employed population from an employer perspective. J Clin Psychiatry 2006; 67(8): 1209-1218.

14. Laxman KE, Lovibond KS, Hassan MK. Impact of bipolar disorder in employed populations. The American journal of managed care 2008; 14(11): 757-764.

15. Sajatovic M. Bipolar disorder: disease burden. The American journal of managed care $2005 ; 11(3$ Suppl): S80-84.

16. Kupfer DJ. The increasing medical burden in bipolar disorder. Jama 2005; 293(20): 2528-2530.

17. Murray CJL, Lopez, A.D. eds. The global burden of disease: A comprehensive assessment of mortality and diability from disease, injuries, and risk factors in 1990 and projected to 2020. Harvard University Press: Cambridge, Mass, 1996.

18. McIntyre RS, Nguyen HT, Soczynska JK, Lourenco MT, Woldeyohannes HO, Konarski JZ. Medical and substance-related comorbidity in bipolar disorder: translational research and treatment opportunities. Dialogues Clin Neurosci 2008; 10(2): 203-213.

19. Fagiolini A, Chengappa KN, Soreca I, Chang J. Bipolar disorder and the metabolic syndrome: causal factors, psychiatric outcomes and economic burden. CNS Drugs 2008; 22(8): 655-669.

20. Soreca I, Frank E, Kupfer DJ. The phenomenology of bipolar disorder: what drives the high rate of medical burden and determines long-term prognosis? Depress Anxiety 2009; 26(1): 73-82. 
21. Perron BE, Howard MO, Nienhuis JK, Bauer MS, Woodward AT, Kilbourne AM. Prevalence and burden of general medical conditions among adults with bipolar I disorder: results from the National Epidemiologic Survey on Alcohol and Related Conditions. J Clin Psychiatry 2009; 70(10): 1407-1415.

22. McIntyre RS, Muzina DJ, Kemp DE, Blank D, Woldeyohannes HO, Lofchy J et al. Bipolar disorder and suicide: research synthesis and clinical translation. Curr Psychiatry Rep 2008; 10(1): 66-72.

23. Roshanaei-Moghaddam B, Katon W. Premature mortality from general medical illnesses among persons with bipolar disorder: a review. Psychiatr Serv 2009; 60(2): 147-156.

24. Huxley N, Baldessarini RJ. Disability and its treatment in bipolar disorder patients. Bipolar Disord 2007; 9(1-2): 183-196.

25. Sanchez-Moreno J, Martinez-Aran A, Tabares-Seisdedos R, Torrent C, Vieta E, Ayuso-Mateos JL. Functioning and disability in bipolar disorder: an extensive review. Psychother Psychosom 2009; 78(5): 285-297.

26. Dean BB, Gerner D, Gerner RH. A systematic review evaluating health-related quality of life, work impairment, and healthcare costs and utilization in bipolar disorder. Current medical research and opinion 2004; 20(2): 139-154.

27. Michalak EE, Yatham LN, Lam RW. Quality of life in bipolar disorder: a review of the literature. Health and quality of life outcomes 2005; 3: 72.

28. Bauer M, Glenn T, Grof P, Pfennig A, Rasgon NL, Marsh W et al. Self-reported data from patients with bipolar disorder: frequency of brief depression. J Affect Disord 2007; 101(1-3): 227-233.

29. Michalak EE, Murray G, Young AH, Lam RW. Burden of bipolar depression: impact of disorder and medications on quality of life. CNS Drugs 2008; 22(5): 389-406.

30. Keitner GI, Solomon DA, Ryan CE, Miller IW, Mallinger A, Kupfer DJ et al. Prodromal and residual symptoms in bipolar I disorder. Compr Psychiatry 1996; 37(5): 362-367.

31. Martinez-Aran A, Vieta E, Colom F, Torrent C, Reinares M, Goikolea JM et al. Do Cognitive Complaints in Euthymic Bipolar Patients Reflect Objective Cognitive Impairment? Psychother Psychosom 2005; 74(5): 295-302.

32. Burdick KE, Endick CJ, Goldberg JF. Assessing cognitive deficits in bipolar disorder: Are selfreports valid? Psychiatry Res 2005; 136(1): 43-50.

33. Varga M, Magnusson A, Flekkoy K, Ronneberg U, Opjordsmoen S. Insight, symptoms and neurocognition in bipolar I patients. J Affect Disord 2006; 91(1): 1-9.

34. Dias VV, Brissos S, Carita AI. Clinical and neurocognitive correlates of insight in patients with bipolar I disorder in remission. Acta Psychiatr Scand 2008; 117(1): 28-34.

35. Adida M, Clark L, Pomietto P, Kaladjian A, Besnier N, Azorin JM et al. Lack of insight may predict impaired decision making in manic patients. Bipolar Disord 2008; 10(7): 829-837.

36. Aleman A, Agrawal N, Morgan KD, David AS. Insight in psychosis and neuropsychological function: meta-analysis. Br J Psychiatry 2006; 189: 204-212.

37. Gard DE, Fisher M, Garrett C, Genevsky A, Vinogradov S. Motivation and its relationship to neurocognition, social cognition, and functional outcome in schizophrenia. Schizophr Res 2009; 115(1): 74-81.

38. Rosa AR, Marco M, Fachel JM, Kapczinski F, Stein AT, Barros HM. Correlation between drug treatment adherence and lithium treatment attitudes and knowledge by bipolar patients. Prog Neuropsychopharmacol Biol Psychiatry 2007; 31(1): 217-224.

39. Pompili M, Serafini G, Del Casale A, Rigucci S, Innamorati M, Girardi P et al. Improving adherence in mood disorders: the struggle against relapse, recurrence and suicide risk. Expert Rev Neurother 2009; 9(7): 985-1004.

40. Keck PE, Jr., McElroy SL, Strakowski SM, Bourne ML, West SA. Compliance with maintenance treatment in bipolar disorder. Psychopharmacol Bull 1997; 33(1): 87-91.

41. Colom F, Vieta E, Martinez-Aran A, Reinares M, Benabarre A, Gasto C. Clinical factors associated with treatment noncompliance in euthymic bipolar patients. J Clin Psychiatry 2000; 61(8): 549-555.

42. Byrne N, Regan C, Livingston G. Adherence to treatment in mood disorders. Curr Opin Psychiatry 2006; 19(1): 44-49. 
43. Gitlin MJ, Cochran SD, Jamison KR. Maintenance lithium treatment: side effects and compliance. J Clin Psychiatry 1989; 50(4): 127-131.

44. Martinez-Aran A, Scott J, Colom F, Torrent C, Tabares-Seisdedos R, Daban C et al. Treatment nonadherence and neurocognitive impairment in bipolar disorder. J Clin Psychiatry 2009; 70(7): 1017-1023.

45. Marzuk PM, Hartwell N, Leon AC, Portera L. Executive functioning in depressed patients with suicidal ideation. Acta Psychiatr Scand 2005; 112(4): 294-301.

46. Green MJ, Cahill CM, Malhi GS. The cognitive and neurophysiological basis of emotion dysregulation in bipolar disorder. J Affect Disord 2007.

47. Deckersbach T, Ametrano, R.M., Carlson, L.E., Lund, H.G., Sachs, G.S., Nierenberg, A.A. Cognitive rehabilitation for bipolar disorder: preliminary results and predictors of treatment response. Bipolar Disord 2009; 11 (Suppl. 1): 32-33.

48. Mur M, Portella MJ, Martinez-Aran A, Pifarre J, Vieta E. Influence of clinical and neuropsychological variables on the psychosocial and occupational outcome of remitted bipolar patients. Psychopathology 2009; 42(3): 148-156.

49. Martino DJ, Marengo E, Igoa A, Scapola M, Ais ED, Perinot L et al. Neurocognitive and symptomatic predictors of functional outcome in bipolar disorders: A prospective 1 year follow-up study. $J$ Affect Disord 2009; 116(1-2): 37-42.

50. Bonnin CM, Martinez-Aran A, Torrent C, Pacchiarotti I, Rosa AR, Franco C et al. Clinical and neurocognitive predictors of functional outcome in bipolar euthymic patients: a long-term, followup study. J Affect Disord 2010; 121(1-2): 156-160.

51. Wingo AP, Harvey PD, Baldessarini RJ. Neurocognitive impairment in bipolar disorder patients: functional implications. Bipolar Disord 2009; 11(2): 113-125.

52. Martinez-Aran A, Vieta E, Colom F, Torrent C, Sanchez-Moreno J, Reinares M et al. Cognitive impairment in euthymic bipolar patients: implications for clinical and functional outcome. Bipolar Disord 2004; 6(3): 224-232.

53. Dickerson FB, Boronow JJ, Stallings CR, Origoni AE, Cole S, Yolken RH. Association between cognitive functioning and employment status of persons with bipolar disorder. Psychiatr Serv 2004; 55(1): 54-58.

54. Altshuler LL, Bearden CE, Green MF, van Gorp W, Mintz J. A relationship between neurocognitive impairment and functional impairment in bipolar disorder: A pilot study. Psychiatry Res 2008; 157(1-3): 289-293.

55. Kaya E, Aydemir O, Selcuki D. Residual symptoms in bipolar disorder: the effect of the last episode after remission. Prog Neuropsychopharmacol Biol Psychiatry 2007; 31(7): 1387-1392.

56. Jaeger J, Berns S, Loftus S, Gonzalez C, Czobor P. Neurocognitive test performance predicts functional recovery from acute exacerbation leading to hospitalization in bipolar disorder. Bipolar Disord 2007; 9(1-2): 93-102.

57. Gildengers AG, Butters MA, Chisholm D, Rogers JC, Holm MB, Bhalla RK et al. Cognitive functioning and instrumental activities of daily living in late-life bipolar disorder. Am J Geriatr Psychiatry 2007; 15(2): 174-179.

58. Dickerson F, Origoni A, Stallings C, Khushalani S, Dickinson D, Medoff D. Occupational status and social adjustment six months after hospitalization early in the course of bipolar disorder: a prospective study. Bipolar Disord 2010; 12(1): 10-20.

59. Bora E, Yucel M, Pantelis C. Theory of mind impairment: a distinct trait-marker for schizophrenia spectrum disorders and bipolar disorder? Acta Psychiatr Scand 2009; 120(4): 253-264.

60. Bora E, Vahip S, Gonul AS, Akdeniz F, Alkan M, Ogut M et al. Evidence for theory of mind deficits in euthymic patients with bipolar disorder. Acta Psychiatr Scand 2005; 112(2): 110-116.

61. Lahera G, Montes JM, Benito A, Valdivia M, Medina E, Mirapeix I et al. Theory of mind deficit in bipolar disorder: Is it related to aprevious history of psychotic symptoms? Psychiatry Res 2008; 161(3): 309-317.

62. Murphy FC, Sahakian BJ. Neuropsychology of bipolar disorder. Br J Psychiatry Suppl 2001; 41: s120-127. 
63. Tavares JV, Drevets WC, Sahakian BJ. Cognition in mania and depression. Psychol Med 2003; 33(6): 959-967.

64. Chamberlain SR, Sahakian BJ. Cognition in mania and depression: psychological models and clinical implications. Curr Psychiatry Rep 2004; 6(6): 451-458.

65. Martinez-Aran A, Vieta E, Colom F, Reinares M, Benabarre A, Gasto C et al. Cognitive dysfunctions in bipolar disorder: evidence of neuropsychological disturbances. Psychother Psychosom 2000; 69(1): $2-18$.

66. Clark L, Iversen SD, Goodwin GM. A neuropsychological investigation of prefrontal cortex involvement in acute mania. Am J Psychiatry 2001; 158(10): 1605-1611.

67. Strakowski SM, Fleck DE, DelBello MP, Adler CM, Shear PK, McElroy SL et al. Characterizing impulsivity in mania. Bipolar Disord 2009; 11(1): 41-51.

68. Najt P, Glahn D, Bearden CE, Hatch JP, Monkul ES, Kaur S et al. Attention deficits in bipolar disorder: a comparison based on the Continuous Performance Test. Neurosci Lett 2005; 379(2): 122-126.

69. Sweeney JA, Kmiec JA, Kupfer DJ. Neuropsychologic impairments in bipolar and unipolar mood disorders on the CANTAB neurocognitive battery. Biol Psychiatry 2000; 48(7): 674-684.

70. Fleck DE, Shear PK, Zimmerman ME, Getz GE, Corey KB, Jak A et al. Verbal memory in mania: effects of clinical state and task requirements. Bipolar Disord 2003; 5(5): 375-380.

71. Martinez-Aran A, Vieta E, Reinares M, Colom F, Torrent C, Sanchez-Moreno J et al. Cognitive function across manic or hypomanic, depressed, and euthymic states in bipolar disorder. Am J Psychiatry 2004; 161(2): 262-270.

72. Murphy FC, Rubinsztein JS, Michael A, Rogers RD, Robbins TW, Paykel ES et al. Decision-making cognition in mania and depression. Psychol Med 2001; 31(4): 679-693.

73. Dixon T, Kravariti, E., Frith, C., Murray, R.M., McGuire, P.K. Effect of symptoms on executive function in bipolar illness. Psychol Med 2004; 34: 811-821.

74. Fleck DE, Shear PK, Madore M, Strakowski SM. Wisconsin Card Sorting Test performance in bipolar disorder: effects of mood state and early course. Bipolar Disord 2008; 10(4): 539-545.

75. Cohen R, Lohr I, Paul R, Boland R. Impairments of attention and effort among patients with major affective disorders. J Neuropsychiatry Clin Neurosci 2001; 13(3): 385-395.

76. Burdick KE, Gunawardane N, Goldberg JF, Halperin JM, Garno JL, Malhotra AK. Attention and psychomotor functioning in bipolar depression. Psychiatry Res 2009; 166(2-3): 192-200.

77. Fossati P, Harvey PO, Le Bastard G, Ergis AM, Jouvent R, Allilaire JF. Verbal memory performance of patients with a first depressive episode and patients with unipolar and bipolar recurrent depression. J Psychiatr Res 2004; 38(2): 137-144.

78. Bearden CE, Glahn DC, Monkul ES, Barrett J, Najt P, Villarreal V et al. Patterns of memory impairment in bipolar disorder and unipolar major depression. Psychiatry Res 2006; 142(2-3): 139150.

79. Lembke A, Ketter TA. Impaired recognition of facial emotion in mania. Am J Psychiatry 2002; 159(2): 302-304.

80. Getz GE, Shear PK, Strakowski SM. Facial affect recognition deficits in bipolar disorder. J Int Neuropsychol Soc 2003; 9(4): 623-632.

81. Lennox BR, Jacob, R., Calder, A.J., Lupson, V., Bullmore, E.T. Behavioural and neurocognitive responses to sad facial affect are attenuated in patients with mania. Psychological Medicine 2004; 34 : 795-802.

82. Murphy FC, Sahakian BJ, Rubinsztein JS, Michael A, Rogers RD, Robbins TW et al. Emotional bias and inhibitory control processes in mania and depression. Psychol Med 1999; 29(6): 1307-1321.

83. Gray J, Venn H, Montagne B, Murray L, Burt M, Frigerio E et al. Bipolar patients show moodcongruent biases in sensitivity to facial expressions of emotion when exhibiting depressed symptoms, but not when exhibiting manic symptoms. Cognit Neuropsychiatry 2006; 11(6): 505-520.

84. Murphy FC, Michael A, Robbins TW, Sahakian BJ. Neuropsychological impairment in patients with major depressive disorder: the effects of feedback on task performance. Psychol Med 2003; 33(3): 455-467.

85. Roiser JP, Cannon DM, Gandhi SK, Taylor Tavares J, Erickson K, Wood S et al. Hot and cold cognition in unmedicated depressed subjects with bipolar disorder. Bipolar Disord 2009; 11(2): 178-189. 
86. Rubinsztein JS, Fletcher PC, Rogers RD, Ho LW, Aigbirhio FI, Paykel ES et al. Decision-making in mania: a PET study. Brain 2001; 124(Pt 12): 2550-2563.

87. Thompson JM, Gallagher P, Hughes JH, Watson S, Gray JM, Ferrier IN et al. Neurocognitive impairment in euthymic patients with bipolar affective disorder. Br J Psychiatry 2005; 186: 32-40.

88. Rubinsztein JS, Michael A, Paykel ES, Sahakian BJ. Cognitive impairment in remission in bipolar affective disorder. Psychol Med 2000; 30(5): 1025-1036.

89. Robinson LJ, Ferrier IN. Evolution of cognitive impairment in bipolar disorder: a systematic review of cross-sectional evidence. Bipolar Disord 2006; 8(2): 103-116.

90. Glahn DC, Bearden CE, Barguil M, Barrett J, Reichenberg A, Bowden CL et al. The Neurocognitive Signature of Psychotic Bipolar Disorder. Biol Psychiatry 2007.

91. Martinez-Aran A, Torrent C, Tabares-Seisdedos R, Salamero M, Daban C, Balanza-Martinez V et al. Neurocognitive impairment in bipolar patients with and without history of psychosis. J Clin Psychiatry 2008; 69(2): 233-239.

92. Savitz J, van der Merwe L, Stein DJ, Solms M, Ramesar R. Neuropsychological status of bipolar I disorder: impact of psychosis. Br J Psychiatry 2009; 194(3): 243-251.

93. Holmes MK, Erickson K, Luckenbaugh DA, Drevets WC, Bain EE, Cannon DM et al. A comparison of cognitive functioning in medicated and unmedicated subjects with bipolar depression. Bipolar Disord 2008; 10(7): 806-815.

94. Goswami U, Sharma A, Varma A, Gulrajani C, Ferrier IN, Young AH et al. The neurocognitive performance of drug-free and medicated euthymic bipolar patients do not differ. Acta Psychiatr Scand 2009; 120(6): 456-463.

95. Goldberg JF, Chengappa KN. Identifying and treating cognitive impairment in bipolar disorder. Bipolar Disord 2009; 11 Suppl 2: 123-137.

96. Engelsmann F, Katz J, Ghadirian AM, Schachter D. Lithium and memory: a long-term follow-up study. J Clin Psychopharmacol 1988; 8(3): 207-212.

97. Balanza-Martinez V, Tabares-Seisdebos, R., Selva-Vera, G., Martinez-Aran, A., Torrent, C., SalazarFraile, J., Leal-Cerbos, C., Vieta, E., Gomez-Beneyto, M. Persistent Cognitive Dysfunctions in Bipolar I Disorder and Schizophrenic Patients: A 3-Year Follow-Up Study. Psychotherapy and Psychosomatics 2005; 74: 113-119.

98. Mur M, Portella MJ, Martinez-Aran A, Pifarre J, Vieta E. Long-Term Stability of Cognitive Impairment in Bipolar Disorder: A 2-Year Follow-Up Study of Lithium-Treated Euthymic Bipolar Patients. J Clin Psychiatry 2008: e1-e8.

99. Bearden CE, Hoffman KM, Cannon TD. The neuropsychology and neuroanatomy of bipolar affective disorder: a critical review. Bipolar Disord 2001; 3(3): 106-150; discussion 151-103.

100. Quraishi S, Frangou S. Neuropsychology of bipolar disorder: a review. J Affect Disord 2002; 72(3): 209-226.

101. Ferrier IN, Thompson JM. Cognitive impairment in bipolar affective disorder: implications for the bipolar diathesis. Br J Psychiatry 2002; 180: 293-295.

102. Robinson LJ, Thompson JM, Gallagher P, Goswami U, Young AH, Ferrier IN et al. A meta-analysis of cognitive deficits in euthymic patients with bipolar disorder. J Affect Disord 2006; 93(1-3): 105115.

103. Clark L, Iversen SD, Goodwin GM. Sustained attention deficit in bipolar disorder. Br J Psychiatry 2002; 180: 313-319.

104. Ferrier IN, Stanton BR, Kelly TP, Scott J. Neuropsychological function in euthymic patients with bipolar disorder. Br J Psychiatry 1999; 175: 246-251.

105. Thompson JM, Gray, J.M., Wilkinson, B. S. Impaired working memory monitoring on the SelfOrdered Pointing Task in euthymic bipolar patients. Bipolar Disord 2001; 15: A67.

106. Thompson JM, Ferrier, I.N., Hughes, J.H. Neuropsychological function in a cohort of bipolar patients prospectively verified as euthymic. Acta Psychiatr Scand 2000; 12(3): 170.

107. Martino DJ, Strejilevich SA, Scapola M, Igoa A, Marengo E, Ais ED et al. Heterogeneity in cognitive functioning among patients with bipolar disorder. J Affect Disord 2008; 109(1-2): 149-156.

108. Lenox RH, Gould TD, Manji HK. Endophenotypes in bipolar disorder. Am J Med Genet 2002; 114(4): 391-406. 
109. Glahn DC, Bearden CE, Niendam TA, Escamilla MA. The feasibility of neuropsychological endophenotypes in the search for genes associated with bipolar affective disorder. Bipolar Disord 2004; 6(3): 171-182.

110. Savitz JB, Solms M, Ramesar RS. Neurocognitive function as an endophenotype for genetic studies of bipolar affective disorder. Neuromolecular Med 2005; 7(4): 275-286.

111. Hasler G, Drevets WC, Gould TD, Gottesman, II, Manji HK. Toward constructing an endophenotype strategy for bipolar disorders. Biol Psychiatry 2006; 60(2): 93-105.

112. Edvardsen J, Torgersen S, Roysamb E, Lygren S, Skre I, Onstad S et al. Heritability of bipolar spectrum disorders. Unity or heterogeneity? J Affect Disord 2008; 106(3): 229-240.

113. Barnett JH, Smoller JW. The genetics of bipolar disorder. Neuroscience 2009.

114. Craddock N, Sklar P. Genetics of bipolar disorder: successful start to a long journey. Trends Genet 2009.

115. Craddock N, Jones I. Molecular genetics of bipolar disorder. Br J Psychiatry Suppl 2001; 41: s128133.

116. Smoller JW, Finn CT. Family, twin, and adoption studies of bipolar disorder. American journal of medical genetics 2003; 123C(1): 48-58.

117. Gottesman, II, Gould TD. The endophenotype concept in psychiatry: etymology and strategic intentions. Am J Psychiatry 2003; 160(4): 636-645.

118. Christensen MV, Kyvik KO, Kessing LV. Cognitive function in unaffected twins discordant for affective disorder. Psychol Med 2006; 36(8): 1119-1129.

119. Meyer SE, Carlson GA, Wiggs EA, Martinez PE, Ronsaville DS, Klimes-Dougan B et al. A prospective study of the association among impaired executive functioning, childhood attentional problems, and the development of bipolar disorder. Dev Psychopathol 2004; 16(2): 461-476.

120. Tiihonen J, Haukka J, Henriksson M, Cannon M, Kieseppa T, Laaksonen I et al. Premorbid intellectual functioning in bipolar disorder and schizophrenia: results from a cohort study of male conscripts. Am J Psychiatry 2005; 162(10): 1904-1910.

121. Klimes-Dougan B, Ronsaville D, Wiggs EA, Martinez PE. Neuropsychological functioning in adolescent children of mothers with a history of bipolar or major depressive disorders. Biol Psychiatry 2006; 60(9): 957-965.

122. Pavuluri MN, Schenkel LS, Aryal S, Harral EM, Hill SK, Herbener ES et al. Neurocognitive function in unmedicated manic and medicated euthymic pediatric bipolar patients. Am J Psychiatry 2006; 163(2): 286-293.

123. Gourovitch ML, Torrey EF, Gold JM, Randolph C, Weinberger DR, Goldberg TE. Neuropsychological performance of monozygotic twins discordant for bipolar disorder. Biol Psychiatry 1999; 45(5): 639-646.

124. Ferrier IN, Chowdhury R, Thompson JM, Watson S, Young AH. Neurocognitive function in unaffected first-degree relatives of patients with bipolar disorder: a preliminary report. Bipolar Disord 2004; 6(4): 319-322.

125. Antila M, Tuulio-Henriksson A, Kieseppa T, Soronen P, Palo OM, Paunio T et al. Heritability of cognitive functions in families with bipolar disorder. Am J Med Genet B Neuropsychiatr Genet 2007; 144B(6): 802-808.

126. Gur RE, Nimgaonkar VL, Almasy L, Calkins ME, Ragland JD, Pogue-Geile MF et al. Neurocognitive endophenotypes in a multiplex multigenerational family study of schizophrenia. Am J Psychiatry 2007; 164(5): 813-819.

127. Szoke A, Trandafir A, Dupont ME, Meary A, Schurhoff F, Leboyer M. Longitudinal studies of cognition in schizophrenia: meta-analysis. Br J Psychiatry 2008; 192: 248-257.

128. Heinrichs RW, Zakzanis KK. Neurocognitive deficit in schizophrenia: a quantitative review of the evidence. Neuropsychology 1998; 12(3): 426-445.

129. Keefe RS, Eesley CE, Poe MP. Defining a cognitive function decrement in schizophrenia. Biol Psychiatry 2005; 57(6): 688-691.

130. Burdick KE, Goldberg JF, Harrow M, Faull RN, Malhotra AK. Neurocognition as a stable endophenotype in bipolar disorder and schizophrenia. J Nerv Ment Dis 2006; 194(4): 255-260. 
131. Frangou S, Hadjulis M, Vourdas A. The maudsley early onset schizophrenia study: cognitive function over a 4-year follow-up period. Schizophr Bull 2008; 34(1): 52-59.

132. Kravariti E, Morgan K, Fearon P, Zanelli JW, Lappin JM, Dazzan P et al. Neuropsychological functioning in first-episode schizophrenia. Br J Psychiatry 2009; 195(4): 336-345.

133. Mesholam-Gately RI, Giuliano AJ, Goff KP, Faraone SV, Seidman LJ. Neurocognition in firstepisode schizophrenia: a meta-analytic review. Neuropsychology 2009; 23(3): 315-336.

134. Voglmaier MM, Seidman LJ, Salisbury D, McCarley RW. Neuropsychological dysfunction in schizotypal personality disorder: a profile analysis. Biol Psychiatry 1997; 41(5): 530-540.

135. Voglmaier MM, Seidman LJ, Niznikiewicz MA, Dickey CC, Shenton ME, McCarley RW. A comparative profile analysis of neuropsychological function in men and women with schizotypal personality disorder. Schizophr Res 2005; 74(1): 43-49.

136. Sitskoorn MM, Aleman A, Ebisch SJ, Appels MC, Kahn RS. Cognitive deficits in relatives of patients with schizophrenia: a meta-analysis. Schizophr Res 2004; 71(2-3): 285-295.

137. Snitz BE, Macdonald AW, 3rd, Carter CS. Cognitive deficits in unaffected first-degree relatives of schizophrenia patients: a meta-analytic review of putative endophenotypes. Schizophr Bull 2006; 32(1): 179-194.

138. Goldberg TE. Some fairly obvious distinctions between schizophrenia and bipolar disorder. Schizophr Res 1999; 39(2): 127-132; discussion 161-122.

139. Zihl J, Gron G, Brunnauer A. Cognitive deficits in schizophrenia and affective disorders: evidence for a final common pathway disorder. Acta Psychiatr Scand 1998; 97(5): 351-357.

140. Rossi A, Arduini L, Daneluzzo E, Bustini M, Prosperini P, Stratta P. Cognitive function in euthymic bipolar patients, stabilized schizophrenic patients, and healthy controls. J Psychiatr Res 2000; 34(45): 333-339.

141. Krabbendam L, Honig A, Wiersma J, Vuurman EF, Hofman PA, Derix MM et al. Cognitive dysfunctions and white matter lesions in patients with bipolar disorder in remission. Acta Psychiatr Scand 2000; 101(4): 274-280.

142. Dickerson FB, Sommerville J, Origoni AE, Ringel NB, Parente F. Outpatients with schizophrenia and bipolar I disorder: Do they differ in their cognitive and social functioning? Psychiatry Res 2001; 102(1): 21-27.

143. Martinez-Aran A, Penades R, Vieta E, Colom F, Reinares M, Benabarre A et al. Executive function in patients with remitted bipolar disorder and schizophrenia and its relationship with functional outcome. Psychother Psychosom 2002; 71(1): 39-46.

144. Crow TJ. The continuum of psychosis and its genetic origins. The sixty-fifth Maudsley lecture. $\mathrm{Br} J$ Psychiatry 1990; 156: 788-797.

145. Murray RM, Sham P, Van Os J, Zanelli J, Cannon M, McDonald C. A developmental model for similarities and dissimilarities between schizophrenia and bipolar disorder. Schizophr Res 2004; 71(2-3): 405-416.

146. Cardno AG, Rijsdijk FV, Sham PC, Murray RM, McGuffin P. A twin study of genetic relationships between psychotic symptoms. Am J Psychiatry 2002; 159(4): 539-545.

147. Berrettini W. Evidence for shared susceptibility in bipolar disorder and schizophrenia. Am J Med Genet 2003; 123C(1): 59-64.

148. Moskvina V, Craddock N, Holmans P, Nikolov I, Pahwa JS, Green E et al. Gene-wide analyses of genome-wide association data sets: evidence for multiple common risk alleles for schizophrenia and bipolar disorder and for overlap in genetic risk. Mol Psychiatry 2009; 14(3): 252-260.

149. Purcell SM, Wray NR, Stone JL, Visscher PM, O’Donovan MC, Sullivan PF et al. Common polygenic variation contributes to risk of schizophrenia and bipolar disorder. Nature 2009.

150. Craddock N, O'Donovan MC, Owen MJ. Genes for schizophrenia and bipolar disorder? Implications for psychiatric nosology. Schizophr Bull 2006; 32(1): 9-16. 



\section{Chapter 2}

\section{Cognitive functioning in patients with schizophrenia and bipolar disorder: A quantitative review}

Lydia Krabbendam ${ }^{1} \mathrm{MA} \mathrm{PhD}$, Baer Arts ${ }^{1} \mathrm{MD}$, Jim van $\mathrm{Os}^{1,2} \mathrm{MD} \mathrm{PhD}$, André Ale$\operatorname{man}^{3} \mathrm{MA} \mathrm{PhD}$

${ }^{1}$ Department of Psychiatry and Neuropsychology, South Limburg Mental Health Research and Teaching Network, EURON, Maastricht University, Maastricht, The Netherlands ${ }^{2}$ Division of Psychological Medicine, Institute of Psychiatry, London, UK

${ }^{3}$ BCN NeuroImaging Center, University of Groningen, Groningen, The Netherlands

Schizophrenia Research 2005; 80, 137-149 


\section{Abstract}

Objective: Evidence suggests that cognitive functioning in bipolar disorder may be impaired even in euthymic states, but it is unclear if the pattern of deficits is similar to the deficits found in schizophrenia. The aim of this study was to review quantitatively the studies on cognitive performance in schizophrenia and bipolar disorder.

Methods: Articles for consideration were identified through a literature search in MEDLINE and PsycLIT in the period between 1985 and October 2004, using the keywords "schizophrenia" combined with "bipolar disorder", or "manic-depress ${ }^{\star ”}$ or "manic" combined with "cogniti*" or "neuropsycholog*". 31 studies were included that: i) evaluated cognitive performance using standardized and reliable neuropsychological testing procedures; ii) compared adult patients with schizophrenia and with bipolar disorder; iii) reported test scores of both patient groups, or exact pvalues, t-values, or F-values; and iv) were published as an original article in a peerreviewed English language journal.

Results: Meta-analyses of all studies indicated that patients with bipolar disorder generally perform better than patients with schizophrenia, but the distribution of effect sizes showed substantial heterogeneity. Results based on a more homogeneous subset of studies that matched patient groups on clinical and demographic characteristics pointed in the same direction, with effect sizes in the moderate range.

Conclusions: Patients with bipolar disorder show better cognitive performance than patients with schizophrenia, even when matched for clinical and demographic characteristics. 


\section{Introduction}

Accumulating evidence has cast doubt on the Kraepelinian notion ${ }^{1}$ that bipolar disorder, in contrast to schizophrenia, is not characterized by cognitive decline. ${ }^{2-5} \mathrm{~A}$ review of 42 studies concluded that cognitive deficits are common in bipolar disorder, predominantly, though not exclusively, during episodes of mania and depression. ${ }^{6}$ During recovery, deficits in the areas of verbal memory, sustained attention, and, less consistently, executive functions and visual memory persist. ${ }^{6}$ Whether the pattern of cognitive deficits in bipolar disorder is comparable to the deficits observed in schizophrenia is still a matter of debate. Some authors have claimed that remitted patients with bipolar disorder perform notably better than stable patients with schizophrenia ${ }^{6,7}$ and that the cognitive profile in bipolar disorder is characterized by selective rather than generalized deficits (e.g., in the area of visual processing), ${ }^{7,8}$ Others have emphasized the similarities, stating that in both disorders the cognitive profile is characterized by a relatively generalized pattern of deficits, even though quantitative differences may exist. ${ }^{3,4,9}$

Any overlap in cognitive impairment in bipolar disorder and schizophrenia would be in line with many other findings. Although classification systems such as DSM-IV and ICD-10 attempt to distinguish between schizophrenia and bipolar disorder, it is a common observation in clinical practice that many patients do not fit properly into the dichotomy. The frequency of schizoaffective disorder testifies to that, ${ }^{10,11}$ as does the finding that the positive symptoms of psychosis and the mood symptoms of mania and depression frequently co-occur in the same patient. ${ }^{12-14}$ In addition, risk factors and epidemiological characteristics tend to overlap between schizophrenia and bipolar disorder. Developmental factors such as low educational achievement and delayed motor and language milestones increase the risk for both schizophrenia and affective disorders, although effect sizes tend to be greater for schizophrenia. ${ }^{15,16}$ Similarly, social factors such as ethnicity and adverse life events affect the risk for affective disorders in particular, but also have their impact on the risk for schizophrenia. ${ }^{17}$ Familial co-aggregation of schizophrenia and bipolar disorder suggest that the overlap may in part be based on a common genetic aetiology. ${ }^{18,19}$ Recent studies have indeed implied shared susceptibility genes. ${ }^{20,21}$

The apparent overlap between the two disorders in expression and aetiology has for more than a century fuelled spirited discussion as to whether schizophrenia and bipolar disorder are truly distinct diseases. ${ }^{22-24}$ To further our understanding of the relationship between the two disorders, it is crucial to identify the similarities and dissimilarities. The aim of this study was (i) to review quantitatively the studies on cognitive performance in schizophrenia and bipolar disorder and (ii) to examine whether the magnitude of any difference in performance is influenced by the clinical state of the study population. 


\section{Methods}

\section{Study Selection}

Articles for consideration were identified through a literature search in MEDLINE and PsycLIT in the period between 1985 and October 2004, using the keywords "schizophrenia" combined with "bipolar disorder", or "manic-depress" or "manic" combined with "cogniti*" or "neuropsycholog*”. Furthermore, the reference list of recent reviews on the neuropsychology of bipolar disorder ${ }^{6,25}$ was screened for any additional studies. The following criteria were used for inclusion of studies in the meta-analysis: i) the study evaluated cognitive performance using standardized and reliable neuropsychological testing procedures; ii) the study compared adult patients with schizophrenia and with bipolar disorder; iii) the study reported test scores (means and standard deviations) of both patient groups, or exact p-values, t-values, or F-values; and iv) the study was published as an original article in a peer-reviewed English language journal. Studies that combined patients with bipolar and unipolar affective disorder into one category were excluded if the data on bipolar disorder patients were not reported separately.

\section{Data Analysis}

For each test parameter an effect size was calculated, which was Cohen's $d$, the difference between the means of both patient groups, divided by the pooled standard deviation. ${ }^{26}$ When means and SDs were not given, $d$-values were computed from exact $p$-values, $t$-values or $F$-values. Data extraction and calculations of effect sizes were performed by two authors independently (LK and BA), who reached consensus in case of discrepancies. Effect sizes were weighted for sample size, in order to correct for upwardly biased estimation of the effect in small sample sizes. ${ }^{27}$ When multiple tests were reported for one cognitive domain, these were combined into one dvalue, to prevent studies reporting multiple subtests from the same sample from dominating the analysis.

The corresponding t-value and significance level provide an indication of the statistical significance of the association. We also calculated a homogeneity statistic, $\mathrm{Q}$, to test whether the studies can be taken to share a common population effect size. A significant Q-statistic indicates heterogeneity of the individual study effect sizes, which poses a threat to a reliable interpretation of the results, as this implies that the mean weighted effect cannot be taken to generalize to the entire population. ${ }^{28}$ Follow-up analyses may then be needed, in order to identify moderating factors. All analyses were carried out in the random effects model, using the Comprehensive Meta-analysis ${ }^{\mathrm{TM}}$ package (www.meta-analysis.com).

In order to investigate whether any difference in neuropsychological test performance between patients with schizophrenia and patients with bipolar disorder 
would vary with clinical state, we performed a second analysis on those studies that included patients who were in remission only.

Additional analyses were done on subsets of studies in which patient groups were matched for a number of variables that are known to influence neuropsychological test performance, namely i) age and education, and ii) illness characteristics, such as illness duration and number of admissions.

\section{Results}

\section{All studies}

The literature search yielded 31 studies that evaluated neuropsychological performance in patients with schizophrenia and patients with bipolar disorder using standardized neuropsychological instruments. These studies are listed in Table 1, along with the sample sizes, the main sample characteristics, and the task parameters yielded by the studies. The studies by Seidman et al. ${ }^{29-31}$ were based on the same sample, as were the studies by Park et al. ${ }^{32,33}$ One study did not report data on test performance of the two patient groups separately, ${ }^{34}$ but these data were provided by the first author upon request. In the study by Addington and Addington ${ }^{35,36}$ the patients with schizophrenia were also tested in the acute phase, but because this was 3 months before the relevant assessment, practice effects were considered negligible. The study by McGrath et al. ${ }^{37}$ assessed both patient groups in the acute and subacute phase separated by 4 weeks; the data for the first assessment were included in the meta-analysis. 


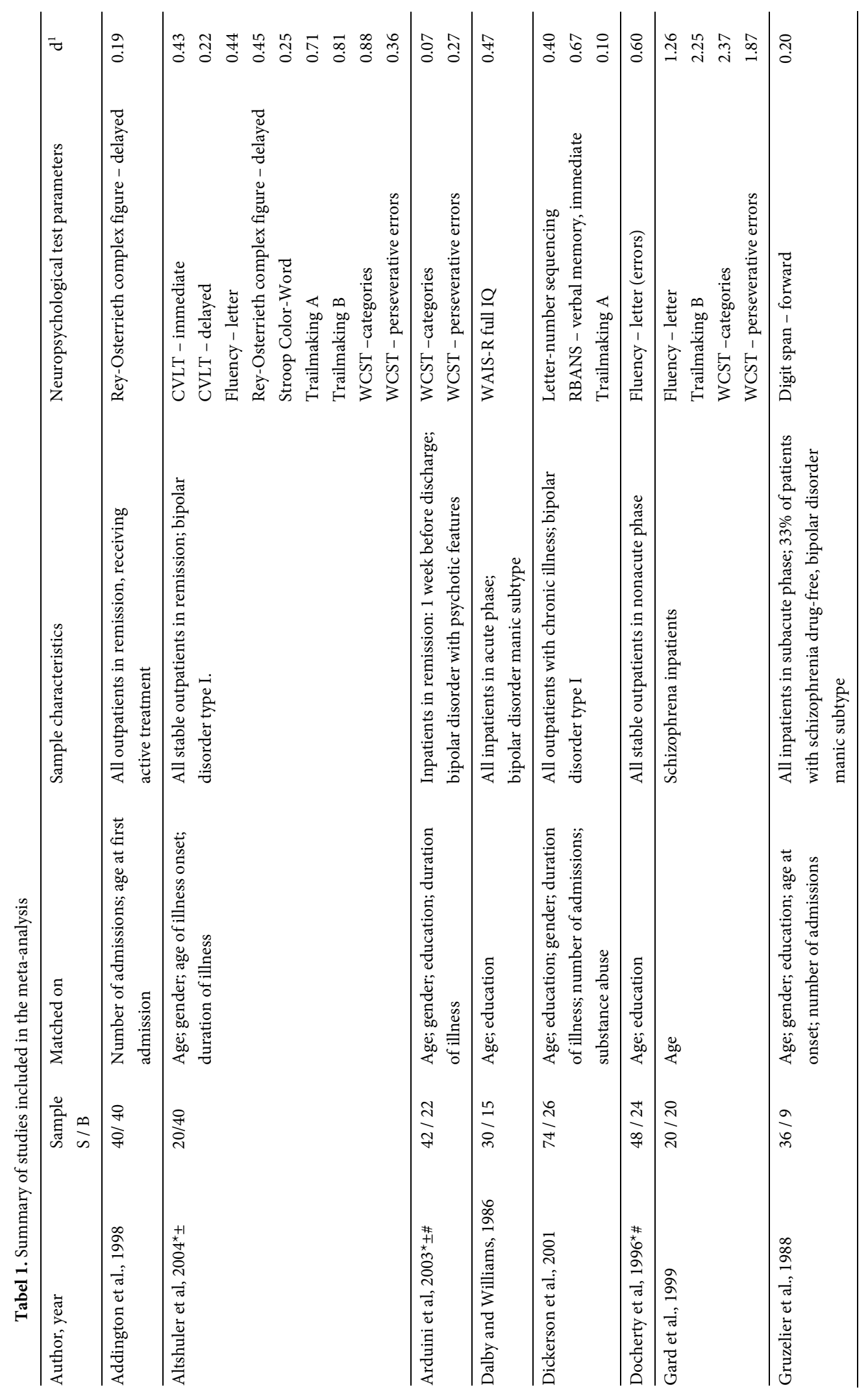




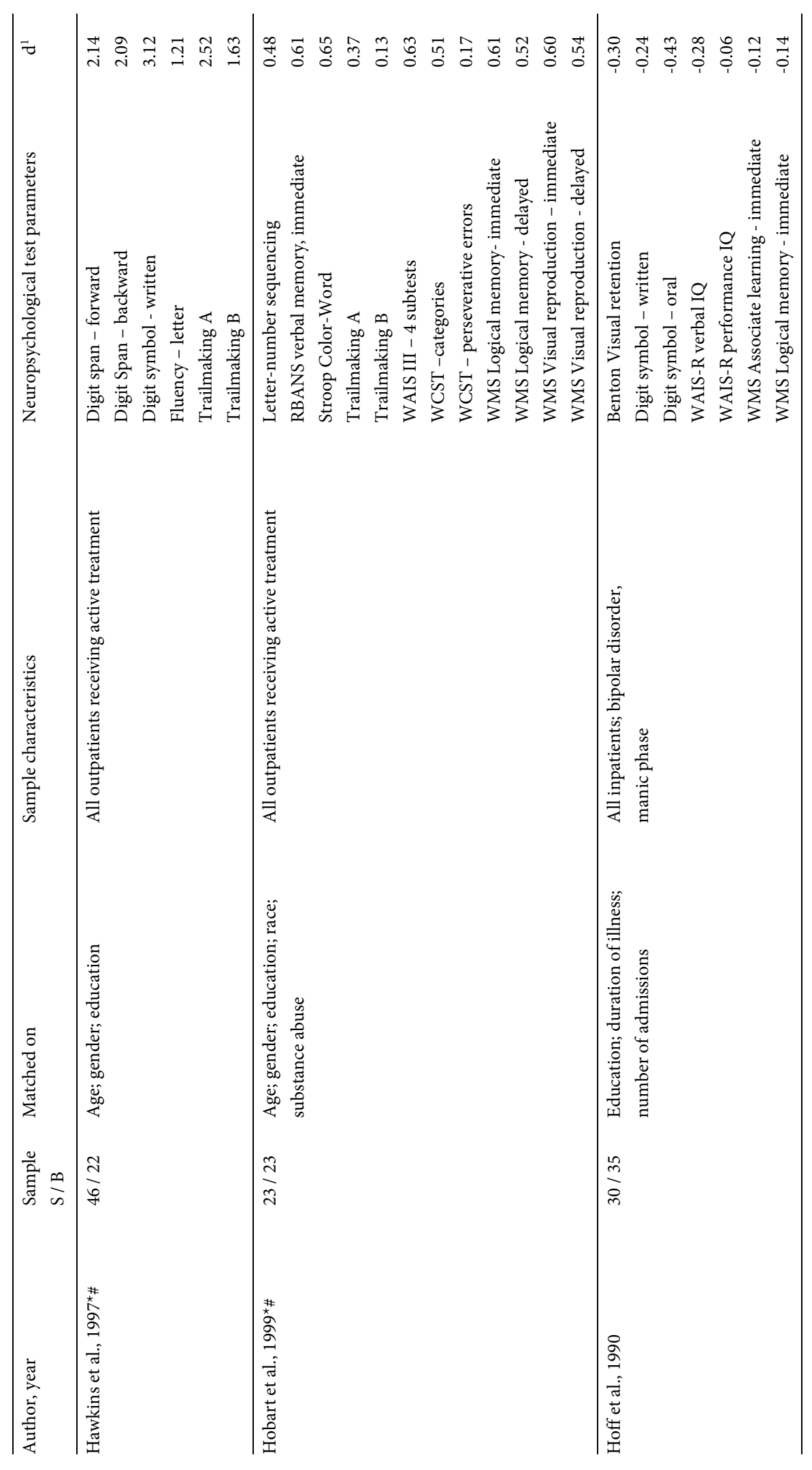




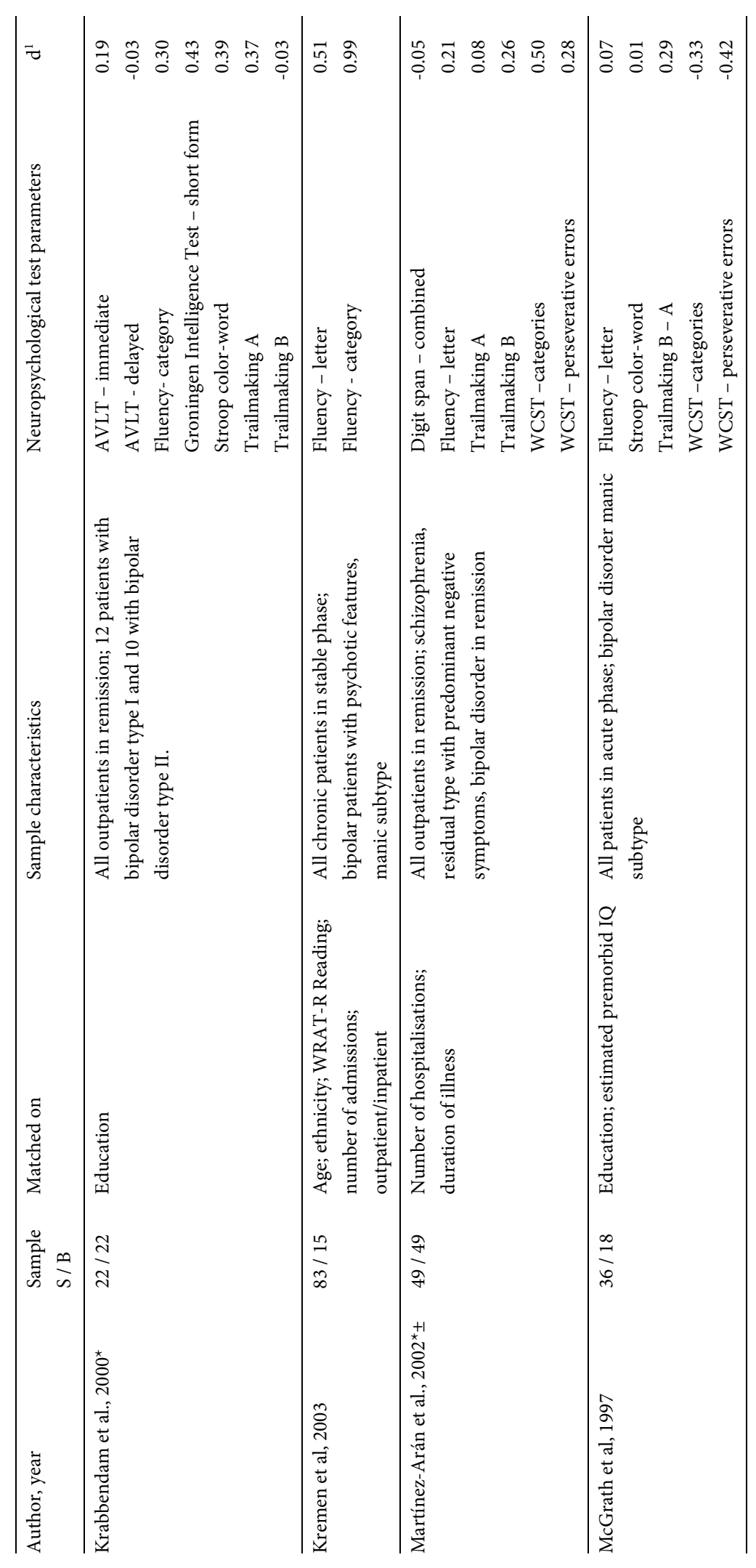




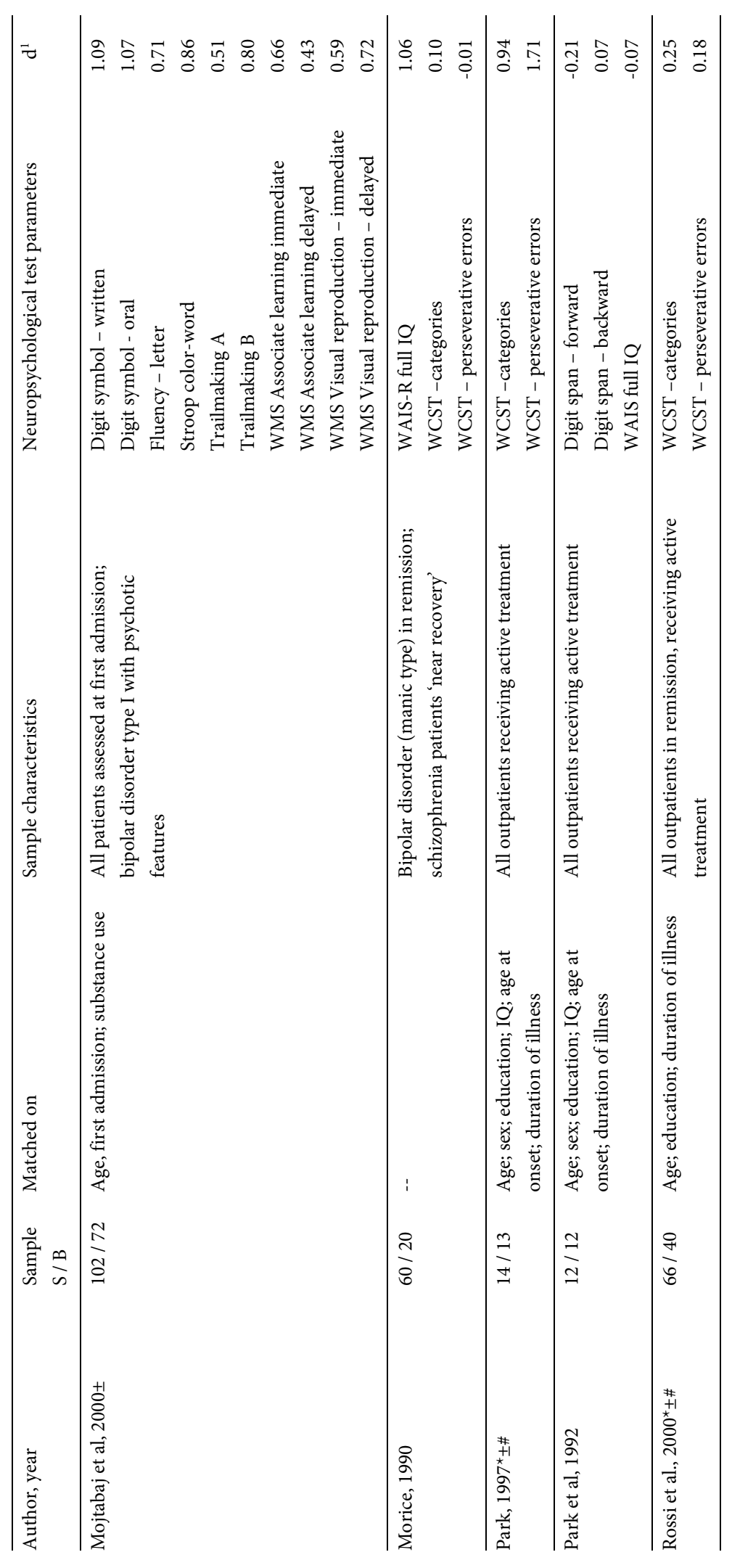




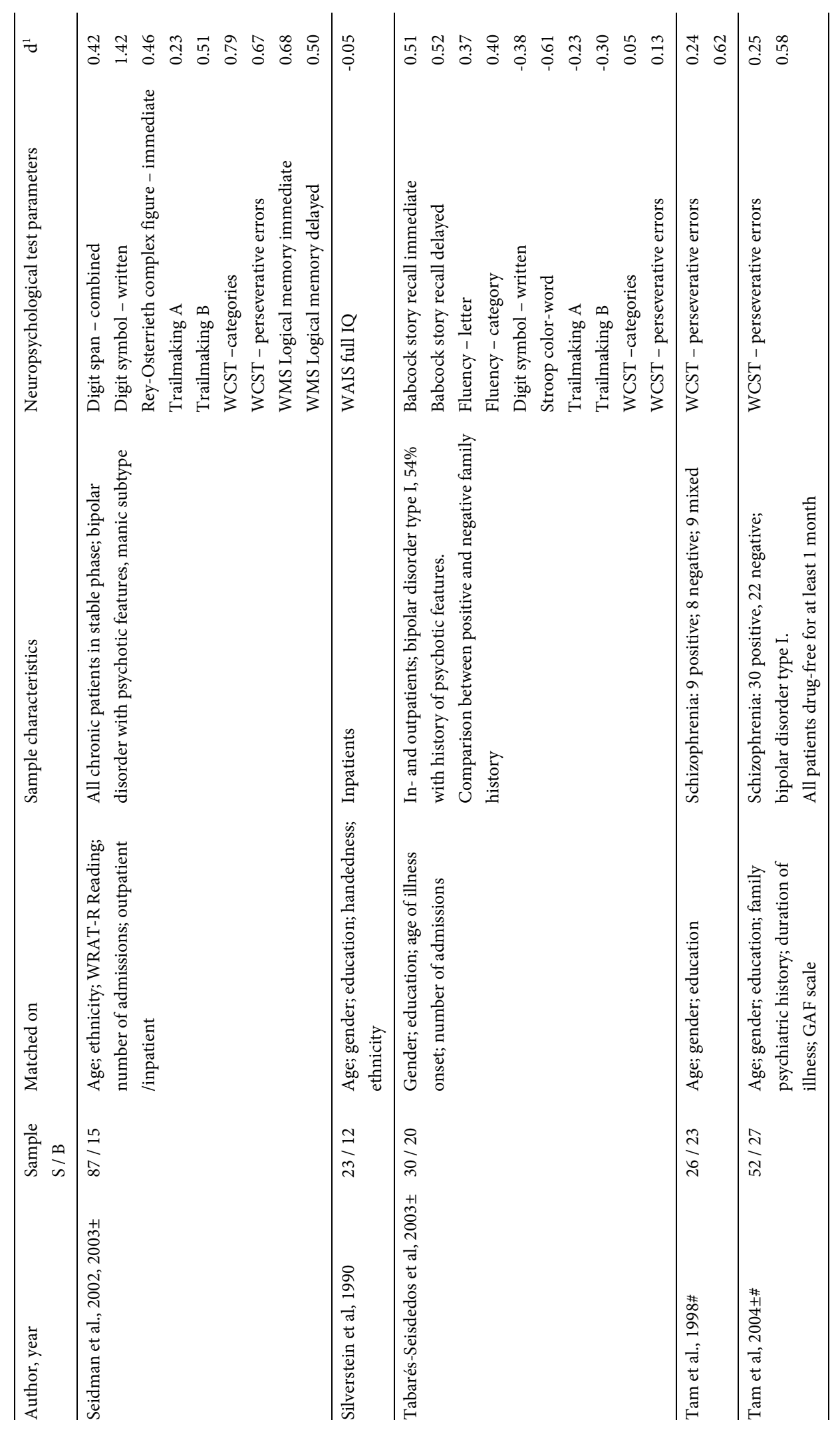




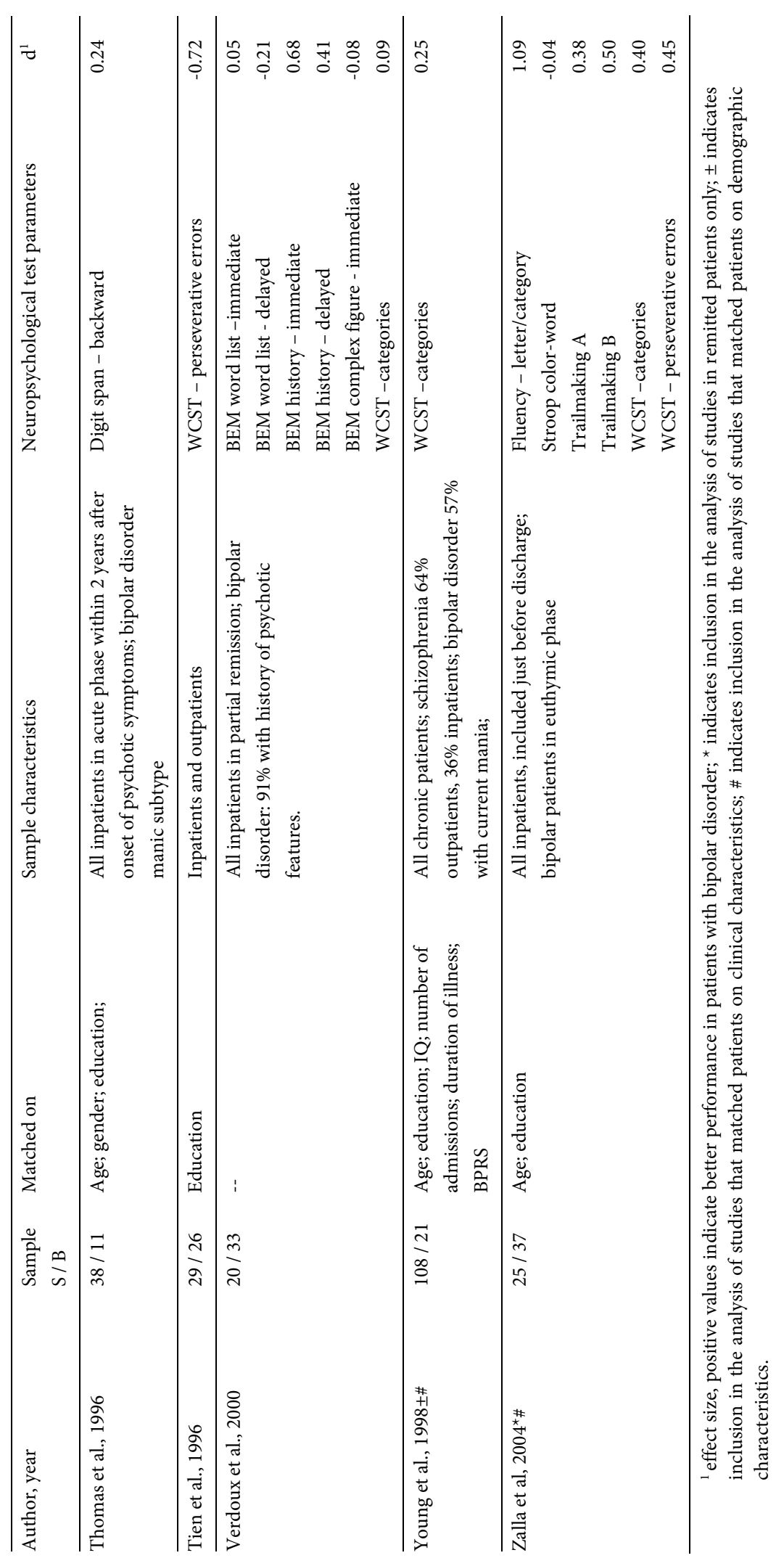


The neuropsychological tests used in these studies were divided into 11 categories that measure approximately the same cognitive construct. ${ }^{38}$ Verbal working memory was assessed with the Digit $\operatorname{Span}^{39}$ in 6 studies, and the Letter-Number $\operatorname{Span}^{40}$ in 2 studies. Verbal fluency, either words from a certain category or beginning with a certain letter, was assessed in 11 studies. Mental speed was measured using the Digit Symbol Substitution Test ${ }^{39}$ in 5 studies and the Trailmaking Test part $\mathrm{A}^{41}$ in 10 studies. The construct of executive control included the Trailmaking Test part $\mathrm{B}$, used in 11 studies, and the Stroop Color-Word interference ${ }^{42}$ reported by 7 studies. Concept formation and shifting was assessed by 17 studies, using the Wisconsin Card Sorting Test (WCST). ${ }^{43}$ Most studies reported two WCST parameters, number of categories achieved and number of perseverative errors; these were pooled into a combined effect size since factor analyses have indicated that these variables load on a single factor of perseveration. ${ }^{44,45}$ Immediate verbal memory was assessed using word list learning tasks in 5 studies (either the California Verbal Learning Test, or the Rey Auditory Verbal Learning Test), ${ }^{46}$ or the Word list from the Battery of Memory Efficiency (BEM), ${ }^{47}$ or the subtest Associate Learning from the Wechsler Memory Scale (WMS); ${ }^{48}$ story recall in 5 studies (either the History subtest from the BEM, the Logical Memory subtest from the WMS, or the Babcock Story recall); and a combined index of word list and story recall based on the Repeatable Battery for the Assessment of Neuropsychological Status (RBANS) ${ }^{49}$ in two studies. Delayed verbal memory was measured using word list recall in 4 studies (either the California Verbal Learning Test, ${ }^{50}$ or the Rey Aditory Verbal Learning Test, or the Word list from the BEM, or the subtest Associate Learning from the WMS), and story recall in 4 studies (either the History subtest from the BEM, the Logical Memory subtest from the WMS, or the Babcock Story recall). Immediate visual memory was measured by 5 studies using the Benton Visual Retention Test, the subtest Visual Reproduction from the WMS, the Rey Osterrieth Complex Figure, ${ }^{51}$ or the complex figure from the BEM. Delayed visual memory was assessed by 4 studies using the delayed recall version of the subtest Visual Reproduction from the WMS, or the Rey Osterrieth Complex Figure. Fine motor skills were assessed by the Purdue Pegboard in 2 studies and Finger Tapping in 2 studies. Data on estimated IQ were reported by 7 studies, 5 of which were based on full scale WAIS or WAIS-R ${ }^{39,52}$ and 2 were based on a short form of either the WAIS-III ${ }^{53}$ or a Dutch Intelligence Test. ${ }^{54}$ We did not include IQ estimates based on one or two subtests of the WAIS. No combined effect sizes were calculated for the domains of sustained attention, language, reasoning, and visuoperceptual and visuospatial functions because of lack of data and substantial heterogeneity between the test measures used to assess these domains. Thus, the following cognitive domains were included in the meta-analysis: verbal working memory, verbal fluency, mental speed, executive control, concept formation and shifting, immediate verbal memory, delayed verbal memory, immediate visual memory, delayed visual memory, fine motor skills, and IQ. Table 2 shows the results of the meta-analysis of differences on these domains between patients with bipolar disorder and schizophrenia. 
Table 2. Results of meta-analyses of cognitive test performance differences between patients with schizophrenia versus bipolar disorder

\begin{tabular}{lrrrrrrrr}
\hline & $\mathrm{K}$ & $\mathrm{N}$ & $\mathrm{d}$ & $95 \% \mathrm{CI}$ & $\mathrm{t}$ & $\mathrm{p}$ & $\mathrm{Q}(\mathrm{w})$ & $\mathrm{P}$ \\
\hline Verbal fluency & 11 & 823 & 0.63 & $0.40-0.85$ & 5.3 & $<0.0001$ & 22.3 & 0.01 \\
Verbal working memory & 8 & 532 & 0.60 & $0.12-1.07$ & 2.5 & 0.01 & 38.0 & $<0.001$ \\
Executive control & 11 & 801 & 0.55 & $0.19-0.91$ & 3.0 & 0.002 & 52.5 & $<0.001$ \\
Visual memory, del & 4 & 360 & 0.51 & $0.25-0.76$ & 4.0 & 0.0009 & 3.8 & 0.28 \\
Mental speed & 11 & 872 & 0.50 & $0.10-0.89$ & 2.5 & 0.01 & 70.5 & $<0.001$ \\
Verbal memory, imm & 9 & 697 & 0.43 & $0.23-0.63$ & 4.2 & $<0.0001$ & 11.6 & 0.17 \\
IQ & 7 & 338 & 0.36 & $0.01-0.71$ & 2.0 & 0.04 & 13.6 & 0.03 \\
Verbal memory, del & 7 & 523 & 0.34 & $0.16-0.53$ & 3.7 & 0.0003 & 3.6 & 0.73 \\
Concept formation & 17 & 1158 & 0.34 & $0.11-0.57$ & 2.9 & 0.004 & 51.0 & $<0.001$ \\
Visual memory, imm & 5 & 431 & 0.26 & $-0.12-0.64$ & 1.4 & 0.17 & 11.9 & 0.02 \\
Fine motor skills & 4 & 339 & 0.06 & $-0.16-0.27$ & 0.5 & 0.61 & 3.0 & 0.39 \\
\hline
\end{tabular}

$\mathrm{K}=$ number of studies included in the analysis; $\mathrm{N}=$ total number of subjects across studies; $\mathrm{d}=$ mean, weighted effect size Cohen's d; 95\% CI $=95 \%$ confidence interval; $t=$ test of significance of effect size (p); $\mathrm{Q}(\mathrm{w})=$ within category heterogeneity between studies

All effect sizes were in the same direction and suggested worse performance in the patients with schizophrenia compared to the patients with bipolar disorder. The largest difference was for verbal fluency (11 effect sizes; mean weighted $d=0.63,95 \% \mathrm{CI}$ $0.40-0.85)$. This effect size is in the moderate range, according to the nomenclature of Cohen. ${ }^{55}$ Other domains for which the effect sizes fell in the moderate range were verbal working memory, mental speed, executive control, immediate verbal memory, delayed visual memory, and IQ. Significant effect sizes in the small to moderate range were obtained for concept formation and shifting and delayed verbal memory. For only two out of twelve cognitive domains the mean weighted effect sizes were nonsignificant, namely for immediate visual memory and for fine motor skills.

However, with the exception of the analyses of immediate and delayed verbal memory, visual delayed memory and fine motor skills, the Q statistic was significant for the majority of analyses, indicating that there was substantial heterogeneity between the results of the different studies. Part of this heterogeneity may have to do with the inclusion of patients with varying severity of psychopathology and part may be related to the inclusion of studies with different levels of methodological stringency. Subsequent analyses were therefore done in (i) studies in remitted patients only, and (ii) studies that matched patients on demographic variables or illness characteristics. For the sake of clarity, and due to a limited number of available studies, we did not rerun the analyses for all twelve cognitive domains. Instead, we included studies that reported data for concept formation and shifting (e.g., WCST), as this was the most frequently reported test parameter, and, if the WCST was not reported, for verbal fluency (which involves active conceptual search and retrieval from memory and has also been associated with frontal lobe functioning), in order to retain an adequate number of effect sizes. 


\section{Studies in remitted patients only}

Only three studies reported objective criteria against which the state of remission was judged. ${ }^{2,56,57}$ Therefore, a less stringent criterion for remission was used, namely inclusion of outpatients only or outpatients and inpatients just before discharge. Of the seventeen studies that included patients in remission according to this criterion, ten reported either the WCST or Verbal fluency and were included in this analysis (indicated with an ${ }^{\star}$ in Table 1). The result of this meta-analysis indicated a significant difference between patients with schizophrenia and patients with bipolar disorder, which was in the moderate range $(\mathrm{d}=0.49,95 \% \mathrm{CI} 0.28,0.70)$ (see Table 3 and Figure 1). Contrary to the analysis of all studies, the non-significant Q-value indicated that this subset of studies can be reliably interpreted as indicators of the same estimated population effect size.

Table 3. Results of meta-analyses on studies that included schizophrenia and bipolar samples in remission only, or matched the groups on illness characteristics or demographic characteristics, respectively. The cognitive variable concerned the WCST or verbal fluency.

\begin{tabular}{lcccccccc}
\hline & $\mathrm{K}$ & $\mathrm{N}$ & $\mathrm{d}$ & $95 \% \mathrm{CI}$ & $\mathrm{t}$ & $\mathrm{p}$ & $\mathrm{Q}(\mathrm{w})$ & $\mathrm{p}$ \\
\hline In remission & 10 & 646 & 0.49 & $0.28-0.70$ & 4.6 & 0.0001 & 14.3 & 0.11 \\
Matched on clinical variables & 10 & 832 & 0.49 & $0.31-0.67$ & 5.2 & $<0.0001$ & 12.6 & 0.19 \\
Matched on demographic variables & 10 & 702 & 0.50 & $0.29-0.71$ & 4.6 & $<0.0001$ & 14.8 & 0.10 \\
\hline
\end{tabular}

$\mathrm{K}=$ number of studies included in the analysis; $\mathrm{N}=$ total number of subjects across studies; $\mathrm{d}=$ mean, weighted effect size Cohen's d; 95\% CI = 95\% confidence interval; $t=$ test of significance of effect size (p); $\mathrm{Q}(\mathrm{w})=$ within category heterogeneity between studies

\begin{tabular}{|c|c|c|c|c|c|c|c|c|}
\hline & Citation & EffectName & Effect & NTotal & -2.00 & -1.00 & 0.00 & 1.00 \\
\hline & Altshuler 2004 & WCST & .53 & 60 & & & & \\
\hline & Arduini 2003 & WCST & .17 & 64 & & & & \\
\hline & Kremen 2003 & verbal fluency & .74 & 98 & & & & \\
\hline & Martínez-Arán 2002 & WCST & .39 & 98 & & & & \\
\hline & Mojtabaj 2000 & verbal fluency & .71 & 174 & & & & \\
\hline & Park 1997 & WCST & 1.28 & 27 & & & & \\
\hline & Rossi 2000 & WCST & .21 & 106 & & & & \\
\hline & Seidman 2002 & WCST & .72 & 102 & & & & \\
\hline & Tabarés-Seisdedos 2003 & WCST & .09 & 54 & & & & \\
\hline & Tam 1998 & WCST & .48 & 49 & & & & \\
\hline Random & Combined (10) & & .49 & 832 & & & & \\
\hline & & & & & & $s>B$ & & $S<B$ \\
\hline
\end{tabular}

Figure 1. Forest plot of studies included in the meta-analysis of the difference between patients with schizophrenia and bipolar disorder in cognitive function.

Only studies that matched both patient groups on clinical variables and that reported on WCST or verbal fluency performance were included. Magnitude of symbols depicting the effect size is proportional to the number of subjects included in the study.

$\mathrm{S}>\mathrm{B}=$ schizophrenia patients perform better than bipolar disorder patients $\mathrm{S}<\mathrm{B}=$ bipolar disorder patients perform better than schizophrenia patients 


\section{Studies in matched patient groups only}

Of the seventeen studies that matched subjects on illness characteristics, such as number of admissions, duration of illness, or age at onset, ten studies reported either the WCST or Verbal fluency (indicated with an \pm in Table 1). The mean weighted effect size of the difference between patients with schizophrenia and patients with bipolar disorder was again in the moderate range $(\mathrm{d}=0.49,95 \%$ CI $0.31,0.67)$ (see Table 3). The non-significant Q-value indicated that the distribution of effect sizes was sufficiently homogeneous.

Of the sixteen studies that matched subjects from both patient groups on age and education, eight studies reported either the WCST or Verbal fluency (indicated with an \# in Table 1). These studies yielded a mean weighted effect size that was largely similar to the previous result $(\mathrm{d}=0.55,95 \%$ CI $0.30,0.81)$ (see Table 3 ). Again, the non-significant Q-value indicated that the distribution of effect sizes was sufficiently homogeneous.

\section{Discussion}

Quantitative analysis of 31 studies that compared neuropsychological performance in patients with schizophrenia and patients with bipolar disorder indicated significantly worse performance in the patients with schizophrenia in nine out of eleven cognitive domains. The only areas in which performance of the two patient groups were not statistically significant were delayed visual memory and fine motor skills. However, the substantial heterogeneity of the effect sizes derived from the individual studies calls on caution in interpreting the results. Notably, the analyses on subsets of studies, whether defined on the basis of inclusion of remitted patients or the quality of the matching of the patient groups, did show sufficiently homogenous distribution of effect sizes. These secondary analyses pointed in the same direction, indicating better performance in the patients with bipolar disorder compared to the patients with schizophrenia, with effect sizes in the moderate range. Thus, patients with bipolar disorder show better cognitive performance than patients with schizophrenia, given similar clinical and demographic characteristics of both patient groups. Admittedly, these analyses were only conducted for the domains of concept formation and shifting and verbal fluency, due to the limited availability of studies that matched on clinical and demographical characteristics. However, the consistency of the findings tentatively suggests that this conclusion can be extended to the other cognitive domains for which the original analysis showed performance differences.

The finding of generally worse cognitive performance in schizophrenia compared to bipolar disorder fits in with current models of the relationship between both disorders. Based on the similarities and dissimilarities between schizophrenia and bipolar disorder, Murray et al. ${ }^{24}$ have recently hypothesized that certain shared 
susceptibility genes may predispose individuals to psychosis in general. Other genes, possible genes involved in neurodevelopment and/or environmental factors may then interact with the genetic vulnerability to put an individual at risk for schizophrenia. Assuming that cognitive deficits are related to abnormalities in neurodevelopment, ${ }^{58,59}$ it would follow from this model that schizophrenia is characterized by poorer cognitive functioning than bipolar disorder. Other evidence in line with the model is the relative severity of abnormalities in premorbid functioning ${ }^{16}$ as well as in brain structural volumes ${ }^{60}$ in schizophrenia as compared to bipolar disorder.

Since this meta-analysis focused on the performance differences between two patient groups, no conclusion could be drawn as to the extent of the deficits in both patient groups compared to normal performance levels. Previous meta-analyses have shown moderate to large mean effect sizes of the magnitude of cognitive deficits in schizophrenia. ${ }^{61-63}$ For example, based on Zakzanis et al. ${ }^{62}$ mean effect sizes ranged from 0.89 for verbal skills (SD 0.60, 82 effect sizes) to 1.39 for delayed recall (SD $0.65,28$ effect sizes), with the mean effect sizes for memory acquisition, attention / concentration, cognitive flexibility and abstraction, performance skill, and manual dexterity varying between these numbers. Given that the effect sizes of the performance differences between schizophrenia and bipolar disorder were noticeably smaller, this would suggest that there are at least slight deviations from the norm in the patients with bipolar disorder, although the evidence for this conclusion is only indirect.

Any meta-analysis is limited by the quality of the data on which it is based. In this respect, the lack of uniform data on the clinical characteristics of the patient groups stands out. First, only three studies used clear criteria for the definition of euthymic state or remission, and therefore our analysis of the effect of clinical state was necessarily based on the rather rough distinction between outpatients and inpatients. However, the fact that the findings for the studies in outpatients only were more homogeneous than the results of all studies adds to the validity of this criterion. Related to this, in order to retain an adequate number of effect sizes, the criteria set for the selection of studies that matched patient groups on clinical characteristics were relatively imprecise. That is, studies could either match on illness duration, or number of hospitalisations, or age of onset, and no further requirements were set as to how these figures were assessed. Again, the homogeneity and consistency of the findings argues in favour of the validity of this approach, although admittedly, these characteristics provide only a crude estimate of severity of illness and may even have different implications for both disorders. Second, it was not possible to take into account the effect of psychoactive medication on cognitive functioning. Only one study (Tam et al, 2004) included patients that were drug-free for at least one month. In most other studies, the majority of the patients received psychoactive medication, either antipsychotics, mood stabilizers, antidepressants, or a combination of these. Few studies reported actual dose in chlorpromazine equivalents and some studies did not report use of medication at all. Third, although the majority of studies used some kind of symptom assessment, the diversity of scales precluded use of these data 
in the meta-analysis. Therefore, we could not investigate the classical hypothesis that in bipolar disorder, the severity of the cognitive deficits is more closely linked to the actual level of psychopathology than in schizophrenia. ${ }^{64}$ Likewise, the available data did not allow exploring the suggestion that severity of cognitive deficits in bipolar disorder is linked to the presence of a history of psychotic symptoms. ${ }^{65}$ Future research calls for more precise matching of clinical and demographic variables in order to examine the determinants of cognitive deficits in bipolar disorder and schizophrenia. 


\section{References}

1. Kraepelin E. Dementia praecox and paraphrenia. Livingstone: Edinburgh, 1913.

2. Altshuler LL, Ventura J, van Gorp WG, Green MF, Theberge DC, Mintz J. Neurocognitive function in clinically stable men with bipolar I disorder or schizophrenia and normal control subjects. Biol Psychiatry 2004; 56(8): 560-569.

3. Martinez-Aran A, Vieta E, Reinares M, Colom F, Torrent C, Sanchez-Moreno J et al. Cognitive function across manic or hypomanic, depressed, and euthymic states in bipolar disorder. Am J Psychiatry 2004; 161(2): 262-270.

4. Krabbendam L, Honig A, Wiersma J, Vuurman EF, Hofman PA, Derix MM et al. Cognitive dysfunctions and white matter lesions in patients with bipolar disorder in remission. Acta Psychiatr Scand 2000; 101(4): 274-280.

5. van Gorp WG, Altshuler L, Theberge DC, Wilkins J, Dixon W. Cognitive impairment in euthymic bipolar patients with and without prior alcohol dependence. A preliminary study. Arch Gen Psychiatry 1998; 55(1): 41-46.

6. Quraishi S, Frangou S. Neuropsychology of bipolar disorder: a review. J Affect Disord 2002; 72(3): 209-226.

7. Goldberg TE. Some fairly obvious distinctions between schizophrenia and bipolar disorder. Schizophr-Res 1999; 39(2): 127-132.

8. Green MF, Nuechterlein KH, Mintz J. Backward masking in schizophrenia and mania. I. Specifying a mechanism. Arch Gen Psychiatry 1994; 51(12): 939-944.

9. Hoff AL, Shukla S, Aronson T, Cook B, Ollo C, Baruch S et al. Failure to differentiate bipolar disorder from schizophrenia on measures of neuropsychological function. Schizophr Res 1990; 3(4): 253260.

10. Tien AY, Eaton WW. Psychopathologic precursors and sociodemographic risk factors for the schizophrenia syndrome. Arch Gen Psychiatry 1992; 49(1): 37-46.

11. Marneros A. The schizoaffective phenomenon: the state of the art. Acta Psychiatr Scand Suppl 2003; (418): 29-33.

12. Siris SG. Depression in schizophrenia: perspective in the era of "Atypical" antipsychotic agents. $A m$ J Psychiatry 2000; 157(9): 1379-1389.

13. Brockington IF, Kendell RE, Wainwright S. Depressed patients with schizophrenic or paranoid symptoms. Psychol Med 1980; 10(4): 665-675.

14. Brockington IF, Kendell RE, Wainwright S, Hillier VF, Walker J. The distinction between the affective psychoses and schizophrenia. Br J Psychiatry 1979; 135: 243-248.

15. van Os J, Jones P, Lewis G, Wadsworth M, Murray R. Developmental precursors of affective illness in a general population birth cohort. Arch Gen Psychiatry 1997; 54(7): 625-631.

16. Jones PB, Tarrant CJ. Specificity of developmental precursors to schizophrenia and affective disorders. Schizophr Res 1999; 39(2): 121-125; discussion 161.

17. Van Os J, Jones P, Sham P, Bebbington P, Murray RM. Risk factors for onset and persistence of psychosis. Soc-Psychiatry-Psychiatr-Epidemiol 1998; 33(12): 596-605.

18. Cardno AG, Rijsdijk FV, Sham PC, Murray RM, McGuffin P. A twin study of genetic relationships between psychotic symptoms. Am J Psychiatry 2002; 159(4): 539-545.

19. Maier W, Lichtermann D, Franke P, Heun R, Falkai P, Rietschel M. The dichotomy of schizophrenia and affective disorders in extended pedigrees. Schizophr Res 2002; 57(2-3): 259-266.

20. Wildenauer DB, Schwab SG, Maier W, Detera-Wadleigh SD. Do schizophrenia and affective disorder share susceptibility genes? Schizophr Res 1999; 39(2): 107-111; discussion 160.

21. Bramon E, Sham PC. The common genetic liability between schizophrenia and bipolar disorder: a review. Curr Psychiatry Rep 2001; 3(4): 332-337.

22. Jablensky A. The conflict of the nosologists: views on schizophrenia and manic- depressive illness in the early part of the 20th century. Schizophr Res 1999; 39(2): 95-100; discussion 159.

23. Crow TJ. From Kraepelin to Kretschmer leavened by Schneider: thextransition from categories of psychosis to dimensions of variation intrinsic to homo sapiens. Arch Gen Psychiatry 1998; 55(6): 502-504. 
24. Murray RM, Sham P, Van Os J, Zanelli J, Cannon M, McDonald C. A developmental model for similarities and dissimilarities between schizophrenia and bipolar disorder. Schizophr Res 2004; 71(2-3): 405-416.

25. Martinez-Aran A, Vieta E, Colom F, Reinares M, Benabarre A, Gasto C et al. Cognitive dysfunctions in bipolar disorder: evidence of neuropsychological disturbances. Psychother Psychosom 2000; 69(1): $2-18$.

26. Shaddish WR, Haddock CK. Combining estimates of effect size. In: Cooper H, Hedges V (eds). The handbook of research synthesis. Sage Publications: New York, 1994, pp 261-285.

27. Rosenthal R. Meta-analytic procedures for social research. Sage Publications: London, 1991.

28. Lipsey MW, Wilson DB. Practical meta-analysis. Sage: Thousand Oaks, CA, 2001.

29. Seidman LJ, Lanca M, Kremen WS, Faraone SV, Tsuang MT. Organizational and visual memory deficits in schizophrenia and bipolar psychoses using the Rey-Osterrieth complex figure: effects of duration of illness. J Clin Exp Neuropsychol 2003; 25(7): 949-964.

30. Seidman LJ, Kremen WS, Koren D, Faraone SV, Goldstein JM, Tsuang MT. A comparative profile analysis of neuropsychological functioning in patients with schizophrenia and bipolar psychoses. Schizophr Res 2002; 53(1-2): 31-44.

31. Kremen WS, Seidman LJ, Faraone SV, Tsuang MT. Is there disproportionate impairment in semantic or phonemic fluency in schizophrenia? J Int Neuropsychol Soc 2003; 9(1): 79-88.

32. Park S, Holzman PS. Schizophrenics show spatial working memory deficits. Arch Gen Psychiatry 1992; 49(12): 975-982.

33. Park S. Association of an oculomotor delayed response task and the Wisconsin Card Sort Test in schizophrenic patients. Int J Psychophysiol 1997; 27(2): 147-151.

34. Tabares Seisdedos R, Balanza Martinez V, Salazar Fraile J, Selva Vera G, Leal Cercos C, Gomez Beneyto M. Specific executive/attentional deficits in patients with schizophrenia or bipolar disorder who have a positive family history of psychosis. J Psychiatr Res 2003; 37(6): 479-486.

35. Addington J, Addington D. Attentional vulnerability indicators in schizophrenia and bipolar disorder. Schizophr Res 1997; 23(3): 197-204.

36. Addington J, Addington D. Facial affect recognition and information processing in schizophrenia and bipolar disorder. Schizophr Res 1998; 32(3): 171-181.

37. McGrath J, Scheldt S, Welham J, Clair A. Performance on tests sensitive to impaired executive ability in schizophrenia, mania and well controls: acute and subacute phases. Schizophr Res 1997; 26(2-3): $127-137{ }^{\star}$ LHM: Journal not available in the University Library, you can make an Interlibrary Lending Request at the Loan Desk ISSN: 0920-9964.

38. Kessels RP, Aleman A, Verhagen WI, van Luijtelaar EL. Cognitive functioning after whiplash injury: a meta-analysis. J Int Neuropsychol Soc 2000; 6(3): 271-278.

39. Wechsler D. Wechsler Adult Intelligence Scale. Manual. Psychological Corporation: New York, 1955.

40. Gold JM, Carpenter C, Randolph C, Goldberg TE, Weinberger DR. Auditory working memory and Wisconsin Card Sorting Test performance in schizophrenia. Arch Gen Psychiatry 1997; 54(2): 159$165{ }^{*}$ LHM: Journal available in the University Library, see the Library Catalogue for exact information ${ }^{\star}$ LHC: MG/SG T 0109 : 1960- . . ISSN: 0003-0990X.

41. Reitan RM. Validity of the Trail Making Test as an indication of organic brain damage. Perceptual and Motor Skills 1958; 8: 271-276.

42. Stroop JR. Studies of interference in serial verbal reactions. Journal of Experimental Psychology 1935; 18: 643-662.

43. Heaton RK. A Manual for the Wisconsin Card Sorting Test. Psychological Assessment Resources: Odessa, 1981.

44. Cuesta MJ, Peralta V, Caro F, de Leon J. Schizophrenic syndrome and Wisconsin Card Sorting Test dimensions. Psychiatry Res 1995; 58(1): 45-51.

45. Koren D, Seidman LJ, Harrison RH, Lyons MJ, Kremen WS, Caplan B et al. Factor structure of the Wisconsin Card Sorting Test: dimensions of deficit in schizophrenia. Neuropsychology 1998; 12(2): 289-302.

46. Rey A. L'examen clinique en psychologie [Clinical assessment in psychology]. Presses Universitaires de France: Paris, 1964. 
47. Signoret JL. BEM-84, Batterie d'efficience mnésique réduite. [Abbreviated battery of memory efficiency]. Editions Elsevier: Paris, 1991.

48. Wechsler D. Wechsler Memory Scale-Revised manual. The Psychological Corporation: San Antonio, TX, 1987.

49. Gold JM, Queern C, Iannone VN, Buchanan RW. Repeatable battery for the assessment of neuropsychological status as a screening test in schizophrenia I: sensitivity, reliability, and validity. Am-JPsychiatry 1999; 156(12): 1944-1950.

50. Delis DC, Kramer JH, Kaplan E, Ober BA. California Verbal Learning Test: Adult version. The Psychological Corporation: San Antonio, TX, 1987.

51. Rey A. L'examen psychologique dans les cas d'encephalopathie traumatique: Les problèmes [The psychological examination in cases of traumatic encephalopathy: Problems]. Archives de Psychologie 1941; 28: 215-285.

52. Wechsler D. Wechsler Adult Intelligence Scale-Revised. Psychological Corporation: New York, 1981.

53. Wechsler D. WAIS-III: Wechsler Adult Intelligence Scale (3rd ed.) Administration and Scoring Manual. Psychological Corporation: San Antonio, TX, 1997.

54. Luteijn F, van der Ploeg FAE. Handleiding Groninger Intelligentietest (GIT) [Manual Groningen Intelligence Test]. Swets \& Zeitlinger: Lisse, The Netherlands, 1983.

55. Cohen J. Statistical power analysis for the behavioral sciences. Erlbaum: Hilssdale, NJ, 1988.

56. Martinez-Aran A, Penades R, Vieta E, Colom F, Reinares M, Benabarre A et al. Executive function in patients with remitted bipolar disorder and schizophrenia and its relationship with functional outcome. Psychother Psychosom 2002; 71(1): 39-46.

57. Zalla T, Joyce C, Szoke A, Schurhoff F, Pillon B, Komano O et al. Executive dysfunctions as potential markers of familial vulnerability to bipolar disorder and schizophrenia. Psychiatry Res 2004; 121(3): 207-217.

58. Chua SE, Murray RM. The neurodevelopmental theory of schizophrenia: evidence concerning structure and neuropsychology. Ann Med 1996; 28(6): 547-555 ${ }^{\star}$ LHM: Journal not available in the University Library, you can make an Inter-library Lending Request at the Loan Desk ISSN: 07853890.

59. Asarnow RF. Neurocognitive impairments in schizophrenia: a piece of the epigenetic puzzle. Eur Child Adolesc Psychiatry 1999; 8(1): I5-8.

60. Baumann B, Bogerts B. The pathomorphology of schizophrenia and mood disorders: similarities and differences. Schizophr Res 1999; 39(2): 141-148; discussion 162.

61. Heinrichs RW, Zakzanis KK. Neurocognitive deficit in schizophrenia: a quantitative review of the evidence. Neuropsychology 1998; 12(3): 426-445.

62. Zakzanis KK, Leach L, Kaplan E. Neuropsychological differential diagnosis. Swets and Zeitlinger: Lisse, the Netherlands, 1999, 139-152pp.

63. Aleman A, Hijman R, De Haan EHF, Kahn RS. Memory impairment in schizophrenia: A metaanalysis. American Journal of Psychiatry 1999; 156: 1358-1366.

64. Goldberg TE, Gold JM, Greenberg R, Griffin S, Schulz SC, Pickar D et al. Contrasts between patients with affective disorders and patients with schizophrenia on a neuropsychological test battery. Am J Psychiatry 1993; 150(9): 1355-1362.

65. Albus M, Hubmann W, Wahlheim C, Sobizack N, Franz U, Mohr F. Contrasts in neuropsychological test profile between patients with first-episode schizophrenia and first-episode affective disorders. Acta Psychiatr Scand 1996; 94(2): 87-93. 


\section{Chapter 3 \\ Meta-analyses of cognitive functioning in euthymic bipolar patients and their first- degree relatives}

Baer Arts ${ }^{1}$, Nienke Jabben ${ }^{1}$, Lydia Krabbendam ${ }^{1}$, Jim van $\mathrm{Os}^{1,2}$

${ }^{1}$ Department of Psychiatry and Neuropsychology, South Limburg Mental Health Research and Teaching Network, EURON, Maastricht University, PO Box 616 (VIJV), 6200 MD Maastricht, The Netherlands

${ }^{2}$ Division of Psychological Medicine, Institute of Psychiatry, London, UK

Psychological Medicine 2008; 38, 771-185 


\section{Abstract}

Background: Previous work suggests that in particular impairments in executive function and verbal memory may persist in euthymic bipolar patients and serve as an indicator of genetic risk (endophenotype).

Methods: A systematic review of the literature was undertaken. Effects sizes were extracted from selected papers and pooled using meta-analytic techniques.

Results: In bipolar patients, large effect sizes $(\mathrm{d}>0.8)$ were noted for executive function (working memory), mental speed and verbal memory. Medium effect sizes $(0.5<\mathrm{d}<0.8)$ were reported for aspects of executive function (fluency, concept shifting, executive control), visual memory, and sustained attention. Small effect sizes $(d<0.5)$ were found for visuoperception. In first-degree relatives, effect sizes were small $(\mathrm{d}<0.5)$, and only significantly different from healthy controls for executive function.

Conclusions: Executive function is a candidate bipolar endophenotype given medium deficits in these domains in bipolar patients and small, but intermediate, cognitive impairments in first-degree relatives. 


\section{Introduction}

Christensen and colleagues (2006) investigated cognitive function in healthy twins discordant for bipolar disorder and found evidence for an association between cognitive dysfunction and genetic liability. The authors concluded that cognitive dysfunction may be a candidate indicator of genetic risk or endophenotype ${ }^{1}$ for bipolar disorder. Thus, there is evidence that cognitive dysfunction persists in euthymic bipolar patients ${ }^{2,3}$ and also non-twin genetically sensitive studies suggest that aspects of cognition can possibly be regarded as endophenotype for bipolar disorder. ${ }^{4-6}$ Possible candidate neurocognitive endophenotypes in bipolar disorder are executive function, ${ }^{4,5}$ attention, ${ }^{6,7}$ and verbal memory. ${ }^{4,6}$ A recent meta-analysis of cognitive deficits in euthymic bipolar patients ${ }^{3}$ provides further evidence for executive function and verbal learning as possible endophenotypes for bipolar disorder.

The aim of the present review was to estimate the meta-analytic effect size of cognitive functioning in euthymic bipolar patients and their first-degree relatives, thus updating a previous systematic review of patients, ${ }^{3}$ and adding a new review for first degree relatives. The hypothesis was that first-degree relatives show cognitive deficits in the same areas as bipolar patients, albeit to a lesser degree.

\section{Methods}

\section{Study selection}

Articles were identified through a literature search in PUBMED / MEDLINE, PSYCHINFO, and EMBASE covering the period between January 1985 and September 2006, using the keywords "bipolar disorder" or "manic depress" and "family"/ "familial" or "first-degree relative" with "cognit*" or "neuropsych".

The following criteria were used for inclusion: i) the study evaluated cognitive performance using standardized and reliable neuropsychological testing procedures; ii) the study compared adult asymptomatic bipolar patients who were diagnosed using a recognised criterion-based diagnostic system and / or first-degree relatives with a healthy control group, matched for age, sex and education; iii) the study reported uncorrected mean test scores and standard deviations for both the patient and / or family and control group; iv) the study was published as an original article in a peer-reviewed English language journal; and v) the study with bipolar patients clearly defined euthymia or provided scores on mood rating scales indicating that patients were euthymic (euthymia defined as a cut-off score of $<8$ on the Hamilton Depression Rating Scale and the Young Mania Rating Scale, and / or a score on mood rating scales below this cut-off point).

The references of retrieved articles were hand-searched for further relevant articles. A second study on the same patient group was only included if it reported different tests. 


\section{Data Analysis}

Meta-analyses were performed using STATA (version 9.2), using a random effects model. For each test parameter an effect size was calculated, which was Cohen's $d$, the difference between the means of both groups (bipolar patients and / or firstdegree relatives vs. controls) divided by the pooled standard deviation. Effect sizes were weighted for sample size, in order to correct for upwardly biased estimation of the effect in small samples. Effect sizes were expressed in such a way that positive effect sizes always indicated poorer performance by the patient or family group. The corresponding $z$-value and significance level provide an indication of the two-sided statistical significance of the association at 5\% alpha. A homogeneity statistic was calculated in order to test to what degree the studies can be taken to share a common population effect size. A significant Chi-square-statistic indicated heterogeneity of the individual effect sizes.

Meta-regression is a technique for trying to work out whether particular characteristics of studies are related to the sizes of the treatment effect. Thus, in the case of significant heterogeneity, meta-regression, using STATA (version 9.2), was performed in order to examine whether any heterogeneity found could possibly be explained by study differences in age structure, sex ratio, and mean educational level.

\section{Results}

\section{Bipolar patients}

Twenty-eight studies were included in the meta-analysis (Table 1, appendix). Four of these stratified their samples by a third variable ${ }^{8-11}$. For reasons of homogeneity, in the case of stratification, only one study group was included, with bias to the less severe patients or those with a better established diagnosis. Thus, Ferrier et al. (1999) stratified by outcome, contrasting a good outcome versus a poor outcome group; for the purpose of the current meta-analysis only the good outcome group was included. The study by Nehra and colleagues (2006) used first and multiple episode patients, only established bipolar patients with multiple episodes were included in the current analysis. Van Gorp and colleagues (1998) included patients with and without prior alcohol dependence, only the group without alcohol dependence was used in the analysis. Finally, Torrent and colleagues (2006) used BP-I and BP-II patients, only BP-I patients were included.

\section{Neuropsychological domains}

The neuropsychological tests used in these studies were divided into 11 categories measuring approximately the same cognitive construct (adapted from Krabbendam et al. 2005). A neuropsychological test was included by the a priori criterion of hav- 
ing been used in at least four different studies. Immediate verbal memory was assessed using word list learning (California Verbal Learning Test (CVLT); ${ }^{12}$ Rey Auditory Verbal Learning Test (RAVLT); ${ }^{13}$ Auditory Verbal Learning Test $\left.(\mathrm{AVLT})^{14}\right)$. For the purposes of the analysis, results of these comparable tests were included together. Delayed verbal memory was assessed using the delayed recall version of the CVLT, RAVLT, and AVLT. Delayed visual memory was measured using the delayed recall version of the Rey Osterrieth Complex Figure. ${ }^{15}$ Working memory was assessed using the Digit Span. ${ }^{16}$ Verbal fluency was measured using either words from a certain category or beginning with a certain letter (FAS). ${ }^{17} \mathrm{Con}$ cept formation and shifting was assessed with the Wisconsin Card Sorting Test (WCST) $;^{18}$ number of perseverative errors and categories achieved were separately analysed. Executive control was measured using the Stroop Color-Word interference ${ }^{19}$ and Trailmaking Test part B. ${ }^{20}$ Sustained attention was assessed using a variant of the Continuous Performance Test. ${ }^{21}$ The test parameter used was number and/or percentage correct response. Mental Speed was measured using the Digit Symbol Substitution Test (DSST) ${ }^{16}$ and the Trailmaking Test part A. ${ }^{20}$ Visuoperception was assessed using the copy version of the Rey Osterrieth Complex Figure. ${ }^{15}$ Intelligence was measured using the full scale $\mathrm{NART}^{22}$ or the WAIS-R vocabulary score, ${ }^{23}$ both good estimates of premorbid intelligence.

\section{Meta-analytic results patients}

All effect sizes were in the same direction (Table 2), suggesting worse performance in euthymic bipolar patients compared to healthy controls.

In all instances, with the exception of visuoconstruction (Rey copy) and intelligence, bipolar patients displayed significantly poorer performance compared to controls. The largest effect sizes were evident for working memory (Digit Span backward), delayed and immediate verbal recall (CVLT), and mental speed (DSST) (effect sizes $>0.8)$. Medium effect sizes $(0.5<\mathrm{d}<0.8)$ were observed for fluency (categories), executive control (Trail B, Stroop), concept shifting (WCST perseverative errors), delayed visual memory (Rey figure), sustained attention (CPT) and mental speed (Trail A). A small effect size $(0.2<\mathrm{d}<0.5)$ was noted for concept shifting (WCST categories), fluency (FAS) and working memory (Digit Span forward). 
Table 2. Results of meta-analyses of cognitive test performance differences between bipolar patients versus normal controls

\begin{tabular}{|c|c|c|c|c|c|c|c|c|c|}
\hline Test & $\mathrm{K}^{1}$ & $\begin{array}{c}\mathrm{N} \\
\mathrm{BP}\end{array}$ & $\begin{array}{c}\mathrm{N} \\
\text { Cont }\end{array}$ & $\mathrm{d}^{2}$ & $95 \% \mathrm{CI}^{3}$ & $\mathrm{Z}^{4}$ & $\mathrm{p}$ & $\mathrm{Chi}^{5}$ & $\mathrm{p}$ \\
\hline Digit backward & 6 & 222 & 205 & 1.02 & 0.49 to 1.54 & 3.85 & 0.000 & 30.50 & 0.000 \\
\hline CVLT delayed recall & 10 & 269 & 282 & 0.85 & 0.60 to 1.09 & 6.83 & 0.000 & 16.27 & 0.061 \\
\hline DSST & 7 & 202 & 249 & 0.84 & 0.53 to 1.14 & 5.32 & 0.000 & 13.76 & 0.032 \\
\hline CVLT immediate rec. & 12 & 369 & 382 & 0.82 & 0.65 to 0.99 & 9.25 & 0.000 & 13.96 & 0.235 \\
\hline Fluency categories & 7 & 178 & 178 & 0.75 & 0.44 to 1.04 & 4.83 & 0.000 & 10.91 & 0.091 \\
\hline Trail B & 10 & 319 & 306 & 0.75 & 0.42 to 1.10 & 4.47 & 0.000 & 33.93 & 0.000 \\
\hline Stroop time & 6 & 116 & 124 & 0.73 & 0.32 to 1.13 & 3.49 & 0.000 & 11.00 & 0.051 \\
\hline WCST Pers. Err. & 10 & 268 & 288 & 0.72 & 0.58 to 0.95 & 5.90 & 0.000 & 15.24 & 0.085 \\
\hline Stroop correct & 8 & 258 & 268 & 0.65 & 0.47 to 0.83 & 7.17 & 0.000 & 2.37 & 0.937 \\
\hline Rey figure & 4 & 98 & 89 & 0.62 & 0.32 to 0.92 & 4.04 & 0.000 & 2.01 & 0.570 \\
\hline CPT correct & 4 & 74 & 85 & 0.58 & 0.09 to 1.08 & 2.31 & 0.021 & 6.52 & 0.089 \\
\hline Trail A & 10 & 319 & 306 & 0.58 & 0.42 to 0.75 & 7.02 & 0.000 & 4.88 & 0.845 \\
\hline WCST Categories & 10 & 268 & 288 & 0.49 & 0.22 to 0.76 & 3.59 & 0.000 & 19.76 & 0.019 \\
\hline FAS & 12 & 369 & 382 & 0.47 & 0.30 to 0.65 & 5.14 & 0.000 & 15.54 & 0.159 \\
\hline Digit forward & 6 & 222 & 205 & 0.37 & 0.15 to 0.59 & 3.33 & 0.001 & 6.19 & 0.288 \\
\hline Rey copy & 4 & 103 & 94 & 0.22 & -0.06 to 0.51 & 1.52 & 0.129 & 2.89 & 0.409 \\
\hline IQ & 8 & 237 & 247 & 0.16 & -0.11 to 0.44 & 1.15 & 0.250 & 15.36 & 0.032 \\
\hline
\end{tabular}

${ }^{1}$ Number of studies included in the analysis; ${ }^{2}$ mean, weighted effect size Cohen's d; ${ }^{3} 95 \%$ confidence interval; ${ }^{4}$ test of significance of effect size (p); ${ }^{5}$ test of within category heterogeneity between studies ( $p$ )

For five out of 17 analyses there was evidence for significant heterogeneity between the results of the different studies. The largest heterogeneity was found for working memory (Digit Span backward), executive control (Trail B) and concept shifting (WCST categories). Two studies were largely responsible for this heterogeneity, namely the study of Balanza-Martinez and colleagues (2005) and Goswami and colleagues (2006). Both showed larger effect sizes. In a sensitivity analysis of working memory (Digit Span backward) excluding the study of Goswami and colleagues (2006), the observed heterogeneity largely disappeared (before exclusion: $\chi^{2}=30.50$, $\mathrm{p}=0.000$; after exclusion: $\left.\chi^{2}=5.70, \mathrm{p}=0.223\right)$. The effect size reflecting bipolar-control differences remained significant $(\mathrm{d}=0.73 ; \mathrm{p}=0.000)$. The study of Goswami and colleagues (2006) caused most of the heterogeneity in the analysis on executive control (Trail B). Leaving this study out resulted in non-significant heterogeneity (before exclusion: $\chi^{2}=33.93, p=0.000$; after exclusion: $\left.\chi^{2}=10.78, p=0.214\right)$. The effect size reflecting bipolar-control differences remained significant $(\mathrm{d}=0.58 ; \mathrm{p}=0.000)$. In the case of concept shifting (WCST categories), heterogeneity was largely caused by the studies of Balanza-Martinez and colleagues (2005) (before exclusion: $\chi^{2}=19.76$, $\mathrm{p}=0.019$; after exclusion: $\left.\chi^{2}=11.21, \mathrm{p}=0.190\right)$. The effect size reflecting bipolarcontrol differences remained significant $(d=0.39 ; \mathrm{p}=0.000)$. The fact that the most 
significant heterogeneity was due to only two studies, suggests that certain characteristics of these studies may be responsible for this finding. The study by BalanzaMartinez and colleagues (2005) was relatively small and used a bipolar population with rather low educational level and no specification of characteristics of disease (duration, number of episodes etc.). One could speculate that they described a rather severely ill population. Goswami and colleagues (2006) used a rather young population with a relatively long duration of illness and early illness onset. This study too likely included a rather severely ill group of patients.

Meta-regression revealed a significant effect of sex ratio on the concept formation and shifting case-control difference (WCST) $(\mathrm{p}=0.001 ; \mathrm{B}=-2.63 ; 95 \% \mathrm{CI}-4.156$ to -1.11). This finding indicates that studies with higher male / female ratios showed smaller effect sizes. Age had a significant effect on the case-control difference of concept formation (WCST) and working memory (Digit Span backward) ( $\mathrm{p}=0.000$; $\mathrm{B}=-32.51 ; 95 \% \mathrm{CI}-43.6$ to -21.4 , and $\mathrm{p}=0.029 ; \mathrm{B}=-11.18 ; 95 \% \mathrm{CI}-21.2$ to -1.18 ). Thus, studies with higher mean age showed smaller effect sizes. Finally, educational level had a significant effect on the working memory case-control difference (Digit Span backward), fluency (FAS) and concept formation (WCST) $(\mathrm{p}=0.03 ; \mathrm{B}=-0.014$; $95 \%$ CI -0.027 to $-0.001 ; \mathrm{p}=0.007 ; \mathrm{B}=36.93 ; 95 \%$ CI 8.38 to $52.24 ; \mathrm{p}=0.014 ; \mathrm{B}=2.53$; $95 \%$ CI 0.52 to 4.55 ). This points in the direction of larger effect sizes in studies with higher educated participants. In conclusion, part of heterogeneity may be due to differences between the various studies in these independent variables.

\section{Meta-analytic results first-degree relatives}

A total of fourteen studies were included (Table 3, appendix). Two of these studies used more than one family group. ${ }^{24,25}$ In the study by McIntosh et al. (2005), a group of unaffected relatives from bipolar families and a group from "mixed" families was used; only the group from bipolar families was included in the analyses. Sobczak et al.. (2003) used a group of first-degree relatives of BP-I patients and a group of relatives of BP-II patients; only the group of family-members of BP-I patients was used in the meta-analysis.

The neuropsychological tests used in the studies were divided in the same categories as described earlier and included only if used in at least four different studies. This resulted in less cognitive domains analysed than in the bipolar studies. These domains were immediate and delayed verbal memory, working memory, concept formation and shifting, verbal fluency, executive control, mental speed, and intelligence. The Visual Verbal Learning Test used in the study by Sobczak and colleagues (2003), measuring immediate and delayed verbal memory and resembling the CVLT and RAVLT, ${ }^{26}$ was added to the analysis.

Meta-analysis of the neuropsychological domains indicated that all metaanalytic effect sizes were in the direction of worse performance in the first-degree relatives compared to the healthy controls (Table 4). Effect sizes, however, were 
much smaller than in the bipolar-control comparisons $(<0.5)$, and only significantly different for executive control (Stroop and Trail B).

Table 4. Results of meta-analyses of cognitive test performance differences between first-degree relatives versus normal controls

\begin{tabular}{|c|c|c|c|c|c|c|c|c|c|}
\hline Test & $\mathrm{k}^{1}$ & $\begin{array}{c}\mathrm{N} \\
\text { Rel }\end{array}$ & $\begin{array}{c}\mathrm{N} \\
\text { Cont }\end{array}$ & $d^{2}$ & $95 \% \mathrm{CI}^{3}$ & $z^{4}$ & $\mathrm{p}$ value & Chi-square $^{5}$ & $\mathrm{p}$ value \\
\hline Stroop & 4 & 71 & 125 & 0.49 & 0.05 to 0.93 & 2.16 & 0.031 & 5.35 & 0.148 \\
\hline Trail B & 7 & 143 & 234 & 0.37 & 0.15 to 0.60 & 3.27 & 0.001 & 4.98 & 0.546 \\
\hline FAS & 4 & 68 & 102 & 0.27 & -0.04 to 0.59 & 1.70 & 0.090 & 3.01 & 0.391 \\
\hline CVLT immediate & 4 & 73 & 94 & 0.22 & -0.09 to 0.53 & 1.38 & 0.167 & 0.08 & 0.994 \\
\hline CVLT delayed recall & 4 & 75 & 191 & 0.21 & -0.07 to 0.50 & 1.45 & 0.146 & 2.11 & 0.550 \\
\hline IQ & 5 & 119 & 191 & 0.19 & -0.27 to 0.65 & 0.82 & 0.414 & 12.77 & 0.012 \\
\hline Digit span backward & 5 & 79 & 266 & 0.18 & -0.33 to 0.69 & 0.69 & 0.490 & 13.29 & 0.010 \\
\hline WCST Pers. Err. & 6 & 140 & 192 & 0.17 & -0.09 to 0.43 & 1.26 & 0.207 & 6.26 & 0.282 \\
\hline DSST & 4 & 74 & 225 & 0.14 & -0.16 to 0.45 & 0.91 & 0.361 & 3.66 & 0.300 \\
\hline Trail A & 7 & 143 & 234 & 0.13 & -0.09 to 0.35 & 1.14 & 0.256 & 5.28 & 0.508 \\
\hline Digit span forward & 4 & 60 & 152 & 0.04 & -0.72 to 0.81 & 0.11 & 0.911 & 15.23 & 0.002 \\
\hline WCST Categories & 4 & 82 & 127 & 0.04 & -0.36 to 0.43 & 0.18 & 0.861 & 5.35 & 0.148 \\
\hline
\end{tabular}

${ }^{1}$ Number of studies included in the analysis; ${ }^{2}$ mean, weighted effect size Cohen's d; ${ }^{3} 95 \%$ confidence interval; ${ }^{4}$ test of significance of effect size (p); ${ }^{5}$ test of within category heterogeneity between studies ( $p$ )

There was evidence of significant heterogeneity for three out of twelve analyses, namely for the domains of intelligence and working memory (Digit Span). Heterogeneity may be due to the small number of studies with small, heterogeneous groups of first-degree relatives with different family histories and genetic load. The study by Gourovitch and colleagues (1999), for example, using monozygotic twins, showed relatively large but differential effect sizes for working memory and verbal memory, contributing to heterogeneity. Meta-regression revealed no significant effects of the independent variables examined.

\section{Discussion}

\section{Patients}

This meta-analysis of cognitive functioning in euthymic bipolar patients provides evidence of cognitive impairments in these patients, particularly in the realm of executive functioning and verbal memory. Large effect sizes were found for working memory, verbal recall and mental speed.

The finding of both executive and memory impairments has been described in the quantitative meta-analysis by Robinson and colleagues (2006), despite the fact 
that we used somewhat stricter inclusion criteria for euthymia and included more recent studies.

There was substantial heterogeneity between the results of the different studies, the largest heterogeneity being noted for working memory, concept shifting and executive control. Two studies ${ }^{9,27,28}$ largely caused this heterogeneity, possibly because of inclusion of relatively severely ill patients with a higher number of (psychotic) episodes. Thus, greater number of episodes, greater length of illness and higher number of hospitalizations has been associated with greater level of neuropsychological dysfunction in bipolar patients. ${ }^{29}$ Heterogeneity may also be caused by the differential effects of age, sex, and education on the cognitive domains mentioned above, as revealed by meta-regression.

Heterogeneity may additionally be caused by residual mood symptoms, because of the variation in the criteria used to define euthymia. It was not possible to include measures of mood as a variable for the meta-regression, however, as the studies included did not use, or did not report, uniformly measured items of mood. Another confound is medication, the use and reporting of which varied between studies. The effects of different types of medication on cognitive function in bipolar patients are not systematically studied, but the effects of lithium may be rather modest, given the small effect size $(\mathrm{d}=0.3)$ in the study by Goswami and colleagues (2002). Furthermore, cognitive deficits are still evident in medication-free patients. ${ }^{30,31}$ Another source of heterogeneity may be the type of bipolar disorder under investigation. Although most studies used bipolar I patients, not all studies specified the type of patients included. Bipolar I patients may show greater, and or different, deficits in cognitive function than bipolar II patients. ${ }^{10,32}$ Matching on education versus IQ may be a confound too, given the study by Glahn and colleagues (2006), who describe less educational attainment despite comparable IQ levels in bipolar patients versus normal controls. Matching on educational attainment could thus give rise to underestimation of the difference in cognitive function between bipolar patients and normal controls. Finally, differences in somatic comorbidity (and comedication) between bipolar patients and normal controls, could contribute to differences in cognitive performance. $^{33}$

\section{First degree relatives}

The meta-analysis in first-degree relatives showed worse performance in all cognitive domains studied, compared to controls. Effect sizes, however, were small and significant only in the domain of executive functioning. This suggests that executive functioning may be a trait marker for the genetic liability for bipolar disorder. Heterogeneity between the results of the different studies may be due to the small number of studies with relatively small, heterogeneous groups of first-degree relatives with different family histories and genetic load. Contrary to the patient metaanalysis, meta-regression revealed no effects of sex, education and age on the meta- 
analytic effect size, suggesting more robust results and fewer sources for underlying heterogeneity.

The possible influence of family history as a source of heterogeneity is illustrated by the study by Schubert and McNeil (2005), who described greater cognitive impairment in offspring of mothers with schizophrenia-spectrum psychosis versus offspring of mothers with affective-spectrum psychosis. Furthermore, Sobczak and colleagues (2003) found more pronounced cognitive impairments in first-degree relatives of bipolar I patients compared to relatives of bipolar II patients. Another possible source of heterogeneity is the fact that only a small number of studies controlled for subclinical mood symptoms in first-degree relatives and controls. Finally, only a small number of studies directly compared cognitive function between bipolar patients, first-degree relatives and healthy controls. ${ }^{24,34,35}$

Our meta-analysis on cognitive function in first-degree relatives of bipolar patients is, to the best of our knowledge, the first in the literature. Comparison with other meta-analytic reviews is therefore only possible with first-degree relatives of other patient groups, for example patients with schizophrenia. Such a comparison is topical, given the fact that bipolar and schizophrenia phenotypes likely share genetic risk factors. ${ }^{36}$ Various meta-analyses of cognitive function in first-degree relatives of patients with a diagnosis of schizophrenia ${ }^{37-39}$ describe the largest effect sizes $(d=0.5$ to 0.6 ) for executive functioning and verbal memory, with somewhat different effect sizes for different executive tests used and greater effect sizes in multiplex families. ${ }^{40}$ This qualitative pattern of effects sizes and tests are rather similar to those presented here for the relatives of patients with bipolar disorder. In the review by Snitz and colleagues (2006), the type of biological relative, parent, sibling, or offspring did not impact on effect sizes of cognitive deficits in unaffected first-degree relatives of patients with a diagnosis of schizophrenia. Asymmetric psychiatric exclusion criteria and screening controls more stringently than relatives did influence the effect sizes in the review by Snitz and colleagues (2006). Therefore, this source could also contribute to the heterogeneity observed in the current meta-analysis.

Heydebrand (2006), reviewing meta-analyses on cognitive function in relatives of patients with a diagnosis of schizophrenia, concludes that the most consistent deficit shown by relatives is impaired performance on 'maintenance plus' frontallobe tasks, requiring increased effort and higher central executive processing. This cognitive phenotype therefore may be a likely candidate endophenotype for both schizophrenia and bipolar disorder. In this respect it may be important that memory performance is affected by executive dysfunction, as shown by shared variance of $50-60 \% .{ }^{41}$ A quantitative review of cognitive functioning in patients with schizophrenia and bipolar disorder yielded largest (differences in) effect sizes on executive function and verbal memory; bipolar patients generally better performing than patients with schizophrenia. ${ }^{42}$ Important in this respect is the fact that there were only quantitative, and not qualitative, differences between bipolar patients and patients with a diagnosis of schizophrenia, which fits in with current models of the relationship between both disorders. Murray and colleagues (2004) hypothesize that certain 
shared susceptibility genes may predispose individuals to psychosis in general. A candidate gene may be neuregulin 1, which influences susceptibility to bipolar disorder and schizophrenia, especially in bipolar patients with mood-incongruent psychotic features and patients with a diagnosis of schizophrenia with mania. ${ }^{43}$ Polymorphisms of neuregulin, influencing, amongst others, synaptic signalling by glutamate receptors, play possibly a role in cognition. ${ }^{44-46}$ Other candidate genes in this respect are Disc $1^{47-49}$ and $\mathrm{BDNF},{ }^{50}$ both related to susceptibility to schizophrenia as well as bipolar disorder on the one hand, and cognitive dysfunction (executive function and memory) on the other. Finally, COMT-polymorphisms may play a role as well, in particular the COMT Val ${ }^{158}$ Met polymorphism and other polymorphisms on the same gene, that have been associated with prefrontal cognitive functioning in schizophrenia and bipolar patients and their first-degree relatives. ${ }^{51-55}$ Interestingly, the COMT Val ${ }^{158}$ Met polymorphism influences the improvement of cognitive functioning in patients with a diagnosis of schizophrenia treated with clozapine, ${ }^{56}$ and differential effects are described of these polymorphisms on the results of different tests of executive function. ${ }^{57}$ Furthermore, the COMT Met ${ }^{158}$ Met genotype is associated with heightened reactivity and connectivity in corticolimbic circuits, leading to inflexible processing of affective stimuli contributing to emotional dysregulation. ${ }^{58}$ Tunbridge and colleagues (2006), reviewing the literature on COMT polymorphisms, conclude that the Met allele is associated with improved executive function compared with the Val allele, but also with impaired emotional processing. Bilder and colleagues (2004) hypothesize that the COMT Met allele, associated with low enzyme activity, results in increased levels of tonic dopamine (DA) and reciprocal reductions in phasic DA in subcortical regions and increased D1 transmission cortically, leading to increased stability but decreased flexibility of neural networks. This model fits in with results from, amongst others, f-MRI-studies pointing in the direction of dysregulation of prefrontal area influence on subcortical neural regions, explaining cognitive dysfunction and mood symptoms. ${ }^{59-61}$

To summarize, executive function may be a candidate endophenotype for the genetic liability for bipolar disorder, as suggested by the current meta-analyses on bipolar patients and their first-degree relatives.

Guidelines for future research on cognitive deficits in schizophrenia and bipolar patients and their relatives (adapted from) ${ }^{40}$ are: i) sufficient sample size to allow the examination of specific cognitive deficits as well as for genetic testing; ii) use of cognitive measures that are sufficiently specific and sensitive, and have ecological validity; iii) longitudinal studies; iv) recruitment of heterogeneous control samples; v) control for psychopathology; and vi) investigation of heterogeneity of cognitive function in patients and relatives, in relation to neurobiological findings. 


\section{Appendix}

Table 1. Studies with bipolar patients included in the meta-analysis

\begin{tabular}{|c|c|c|c|c|c|}
\hline \multirow[t]{2}{*}{ Author, year } & \multicolumn{2}{|l|}{$\mathrm{N}$} & \multirow{2}{*}{$\begin{array}{l}\text { Definition of } \\
\text { euthymia }\end{array}$} & \multirow{2}{*}{$\begin{array}{l}\text { Neuropsychological test } \\
\text { parameters }\end{array}$} & \multirow[t]{2}{*}{$\mathrm{d}^{1}$} \\
\hline & Patients & Controls & & & \\
\hline \multirow[t]{11}{*}{ Altshuler, 2004} & 40 & 22 & $\mathrm{HDRS}^{2}<6$ & $\mathrm{CVLT}^{11}$ immediate recall & 0.75 \\
\hline & & & $\mathrm{YMRS}^{3}<7$ & CVLT delayed recall & 0.78 \\
\hline & & & $\begin{array}{l}\text { prospectively for } 3 \\
\text { months }\end{array}$ & Rey Figure delayed & 0.57 \\
\hline & & & & FAS $^{12}$ & 0.16 \\
\hline & & & & $\mathrm{WCST}^{13}$ pers. err. & 0.77 \\
\hline & & & & WCST cat. & 0.89 \\
\hline & & & & Stroop time & 0.41 \\
\hline & & & & Trail A & 0.38 \\
\hline & & & & Trail B & 0.40 \\
\hline & & & & IQ & 0.20 \\
\hline & & & & Rey Figure copy & 0.30 \\
\hline \multirow[t]{8}{*}{ Balanza-Martinez, 2005} & 15 & 26 & $\mathrm{HDRS}<8$ & FAS & 1.28 \\
\hline & & & HDRS: 3.4 (2.9) & Fluency cat. & 1.79 \\
\hline & & & $\mathrm{CARS}^{4}<8$ & WCST pers. err. & 1.67 \\
\hline & & & CARS: $1.3(1.8)$ & WCST cat. & 1.48 \\
\hline & & & 2 months euthymia & Stroop time & 1.62 \\
\hline & & & & Trail A & 0.68 \\
\hline & & & & Trail B & 0.89 \\
\hline & & & & $\operatorname{DSST}^{14}$ & 1.05 \\
\hline \multirow[t]{4}{*}{ Blumberg, 2003} & 15 & 20 & HDRS $<8$ & Stroop time & 0.74 \\
\hline & & & HDRS: 7.3 (7.1) & & \\
\hline & & & CARS $<8$ & & \\
\hline & & & CARS: $4.1(5.0)$ & & \\
\hline \multirow[t]{4}{*}{ Bozikas, 2005} & 19 & 30 & MADRS $^{5}<9$ & $\mathrm{CPT}^{15}$ & 0.10 \\
\hline & & & MADRS: 1.53 (2.61) & & \\
\hline & & & YMRS $<9$ & & \\
\hline & & & YMRS: $3.16(2.48)$ & & \\
\hline \multirow[t]{4}{*}{ Cavanagh, 2002} & 20 & 20 & HDRS $<8$ & CVLT delayed recall & 0.96 \\
\hline & & & $1.0(2.9)$ & FAS & 0.29 \\
\hline & & & $\mathrm{MMS}^{6}<3$ & Stroop correct & 0.61 \\
\hline & & & MMS: 0.5 (1.5) & & \\
\hline \multirow[t]{4}{*}{ Clark, 2002} & 30 & 30 & $\mathrm{HDRS}<9$ & CVLT immediate recall & 0.48 \\
\hline & & & HDRS: 2.07 (2.26) & CVLT delayed recall & 0.95 \\
\hline & & & $\mathrm{YMRS}<9$ & CPT & 0.96 \\
\hline & & & YMRS:1.67 (2.22) & & \\
\hline
\end{tabular}




\begin{tabular}{|c|c|c|c|c|c|}
\hline \multirow[t]{2}{*}{ Author, year } & \multicolumn{2}{|l|}{$\mathrm{N}$} & \multirow{2}{*}{$\begin{array}{l}\text { Definition of } \\
\text { euthymia }\end{array}$} & \multirow{2}{*}{$\begin{array}{l}\text { Neuropsychological test } \\
\text { parameters }\end{array}$} & \multirow[t]{2}{*}{$\mathrm{d}^{1}$} \\
\hline & Patients & Controls & & & \\
\hline \multirow[t]{4}{*}{ Clark, 2005} & 15 & 15 & HDRS $<9$ & $\mathrm{CPT}$ & 1.00 \\
\hline & & & HDRS: $3.2(2.5)$ & & \\
\hline & & & YMRS $<9$ & & \\
\hline & & & YMRS: $1.9(2.5)$ & & \\
\hline Deckersbach, 2004 & 30 & 30 & HDRS: $3.4(2.6)$ & CVLT immediate recall & 1.40 \\
\hline \multirow[t]{2}{*}{ Deckersbach, 2004a } & 25 & 25 & HDRS: 3.3 (2.5) & Rey Figure delayed & 0.70 \\
\hline & & & YMRS: $1.2(1.5)$ & Rey Figure copy & 0.06 \\
\hline \multirow[t]{4}{*}{ Dixon, 2004} & 15 & 30 & $\mathrm{BDI}^{7}: 6.5(4.3)$ & FAS & 0.17 \\
\hline & & & YMRS: $2.7(2.2)$ & Fluency cat. & 0.30 \\
\hline & & & & Stroop correct & 0.82 \\
\hline & & & & IQ & -0.32 \\
\hline \multirow[t]{9}{*}{ Ferrier, 1999} & 20 & 20 & HDRS: 2.7 (2.1) & RAVLT $^{16}$ immediate recall & 0.93 \\
\hline & & & $\mathrm{MSS}^{8}: 4.1(1.9)$ & Rey Figure delayed & 0.92 \\
\hline & & & & Digit Span Backward & 1.11 \\
\hline & & & & FAS & 0.40 \\
\hline & & & & Trail A & 0.81 \\
\hline & & & & Trail B & 0.92 \\
\hline & & & & DSST & 0.81 \\
\hline & & & & Digit Span forward & 0.28 \\
\hline & & & & Rey Figure copy & 0.64 \\
\hline \multirow[t]{3}{*}{ Fleck, 2003} & 14 & 40 & HDRS $<10$ & CVLT immediate recall & 1.01 \\
\hline & & & HDRS: 3.7 (2.8) & CVLT delayed recall & 0.77 \\
\hline & & & YMRS $<10$ & & \\
\hline \multirow[t]{5}{*}{ Frangou, 2005a } & 10 & 43 & $\mathrm{HDRS}<6$ & WCST pers. err. & 0.55 \\
\hline & & & HDRS: $3.0(1.2)$ & WCST cat. & 0.04 \\
\hline & & & YMRS $<6$ & & \\
\hline & & & YMRS: $1.1(0.5)$ & & \\
\hline & & & at least 1 month & & \\
\hline \multirow[t]{5}{*}{ Frangou, 2005b } & 44 & 44 & HDRS $<10$ & FAS & 0.88 \\
\hline & & & HDRS: 7 & WCST pers. err. & 0.38 \\
\hline & & & $\mathrm{MRS}^{9}<10$ & WCST cat. & 0.25 \\
\hline & & & MRS: 0 & Stroop correct & 0.57 \\
\hline & & & & IQ & 0.31 \\
\hline \multirow[t]{6}{*}{ Goswami, 2006} & 37 & 37 & euthymia $>1$ month & RAVLT immediate recall & 0.69 \\
\hline & & & HDRS: 2.35 (1.48) & Digit Span backward & 2.28 \\
\hline & & & $\mathrm{MSRS}^{10}: 7.91(4.88)$ & Trail A & 0.54 \\
\hline & & & & Trail B & 1.99 \\
\hline & & & & DSST & 0.19 \\
\hline & & & & Digit Span forward & 0.50 \\
\hline
\end{tabular}




\begin{tabular}{|c|c|c|c|c|c|}
\hline \multirow[t]{2}{*}{ Author, year } & \multicolumn{2}{|l|}{$\mathrm{N}$} & \multirow{2}{*}{$\begin{array}{l}\text { Definition of } \\
\text { euthymia }\end{array}$} & \multirow{2}{*}{$\begin{array}{l}\text { Neuropsychological test } \\
\text { parameters }\end{array}$} & \multirow[t]{2}{*}{$\mathrm{d}^{1}$} \\
\hline & Patients & ontrols & & & \\
\hline \multirow[t]{5}{*}{ Krabbendam, 2000} & 21 & 22 & HDRS: 3.4 (3.0) & $\mathrm{AVLT}^{17}$ immediate recall & 0.94 \\
\hline & & & YMRS: 0.77 (1.5) & AVLT delayed recall & 0.93 \\
\hline & & & & Fluency cat. & 0.54 \\
\hline & & & & Stroop time & 0.67 \\
\hline & & & & DSST & 1.12 \\
\hline \multirow[t]{4}{*}{ Larsson, 2005} & 18 & 18 & HDRS: 3 (3) & IQ & 0.12 \\
\hline & & & YMRS: 2 (3) & & \\
\hline & & & follow-up for 4 to 8 & & \\
\hline & & & weeks & & \\
\hline \multirow[t]{4}{*}{ Malhi, 2005} & 12 & 12 & HDRS $<7$ & Stroop time & 1.02 \\
\hline & & & HDRS: 4.3 (1.1) & & \\
\hline & & & YMRS $<7$ & & \\
\hline & & & YMRS: $0.9(0.5)$ & & \\
\hline \multirow[t]{12}{*}{ Martinez-Aran, 2004} & 44 & 30 & HDRS $<9$ & CVLT immediate recall & 0.84 \\
\hline & & & HDRS: $3.6(2.6)$ & CVLT delayed recall & 0.96 \\
\hline & & & YMRS $<7$ & Digit Span backward & 0.86 \\
\hline & & & YMRS: $1.4(1.8)$ & FAS & 0.56 \\
\hline & & & 6 months remission & Fluency cat. & 0.83 \\
\hline & & & & WCST pers. err. & 0.62 \\
\hline & & & & WCST cat. & 0.38 \\
\hline & & & & Stroop correct & 0.59 \\
\hline & & & & Trail A & 0.90 \\
\hline & & & & Trail B & 0.57 \\
\hline & & & & Digit Span forward & 0.56 \\
\hline & & & & IQ & 0.75 \\
\hline \multirow[t]{3}{*}{ McIntosh, 2005} & 27 & 50 & HDRS: 5 & FAS & 0.71 \\
\hline & & & YMRS: 2 & DSST & 1.34 \\
\hline & & & & IQ & -0.07 \\
\hline \multirow[t]{6}{*}{ Nehra, 2006} & 30 & 20 & HDRS $<8$ & FAS & 0.45 \\
\hline & & & HDRS: 2.67 (0.92) & Fluency cat. & 0.46 \\
\hline & & & $\mathrm{YMRS}<8$ & WCST pers. err. & $0 . .37$ \\
\hline & & & YMRS: 1.47 (1.25) & WCST cat. & 0.07 \\
\hline & & & & Trail A & 0.41 \\
\hline & & & & Trail B & 0.69 \\
\hline \multirow[t]{4}{*}{ Strakowski, 2004} & 10 & 10 & HDRS $<8$ & $\mathrm{CPT}$ & 0.21 \\
\hline & & & HDRS: 3.1 (2.5) & & \\
\hline & & & YMRS $<6$ & & \\
\hline & & & YMRS: $1.6(1.8)$ & & \\
\hline
\end{tabular}




\begin{tabular}{|c|c|c|c|c|c|}
\hline \multirow[t]{2}{*}{ Author, year } & \multicolumn{2}{|l|}{$\mathrm{N}$} & \multirow{2}{*}{$\begin{array}{l}\text { Definition of } \\
\text { euthymia }\end{array}$} & \multirow{2}{*}{$\begin{array}{l}\text { Neuropsychological test } \\
\text { parameters }\end{array}$} & \multirow[t]{2}{*}{$\mathrm{d}^{1}$} \\
\hline & Patients & Controls & & & \\
\hline \multirow[t]{8}{*}{ Thompson, 2005} & 63 & 63 & HDRS $<8$ & RAVLT immediate recall & 0.59 \\
\hline & & & HDRS: 2.1 (1.7) & Digit Span backward & 0.37 \\
\hline & & & $\mathrm{YMRS}<8$ & FAS & 0.36 \\
\hline & & & YMRS: $1.4(2.0)$ & Stroop correct & 0.58 \\
\hline & & & $\begin{array}{l}\text { Prosp. verified for } 1 \\
\text { month }\end{array}$ & Trail A & 0.47 \\
\hline & & & & Trail B & 0.23 \\
\hline & & & & DSST & 0.91 \\
\hline & & & & Digit Span forward & 0.05 \\
\hline \multirow[t]{4}{*}{ Thompson, 2006} & 20 & 20 & HDRS $<8$ & Digit Span backward & 0.75 \\
\hline & & & HDRS: 1.90 (2.38) & Digit Span forward & 0.25 \\
\hline & & & YMRS $<8$ & & \\
\hline & & & YMRS: 1.40 (2.08) & & \\
\hline \multirow[t]{11}{*}{ Torrent, 2006} & 38 & 35 & HDRS $<9$ & CVLT immediate recall & 0.58 \\
\hline & & & HDRS: 4.29 (2.51) & CVLT delayed recall & 0.80 \\
\hline & & & YMRS $<7$ & Digit Span backward & 0.86 \\
\hline & & & YMRS: 0.79 (1.19) & FAS & 0.41 \\
\hline & & & & Fluency cat. & 0.76 \\
\hline & & & & WCST pers. err. & 0.56 \\
\hline & & & & WCST cat. & 0.23 \\
\hline & & & & Stroop correct & 0.58 \\
\hline & & & & Trail A & 0.80 \\
\hline & & & & Trail B & 0.57 \\
\hline & & & & Digit Span forward & 0.70 \\
\hline \multirow[t]{10}{*}{ Van Gorp, 1998} & 13 & 22 & HDRS $<7$ & CVLT immediate recall & 0.70 \\
\hline & & & YMRS $<6$ & CVLT delayed recall & 0.52 \\
\hline & & & & Rey Figure delayed & 0.25 \\
\hline & & & & FAS & -0.11 \\
\hline & & & & WCST pers. err. & 0.95 \\
\hline & & & & WCST cat. & 1.00 \\
\hline & & & & Stroop time & 0.08 \\
\hline & & & & Trail A & 0.32 \\
\hline & & & & Trail B & 0.24 \\
\hline & & & & Rey figure copy & -0.09 \\
\hline
\end{tabular}




\begin{tabular}{|c|c|c|c|c|c|}
\hline \multirow[t]{2}{*}{ Author, year } & \multicolumn{2}{|l|}{$\mathrm{N}$} & \multirow{2}{*}{$\begin{array}{l}\text { Definition of } \\
\text { euthymia }\end{array}$} & \multirow{2}{*}{$\begin{array}{l}\text { Neuropsychological test } \\
\text { parameters }\end{array}$} & \multirow[t]{2}{*}{$\mathrm{d}^{1}$} \\
\hline & Patient & ntrols & & & \\
\hline \multirow[t]{9}{*}{ Varga, 2006} & 19 & 31 & MADRS: 2.26 (3.69) & AVLT immediate recall & 1.52 \\
\hline & & & MRS: $2.32(4.10)$ & AVLT delayed recall & 1.04 \\
\hline & & & & WCST pers. err. & 0.55 \\
\hline & & & & WCST cat. & 0.15 \\
\hline & & & & Stroop correct & 0.80 \\
\hline & & & & Trail A & 0.53 \\
\hline & & & & Trail B & 1.24 \\
\hline & & & & DSST & 0.54 \\
\hline & & & & IQ & 0.57 \\
\hline \multirow[t]{6}{*}{ Zubieta, 2001} & 15 & 15 & HDRS $<6$ & Fluency cat. & 0.77 \\
\hline & & & HDRS: $3.4(2.1)$ & WCST pers. err. & 1.52 \\
\hline & & & $\mathrm{YMRS}<4$ & WCST cat. & 0.84 \\
\hline & & & YMRS: $0.4(0.6)$ & Stroop correct & 1.12 \\
\hline & & & at least 6 months & & \\
\hline & & & euthymia & & \\
\hline
\end{tabular}

${ }^{1}$ Effect size, positive values indicate better performance in controls; ${ }^{2}$ Hamilton depression Rating Scale; ${ }^{3}$ Young Mania Rating Scale; ${ }^{4}$ Clinician Administered Rating Scale for Mania; ${ }^{5}$ Montgomery-Asberg Depressive Rating Scale; ${ }^{6}$ Modified Manic Scale; ${ }^{7}$ Beck Depression Inventory; ${ }^{8}$ Manic State Scale; ${ }^{9}$ Manic Rating Scale; ${ }^{10}$ Manic State Rating Scale; ${ }^{11}$ California Verbal Learning Test; ${ }^{12}$ Verbal fluency test; ${ }^{13}$ Wisconsin Card Sorting Test; ${ }^{14}$ Digit Symbol Substitution Test; ${ }^{15}$ Continuous Performance Test; ${ }^{16}$ Rey Auditory Verbal Learning Test; ${ }^{17}$ Auditory Verbal Learning Test

Table 3. Studies with first-degree family members included in the meta-analysis

\begin{tabular}{|c|c|c|c|c|c|}
\hline \multirow[t]{2}{*}{ Author, year } & \multicolumn{2}{|l|}{$\mathrm{N}$} & \multirow{2}{*}{$\begin{array}{l}\text { Sample } \\
\text { characteristics }\end{array}$} & \multirow{2}{*}{$\begin{array}{l}\text { Neuropsychological test } \\
\text { parameters }\end{array}$} & \multirow[t]{2}{*}{$\mathrm{d}^{1}$} \\
\hline & Relatives & Controls & & & \\
\hline \multirow[t]{4}{*}{ Christensen, 2006a } & 7 & 36 & \multicolumn{3}{|l|}{ MZ twins discordant for } \\
\hline & & & bipolar disorder & Stroop & 0.37 \\
\hline & & & & Trail A & 0.20 \\
\hline & & & & Trail B & 0.63 \\
\hline \multirow[t]{4}{*}{ Christensen, 2006b } & 14 & 52 & \multicolumn{3}{|l|}{ DZ twins discordant for } \\
\hline & & & bipolar & Stroop & 0.45 \\
\hline & & & disorder & Trail A & -0.10 \\
\hline & & & & Trail B & 0.25 \\
\hline \multirow[t]{4}{*}{ Clark, 2005} & 27 & 47 & \multicolumn{3}{|l|}{10 parents; 12 siblings; 5} \\
\hline & & & children & CVLT $^{6}$ immediate recall & 0.20 \\
\hline & & & HDRS $^{2}: 1.2(1.9)$ & CVLT delayed recall & 0.12 \\
\hline & & & YMRS $^{3}: 0.4(1.1)$ & & \\
\hline
\end{tabular}




\begin{tabular}{|c|c|c|c|c|c|}
\hline \multirow[t]{2}{*}{ Author, year } & \multicolumn{2}{|l|}{$\mathrm{N}$} & \multirow{2}{*}{$\begin{array}{l}\text { Sample } \\
\text { characteristics }\end{array}$} & \multirow{2}{*}{$\begin{array}{l}\text { Neuropsychological test } \\
\text { parameters }\end{array}$} & \multirow[t]{2}{*}{$\mathrm{d}^{1}$} \\
\hline & Relatives & Controls & & & \\
\hline \multirow[t]{8}{*}{ Ferrier, 2004} & 17 & 17 & first-degree relatives & RAVLT $^{7}$ immediate recall & 0.18 \\
\hline & & & HDRS: $0.82(1.01)$ & Digit Span backward & 0.99 \\
\hline & & & YMRS: 0.47 (1.28) & FAS $^{8}$ & -0.12 \\
\hline & & & controls & Stroop & 0.00 \\
\hline & & & HDRS: $0.35(0.86)$ & Trail A & -0.07 \\
\hline & & & YMRS: $0.18(0.53)$ & Trail B & 0.37 \\
\hline & & & & DSST $^{9}$ & 0.24 \\
\hline & & & & Digit Span forward & 0.39 \\
\hline \multirow[t]{4}{*}{ Frangou, 2005} & 15 & 43 & unaffected offspring of & & \\
\hline & & & bipolar probands & $\mathrm{WCST}^{10}$ pers. err. & -0.42 \\
\hline & & & & WCST cat. & -0.53 \\
\hline & & & & WAIS-R IQ & -0.09 \\
\hline \multirow[t]{9}{*}{ Gourovitch, 1999} & 7 & 15 & MZ twins & CVLT immediate recall & 0.33 \\
\hline & & & & CVLT delayed recall & 0.80 \\
\hline & & & & Digit Span backward & 0.97 \\
\hline & & & & FAS & 0.28 \\
\hline & & & & WCST pers. err. & 0.52 \\
\hline & & & & Trail A & -0.10 \\
\hline & & & & Trail B & 0.01 \\
\hline & & & & Digit Span forward & 1.16 \\
\hline & & & & WAIS-R IQ & 0.40 \\
\hline \multirow[t]{5}{*}{ Keri, 2001} & 20 & 20 & unaffected siblings & Digit Span backward & 0.18 \\
\hline & & & BP-I probands & FAS & 0.12 \\
\hline & & & & WCST pers. err. & 0.10 \\
\hline & & & & WCST cat. & 0.11 \\
\hline & & & & Digit Span forward & -0.33 \\
\hline \multirow[t]{4}{*}{ Kieseppa, 2005} & 19 & 114 & twins discordant for $\mathrm{BP}$ & & \\
\hline & & & I & CVLT delayed recall & 0.08 \\
\hline & & & & Digit Span backward & -0.18 \\
\hline & & & & DSST & -0.12 \\
\hline \multirow[t]{7}{*}{ Kremen, 1998} & 14 & 44 & relatives of psychotic & & \\
\hline & & & bipolar probands & WCST pers. err. & 0.09 \\
\hline & & & & WCST cat. & 0.45 \\
\hline & & & & Trail A & -0.28 \\
\hline & & & & Trail B & 0.11 \\
\hline & & & & DSST & -0.05 \\
\hline & & & & WAIS-R IQ & -0.58 \\
\hline
\end{tabular}




\begin{tabular}{|c|c|c|c|c|c|}
\hline \multirow[t]{2}{*}{ Author, year } & \multicolumn{2}{|l|}{$\mathrm{N}$} & \multirow{2}{*}{$\begin{array}{l}\text { Sample } \\
\text { characteristics }\end{array}$} & \multirow{2}{*}{$\begin{array}{l}\text { Neuropsychological test } \\
\text { parameters }\end{array}$} & \multirow[t]{2}{*}{$\mathrm{d}^{1}$} \\
\hline & Relatives & Controls & & & \\
\hline \multirow[t]{8}{*}{ McIntosh, 2005} & 24 & 50 & \multirow{2}{*}{\multicolumn{2}{|c|}{$\begin{array}{l}\text { unaffected relatives with FAS } \\
>1 \text { first-or second }\end{array}$}} & 0.58 \\
\hline & & & & & \\
\hline & & & degree BP-proband & DSST & 0.50 \\
\hline & & & HDRS: 1.5 (median) & & \\
\hline & & & YMRS: 0 & & \\
\hline & & & controls & & \\
\hline & & & HDRS: 0 & & \\
\hline & & & YMRS: 0 & & \\
\hline \multirow[t]{2}{*}{ Pirkola, 2005} & 16 & 100 & unaffected co-twins & Digit Span backward & -0.30 \\
\hline & & & $3 \mathrm{MZ} 13 \mathrm{DZ}$ & Digit Span forward & -0.78 \\
\hline \multirow[t]{3}{*}{ Sobczak, 2003} & 22 & 15 & \multicolumn{3}{|l|}{ first-degree relatives BP- } \\
\hline & & & I & VVLT immediate recall & 0.25 \\
\hline & & & & VVLT delayed recall & 0.34 \\
\hline \multirow[t]{3}{*}{ Szoke, 2006} & 51 & 50 & first-degree relatives & WCST pers. err. & 0.22 \\
\hline & & & of BP-I patients & Trail A & 0.41 \\
\hline & & & & Trail B & 0.54 \\
\hline \multirow[t]{2}{*}{ Toulopoulou, 2006} & 50 & 69 & 17 parents, 23 siblings & WAIS-R IQ & 0.42 \\
\hline & & & 10 children & & \\
\hline \multirow[t]{6}{*}{ Zalla, 2004} & 33 & 20 & 11 parents, 22 siblings & WCST pers. err. & 0.57 \\
\hline & & & $\mathrm{MADRS}^{4}<16$ & WCST cat. & 0.12 \\
\hline & & & MAS $^{5}<7$ & Stroop & 1.03 \\
\hline & & & & Trail A & 0.31 \\
\hline & & & & Trail B & 0.60 \\
\hline & & & & WAIS-R IQ & 0.79 \\
\hline
\end{tabular}

${ }^{1}$ effect size, positive values indicate better performance in controls; ${ }^{2}$ Hamilton Depression Rating Scale; ${ }^{3}$ Young Mania Rating Scale; ${ }^{4}$ Montgomery-Asberg Depressive Rating Scale; ${ }^{5}$ MAS Beck and Rafaelsen Mania Scale; ${ }^{6}$ California Verbal Learning Test; ${ }^{7}$ Rey Auditory verbal Learning Test; ${ }^{8}$ Verbal fluency; ${ }^{9}$ Digit Symbol Substitution Test; ${ }^{10} \mathrm{~W}$ isconsin Card Sorting Test 


\section{References}

1. Gottesman, II, Gould TD. The endophenotype concept in psychiatry: etymology and strategic intentions. Am J Psychiatry 2003; 160(4): 636-645.

2. Savitz J, Solms M, Ramesar R. Neuropsychological dysfunction in bipolar affective disorder: a critical opinion. Bipolar Disord 2005; 7(3): 216-235.

3. Robinson LJ, Thompson JM, Gallagher P, Goswami U, Young AH, Ferrier IN et al. A meta-analysis of cognitive deficits in euthymic patients with bipolar disorder. J Affect Disord 2006; 93(1-3): 105115.

4. Glahn DC, Bearden CE, Niendam TA, Escamilla MA. The feasibility of neuropsychological endophenotypes in the search for genes associated with bipolar affective disorder. Bipolar Disord 2004; 6(3): 171-182.

5. Savitz JB, Solms M, Ramesar RS. Neurocognitive function as an endophenotype for genetic studies of bipolar affective disorder. Neuromolecular Med 2005; 7(4): 275-286.

6. Hasler G, Drevets WC, Gould TD, Gottesman, II, Manji HK. Toward constructing an endophenotype strategy for bipolar disorders. Biol Psychiatry 2006; 60(2): 93-105.

7. Burdick KE, Goldberg JF, Harrow M, Faull RN, Malhotra AK. Neurocognition as a stable endophenotype in bipolar disorder and schizophrenia. J Nerv Ment Dis 2006; 194(4): 255-260.

8. Ferrier IN, Stanton BR, Kelly TP, Scott J. Neuropsychological function in euthymic patients with bipolar disorder. Br J Psychiatry 1999; 175: 246-251.

9. Nehra R, Chakrabarti S, Pradhan BK, Khehra N. Comparison of cognitive functions between firstand multi-episode bipolar affective disorders. J Affect Disord 2006; 93(1-3): 185-192.

10. Torrent C, Martinez-Aran A, Daban C, Sanchez-Moreno J, Comes M, Goikolea JM et al. Cognitive impairment in bipolar II disorder. Br J Psychiatry 2006; 189: 254-259.

11. van Gorp WG, Altshuler L, Theberge DC, Wilkins J, Dixon W. Cognitive impairment in euthymic bipolar patients with and without prior alcohol dependence. A preliminary study. Arch Gen Psychiatry 1998; 55(1): 41-46.

12. Delis D, C., Kramer, J.H., Kaplan, E., Ober, B.A. California Verbal Learning Test : Adult version. The Psychological Corporation: San Antonio, TX, 1987.

13. Rey A. L'examen psychologique dans les cas d'encephalopathie traumatique. Presses Universitaires de France: Paris, 1964.

14. Brand N, Jolles J. Learning and retrieval rate of words presented auditorily and visually. J Gen Psychol 1985; 112(2): 201-210.

15. Rey A. L'examen psychologique dans les cas d' encephalopathie traumatique: les problemes [ The psychological examination in cases of traumatic encephalopathy: problems ]. Archives de Psychologie 1941; 28: 215-285.

16. Wechsler D. Wechsler Adult Intelligence Scale. Manual. Psychological Corporation: New York, 1955.

17. Benton AL, Hamsher, K. Multilingual Aphasia Examination Manual Revised. University of Iowa: Iowa, 1978.

18. Heaton RK. A Manual for the Wisconsin Card Sorting Test. Psychological Assessment Resources: Odessa, 1981.

19. Stroop JR. Studies of interference in serial verbal reactions. Journal of Experimental Psychology 1935; 18: 643-662.

20. Reitan RM. Validity of the Trail Making Test as an indicator of organic brain damage. Percept Mot Skills 1958; 8: 271-276.

21. Kurtz MM, Ragland, J.D., Bilker, W., Gur, R.C., Gur, R.E. Comparison of the continuous performance test with and without working memory demands in healthy controls and patients with schizophrenia. Schizophr Res 2001; 48: 307-316.

22. Grober E, Sliwinski, M. Development and validation of a model for estimating premorbid verbal intelligence in the elderly. J Clin Exp Neuropsychol 1991; 19: 933-949.

23. Wechsler D. Wechsler Adult Intelligence Scale-Revised. Psychological Corporation: New York, 1981. 
24. McIntosh AM, Harrison LK, Forrester K, Lawrie SM, Johnstone EC. Neuropsychological impairments in people with schizophrenia or bipolar disorder and their unaffected relatives. Br J Psychiatry 2005; 186: 378-385.

25. Sobczak S, Honig A, Schmitt JA, Riedel WJ. Pronounced cognitive deficits following an intravenous L-tryptophan challenge in first-degree relatives of bipolar patients compared to healthy controls. Neuropsychopharmacology 2003; 28(4): 711-719.

26. Lezak MD. Neuropsychological assessment. 3rd ed. edn. Oxford University Press: New York, 1995.

27. Balanza-Martinez V, Tabares-Seisdebos, R., Selva-Vera, G., Martinez-Aran, A., Torrent, C., SalazarFraile, J., Leal-Cerbos, C., Vieta, E., Gomez-Beneyto, M. Persistent Cognitive Dysfunctions in Bipolar I Disorder and Schizophrenic Patients: A 3-Year Follow-Up Study. Psychotherapy and Psychosomatics 2005; 74: 113-119.

28. Goswami U, Sharma A, Khastigir U, Ferrier IN, Young AH, Gallagher P et al. Neuropsychological dysfunction, soft neurological signs and social disability in euthymic patients with bipolar disorder. Br J Psychiatry 2006; 188: 366-373.

29. Robinson LJ, Ferrier IN. Evolution of cognitive impairment in bipolar disorder: a systematic review of cross-sectional evidence. Bipolar Disord 2006; 8(2): 103-116.

30. Goswami U, Gulrajani, C., Moore, P.B., Varma, A., Young, A.H., Khastgir, U., Sharma, A.N. Neurocognitive decline in bipolar mood disorder: role of mood stabilizers. JPsychopharmacology 2002; 16: A45.

31. Strakowski SM, Adler CM, Holland SK, Mills N, DelBello MP. A preliminary FMRI study of sustained attention in euthymic, unmedicated bipolar disorder. Neuropsychopharmacology 2004; 29(9): 1734-1740.

32. Harkavy-Friedman JM, Keilp JG, Grunebaum MF, Sher L, Printz D, Burke AK et al. Are BPI and BPII suicide attempters distinct neuropsychologically? J Affect Disord 2006; 94(1-3): 255-259.

33. Newcomer JW. Medical risk in patients with bipolar disorder and schizophrenia. J Clin Psychiatry 2006; 67 (suppl 9): 25-30.

34. Ferrier IN, Chowdhury R, Thompson JM, Watson S, Young AH. Neurocognitive function in unaffected first-degree relatives of patients with bipolar disorder: a preliminary report. Bipolar Disord 2004; 6(4): 319-322.

35. Frangou S, Haldane M, Roddy D, Kumari V. Evidence for Deficit in Tasks of Ventral, but not Dorsal, Prefrontal Executive Function as an Endophenotypic Marker for Bipolar Disorder. Biol Psychiatry 2005.

36. Craddock N, O’Donovan MC, Owen MJ. Genes for schizophrenia and bipolar disorder? Implications for psychiatric nosology. Schizophr Bull 2006; 32(1): 9-16.

37. Sitskoorn MM, Aleman A, Ebisch SJ, Appels MC, Kahn RS. Cognitive deficits in relatives of patients with schizophrenia: a meta-analysis. Schizophr Res 2004; 71(2-3): 285-295.

38. Snitz BE, Macdonald AW, 3rd, Carter CS. Cognitive deficits in unaffected first-degree relatives of schizophrenia patients: a meta-analytic review of putative endophenotypes. Schizophr Bull 2006; 32(1): 179-194.

39. Szoke A, Schurhoff F, Mathieu F, Meary A, Ionescu S, Leboyer M. Tests of executive functions in first-degree relatives of schizophrenic patients: a meta-analysis. Psychol Med 2005; 35(6): 771-782.

40. Heydebrand G. Cognitive deficits in the families of patients with schizophrenia. Curr Opin Psychiatry 2006; 19(3): 277-281.

41. Duff K, Schoenberg MR, Scott JG, Adams RL. The relationship between executive functioning and verbal and visual learning and memory. Arch Clin Neuropsychol 2005; 20(1): 111-122.

42. Krabbendam L, Arts B, van Os J, Aleman A. Cognitive functioning in patients with schizophrenia and bipolar disorder: a quantitative review. Schizophr Res 2005; 80(2-3): 137-149.

43. Green EK, Raybould R, Macgregor S, Gordon-Smith K, Heron J, Hyde S et al. Operation of the schizophrenia susceptibility gene, neuregulin 1, across traditional diagnostic boundaries to increase risk for bipolar disorder. Arch Gen Psychiatry 2005; 62(6): 642-648.

44. Schillo S, Pejovic V, Hunzinger C, Hansen T, Poznanovic S, Kriegsmann J et al. Integrative proteomics: functional and molecular characterization of a particular glutamate-related neuregulin isoform. J Proteome Res 2005; 4(3): 900-908. 
45. Harrison PJ, Law AJ. Neuregulin 1 and schizophrenia: genetics, gene expression, and neurobiology. Biol Psychiatry 2006; 60(2): 132-140.

46. Scolnick EM, Petryshen T, Sklar P. Schizophrenia: do the genetics and neurobiology of neuregulin provide a pathogenesis model? Harv Rev Psychiatry 2006; 14(2): 64-77.

47. Cannon TD, Hennah W, van Erp TG, Thompson PM, Lonnqvist J, Huttunen M et al. Association of DISC1/TRAX haplotypes with schizophrenia, reduced prefrontal gray matter, and impaired shortand long-term memory. Arch Gen Psychiatry 2005; 62(11): 1205-1213.

48. Porteous DJ, Thomson P, Brandon NJ, Millar JK. The genetics and biology of DISC1--an emerging role in psychosis and cognition. Biol Psychiatry 2006; 60(2): 123-131.

49. Ross CA, Margolis RL, Reading SA, Pletnikov M, Coyle JT. Neurobiology of schizophrenia. Neuron 2006; 52(1): 139-153.

50. Bath KG, Lee FS. Variant BDNF (Val66Met) impact on brain structure and function. Cogn Affect Behav Neurosci 2006; 6(1): 79-85.

51. Goldberg TE, Egan MF, Gscheidle T, Coppola R, Weickert T, Kolachana BS et al. Executive subprocesses in working memory: relationship to catechol-O-methyltransferase Val158Met genotype and schizophrenia. Arch Gen Psychiatry 2003; 60(9): 889-896.

52. Rosa A, Peralta V, Cuesta MJ, Zarzuela A, Serrano F, Martinez-Larrea A et al. New evidence of association between COMT gene and prefrontal neurocognitive function in healthy individuals from sibling pairs discordant for psychosis. Am J Psychiatry 2004; 161(6): 1110-1112.

53. Bertolino A, Caforio G, Petruzzella V, Latorre V, Rubino V, Dimalta S et al. Prefrontal dysfunction in schizophrenia controlling for COMT Val158Met genotype and working memory performance. Psychiatry Res 2006; 147(2-3): 221-226.

54. Mata I, Arranz MJ, Staddon S, Lopez-Ilundain JM, Tabares-Seisdedos R, Murray RM. The highactivity Val allele of the catechol-O-methyltransferase gene predicts greater cognitive deterioration in patients with psychosis. Psychiatr Genet 2006; 16(5): 213-216.

55. Minzenberg MJ, Xu K, Mitropoulou V, Harvey PD, Finch T, Flory JD et al. Catechol-Omethyltransferase Val158Met genotype variation is associated with prefrontal-dependent task performance in schizotypal personality disorder patients and comparison groups. Psychiatr Genet 2006; 16(3): 117-124.

56. Woodward ND, Jayathilake K, Meltzer HY. COMT val108/158met genotype, cognitive function, and cognitive improvement with clozapine in schizophrenia. Schizophr Res 2007.

57. Tunbridge EM, Harrison PJ, Weinberger DR. Catechol-o-methyltransferase, cognition, and psychosis: Val158Met and beyond. Biol Psychiatry 2006; 60(2): 141-151.

58. Drabant EM, Hariri AR, Meyer-Lindenberg A, Munoz KE, Mattay VS, Kolachana BS et al. Catechol O-methyltransferase Val158Met Genotype and Neural Mechanisms Related to Affective Arousal and Regulation. Arch Gen Psychiatry 2006; 63(12): 1396-1406.

59. Strakowski SM, Delbello MP, Adler CM. The functional neuroanatomy of bipolar disorder: a review of neuroimaging findings. Mol Psychiatry 2005; 10(1): 105-116.

60. Brooks JO, 3rd, Wang PW, Strong C, Sachs N, Hoblyn JC, Fenn R et al. Preliminary evidence of differential relations between prefrontal cortex metabolism and sustained attention in depressed adults with bipolar disorder and healthy controls. Bipolar Disord 2006; 8(3): 248-254.

61. Yurgelun-Todd DA, Ross, A.J. Functional magnetic resonance imaging studies in bipolar disorder. CNS Spectrums 2006; 11(4): 287-297. 



\section{Chapter 4 \\ Investigating the association between neurocognition and psychosis in bipolar disorder: Further evidence for the overlap with schizophrenia}

Nienke Jabben ${ }^{1}$, Baer Arts $^{1}$, Lydia Krabbendam ${ }^{1}$ and Jim van Os ${ }^{1,2}$

\footnotetext{
${ }^{1}$ Department of Psychiatry and Neuropsychology, South Limburg Mental Health Research and Teaching Network, EURON, Maastricht University, PO Box 616 (VIJV), 6200 MD Maastricht, The Netherlands

${ }^{2}$ Division of Psychological Medicine, Institute of Psychiatry, London, UK
}

Bipolar Disorders 2009; 11(2), 166-177 


\begin{abstract}
Objective: In schizophrenia a distinction is made between psychosis with developmental impairment and cognitive impairment on the one hand and psychosis without developmental impairment and positive symptoms on the other. In this study it was investigated whether this model can be extended to bipolar disorder by testing the hypothesis that neurocognitive functioning is inversely related to positive psychotic symptoms in bipolar disorder.

Methods: Neurocognitive functioning and psychopathology were assessed in i) 76 patients with bipolar disorder, ii) 39 of their healthy first-degree relatives, and iii) 61 healthy controls. Cognitive performance of bipolar patients and that of their firstdegree relatives was investigated taking into account the possible moderating effect of the level of expression of psychosis in patients and relatives.

Results: Bipolar patients showed impaired cognitive performance on multiple cognitive domains, whereas performance of their relatives was comparable to that of controls. A history of psychotic symptoms in patients was suggestive of less likelihood of cognitive alterations in relatives, and the presence of subclinical psychotic symptoms within the group of relatives predicted better cognitive performance.

Conclusions: The finding of similar psychosis-cognition associations in bipolar disorder as implied by the two pathways leading to non-affective psychotic disorders, suggests that this model might be extended to the continuum spanning affective and non-affective psychosis. This is in line with the idea of a partially overlapping vulnerability to bipolar disorder and schizophrenia and provides an explanation for the apparent differences in cognitive alterations in those at risk for the two disorders.
\end{abstract}




\section{Introduction}

In the search for causal mechanisms of affective and non-affective psychosis, a productive focus may be the study of underlying markers of vulnerability. Intermediary phenotypes associated with genetic risk may be closer to underlying mechanisms than illness symptoms that are the consequence of complex and varying geneenvironment interactions. ${ }^{1}$

Genetic and epidemiological studies suggest that there is substantial overlap in genetic risk for bipolar and non-affective psychotic disorders ${ }^{2-4}$ and cognitive impairment is one of the most frequently investigated intermediary phenotypes. The presence of neurocognitive dysfunctions in patients with bipolar disorder is well established. Although deficits are generally worse during periods of affective disturbance, two recent meta-analyses ${ }^{5,6}$ provide evidence for trait-like cognitive dysfunctions in euthymic bipolar patients, in particular in the domains of executive functioning and declarative memory. If neurocognitive deficits truly represent markers of genetic risk for bipolar disorder, ${ }^{7}$ cognitive alterations should be detectable in subjects with a genetic vulnerability to bipolar disorder, such as first-degree relatives of patients. In a recent systematic review and meta-analysis of 14 studies of relatives of bipolar patients, Arts and colleagues ${ }^{5}$ concluded that individuals at risk differed on some cognitive measures from controls, but that effect sizes were rather small and present only for the domain of executive control. The evidence for cognitive alterations as intermediary phenotype associated with genetic risk is much stronger for non-affective psychotic disorders such as schizophrenia. Not only are cognitive deficits in bipolar disorder less severe than those found in schizophrenia, ${ }^{8}$ relatives of patients with bipolar disorder appear to have, if present at all, milder cognitive alterations ${ }^{9}$ compared to relatives of schizophrenia. These findings are in line with studies showing that in children destined to develop schizophrenia or bipolar disorder, developmental cognitive impairment is present in the former but not the latter group. ${ }^{10,11}$

Any theory explaining the apparent genetic overlap between bipolar disorder and schizophrenia should be able to explain these rather different cognitive profiles in individuals at genetic and developmental risk for the two disorders. Thus, one way to explain the weaker presence of cognitive impairments in relatives of patients with bipolar disorder is to assume that most of the cognitive impairments seen in patients is related to the ongoing illness process and its treatment, but that some is also due to genetic effects that are shared to a small degree with schizophrenia and measurable in the relatives of patients. In an attempt to explain the similarities and dissimilarities between bipolar disorder and schizophrenia, Murray and colleagues ${ }^{12}$ suggested that bipolar disorder and schizophrenia share some susceptibility genes that can cause a predisposition to psychosis in general. When, in addition to this predisposition, neurodevelopmental impairment is present, a schizophrenia-like phenotype will emerge. The neurodevelopmental impairment predisposition will contribute to the expression of negative and deficit symptoms and, in association with these 
symptom domains ${ }^{13}$ to the cognitive deficits characteristic of schizophrenia. In the absence of these neurodevelopmental impairments, however, a more affective psychotic phenotype like bipolar disorder will emerge. The hypothesised distinction between good outcome psychotic disorder without developmental impairment (characterised by positive and affective symptoms) and poor outcome psychotic disorder with developmental impairment (with negative and cognitive symptoms) in fact goes back to the seminal publication by Robins and Guze ${ }^{14}$ that hypothesised, albeit within the more narrow domain of schizophrenia alone, two broad dimensions separated along similar lines. The extension of this model to the continuum spanning affective and non-affective psychosis, results in testable hypotheses regarding the cognitive profile of relatives of patients with bipolar disorder. Thus, if the distinction between psychosis with developmental impairment and cognitive impairment on the one hand and psychosis without developmental impairment and positive symptoms on the other is also valid in bipolar disorder, than bipolar patient-relative dyads with more expression of cognitive impairment should have less expression of positive psychotic symptoms.

To this end, three hypotheses were investigated: (i) the presence of a history of positive psychotic symptoms in patients with bipolar disorder will be associated with less likelihood of altered cognitive functioning in the proband relative, and, similarly, (ii) within the group of relatives of bipolar patients, presence of subclinical positive psychotic symptoms will be associated with less likelihood of cognitive alterations. Further, if cognitive impairment in patients with bipolar disorder is mainly illness-related while in relatives, if present at all, it may be the genetic expression of developmental impairment that is weakly shared with schizophrenia, iii) neurocognition in patients and relatives should be at best weakly correlated.

These hypotheses were investigated by comparing cognitive performance of bipolar patients and that of their first-degree relatives with that of a group of healthy controls, taking into account the possible moderating effect of the level of expression of positive psychotic symptoms in patients and relatives.

\section{Methods}

\section{Subjects}

The individuals in this study were participants in the BIPOLCOG study, a study on cognitive functioning in bipolar disorder (BD) in which three groups were investigated i) patients with bipolar disorder, ii) healthy first-degree relatives of patients with bipolar disorder, and iii) healthy control participants. All subjects were between the ages of 18 and 60 years, fluent in Dutch, had an IQ>70 and were without a history of neurological disorders such as epilepsy and concussion with loss of consciousness. 
Patients were recruited through in-patient and out-patient mental health service facilities in South-Limburg, the Netherlands and through the local association of bipolar patients and their families. Initial inclusion criteria for patients were the lifetime prevalence of bipolar disorder according to the RDC (Research Diagnostic Criteria). ${ }^{15}$ The computer program OPCRIT was used to derive and confirm diagnoses on the basis of current and lifetime recorded symptomatology listed in the Operational Criteria Checklist for Psychotic Illness (OCCPI) ${ }^{16}$

First-degree relatives, free from a lifetime history of BD or psychosis, were sampled through participating patients and had at least one first-degree relative with a diagnosis of $\mathrm{BD}$. Control subjects were recruited from the general population through a random mailing. First-degree relatives and controls were clinically and diagnostically interviewed with The Comprehensive Assessment of Symptoms and History $(\mathrm{CASH})^{17}$ and OPCRIT criteria to exclude those presenting a diagnosis of $\mathrm{BD}$ or psychotic disorder. Healthy controls were additionally interviewed with the FIGS $^{18}$ in order to confirm the absence of family histories of psychotic or bipolar disorders.

The initial sample consisted of 81 patients, 39 first-degree relatives and 61 healthy control subjects. Three patients were excluded because data on diagnosis were missing. Data on neuropsychological performance were missing for two patients. As a consequence, the risk set for the current study consisted of 76 patients with $\mathrm{BD}, 39$ relatives and 61 controls.

There were 45 patients with an RDC diagnosis of bipolar I disorder, 17 patients with an RDC diagnosis of schizoaffective disorder bipolar or manic type, 13 patients with an RDC diagnosis of bipolar II disorder and one patient with an RDC diagnosis of mania. In the group of relatives, 8 had an RDC diagnosis of major depression in the past and one of hypomania. The other relatives were free from a history of psychiatric disorder. Three controls had a history of major depression.

Forty-five patients were included without a participating first-degree relative. The remaining patients and relatives originated from 26 families, of which 16 families contributed one patient and one relative, six families contributed one patient and at least two relatives, two families contributed two patients, one family contributed two patients and five relatives and one family contributed two relatives. The 39 participating relatives were 31 siblings, 5 sons and 3 daughters.

\section{Procedure}

Participants were examined during two sessions with an interval of approximately two months. The double session served to enhance statistical power. During both sessions, neuropsychological testing and psychiatric interviewing took place and questionnaires were filled out. In the first session, basic demographic information was collected from all subjects, and in the BD group information on illness characteristics was obtained. Written informed consent, conforming to the local ethics committee guidelines, was obtained from all subjects. Neuropsychological tests and 
psychiatric interviews were conducted by trained psychologists, and each session took approximately two hours to complete.

\section{Psychopathology}

In each session, current depressive and manic psychopathology of all subjects was assessed using the 21-item Hamilton Rating Scale for Depression ${ }^{19}$ and the Young Mania Rating Scale ${ }^{20}$ respectively. To further asses the presence of psychiatric symptoms at the time of testing, the extended Brief Psychiatric Rating Scale (BPRS-E) ${ }^{21}$ was administered. This scale assesses a wider range of current psychopathology, including symptoms of depression, mania, psychosis, anxiety, and withdrawal in the past two weeks.

The Community Assessment of Psychic Experiences (CAPE), a 42-item selfreport instrument, was used to assess dimensions of the subclinical psychosis and depressive phenotype. In this questionnaire, 20 items measure positive psychotic experiences, 14 items rate negative experiences and 8 cognitive depressive experiences. The frequency of the experience was rated on a four-point scale of "never", "sometimes", "often" and "nearly always". For a detailed description of the CAPE, see http://www.cape42.homestead.com. ${ }^{22-24}$ The scale has been validated against clinical interview measures of schizotypy and psychosis-proneness ${ }^{25}$ and discriminatory validity was shown contrasting different patient groups. ${ }^{26}$ OPCRIT criteria were used to derive the presence of a history of positive psychotic symptoms in patients on the basis of current and lifetime recorded symptomatology listed in the OCCPI. ${ }^{16}$ Information was obtained from patients' reports and medical files.

\section{Neurocognitive assessment}

Neurocognitive tests were administered by computer, using E-prime for Windows on a 15-inch monitor Toshiba Tecra laptop. The neurocognitive test battery included tasks measuring various neurocognitive domains, guided by previous evidence of impaired performance among these domains in BD patients and their relatives. ${ }^{5,6,27-29}$

Overall intellectual functioning was estimated using three Groningen Intelligence Test (GIT) subtests (Mental Rotation, Word Analogies and Mental Arithmetic) ${ }^{30}$ yielding results that are comparable to those of the Wechsler Adult Intelligence Scale. ${ }^{31}$ Verbal learning and memory was assessed with the standardized Dutch version of the Visual Verbal Learning Test. ${ }^{32}$ In three consecutive trials, 15 monosyllabic non-related words had to be memorized and reproduced. The total number of words recalled over the three trials was used as a measure of immediate recall. Delayed recall and recognition memory were measured after a 20 minute delay.

Digit Span Forward and Digit Span Backward of the Wechsler intelligence Scale $\mathrm{III}^{33}$ were used as measures of attention - working memory, respectively. Sustained attention was measured with a continuous performance test, the CPT-HQ version, a 
variant of the CPT-AX. Subjects were instructed to respond as quickly as possible by pressing the spacebar whenever target stimulus ' $Q$ ' was preceded by an ' $H$ ' on the screen. Outcome measures were expressed as the proportion correct detections, the reaction time of correct detections, and the proportion false alarms. ${ }^{34}$

The Tapping Speed test (Cogtest plc, London) is a finger tapping test alternating between the right and left hand, that was used as a simple measure of motor speed and manual dexterity. The Cogtest version is similar to the Finger Tapping Test or the Finger Oscillation Test of the Halstead Reitan Neuropsychological Battery. ${ }^{35}$ Subjects were asked to tap a key on the keyboard with their index finger as fast as they could for 8 seconds in five trials for each hand. Outcome measures were the total number of taps with the index finger of each hand and the latency to each and every response, thereby generating an index of the variance in tapping speed.

The Flanker CPT (Cogtest plc, London) ${ }^{36,37}$ is a measure of selective visual control of attention. Subjects are instructed to respond by pressing the right or left mouse button depending on whether the middle element in a display of five lines has an arrowhead pointing to the right or left. There are three trial types: i) neutral trials in which the flankers are just horizontal lines without arrowheads, ii) congruent trials in which all flankers have an arrowhead pointing in the same direction as the target, and iii) incongruent trials, in which flankers are pointing in opposite direction from the target. The test consists of 144 trials of neutral, congruent and incongruent flankers, which are presented randomly. Outcome measures were the mean reaction time for correct responses (RT) and the sum of correct trials in each condition.

The Strategic Target Detection Task (STDT: Cogtest plc, London) ${ }^{38}$ is a task similar to the paper and pen 'cancellation'-tests or the 'cross-out' subtest of the WAIS III, where subjects are required to cross-out target stimuli embedded among distracters. In this computerized version, subjects are not told in advance which of the various stimuli is the target but have to learn by given feedback and thereby modifying their future responses. This is an aspect of the SDTD similar to the Wisconsin Card Sorting Test. Performance was scored by the mean reaction time for correct responses and the total number of correct and incorrect responses and perseverative errors.

In the Set Shifting Test (SST: Cogtest plc, London), ${ }^{39}$ subjects are asked to respond as fast as possible to the direction in which a square appears on the computer screen by pressing the corresponding key on the keyboard. In the first phase, the square appears randomly on either the left or the right side of the screen, in order to establish baseline reaction time. Subsequently, the participant learns the first 'response set', which is a simple right-right-left sequence. After some experience with this rule, reaction time usually decreases from the baseline reaction time as subjects learn to anticipate the next stimulus in the sequence. This provides a measure of set acquisition, or implicit learning. Then, without prior warning, the response set is reversed (to left-left-right). This shift in response set is usually associated with an increase in reaction time, slower than the baseline reaction time. This is called the set 
shifting effect. The subject goes through 3 reversals altogether to obtain reliable measures. Outcome measures are reaction times and errors in the imitation and reversal conditions.

\section{Statistical Analyses}

Before analyses, cognitive variables were inspected for outliers. Since observations in which a mechanical failure took place were already registered as missing, it was decided to replace values with deviation more than three standard deviations from the mean with the closest value within the same group. ${ }^{40}$ Statistical analyses were performed using STATA $10.0 .^{41}$

In order to reduce the number of dependent neuropsychological variables in the analyses $^{42}$ a principal component analysis (PCA) followed by varimax rotation was performed on the neuropsychological variables and interpreted on the basis of scree plot and eigenvalues. Based on the component loadings, a summary measure for each component was calculated, composed of the relative loading of each variable that loaded on this particular component. These scores were transformed to $\mathrm{z}$-scores which were subsequently used as neurocognitive variables in the regression analyses.

A dummy variable indicating bipolar vulnerability was constructed with value 1 for controls, value 2 for first-degree relatives and value 3 for patients, reflecting increasing risk for BD (hereafter: group).

Observations of subjects were clustered at the level of session and the level of family. In order to take these different levels of clustering into account, the main effect of group on cognition was assessed with multilevel random regression analyses, controlling for session and including a family random effect in the model, using the XTREG routine in STATA, with cognitive test values as dependent variables and bipolar liability as the independent variable. Analyses were repeated entering residual depressive and manic symptom scores in the equation, examining the mediating effect of residual affective symptoms. All analyses were a priori adjusted for the possible confounding effects of age and sex by entering these variables into the equation.

In order to investigate the first hypothesis, pairwise comparisons of all available patient-relative pairs within the same family were used to examine, using multilevel regression analyses, the relationship between a history of psychosis in the patients and neurocognition in the relatives. A history of psychosis was coded as a dichotomous ('yes' or 'no') variable defined by the life time presence of at least one positive psychotic symptom in OPCRIT. ${ }^{16}$

Subsequently, to investigate the second hypothesis, multilevel random regression analyses with Group X CAPE trait psychosis interactions were fitted to examine a possible moderating effect of subclinical positive psychotic symptoms on neurocognitive performance within the group of relatives. Analyses were additionally adjusted for the possible confounding effect of education. For significant interactions, the STATA LINCOM routine was used to calculate stratified effect sizes according to the appropriate linear combinations. Stratified effect sizes were calculated 
for CAPE trait psychosis scores of one and two standard deviations below and above average in relatives compared to controls.

The third hypothesis was investigated, similar to the first hypothesis, by examining pairwise associations between patients' and relatives' neurocognitive functioning.

\section{Results}

Demographic characteristics, psychiatric measures and neuropsychological test scores are presented in Table 1. Five controls, one relative and six patients did not participate during the second session, as a result of which neurocognitive data on the second session were missing for these subjects.

Table 1. Demographics, clinical characteristics and results of neurocognitive assessment

\begin{tabular}{|c|c|c|c|c|c|c|}
\hline & \multicolumn{2}{|c|}{$\begin{array}{l}\text { Control subjects } \\
\qquad(\mathrm{n}=61)\end{array}$} & \multicolumn{2}{|c|}{$\begin{array}{l}\text { First-degree relatives } \\
\qquad(\mathrm{n}=39)\end{array}$} & \multicolumn{2}{|c|}{$\begin{array}{l}\text { BD patients } \\
\quad(n=76)\end{array}$} \\
\hline & Mean & SD & Mean & $\mathrm{SD}$ & Mean & $\mathrm{SD}$ \\
\hline Gender M / F & & $23 / 38$ & & $20 / 19$ & & $37 / 39$ \\
\hline Age range & & $25-56$ & & $18-58$ & & $27-60$ \\
\hline Age (years) & 45.3 & 8.7 & 40.7 & 12.2 & 44.7 & 7.9 \\
\hline Educational level & 5.8 & 1.7 & 6.3 & 2.0 & 5.5 & 2.2 \\
\hline GIT IQ & 119.5 & 9.6 & 117.6 & 14.0 & 113.2 & 11.7 \\
\hline BPRS total score (24 - 57) & 25.2 & 2.3 & 27.4 & 4.3 & 33.1 & 6.3 \\
\hline HDRS total score $(0-25)$ & 0.34 & 1.44 & 1.03 & 2.32 & 4.05 & 4.45 \\
\hline YMRS total score $(0-9)$ & 0.06 & 0.30 & 0.32 & 0.87 & 1.37 & 2.17 \\
\hline CAPE psychosis & 0.18 & 0.19 & 0.23 & 0.16 & 0.35 & 0.25 \\
\hline \multicolumn{7}{|l|}{ Clinical characteristics: } \\
\hline age at onset & & & & & 27.4 & 8.9 \\
\hline duration of illness & & & & & 6.1 & 5.1 \\
\hline total number of episodes & & & & & 8.4 & 6.2 \\
\hline number of hospitalizations & & & & & 1.6 & 2.2 \\
\hline$\%$ previous psychotic & & & & & & 50.7 \\
\hline \multicolumn{7}{|l|}{ Verbal learning and memory } \\
\hline \multicolumn{7}{|l|}{ Word List Learning } \\
\hline total immediate recall & 26.0 & 5.5 & 26.7 & 6.5 & 22.6 & 6.9 \\
\hline delayed recall & 8.5 & 2.6 & 9.2 & 3.3 & 6.8 & 3.1 \\
\hline recognition & 13.9 & 1.1 & 13.9 & 1.3 & 13.0 & 2.2 \\
\hline \multicolumn{7}{|l|}{ Attention and concentration } \\
\hline \multicolumn{7}{|l|}{ Digit Span } \\
\hline forward & 9.0 & 1.7 & 9.2 & 2.0 & 8.5 & 1.8 \\
\hline backward & 6.9 & 2.0 & 7.6 & 2.5 & 5.9 & 1.9 \\
\hline \multicolumn{7}{|l|}{ Flanker CPT } \\
\hline correct-neutral & 45.7 & 3.0 & 46.3 & 1.9 & 43.9 & 5.3 \\
\hline
\end{tabular}




\begin{tabular}{|c|c|c|c|c|c|c|}
\hline & \multicolumn{2}{|c|}{$\begin{array}{l}\text { Control subjects } \\
\qquad(\mathrm{n}=61)\end{array}$} & \multicolumn{2}{|c|}{$\begin{array}{l}\text { First-degree relatives } \\
\qquad(\mathrm{n}=39)\end{array}$} & \multicolumn{2}{|c|}{$\begin{array}{l}\text { BD patients } \\
\quad(n=76)\end{array}$} \\
\hline & Mean & $\mathrm{SD}$ & Mean & $\mathrm{SD}$ & Mean & SD \\
\hline correct-congruent & 46.4 & 2.1 & 46.4 & 1.7 & 44.0 & 5.6 \\
\hline correct-incongruent & 43.2 & 4.1 & 44.1 & 3.2 & 39.9 & 8.0 \\
\hline RT-neutral & 634.2 & 53.0 & 623.4 & 58.5 & 679.6 & 86.5 \\
\hline RT-congruent & 632.6 & 49.2 & 629.3 & 60.7 & 679.6 & 84.7 \\
\hline RT-incongruent & 691.5 & 53.4 & 688.0 & 68.6 & 730.1 & 81.6 \\
\hline \multicolumn{7}{|l|}{ CPT-HQ } \\
\hline RT correct detections & 471.9 & 76.7 & 489.8 & 93.4 & 479.2 & 94.1 \\
\hline$\%$ correct detections & 98.9 & 2.5 & 97.1 & 9.0 & 95.4 & 6.7 \\
\hline \multicolumn{7}{|l|}{ Executive functioning } \\
\hline \multicolumn{7}{|l|}{ STDT } \\
\hline number correct & 85.0 & 6.6 & 85.3 & 7.0 & 83.6 & 5.7 \\
\hline number incorrect & 24.3 & 11.0 & 22.1 & 6.4 & 24.8 & 10.3 \\
\hline perseverative errors & 4.1 & 3.3 & 4.7 & 2.5 & 4.6 & 2.9 \\
\hline RT correct & 701.9 & 199.2 & 656.0 & 225.8 & 732.9 & 256.7 \\
\hline \multicolumn{7}{|l|}{ SST } \\
\hline basal RT & 362.5 & 40.1 & 376.9 & 55.1 & 417.5 & 85.0 \\
\hline start imitation RT & 378.9 & 47.9 & 406.0 & 57.1 & 429.8 & 65.8 \\
\hline end imitation RT & 344.4 & 61.6 & 349.6 & 72.7 & 386.5 & 81.4 \\
\hline start reversal RT & 385.1 & 48.9 & 419.1 & 50.3 & 442.6 & 72.8 \\
\hline end reversal RT & 340.4 & 56.6 & 348.3 & 72.9 & 382.7 & 93.2 \\
\hline imitation errors & 0.82 & 1.1 & 0.83 & 0.94 & 1.4 & 1.5 \\
\hline reversal errors & 0.93 & 1.1 & 0.98 & 1.2 & 1.6 & 1.9 \\
\hline \multicolumn{7}{|l|}{ Fine motor speed } \\
\hline \multicolumn{7}{|l|}{ Finger tapping test } \\
\hline tap rate right & 180.2 & 22.6 & 178.1 & 22.2 & 184.4 & 26.1 \\
\hline tap rate left & 192.7 & 23.7 & 190.9 & 27.9 & 204.1 & 29.5 \\
\hline total hits right & 279.4 & 35.3 & 282.0 & 32.9 & 272.5 & 39.5 \\
\hline total hits left & 260.3 & 31.1 & 264.3 & 36.5 & 246.2 & 34.5 \\
\hline
\end{tabular}

All neurocognitive tests and psychiatric interviews were administered during both sessions, with the exception of STDT, SST and the CAPE, that were administered only in the second session.

CPT, Continuous Performance Test; STDT, Strategic Target Detection Test; SST, Set Shifting Test.

\section{Principal Component Analyses}

Based on screen plot and eigenvalues of components after PCA, eight components were retained accounting for $70 \%$ of the variance. Components and component loadings are presented in Table 2. The first component was interpreted to represent fine motor speed, the second set shifting - reaction time, the third attention - accuracy, the fourth attention - reaction time, the fifth verbal memory, the sixth set shifting - accuracy, the seventh mental flexibility, and the eighth attention - working memory. 
Table 2. Component composition and loadings after PCA with varimax rotation

\begin{tabular}{|c|c|c|c|c|c|c|c|c|}
\hline Component: & 1 & 2 & 3 & 4 & 5 & 6 & 7 & 8 \\
\hline WLT immed. recall & -0.0184 & 0.0435 & -0.0378 & -0.0116 & 0.5718 & 0.0560 & 0.0066 & 0.0909 \\
\hline WLT delayed recall & -0.0200 & 0.0246 & -0.0338 & -0.0434 & 0.6165 & 0.0463 & -0.0225 & -0.0470 \\
\hline WLT recog & 0.0057 & -0.1346 & 0.2839 & 0.0300 & 0.3886 & -0.1480 & 0.0889 & -0.2527 \\
\hline CPT HQ - \% corr & 0.0803 & -0.0501 & 0.3037 & 0.0726 & 0.0621 & -0.1324 & 0.0685 & 0.1004 \\
\hline CPT HQ - RT & 0.0459 & 0.0027 & -0.0596 & 0.1334 & 0.1197 & -0.3263 & -0.0328 & 0.1704 \\
\hline Flanker count neu & -0.0215 & 0.0286 & 0.4869 & -0.0072 & -0.0620 & 0.0373 & -0.0122 & 0.0765 \\
\hline Flanker count con & 0.0266 & -0.0164 & 0.4969 & 0.0372 & -0.0097 & 0.0317 & -0.0034 & 0.0236 \\
\hline Flanker count inc & 0.0215 & -0.0125 & 0.4879 & -0.0266 & -0.0144 & 0.0839 & -0.0367 & 0.0274 \\
\hline Flanker RT neu & -0.0176 & 0.0011 & 0.0433 & 0.5437 & -0.0145 & 0.0269 & 0.0016 & -0.0251 \\
\hline Flanker RT con & 0.0014 & -0.0074 & 0.0181 & 0.5399 & 0.0016 & 0.0245 & 0.0080 & -0.0467 \\
\hline Flanker RT inc & -0.0429 & -0.0210 & -0.0355 & 0.5552 & -0.0525 & -0.0162 & -0.0185 & 0.0335 \\
\hline STDT corr & 0.1009 & -0.0588 & -0.0690 & 0.0361 & 0.1302 & -0.0884 & -0.4218 & 0.2241 \\
\hline STDT incor & 0.0232 & -0.0238 & -0.0891 & 0.0558 & 0.0207 & 0.0041 & 0.6260 & 0.0635 \\
\hline STDT persv err & 0.0010 & 0.0360 & 0.0613 & -0.0553 & 0.0227 & -0.0358 & 0.6049 & 0.0579 \\
\hline STDT RT corr & -0.1293 & 0.2185 & 0.1986 & -0.0341 & 0.0746 & -0.0494 & -0.1448 & -0.0617 \\
\hline SST basal RT & 0.0505 & 0.3195 & 0.0491 & 0.1275 & -0.0848 & 0.0454 & -0.0606 & -0.0207 \\
\hline SST start im RT & 0.0238 & 0.4982 & -0.0586 & 0.0151 & -0.0049 & 0.1370 & 0.0304 & -0.0197 \\
\hline SST end im RT & -0.0180 & 0.4911 & -0.0163 & -0.0170 & 0.0126 & -0.0465 & 0.0252 & -0.0018 \\
\hline SST start rev RT & 0.1005 & 0.3511 & -0.0008 & 0.0127 & 0.0916 & -0.0481 & -0.0314 & 0.0204 \\
\hline SST end rev RT & -0.0429 & 0.4280 & 0.0424 & -0.0194 & 0.0498 & -0.1443 & 0.0505 & 0.0255 \\
\hline SST im errors & 0.0186 & 0.0050 & 0.0341 & 0.0327 & 0.0457 & 0.6016 & 0.0571 & -0.0222 \\
\hline SST rev errors & -0.0060 & -0.0091 & 0.0109 & 0.0102 & 0.0311 & 0.6251 & -0.0557 & 0.0517 \\
\hline TST tap rate right & 0.4888 & -0.0459 & -0.0225 & -0.0073 & 0.0529 & 0.0423 & -0.0267 & 0.0176 \\
\hline TST tap rate left & 0.4553 & 0.0733 & 0.0500 & -0.0399 & -0.0910 & -0.0408 & 0.0182 & -0.0743 \\
\hline TST hits right & 0.4768 & -0.0473 & 0.0007 & -0.0027 & 0.0359 & 0.0279 & -0.0197 & 0.0419 \\
\hline TST hits left & 0.4662 & 0.0665 & 0.0356 & -0.0508 & -0.1031 & -0.0302 & 0.0162 & -0.0584 \\
\hline DS forward & -0.0547 & -0.0380 & 0.0977 & -0.0162 & -0.0895 & -0.0735 & 0.0492 & 0.6747 \\
\hline DS backward & 0.0481 & 0.0483 & -0.0648 & -0.0049 & 0.1183 & 0.1294 & 0.0128 & 0.5855 \\
\hline
\end{tabular}

Eight components accounting for $70 \%$ of variance. Groupings for the different components are shaded.

\section{Group differences}

Being a patient predicted neurocognitive performance on all but two cognitive factors (Table 3). First-degree relatives, however, only differed significantly from controls on set shifting - accuracy and set shifting - reaction time, though in opposite 
directions, as for accuracy relative status predicted a better performance whereas for reaction time being a relative was related to worse performance.

Table 3. Association between neurocognitive functioning and the group variable reflecting risk for bipolar disorder (controls were used as reference category)

\begin{tabular}{|c|c|c|c|c|c|}
\hline \multirow{2}{*}{$\begin{array}{l}\text { Outcome measure }^{*} \\
\text { Fine motor speed }\end{array}$} & \multicolumn{3}{|l|}{ Group } & \multicolumn{2}{|c|}{ + Adjustment for HDRS and YMRS } \\
\hline & Relatives (1) & ${ }^{*} \beta=0.12$ & $\mathrm{p}=0.55$ & $ß=0.20$ & $\mathrm{p}=0.32$ \\
\hline & BD patients (2) & $ß=-0.45$ & $\mathrm{p}=0.01$ & $ß=-0.13$ & $\mathrm{p}=0.49$ \\
\hline \multirow[t]{2}{*}{ Set shifting - RT } & Relatives (1) & $B=-0.49$ & $\mathrm{p}=0.01$ & $ß=-0.49$ & $\mathrm{p}=0.01$ \\
\hline & BD patients (2) & $ß=-0.74$ & $\mathrm{p}=0.00$ & $ß=-0.73$ & $\mathrm{p}=0.00$ \\
\hline \multirow[t]{2}{*}{ Attention - accuracy } & Relatives (1) & $ß=-0.05$ & $\mathrm{p}=0.79$ & $ß=-0.05$ & $\mathrm{p}=0.75$ \\
\hline & BD patients (2) & $ß=-0.56$ & $\mathrm{p}=0.00$ & $ß=-0.46$ & $\mathrm{p}=0.00$ \\
\hline \multirow[t]{2}{*}{ Attention - RT } & Relatives (1) & $B=-0.32$ & $\mathrm{p}=0.10$ & $ß=-0.30$ & $\mathrm{p}=0.13$ \\
\hline & BD patients (2) & $ß=-0.75$ & $\mathrm{p}=0.00$ & $ß=-0.72$ & $\mathrm{p}=0.00$ \\
\hline \multirow[t]{2}{*}{ Verbal memory } & Relatives (1) & $B=0.16$ & $\mathrm{p}=0.38$ & $B=0.19$ & $\mathrm{p}=0.29$ \\
\hline & BD patients $(2)$ & $ß=-0.65$ & $\mathrm{p}=0.00$ & $ß=-0.53$ & $\mathrm{p}=0.00$ \\
\hline \multirow[t]{2}{*}{ Set shifting - accuracy } & Relatives (1) & $B=0.44$ & $\mathrm{p}=0.05$ & $ß=0.42$ & $\mathrm{p}=0.06$ \\
\hline & BD patients (2) & $\beta=-0.03$ & $\mathrm{p}=0.88$ & $\beta=-0.13$ & $\mathrm{p}=0.57$ \\
\hline \multirow[t]{2}{*}{ Mental flexibility } & Relatives (1) & $\beta=-0.04$ & $\mathrm{p}=0.86$ & $ß=-0.06$ & $\mathrm{p}=0.79$ \\
\hline & BD patients (2) & $ß=0.02$ & $\mathrm{p}=0.92$ & $ß=0.06$ & $\mathrm{p}=0.80$ \\
\hline \multirow{2}{*}{$\begin{array}{l}\text { Attentional span and } \\
\text { working memory }\end{array}$} & Relatives (1) & $B=0.15$ & $\mathrm{p}=0.44$ & $ß=-0.15$ & $\mathrm{p}=0.44$ \\
\hline & BD patients (2) & $B=-0.63$ & $\mathrm{p}=0.00$ & $ß=-0.54$ & $\mathrm{p}=0.00$ \\
\hline
\end{tabular}

All analyses a priori adjusted for age, sex and session.

${ }^{*}$ For all outcome measures: higher values indicate better performance

${ }^{\star} \mathrm{B}=$ All Betas are standardised regression coeffients indicating the change in outcome associated with the risk for bipolar disorder. HDRS, Hamilton Depression Rating Scale; YMRS, Young Mania Rating Scale

After adjustment for residual mood symptoms, the effect size for the association between patient status and fine motor speed reduced significantly. A slight reduction in effect size was found for the association between patient status and cognitive performance in the domains of verbal memory and attention - working memory. In other cognitive domains, effect sizes did not change after adjustment for residual mood symptoms (Table 3 ).

\section{Pairwise comparisons}

Forty-two pairs of patient and sib within the same family were used to investigate pairwise associations. The presence of a history of positive psychotic symptoms in patients accounted for a significant proportion of the variance in neurocognitive functioning in the corresponding relatives in the domain of fine motor speed $(\beta=0.94, \mathrm{p}=0.00)$. For set shifting - reaction time $(\beta=0.48, \mathrm{p}=0.11)$, attention - accu- 
racy $(\beta=0.21, \mathrm{p}=0.12)$, verbal memory $(\beta=0.56, \mathrm{p}=0.15)$ and attention - working memory $(\beta=0.74, p=0.10)$ the findings were suggestive of an association. Associations were consistently in the direction that relatives of patients with a history of positive psychotic symptoms showed a better cognitive performance. The presence of a history of psychotic symptoms in patients did not predict neurocognitive functioning in corresponding relatives in domains of attention - reaction time $(B=0.22$, $\mathrm{p}=0.51)$, set shifting - accuracy $(\beta=-0.28, \mathrm{p}=0.55)$, and mental flexibility $(\beta=-0.08$, $\mathrm{p}=0.81)$.

Examination of pairwise associations between patients' and relatives' neurocognitive functioning showed that cognitive performance in patients did not account for variance in cognitive performance in corresponding relatives (all Beta's between 0.13 and $0.11, \mathrm{p}>0.21)$.

\section{Does subclinical psychosis affect relative-control differences?}

There were significant two-way Group X CAPE trait interactions in the neurocognitive domains of fine motor speed $(\beta=0.44, p=0.05,95 \%$ confidence interval $(C I): 0.01$, $0.87)$, set shifting - reaction time $(\beta=0.53, p=0.00,95 \% \mathrm{CI}: 0.23,0.84)$, attention reaction time $(ß=0.39, \mathrm{p}=0.04,95 \% \mathrm{CI}: 0.01,0.76)$, and verbal memory $(ß=0.46, \mathrm{p}=$ $0.02,95 \%$ CI: $0.08,0.83$ ), indicating that the association between group and cognition was moderated by subclinical psychotic symptoms in the relatives.

Stratified effect sizes (Table 4) indicate that for relatives an above average subclinical psychosis score predicted better fine motor speed compared to controls. A similar interaction pattern was found for verbal memory. In relatives, a lower subclinical psychosis score predicted more cognitive alterations in attention - reaction time compared to controls. For set shifting - reaction time, stratification showed that in relatives, an above average subclinical psychosis score predicted better cognitive performance than in controls, whereas a below average subclinical psychosis score was related to worse performance. 
Table 4. Group X CAPE trait psychosis interactions (in relatives, controls as reference)

\begin{tabular}{|c|c|c|c|c|c|}
\hline \multirow[t]{2}{*}{ Outcome measure } & \multicolumn{5}{|c|}{ CAPE subclinical psychosis } \\
\hline & $-2 \mathrm{SD}^{*}$ & $-1 \mathrm{SD}$ & mean & $+1 \mathrm{SD}$ & $+2 \mathrm{SD}$ \\
\hline \multirow[t]{2}{*}{ Fine motor speed } & $ß=-0.62, p=0.15$ & $ß=-0.19, p=0.49$ & $ß=0.25, p=0.26$ & $ß=0.69, p=0.05$ & $ß=1.13, p=0.04$ \\
\hline & CI\#:-1.49, 0.24 & CI: $-0.72,0.35$ & CI: $-0.18,0.69$ & CI: $0.01,1.37$ & CI: $0.08,2.18$ \\
\hline \multirow[t]{2}{*}{ Set shifting - RT } & $ß=-1.00, p=0.00$ & $ß=-0.46, p=0.06$ & $ß=0.07, p=0.76$ & $ß=0.60, p=0.05$ & $ß=1.14, p=0.01$ \\
\hline & CI: $-1.67,-0.33$ & CI: $-0.94,0.02$ & CI: $-0.37,0.51$ & CI: $0.01,1.19$ & CI: $0.31,1.96$ \\
\hline \multirow[t]{2}{*}{ Attention - acc } & $ß=-0.20, p=0.38$ & $ß=-0.05, p=0.74$ & $ß=0.11, p=0.38$ & $ß=0.26, p=0.17$ & $ß=0.41, p=0.15$ \\
\hline & CI: $-0.65,0.25$ & CI: $-0.32,0.23$ & CI: $-0.13,0.34$ & CI: $-0.11,0.63$ & CI: $-0.16,0.98$ \\
\hline \multirow[t]{2}{*}{ Attention - RT } & $ß=-0.78, p=0.03$ & $ß=-0.40, p=0.08$ & $ß=0.01, p=0.95$ & $ß=0.37, p=0.22$ & $ß=0.76, p=0.11$ \\
\hline & CI: $-1.51,-0.06$ & CI: $-0.84,0.04$ & CI: $-0.38,0.36$ & CI: $-0.22,0.97$ & CI: $-0.16,1.68$ \\
\hline \multirow[t]{2}{*}{ Verbal memory } & $ß=-0.56, p=0.09$ & $ß=-0.20, p=0.43$ & $ß=0.26, p=0.23$ & $ß=0.71, p=0.03$ & $ß=1.17,0=0.02$ \\
\hline & CI: $-1.43,0.11$ & CI: $-0.69,0.29$ & CI: $-0.16,0.67$ & CI: $0.09,1.33$ & CI: $0.23,2.11$ \\
\hline \multirow[t]{2}{*}{ Set shifting - acc } & $ß=0.70, p=0.16$ & $ß=0.53, p=0.09$ & $ß=0.37, p=0.16$ & $ß=0.20, p=0.61$ & $ß=0.04, p=0.95$ \\
\hline & CI: $-0.27,1.66$ & CI: $-0.08,1.14$ & CI: $-0.14,0.88$ & CI: $-0.57,0.97$ & CI: $-1.13,1.20$ \\
\hline \multirow[t]{2}{*}{ Mental flexibility } & $ß=0.05, p=0.91$ & $B=-0.04, p=0.90$ & $ß=-0.12, p=0.65$ & $ß=-0.21, p=0.57$ & $ß=-0.30, p=0.58$ \\
\hline & CI: $-0.83,0.92$ & CI: $-0.65,0.57$ & CI: $-0.67,0.42$ & CI: $-0.95,0.53$ & CI: $-1.35,0.76$ \\
\hline Attentional span - & $ß=0.47, p=0.32$ & $ß=0.26, p=0.36$ & $ß=0.06, p=0.80$ & $ß=-0.14, p=0.69$ & $ß=-0.35, p=0.54$ \\
\hline working memory & CI: $-0.45,1.38$ & CI: $-0.30,0.83$ & CI: $-0.40,0.52$ & CI: $-0.86,0.57$ & CI: $-1.45,0.75$ \\
\hline
\end{tabular}

All analyses adjusted for age, sex, session and education.

For Attention - accuracy, Set Shifting - accuracy, Mental flexibility and Attention - Working memory, Group X CAPE trait interactions were non significant (all Beta's between -0.12 and 0.37 , and p $>0.38$ ).

${ }^{\star}$ Effect sizes indicate the change in cognition scores associated with CAPE trait scores of -2 to +2 standard deviations below and above average in relatives compared to controls.

$\# \mathrm{CI}=95 \%$ confidence interval

\section{Discussion}

\section{Summary of findings}

The results of this study can be summarised as follows. Patients with bipolar disorder showed impaired performance on multiple cognitive domains, whereas cognitive performance of their first-degree relatives was comparable to that of controls on most cognitive tasks. The presence of a history of positive psychotic symptoms in patients was associated with less likelihood of cognitive alterations in relatives and the presence of subclinical psychotic symptoms within the group of relatives predicted less likelihood of cognitive alterations. Additionally it was found that cognition in patients did not account for variance in cognitive functioning in corresponding relatives. 


\section{Neurocognitive functioning in bipolar patients and their relatives}

The finding of cognitive dysfunctions in bipolar patients is consistent with previous studies reporting deficits in verbal memory, ${ }^{43-46}$ attention ${ }^{47-49}$ and executive functioning. ${ }^{50-53}$ Patients did not show impairment in all executive domains, as a deficit was found on set shifting - reaction time, but not on measures of mental flexibility. This is in line with a previous suggestion by Ferrier and colleagues ${ }^{54}$ who concluded that $\mathrm{BD}$ patients do not show a global dysexecutive syndrome but are more impaired on tasks requiring a stronger working memory component.

First-degree relatives in this study performed significantly worse than controls only on set shifting - reaction time measures. This finding is consistent with that of Clark and colleagues, ${ }^{55}$ who also found deficits in relatives on an attentional shift task but not in verbal memory. The absence of cognitive alterations on other cognitive functions is inconsistent with studies reporting cognitive alterations in relatives in verbal memory, ${ }^{56-58}$ attention and psychomotor speed. ${ }^{29,59,60}$ In a recent review and meta-analysis of studies on cognition in relatives, individuals at risk for bipolar disorder differed from controls, but effect sizes were small and significant only for executive control. ${ }^{5}$

\section{Cognitive alterations and positive psychotic symptoms}

In line with our first hypothesis, the presence of a history of positive psychotic symptoms in patients with bipolar disorder co-occurred with less likelihood of altered cognitive functioning in the proband relative, albeit statistically significant for one domain only. Relatives of patients with a history of psychotic symptoms performed significantly better than relatives of patients without such history on a measure of fine motor speed, whereas for set shifting - reaction time, attention - accuracy, verbal memory and attention - working memory findings were suggestive of an association in the same direction.

The second hypothesis was also confirmed. Cognitive alterations, in partially overlapping domains of fine motor speed, set shifting - reaction time, attention reaction time, and verbal memory, were more likely to occur in relatives with lower subclinical psychosis scores, whereas relatives with a higher degree of subclinical psychosis showed better cognitive functioning compared to controls.

This is, to our best knowledge, the first study investigating the association between positive psychotic symptoms in patients with bipolar disorder and cognitive functioning in their proband relatives, and between subclinical psychotic symptoms and cognitive alterations within relatives. Several studies, however, have investigated the relationship between a history of psychosis and cognitive functioning in patients with bipolar disorder, but results are inconsistent. ${ }^{46,61-63}$ Some studies found that a history of psychosis was associated with impaired verbal memory ${ }^{46}$ and executive control functioning, ${ }^{63}$ whereas other studies failed to find an association with neurocognition. ${ }^{62,64}$ 
It can be suggested that in patients, cognitive dysfunctions reflect the neuropsychological consequences of the disorder and possible history of psychosis, which can lead to disrupted brain processing and resulting functioning. Studies in individuals at risk for bipolar disorder are entirely different, as they are not confounded by the influence of disease and treatment variables, and therefore represent a valuable strategy for studying the role of cognitive alterations as genetic vulnerability makers. Support for the third hypothesis, that cognition in patients and relatives are unrelated, is in line with the idea that cognitive impairment in patients is mainly illnessrelated and in relatives, if at all present, the genetic expression of developmental impairment.

Based on the current study, the evidence for cognitive alterations as intermediary phenotype associated with genetic risk for bipolar disorder is not strong, at least not for the broad range of phenotypical expressions of bipolar disorder. It was found, however, that bipolar patient-relative dyads with more expression of cognitive impairment had less expression of positive psychotic symptoms. Given the suggested genetic overlap between bipolar disorder and schizophrenia, ${ }^{2-4}$ these findings suggest that the hypothesised distinction in schizophrenia between good outcome psychosis without developmental impairment (characterised by positive and affective symptoms) and poor outcome psychosis with developmental impairment (with negative and cognitive symptoms), ${ }^{14,65}$ might be extended to the continuum spanning affective and non-affective psychosis. ${ }^{12}$ The finding of a similar psychosiscognition association in bipolar disorder, as implied by the two pathways leading to non-affective psychotic disorders, ${ }^{14}$ is in line with the idea of a partially overlapping vulnerability to bipolar disorder and schizophrenia, and provides an explanation for the apparent differences in cognitive alterations in those at risk for the two disorders. Some of the cognitive variation in bipolar disorder appears to be due to genetic effects that is shared to a small degree with schizophrenia and is measurable in relatives of patients. Dissimilarities in cognitive alterations can be explained by additional developmental impairment in schizophrenia, resulting in negative and deficit symptoms and the cognitive deficits characteristic of schizophrenia. ${ }^{12}$ In the absence of these neurodevelopmental impairments, a more affective psychotic phenotype may emerge.

\section{Methodological issues}

The present results must be regarded within the context of some methodological issues. First, a broad range of cognitive domains was investigated with recently developed tasks, what can make direct comparison of cognitive effect sizes between studies more difficult. However, the use of these different, recently developed tasks also has benefits, as replication of previous findings in similar cognitive domains with different tasks increases the strengths of the findings. Second, although sample sizes were sufficiently large for group comparisons, the fact that not each patient had a participating sib may have caused a lack of power in the pairwise sib-patient analy- 
ses. This may have caused some associations to be only suggestive whereas with a larger relatives group, effects might have been more precise but similar in pattern. Finally, all patients were taking medication. However, patients were relatively stable when tested and studies on the cognitive effects of lithium ${ }^{66,67}$ and valproate ${ }^{68,69}$ are not consistent. In addition, in the current paper the focus was on relatives who did not use medication.

\section{Conclusion}

Given the suggested genetic overlap bipolar disorder and schizophrenia, the current findings suggest that the hypothesised distinction in schizophrenia between good outcome psychosis without developmental impairment (characterised by positive and affective symptoms) and poor outcome psychosis with developmental impairment (with negative and cognitive symptoms) might be extended to the continuum spanning affective and non-affective psychosis. This is in line with the idea of a partially overlapping vulnerability to bipolar disorder and schizophrenia and provides an explanation for the apparent differences in cognitive alterations in those at risk for the two disorders. 


\section{References}

1. Kendler KS. Twin studies of psychiatric illness: an update. Arch Gen Psychiatry 2001; 58(11): 10051014.

2. Berrettini W. Evidence for shared susceptibility in bipolar disorder and schizophrenia. Am J Med Genet C Semin Med Genet 2003; 123(1): 59-64.

3. Cardno AG, Rijsdijk FV, Sham PC, Murray RM, McGuffin P. A twin study of genetic relationships between psychotic symptoms. Am J Psychiatry 2002; 159(4): 539-545.

4. Potash JB. Carving chaos: Genetics and the classification of mood and psychotic syndromes. Harv Rev Psychiatry 2006; 14(2): 47-63.

5. Arts B, Jabben N, Krabbendam L, Van Os J. Meta-analyses of cognitive functioning in euthymic bipolar patients and their first-degree relatives. Psychol Med 2007; in press.

6. Robinson LJ, Thompson JM, Gallagher P, Goswami U, Young AH, Ferrier IN et al. A meta-analysis of cognitive deficits in euthymic patients with bipolar disorder. J Affect Disord 2006; 93(1-3): 105115.

7. Glahn DC, Bearden CE, Niendam TA, Escamilla MA. The feasibility of neuropsychological endophenotypes in the search for genes associated with bipolar affective disorder. Bipolar Disord 2004; 6(3): 171-182.

8. Krabbendam L, Arts B, van Os J, Aleman A. Cognitive functioning in patients with schizophrenia and bipolar disorder: a quantitative review. Schizophr Res 2005; 80(2-3): 137-149.

9. Sitskoorn MM, Aleman A, Ebisch SJ, Appels MC, Kahn RS. Cognitive deficits in relatives of patients with schizophrenia: a meta-analysis. Schizophr Res 2004; 71(2-3): 285-295.

10. Cannon M, Jones P, Gilvarry C, Rifkin L, McKenzie K, Foerster A et al. Premorbid social functioning in schizophrenia and bipolar disorder: similarities and differences. Am J Psychiatry 1997; 154(11): 1544-1550.

11. Reichenberg A, Weiser M, Rabinowitz J, Caspi A, Schmeidler J, Mark M et al. A population-based cohort study of premorbid intellectual, language, and behavioral functioning in patients with schizophrenia, schizoaffective disorder, and nonpsychotic bipolar disorder. Am J Psychiatry 2002; 159(12): 2027-2035.

12. Murray RM, Sham P, Van Os J, Zanelli J, Cannon M, McDonald C. A developmental model for similarities and dissimilarities between schizophrenia and bipolar disorder. Schizophr Res 2004; 71(2-3): 405-416.

13. Dominguez M, Viechtbauer W, Simons C, van Os J, Krabbendam L. Are psychotic psychopathology and neurocognition orthogonal? A systematic review of their associations. 2008.

14. Robins E, Guze SB. Establishment of diagnostic validity in psychiatric illness: its application to schizophrenia. Am J Psychiatry 1970; 126(7): 983-987.

15. Spitzer RL, Endicott J, Robins E. Research diagnostic criteria: rationale and reliability. Arch Gen Psychiatry 1978; 35(6): 773-782.

16. Mc Guffin P, Farmer A, Harvey I. A polydiagnostic application of operational criteria in studies of psychotic illness: development and reliability of the OPCRIT system. Arch Gen Psychiatry 1991; 48: 764-770.

17. Andreasen NC, Flaum M, Arndt S. The Comprehensive Assessment of Symptoms and History (CASH). An instrument for assessing diagnosis and psychopathology. Arch Gen Psychiatry 1992; 49(8): 615-623.

18. Maxwell ME. Manual for the family interview for genetic studies (FIGS): Bethesda, Maryland: National Institute of Mental Health, 1992.

19. Hamilton M. A rating scale for depression. J Neurol Neurosurg Psychiatry 1960; 23: 56-62.

20. Young RC, Biggs JT, Ziegler VE, Meyer DA. A rating scale for mania: reliability, validity and sensitivity. Br J Psychiatry 1978; 133: 429-435.

21. Lukoff D, Nuechterlein KH, Ventura J. Manual for the Expanded BPRS. Schizophrenia Bulletin 1986; 12: 594-602. 
22. Stefanis NC, Hanssen M, Smirnis NK, Avramopoulos DA, Evdokimidis IK, Stefanis CN et al. Evidence that three dimensions of psychosis have a distribution in the general population. Psychol Med 2002; 32(2): 347-358.

23. Hanssen M, Krabbendam L, Vollema M, Delespaul P, Van Os J. Evidence for instrument and family-specific variation of subclinical psychosis dimensions in the general population. J Abnorm Psychol 2006; 115(1): 5-14.

24. Verdoux H, van Os J. Psychotic symptoms in non-clinical populations and the continuum of psychosis. Schizophr Res 2002; 54(1-2): 59-65.

25. Konings M, Bak M, Hanssen M, van Os J, Krabbendam L. Validity and reliability of the CAPE: a self-report instrument for the measurement of psychotic experiences in the general population. Acta Psychiatr Scand 2006; 114(1): 55-61.

26. Hanssen MS, Bijl RV, Vollebergh W, van Os J. Self-reported psychotic experiences in the general population: a valid screening tool for DSM-III-R psychotic disorders? Acta Psychiatr Scand 2003; 107(5): 369-377.

27. Murphy FC, Sahakian BJ. Neuropsychology of bipolar disorder. Br J Psychiatry Suppl 2001; 41: s120-127.

28. Ferrier IN, Thompson JM. Cognitive impairment in bipolar affective disorder: implications for the bipolar diathesis. Br J Psychiatry 2002; 180: 293-295.

29. Antila M, Tuulio-Henriksson A, Kieseppa T, Eerola M, Partonen T, Lonnqvist J. Cognitive functioning in patients with familial bipolar I disorder and their unaffected relatives. Psychol Med 2007; 37(5): 679-687.

30. Luteijn F, van der Ploeg FAE. Handleiding Groninger Intelligentietest (GIT) [Manual Groningen Intelligence Test]. Lisse, The Netherlands: Swets \& Zeitlinger, 1983.

31. Wechsler D. Wechsler Adult Intelligence Scale. Revised. New York: Psychological Corporation, 1981.

32. Rey A. L'examen Clinique en Psychologie. Presses Universitaires de France: Paris, France, 1964.

33. Wechsler D. WAIS-III, Nederlandstalige bwerking: Technische handleiding. Swets \& Zeitlinger B.V.: Lisse, 2000.

34. Nestor PG, Faux SF, McCarley RW, Shenton ME, Sands SF. Measurement of visual sustained attention in schizophrenia using signal detection analysis and a newly developed computerized CPT task. Schizophr Res 1990; 3(5-6): 329-332.

35. Reitan RM, Wolfson D. The Halstead-Reitan Neuropsychological Test Battery: Theory and clinical interpretation. Neuropsychology: Tucson, 1985.

36. Posner MI, Inhoff AW, Friedrich FJ, Cohen A. Isolating attentional systems: A cognitive-anatomical analysis. Psychobiology 1987; 15: 107-121.

37. Eriksen CW, Schultz DW. Information processing in visual search: a continuous flow conception and experimental results. Percept Psychophys 1979; 25(4): 249-263.

38. Weintraub S, Mesulam MM. Right cerebral dominance in spatial attention - Further evidence based on ipsilateral neglect. Archives of Neurology 1987; 44: 621-625.

39. Bilder RM, Turkel E, Lipschutz-Broch L, Lieberman JA. Antipsychotic medication effects on neuropsychological functions. Psychopharmacol Bull 1992; 28(4): 353-366.

40. Tabachnick BG, Fidell LS. Using Multivariate Statistics. third ed. edn. HarperCollins College Publishers: New York, 1996.

41. Statacorp. STATA Statistical Software: Release 10.0. Texas, College Station 2007.

42. Krabbendam L, Marcelis M, Delespaul P, Jolles J, van Os J. Single or multiple familial cognitive risk factors in schizophrenia? Am J Med Genet 2001; 105(2): 183-188.

43. Altshuler LL, Ventura J, van Gorp WG, Green MF, Theberge DC, Mintz J. Neurocognitive function in clinically stable men with bipolar I disorder or schizophrenia and normal control subjects. Biol Psychiatry 2004; 56(8): 560-569.

44. Fleck DE, Shear PK, Zimmerman ME, Getz GE, Corey KB, Jak A et al. Verbal memory in mania: effects of clinical state and task requirements. Bipolar Disord 2003; 5(5): 375-380.

45. Krabbendam L, Honig A, Wiersma J, Vuurman EF, Hofman PA, Derix MM et al. Cognitive dysfunctions and white matter lesions in patients with bipolar disorder in remission. Acta Psychiatr Scand 2000; 101(4): 274-280. 
46. Martinez-Aran A, Vieta E, Reinares M, Colom F, Torrent C, Sanchez-Moreno J et al. Cognitive function across manic or hypomanic, depressed, and euthymic states in bipolar disorder. Am J Psychiatry 2004; 161(2): 262-270.

47. Bora E, Vahip S, Akdeniz F. Sustained attention deficits in manic and euthymic patients with bipolar disorder. Prog Neuropsychopharmacol Biol Psychiatry 2006; 30(6): 1097-1102.

48. Clark L, Iversen SD, Goodwin GM. Sustained attention deficit in bipolar disorder. Br J Psychiatry 2002; 180: 313-319.

49. Thompson JM, Gallagher P, Hughes JH, Watson S, Gray JM, Ferrier IN et al. Neurocognitive impairment in euthymic patients with bipolar affective disorder. Br J Psychiatry 2005; 186: 32-40.

50. Frangou S, Donaldson S, Hadjulis M, Landau S, Goldstein LH. The Maudsley Bipolar Disorder Project: executive dysfunction in bipolar disorder I and its clinical correlates. Biol Psychiatry 2005; 58(11): 859-864.

51. Goswami U, Sharma A, Khastigir U, Ferrier IN, Young AH, Gallagher P et al. Neuropsychological dysfunction, soft neurological signs and social disability in euthymic patients with bipolar disorder. Br J Psychiatry 2006; 188: 366-373.

52. Zalla T, Joyce C, Szoke A, Schurhoff F, Pillon B, Komano O et al. Executive dysfunctions as potential markers of familial vulnerability to bipolar disorder and schizophrenia. Psychiatry Res 2004; 121(3): 207-217.

53. Dixon T, Kravariti E, Frith C, Murray RM, McGuire PK. Effect of symptoms on executive function in bipolar illness. Psychol Med 2004; 34(5): 811-821.

54. Ferrier IN, Stanton BR, Kelly TP, Scott J. Neuropsychological function in euthymic patients with bipolar disorder. Br J Psychiatry 1999; 175: 246-251.

55. Clark L, Sarna A, Goodwin GM. Impairment of executive function but not memory in first-degree relatives of patients with bipolar I disorder and in euthymic patients with unipolar depression. Am J Psychiatry 2005; 162(10): 1980-1982.

56. Ferrier IN, Chowdhury R, Thompson JM, Watson S, Young AH. Neurocognitive function in unaffected first-degree relatives of patients with bipolar disorder: a preliminary report. Bipolar Disord 2004; 6(4): 319-322.

57. McIntosh AM, Harrison LK, Forrester K, Lawrie SM, Johnstone EC. Neuropsychological impairments in people with schizophrenia or bipolar disorder and their unaffected relatives. Br J Psychiatry 2005; 186: 378-385.

58. Keri S, Kelemen O, Benedek G, Janka Z. Different trait markers for schizophrenia and bipolar disorder: a neurocognitive approach. Psychol Med 2001; 31(5): 915-922.

59. Sobczak S, Riedel WJ, Booij I, Aan Het Rot M, Deutz NE, Honig A. Cognition following acute tryptophan depletion: difference between first-degree relatives of bipolar disorder patients and matched healthy control volunteers. Psychol Med 2002; 32(3): 503-515.

60. Pierson A, Jouvent R, Quintin P, Perez-Diaz F, Leboyer M. Information processing deficits in relatives of manic depressive patients. Psychol Med 2000; 30(3): 545-555.

61. Albus M, Hubmann W, Wahlheim C, Sobizack N, Franz U, Mohr F. Contrasts in neuropsychological test profile between patients with first-episode schizophrenia and first-episode affective disorders. Acta Psychiatr Scand 1996; 94(2): 87-93.

62. Selva G, Salazar J, Balanza-Martinez V, Martinez-Aran A, Rubio C, Daban C et al. Bipolar I patients with and without a history of psychotic symptoms: do they differ in their cognitive functioning? $J$ Psychiatr Res 2007; 41(3-4): 265-272.

63. Glahn DC, Bearden CE, Barguil M, Barrett J, Reichenberg A, Bowden CL et al. The neurocognitive signature of psychotic bipolar disorder. Biol Psychiatry 2007; 62(8): 910-916.

64. Goldberg TE, Gold JM, Greenberg R, Griffin S, Schulz SC, Pickar D et al. Contrasts between patients with affective disorders and patients with schizophrenia on a neuropsychological test battery. Am J Psychiatry 1993; 150: 1355-1362

65. Myin-Germeys I, Krabbendam L, Jolles J, Delespaul PA, van Os J. Are cognitive impairments associated with sensitivity to stress in schizophrenia? An experience sampling study. Am J Psychiatry 2002; 159(3): 443-449. 
66. Honig A, Arts BM, Ponds RW, Riedel WJ. Lithium induced cognitive side-effects in bipolar disorder: a qualitative analysis and implications for daily practice. Int Clin Psychopharmacol 1999; 14(3): 167-171.

67. Engelsmann F, Katz J, Ghadirian AM, Schachter D. Lithium and memory: a long-term follow-up study. J Clin Psychopharmacol 1988; 8(3): 207-212.

68. Devinsky O. Cognitive and behavioral effects of antiepileptic drugs. Epilepsia 1995; 36 Suppl 2: S4665.

69. Senturk V, Goker C, Bilgic A, Olmez S, Tugcu H, Oncu B et al. Impaired verbal memory and otherwise spared cognition in remitted bipolar patients on monotherapy with lithium or valproate. Bipolar Disord 2007; 9 Suppl 1: 136-144. 



\section{Chapter 5}

\section{A 2-year naturalistic study on cognitive functioning in bipolar disorder}

Baer Arts ${ }^{\mathrm{a}}$, Nienke Jabben ${ }^{\mathrm{a}}$, Lydia Krabbendam ${ }^{\mathrm{b}}$, Jim van Os ${ }^{\mathrm{a}, \mathrm{c}}$

a Department of Psychiatry and Psychology, South Limburg Mental Health Research and Teaching Network, EURON, Maastricht University, PO Box 616 (KAP2), 6200 MD Maastricht, The Netherlands

${ }^{\mathrm{b}}$ Centre Brain and Learning, Faculty of Psychology and Education, VU University, Amsterdam

${ }^{c}$ Division of Psychological Medicine, Institute of Psychiatry, London, UK

Acta Psychiatrica Scandinavica, 2011; 123(3), 190-205 


\section{Abstract}

Objective: Cognitive alterations in bipolar disorder may reflect genetic influence. However, to what degree mood, medication, thyroid function and other factors impact on longitudinal cognitive functioning remains unclear.

Methods: A group of bipolar (spectrum) patients $(n=76)$ underwent 2-monthly cognitive assessments over a 2 -year period in a prospective, repeated measures design. Regression models were used to investigate associations with predictors, corrected for multiple testing.

Results: Bipolar patients performed worse than healthy controls $(n=61)$ on all cognitive domains tested. Effect sizes were small, with a maximum of -0.36 for sustained attention. However, cognitive performance varied substantially over the 2 year follow-up, co-varying with subjective cognitive complaints, and impacting on functioning. Alterations in sustained attention and motor speed were the only impairments that were invariant over time. Predictors had very limited explanatory power on temporal variation in cognition. Use of second generation antipsychotics was associated with the largest negative effects on cognition, which were evident in the areas of motor speed and basic information processing $(-0.35<\beta<-.5)$.

Conclusions: Cognitive function in bipolar disorder varies significantly over time, largely independent of clinical factors. The temporal stability of sustained attention is the exception, suggesting it may represent a possible candidate intermediary phenotype. 


\section{Introduction}

Cognitive dysfunction in patients with bipolar disorder in part may reflect the expression of genetic risk for bipolar disorder. ${ }^{1}$ Evidence for an association between cognitive dysfunction and genetic liability in healthy twins discordant for bipolar disorder, ${ }^{2}$ presence of premorbid cognitive alterations in at risk populations ${ }^{3}$ and cognitive alterations in bipolar children, independent of mood and medication, ${ }^{4}$ support this hypothesis. Furthermore, there is evidence that certain cognitive dysfunctions are stable over time $e^{5,6}$ and persist during euthymia, as shown in several recent meta-analyses. ${ }^{7,8}$ To the degree that cognitive alterations reflect genetic risk for the disorder, values outside the control range would also be expected in the unaffected family members of patients with bipolar disorder. Studies using this paradigm display heterogeneous results suggesting that response inhibition ${ }^{7,8}$ as well as verbal learning and working memory ${ }^{9}$ may represent so-called intermediary phenotypes of bipolar disorder. The heterogeneity in results is possibly due to multiple familial cognitive risk factors ${ }^{10}$ and further illustrated by two recent studies finding comparable cognitive functioning in relatives and controls in one, ${ }^{11}$ and worse verbal learning in relatives in the other. ${ }^{12}$ Cognitive dysfunctions in relatives are subtle and not as widespread as in bipolar patients, suggesting that the greatest part of cognitive dysfunction in patients is associated with disease-related factors. ${ }^{9}$ Examples of these factors suggested in the literature are: number of episodes, ${ }^{13}$ age of onset ${ }^{8}$ and (antipsychotic) medication. ${ }^{8,14}$ Another potential moderator of cognition is thyroid function, given the association between bipolar disorder and thyroid dysregulation ${ }^{15}$ and the possible negative cognitive effects of thyroid dysfunction. ${ }^{16}$ Furthermore, the anti-thyroid effects of lithium ${ }^{17}$ may contribute to the cognitive deficits seen in lithium-treated bipolar patients. ${ }^{18}$

There are conflicting reports as to whether neurocognitive impairments in patients with bipolar disorder are associated with the subjective cognitive complaints that many patients present with. ${ }^{19,20}$ This question is of major importance for longitudinal treatment trajectories, given the fact that changes in subjective cognitive complaints over time may reflect underlying changes in neurocognition. There have been no previous studies attempting to link longitudinal changes in neurocognition to subjective cognitive complaints over time, and how these relate to functioning.

\section{Aims of the study}

The aim of the present explorative and naturalistic study was to analyse multiple time point, longitudinal associations between neurocognition on the one hand and disease characteristics, symptoms, global functioning and medication on the other in a cohort of bipolar patients followed-up for 2 years and assessed at 2-monthly intervals. 


\section{Material and methods}

\section{Subjects}

Individuals were participants in the BIPOLCOG (BIPOLar and COGnition) study, ${ }^{11}$ a study on cognitive functioning in bipolar disorder (BD) in which three groups were investigated: (i) patients with bipolar disorder, (ii) healthy first-degree relatives of patients with bipolar disorder, and (iii) healthy control participants. All subjects were between the ages of 18 and 60 years, fluent in Dutch, had an IQ > 70 and were without a history of neurological disorders such as epilepsy and concussion with loss of consciousness. Cross-sectional baseline data were reported elsewhere; ${ }^{11}$ in the current longitudinal study, healthy controls, tested twice at 2-monthly intervals, were used as reference group only.

Patients with a diagnosis of bipolar spectrum disorder according to DSM-IV ${ }^{21}$ were recruited through in-patient and out-patient mental health facilities in South Limburg, and through the local association of bipolar patients and their families. The computer program OPCRIT was used to confirm DSM-IV diagnoses on the basis of current and lifetime recorded symptomatology listed in the Operational Criteria Checklist for Psychotic Illness, scored by the clinical researcher on the basis of all interview and historical case note data (OCCPI) ${ }^{22}$

Control subjects were recruited from the general population using random mailing methodology. Controls were clinically interviewed with The Comprehensive Assessment of Symptoms and History $(\mathrm{CASH})^{23}$ in order to rate OPCRIT criteria, yielding DSM-IV diagnoses, allowing exclusion of those presenting with a diagnosis of $\mathrm{BD}$ or psychotic disorder. Healthy controls were additionally interviewed with the FIGS $^{24}$ in order to confirm the absence of a family history of psychotic or bipolar disorder.

The initial sample consisted of 81 patients and 61 healthy control subjects. Three patients were excluded because data on diagnosis were missing. Data on neuropsychological performance were missing for two patients. As a consequence, the risk set for the current study consisted of 76 patients and 61 controls.

There were 57 patients with a diagnosis of bipolar I disorder, 17 patients with a diagnosis of bipolar II disorder and 2 patients were diagnosed with schizoaffective disorder bipolar type. Three controls had a history of major depression - these were not excluded so as to not bias the findings by selection of "supernormal"controls.

\section{Procedure}

Patients were examined at 2-monthly intervals over a period of 2 years, yielding a maximum of 12 assessments. At all time points, neuropsychological testing and psychiatric interviewing took place and questionnaires were completed (regarding social functioning, medication, use of drugs etc.). Blood samples were collected at each time point in order to determine mood stabiliser plasma level, TSH and free T4. 
During the baseline interview, basic demographic information was collected and information on illness characteristics was obtained. Written informed consent, conforming to the local ethics committee guidelines, was obtained from all subjects. Neuropsychological tests and psychiatric interviews were conducted by trained psychologists, each interview occasion taking approximately 2 hours to complete. Recent use of drugs prior to neuropsychological interview was checked by asking the patient at every 2-monthly visit prior to testing. Recent drug use, assessed this way, was non-existent in our sample.

\section{Psychopathology}

At each interview occasion, current depressive and manic psychopathology was assessed using the 21-item Hamilton Rating Scale for Depression ${ }^{25}$ and the Young Mania Rating Scale ${ }^{26}$ respectively. In order to assess domains of psychopathology at the time of testing, the extended Brief Psychiatric Rating Scale (BPRS-E) ${ }^{27}$ was administered by the clinical investigator. This scale assesses a wider range of current psychopathology, including symptoms of depression, mania, psychosis, anxiety and withdrawal in the past two weeks.

Presence of a history of positive psychotic symptoms in patients on the basis of current and lifetime recorded symptomatology as listed in the OCCPI ${ }^{22}$ was used to define a measure of psychotic symptoms at baseline. Information was obtained from patient interviews and case notes. Subjective mood was assessed by the self-report version of the Life-Chart (LCM). ${ }^{28}$ Psychosocial functioning was assessed using the Global Assessment of Functioning scale (GAF). ${ }^{21}$

\section{Subjective cognitive complaints}

Patients' subjective cognitive complaints were measured using the Cognitive Failure Questionnaire (CFQ) ${ }^{29}$ higher scores indicating less cognitive failures.

\section{Neurocognitive assessment}

Neurocognitive tests were administered by computer, using E-prime for Windows on a 15-inch monitor Toshiba Tecra laptop. The test battery included tasks measuring various neurocognitive domains, guided by previous evidence of impaired performance in these domains in bipolar patients. ${ }^{7,8}$

Overall intellectual functioning was estimated at baseline using three Groningen Intelligence Test (GIT) subtests (Mental Rotation, Word Analogies and Mental Arithmetic), ${ }^{30}$ yielding results that are comparable to those of the Wechsler Adult Intelligence Scale III. ${ }^{31}$

Verbal learning and memory was assessed with the standardized Dutch version of the Visual Verbal Learning Test. ${ }^{32}$ In three consecutive trials, 15 monosyllabic non-related words had to be memorized and reproduced. The total number of words 
recalled over the three trials was used as a measure of immediate recall. Delayed recall was measured after a 20 -minute delay. Parallel versions of this test were used, in order to avoid test-retest-effects.

Sustained attention was measured with a continuous performance test, the CPTHQ version, a variant of the CPT-AX. Subjects were instructed to respond as quickly as possible by pressing the spacebar of the PC keyboard whenever target stimulus ' $Q$ ' was preceded by an ' $\mathrm{H}$ ' on the screen. In the CPT-HQ, 300 stimuli (i.e., letters) were presented in a randomized sequence, at a rate of one per second. Each letter was presented for $150 \mathrm{~ms}$, after which an empty screen was presented for $850 \mathrm{~ms}$. Presentation of an H-Q target-pair had a probability of .18 ( $n=28)$ among the 150 sequential letter-pairs. In a similar number of sequential letter-pairs, the letter $\mathrm{Q}$ was presented following another letter than $\mathrm{H}$ (I,L,J, or T). In another 28 pairs, the letter $\mathrm{H}$ was presented followed by another letter than Q (I, L, J, or T). Outcome measures were expressed as the proportion correct detections and the reaction time of correct detections. $^{33,34}$

The Flanker CPT (Cogtest plc, London) ${ }^{35}$ is a measure of selective visual control of attention. Subjects are instructed to respond by pressing the right or left mouse button depending on whether the middle element in a display of five lines has an arrowhead pointing to the right or left. There are three trial types: (i) neutral trials in which the flankers are just horizontal lines without arrowheads, (ii) congruent trials in which all flankers have an arrowhead pointing in the same direction as the target, and (iii) incongruent trials, in which flankers are pointing in the opposite direction from the target. The incongruent condition involves more cognitive effort, because the flankers are associated with a response that needs to be suppressed (measure of response inhibition). One-half of the trials was presented with the stimuli above the fixation cross and the other half were presented below fixation, in order to prevent the subjects from keeping their gaze fixed in one position. The test consisted of 144 trials of neutral, congruent and incongruent flankers, which were presented randomly. Outcome measures were the mean reaction time for correct responses (RT) and the sum of correct trials in each condition.

The Tapping Speed test (Cogtest plc, London) is a finger tapping test alternating between the right and left hand, used as a simple measure of motor speed and manual dexterity. The Cogtest version is similar to the Finger Tapping Test or the Finger Oscillation Test of the Halstead Reitan Neuropsychological Battery. ${ }^{36}$ Subjects were asked to tap a key on the keyboard with their index finger as fast as they could for 8 seconds in five trials for each hand. Outcome measures were the total number of taps with the index finger of each hand and the latency to each and every response, generating an index of the variance in tapping speed.

Finally, Digit Span Forward and Digit Span Backward of the Wechsler intelligence Scale III ${ }^{37}$ were used as measures of attention and working memory, respectively.

All 14 cognitive measures were standardised, higher scores reflecting better performance. The 14 cognitive measures reflect the following higher-order cognitive 
domains: verbal learning (immediate recall Visual Verbal Learning Test), verbal memory (delayed recall Visual Verbal learning Test), sustained attention (Continuous Performance Test), basic information processing (neutral and congruent condition of Flanker CPT), selective attention and response inhibition (incongruent condition of Flanker CPT), motor speed (Tapping Speed Test), attentional span (Digit Span, forward condition), and working memory (Digit Span, backward condition).

\section{Statistical Analyses}

Regression analyses were carried out using the statistical software program STATA ${ }^{38}$ (version 10.1). The Simes modification of the Bonferroni correction for multiple testing ${ }^{39}$ was applied, given the large number of statistical tests $(n=476)$, yielding a corrected $\mathrm{p}$-value for significance of $\mathrm{p}<0.014$.

Data were hierarchical with multiple observations (interview occasion or time; level 1) clustered within subjects (level 2). Unless stated otherwise, data were analysed using the STATA XTREG multilevel random regression routine with time as a random factor.

Standardized beta-scores (ß) are reported. In order to assess whether multiple time point associations between predictor variables and neurocognition varied over time, interactions with interview occasion were fitted for variables significantly associated with neurocognition in the multilevel random regression models.

TSH had a high proportion of missing values. Under the assumption that data generally is missing at random, ${ }^{40}$ meaning that missingness is probabilistic and thus can be predicted by variables observed, missing values can be imputed using multiple imputation. ${ }^{41}$ Thus, for TSH, 20 datasets were imputed using the ICE routine ${ }^{42}$ in STATA. This increased the (maximum) number of observations from 463 to 530.

\section{Multiple time point associations between cognition and time-varying and fixed exposures}

Multiple time point associations between cognition on the one hand and timevarying as well as fixed demographic, psychopathology, medication, global functioning and illness-related factors on the other were assessed in two stages in the multilevel random regression models. In the first stage, the effect of groups of variables was assessed by comparing models with and without the group in question by likelihood ratio test (STATA LRTEST routine). This strategy tests the broad hypothesis whether certain types of variables (medication, psychopathology) impact on cognition. In the second stage, the separate effect of specific variables within these groups was assessed.

The analyses of the effects of medication and psychopathology were $a$ priori adjusted for the possible confounding effects of demographic (age, sex, education) and disease characteristics (number of episodes, alcohol use) by entering them into the equations. In addition, effects of medication on cognitive functions were tested adjusting a priori for the possible confounding effect of symptoms (BPRS) in all cases, 
and for thyroid function in the case of lithium. Dummies were constructed for all medication variables with value 1 for using a certain type of medication, and value 0 for not using this medication.

Finally, the specific effects of thyroid function (TSH) and subjective mood (LCM), both not included in the models described above, owing to the large number of missing data (TSH) and the small number of observations (LCM), were determined separately.

\section{Variability of cognitive measures over time}

In order to assess variability of cognitive measures over time, time was modelled as the k-1 dummy variables of the number of interview occasions (i.e. maximum of 11 dummies for individuals with 12 interviews), and assessed using a Wald test with 11 degrees of freedom, testing that the parameters of all dummies equalled zero using the STATA TEST command. The effect of time, thus tested, reflects both practice effects (i.e., new learning) associated with repeated administration of neurocognitive tests, as well as remaining variation in cognition associated with changes in medication and mental state over time. In order to quantify new learning, time was modelled as a linear variable, the $B$ thus reflecting the summary change in cognition with each subsequent follow-up.

\section{Can variability over time be reduced to clinical and other variables?}

In order to assess to what degree variability over time could be reduced to the effects of demographics (age, sex, education), psychopathology (BPRS, HDRS, YMRS, CFQ, psychotic symptoms in past), medication (lithium, second generation antipsychotics, anticonvulsants, antidepressants, benzodiazepines, polypharmacy [0 for using no medication, 1 for using one type of medication, and 2 for using two or more different types of medication]), global functioning (GAF) and illness-related factors (number of episodes, age first onset, units alcohol use in last 2 months), the above described analysis of variability over time, testing that the parameters of all dummies of time equalled zero, was compared between models without other independent variables and models with variable groups representing demographics, mood, medication, global functioning and other clinical factors.

\section{Directional changes over time: cognitive improvement and cognitive deterioration}

In order to assess the rate of significant improvement and deterioration of cognitive function over time, the rate of $0.5 \mathrm{SD}$ improvement, compared to baseline, (hereafter: cognitive improvement) or $0.5 \mathrm{SD}$ deterioration, compared to baseline, (hereafter: cognitive deterioration) was calculated using survival analysis in multiplerecord-per-subject survival data. Although cognitive improvement partly will reflect non-declarative learning, the rate of such non-declarative learning will also be subject to variation between persons (i.e. one person will have more or less increases over time than another) that may in part be attributable to, for example, illness characteristics or changes in mood and medication. 


\section{Predictors of cognitive improvement and cognitive deterioration}

In order to assess the impact of selected time-varying as well as fixed variables on rate of cognitive improvement and cognitive deterioration over time as defined above, Cox proportional hazard models were fitted to multiple-record-per-subject survival data, yielding measures of relative risk (hazard ratio; HR). Exposure variables selected for these analyses were those with significant main effects in the multiple time point analyses using multilevel random regression above. Kaplan-Meier survivor functions were graphed for key findings.

\section{Impact on functioning}

In order to prospectively assess the impact of cognitive measures on functioning, the rate of 1.0 SD deterioration in functioning, compared to baseline, was calculated using survival analysis and modelled with Cox proportional hazard models as described above.

\section{Results}

Demographic data, disease characteristics, medication, symptom scores and neurocognitive test results are presented in Table 1.

Table 1. Demographics, symptom scores and neurocognitive test results at baseline

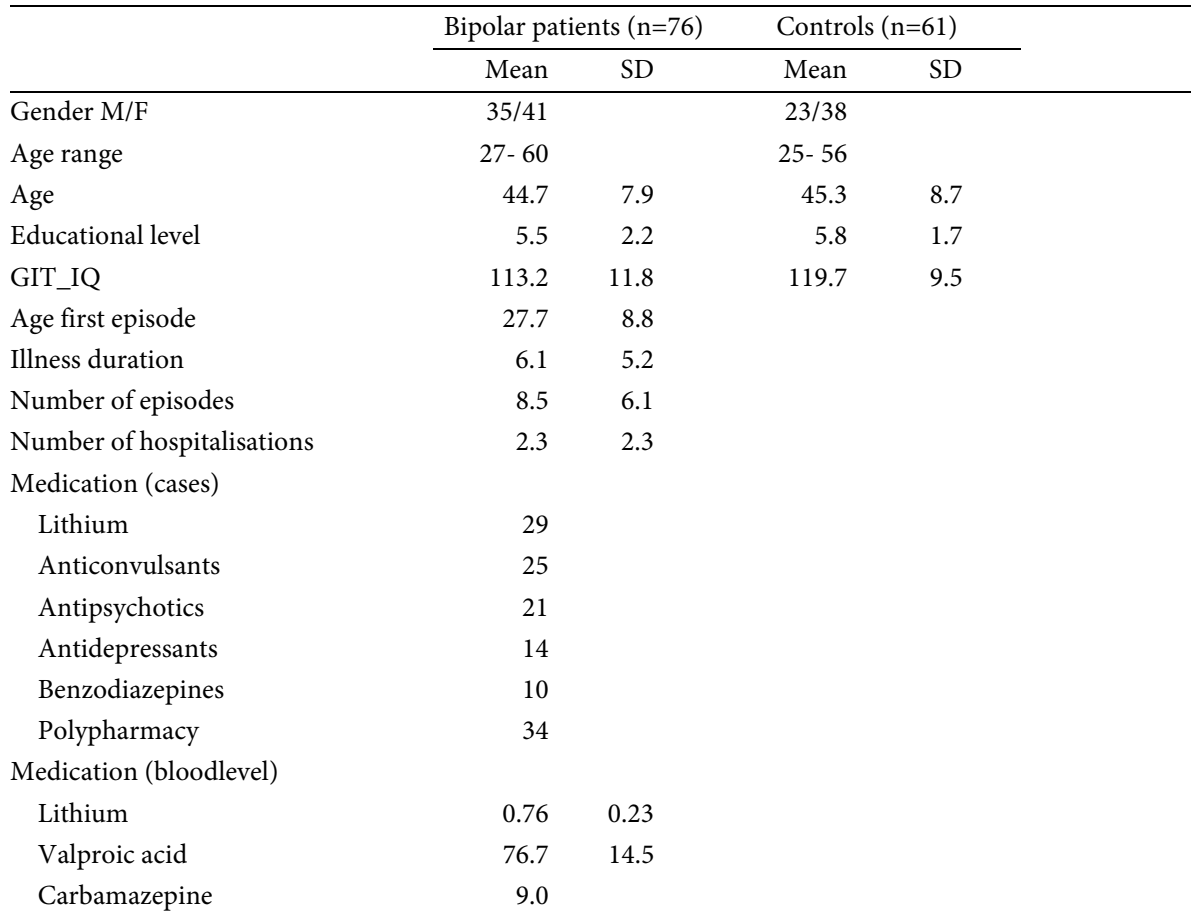




\begin{tabular}{|c|c|c|c|c|}
\hline & \multicolumn{2}{|c|}{ Bipolar patients $(\mathrm{n}=76)$} & \multicolumn{2}{|c|}{ Controls $(n=61)$} \\
\hline & Mean & SD & Mean & SD \\
\hline Lamotrigine & 2.7 & 1.5 & & \\
\hline TSH & 1.8 & 0.9 & & \\
\hline BPRS & 34.8 & 6.6 & 26.0 & 1.8 \\
\hline HDRS & 4.0 & 4.3 & 1.1 & 1.6 \\
\hline YMRS & 1.6 & 2.4 & 0.4 & 0.7 \\
\hline \multicolumn{5}{|c|}{ Verbal learning and memory } \\
\hline Immediate recall & 23.0 & 5.3 & 26.0 & 4.5 \\
\hline Delayed recall & 7.1 & 2.9 & 8.6 & 2.5 \\
\hline \multicolumn{5}{|l|}{ Sustained attention } \\
\hline$\%$ correct detections & 0.95 & 0.07 & 0.99 & 0.02 \\
\hline RT correct detections & 482.1 & 95.5 & 473.1 & 78.0 \\
\hline \multicolumn{5}{|l|}{ Information processing } \\
\hline Correct-neutral & 43.1 & 6.1 & 44.9 & 4.0 \\
\hline Correct-congruent & 43.2 & 6.4 & 45.7 & 3.3 \\
\hline RT-neutral & 673.4 & 89.1 & 647.2 & 65.1 \\
\hline RT-congruent & 673.5 & 87.0 & 644.2 & 55.8 \\
\hline \multicolumn{5}{|l|}{ Selective attention } \\
\hline Correct-incongruent & 38.8 & 8.8 & 42.1 & 5.1 \\
\hline RT-incongruent & 725.1 & 83.9 & 706.3 & 64.6 \\
\hline \multicolumn{5}{|l|}{ Motor speed } \\
\hline Rate & 187.0 & 36.3 & 180.8 & 22.2 \\
\hline Hits & 272.2 & 44.3 & 278.1 & 34.1 \\
\hline \multicolumn{5}{|l|}{ Attentional span } \\
\hline Forward condition & 8.5 & 1.9 & 9.0 & 1.9 \\
\hline \multicolumn{5}{|l|}{ Working memory } \\
\hline Backward condition & 5.7 & 1.9 & 6.6 & 1.9 \\
\hline
\end{tabular}

Bipolar patients were adequately frequency-matched with healthy controls, moderately ill and relatively asymptomatic.

\section{Attrition}

The study started with 76 bipolar patients at baseline; 23 patients had left the study after the second interview occasion. Of the 53 remaining patients, 14 dropped out over the 2-year follow-up, with 39 patients remaining at interview occasion 12 .

Patients staying longer in the study did not perform better on any of the cognitive measures, with the exception of basic information processing (correct number of neutral flankers in the Flanker CPT) $(B=0.2$; p: 0.008). At baseline, there was only a single significant difference in sustained attention between patients who dropped out and patients that remained, patients remaining in the study performing faster $(ß=0.27$; p: 0.007). These data suggest that there was little in terms of selective attrition. 


\section{Group differences}

Bipolar patients performed worse on all tasks, significantly so $(\mathrm{p}<0.014)$ for 5 of the 7 cognitive domains, using controls as a reference group (Table 2). Effect sizes were small, with a maximum of -0.36 for sustained attention, and even smaller differences in verbal learning and memory, basic information processing, selective attention and working memory.

Table 2. Associations between group status (BD) and neurocognition (controls as reference)

\begin{tabular}{|c|c|c|}
\hline & \multicolumn{2}{|c|}{ Bipolar patients } \\
\hline & $B^{*}$ & $\mathrm{p}$ \\
\hline \multicolumn{3}{|c|}{ Verbal learning and memory } \\
\hline Immediate recall & -0.22 & 0.002 \\
\hline Delayed recall & -0.23 & 0.004 \\
\hline \multicolumn{3}{|l|}{ Sustained attention } \\
\hline$\%$ correct detections & -0.36 & 0 \\
\hline RT correct detections & -0.05 & 0.55 \\
\hline \multicolumn{3}{|l|}{ Information processing } \\
\hline Correct-neutral & -0.2 & 0.035 \\
\hline Correct-congruent & -0.26 & 0.005 \\
\hline RT-neutral & -0.18 & 0.045 \\
\hline RT-congruent & -0.21 & 0.017 \\
\hline \multicolumn{3}{|l|}{ Selective attention } \\
\hline Correct-incongruent & -0.23 & 0.006 \\
\hline RT-incongruent & -0.13 & 0.14 \\
\hline \multicolumn{3}{|l|}{ Motor speed } \\
\hline Rate & -0.13 & 0.16 \\
\hline Hits & -0.1 & 0.29 \\
\hline \multicolumn{3}{|l|}{ Attentional span } \\
\hline Forward condition & -0.13 & 0.13 \\
\hline \multicolumn{3}{|l|}{ Working memory } \\
\hline Backward condition & -0.23 & 0.003 \\
\hline
\end{tabular}

${ }^{*} \beta$ standardized beta-scores

All analyses adjusted for age, sex and education

For all cognitive variables: higher values indicate better performance

Multiple time point associations with (groups of) time-varying and fixed exposures The main effects of groups of variables on cognitive domains are presented in Table 3. 
Table 3. Effect of demographics, disease characteristics, psychopathology, medication and global function on cognition

\begin{tabular}{|c|c|c|c|c|c|c|c|c|c|c|c|}
\hline & \multirow[b]{2}{*}{$\mathrm{N}$ obs } & \multicolumn{2}{|c|}{ Demographics* } & \multicolumn{2}{|c|}{ Disease char. } & \multicolumn{2}{|c|}{ Psychopathol. } & \multicolumn{2}{|c|}{ Medication } & \multicolumn{2}{|c|}{ Global function } \\
\hline & & s Chi2 (df) & $\mathrm{p}$ & Chi2 (df) & $\mathrm{p}$ & Chi2 (df) & $\mathrm{p}$ & Chi2 (df) & $\mathrm{p}$ & Chi2 (df) & $\mathrm{p}$ \\
\hline \multicolumn{12}{|c|}{ Verbal learning and memory } \\
\hline Immediate recall & 545 & $18.1(3)$ & 0.0004 & 12.5 & 0.0057 & 29.1 & 0.0000 & $2.8(6)$ & 0.8325 & $3.5(1)$ & 0.0601 \\
\hline Delayed recall & 545 & $14.2(3)$ & 0.0026 & $13.1(3)$ & 0.0043 & $14.3(5)$ & 0.0140 & $5.8(6)$ & 0.4412 & $6.4(1)$ & 0.0117 \\
\hline \multicolumn{12}{|l|}{ Sustained attention } \\
\hline$\%$ correct detections & 548 & $16.5(3)$ & 0.0009 & $3.2(3)$ & 0.3695 & $11.8(5)$ & 0.0384 & $6.6(6)$ & 0.3600 & $0.1(1)$ & 0.7551 \\
\hline RT correct detections & 548 & $0.5(3)$ & 0.9224 & $1.2(3)$ & 0.7457 & $10.9(5)$ & 0.0529 & $12.3(6)$ & 0.0560 & $1.1(1)$ & 0.3032 \\
\hline \multicolumn{12}{|l|}{ Information processing } \\
\hline Correct-neutral & 500 & $30.5(3)$ & 0.0000 & $1.8(3)$ & 0.6181 & $8.9(5)$ & 0.1095 & $2.2(6)$ & 0.9029 & $0.2(1)$ & 0.6632 \\
\hline Correct-congruent & 500 & $26.6(3)$ & 0.0000 & $0.4(3)$ & 0.9414 & $10.5(5)$ & 0.0620 & $3.6(6)$ & 0.7278 & $6.1(1)$ & 0.0136 \\
\hline RT-neutral & 500 & $14.1(3)$ & 0.0028 & $3.8(3)$ & 0.2875 & $10.9(5)$ & 0.0527 & $14.9(6)$ & 0.0214 & $1.2(1)$ & 0.2844 \\
\hline RT-congruent & 500 & $12.8(3)$ & 0.0052 & $3.3(3)$ & 0.3503 & $13.0(5)$ & 0.0234 & $15.3(6)$ & 0.0182 & $0.6(1)$ & 0.4543 \\
\hline \multicolumn{12}{|l|}{ Selective attention } \\
\hline Correct-incongruent & 500 & $33.4(3)$ & 0.0000 & $0.1(3)$ & 0.9897 & $8.8(5)$ & 0.1188 & $4.1(6)$ & 0.6627 & $0.5(1)$ & 0.5009 \\
\hline RT-incongruent & 500 & $11.7(3)$ & 0.0085 & $5.8(3)$ & 0.1215 & $12.4(5)$ & 0.0301 & $14.2(6)$ & 0.0279 & $0.6(1)$ & 0.4245 \\
\hline \multicolumn{12}{|l|}{ Motor speed } \\
\hline Rate & 485 & $6.6(3)$ & 0.0861 & $1.3(3)$ & 0.7283 & 24.3 & 0.0002 & $20.3(6)$ & 0.0024 & $0.5(1)$ & 0.4779 \\
\hline Hits & 485 & $7.0(3)$ & 0.0715 & $1.2(3)$ & 0.7470 & $23.8(5)$ & 0.0002 & $15.1(6)$ & 0.0198 & $1.4(1)$ & 0.2359 \\
\hline \multicolumn{12}{|l|}{ Attentional span } \\
\hline Forward condition & 544 & $11.4(3)$ & 0.0097 & $7.6(3)$ & 0.0548 & $11.9(5)$ & 0.0356 & $5.5(6)$ & 0.4824 & $0.1(1)$ & 0.8072 \\
\hline \multicolumn{12}{|l|}{ Working memory } \\
\hline Backward condition & 544 & $5.3(3)$ & 0.1504 & $10.9(3)$ & 0.0124 & $14.6(5)$ & 0.0123 & $5.8(6)$ & 0.4432 & $0.1(1)$ & 0.8042 \\
\hline
\end{tabular}

* Demographics: age, sex, education

Disease characteristics: number of episodes, age of onset, alcohol use

Psychopathology: BPRS, HDRS, YMRS, psychotic symptoms

Medication: lithium, anticonvulsants, antipsychotics, antidepressants, benzodiazepines, polypharmacy

Global function: GAF

\section{Contribution of demographic variables}

When introduced simultaneously as a group, demographic variables had a significant effect on verbal learning and memory $(0.0026<\mathrm{p}<0.0004)$, sustained attention (percentage correct detections; $\mathrm{p}=0.0009$ ), basic information processing $(0.0052<\mathrm{p}<0.0001)$, selective attention $(0.0085<\mathrm{p}<0.0001)$, and attentional span $(\mathrm{p}=0.0097)$. In healthy controls, this group of variables had a significant effect on verbal learning only ( $\mathrm{p}=0.0004)$.

Testing the contribution of individual variables revealed that Age overall displayed small negative effects, but a significant effect was apparent only for basic information processing (correct response condition), with effect sizes between -0.35 
and $-0.38(p=0.001)$, and for selective attention $(\beta=-0.4 ; p=0.000)$. Sex displayed no significant effects. Higher Education had a significant positive effect on verbal learning $(\beta=0.26 ; p=0.002)$, sustained attention (percentage correct detections: $\beta=0.25$; $\mathrm{p}<0.0001)$, basic information processing $(0.25<\beta<0.28 ; 0.008<\mathrm{p}<0.004)$, selective attention $(\beta=0.26 ; p=0.007)$, attentional span $(\beta=0.28 ; p=0.003)$, and working memory $(\beta=0.22 ; \mathrm{p}=0.013)$.

\section{Contribution of disease characteristics}

Tested as a group, the only significant main effects were on verbal learning and memory $(0.0057<\mathrm{p}<0.0043)$ and working memory $(\mathrm{p}=0.0124)$.

Testing the contribution of individual variables revealed that a higher Number of episodes influenced working memory negatively $(\beta=-0.3 ; \mathrm{p}=0.002)$. Later Age of onset had a significant negative effect on verbal learning and memory, with an effect size between -0.3 and $-0.34(0.005<\mathrm{p}<0.002)$. Alcohol use in the last two months had no significant effects on any of the cognitive variables.

\section{Contribution of psychopathology variables}

Tested as a group, psychopathology variables had significant effects on verbal learning $(\mathrm{p}<0.0001)$, motor speed ( $\mathrm{p}=0.0002)$, and working memory $(\mathrm{p}=0.0123)$.

In healthy controls, symptoms (BPRS, CFQ) influenced only basic information processing (number correct; $\mathrm{p}=0.009$ ) and selective attention (number correct; $\mathrm{p}=0.0026)$.

Testing the contribution of individual variables revealed that higher BPRS-score had small negative effects on all the cognitive domains, with significant effects on verbal learning and memory $(-0.11<\beta<-0.16 ; 0.002<\mathrm{p}<0.0001)$, basic information processing (correct response: $\beta=-0.19 ; \mathrm{p}=0$ ), selective attention $(\beta=-0.12 ; \mathrm{p}=0)$ and motor speed $(-0.11<\beta<-0.12 ; 0.003<\mathrm{p}<0.002)$. Higher HDRS-scores impacted negatively on verbal learning $(ß ;-0.13 ; \mathrm{p}<0.0001)$, motor speed $(-0.11<ß<-0.13$; $0.001<\mathrm{p}<0.0001$ ), and basic information processing (correct response, congruent condition; $ß=-0.19 ; \mathrm{p}<0.0001)$. YMRS-scores were not associated with cognitive measures. Psychotic symptoms in the past had no significant effect on cognitive functioning. Higher CFQ-scores negatively influenced all the cognitive domains, with effect sizes between -0.14 and $-0.24(0.011<\mathrm{p}<0.0001)$, with the largest effects on selective attention and verbal learning.

\section{Contribution of medication variables}

Tested as a group, as shown in table 3 , effects of medication variables were significant only for motor speed (tapping rate; $\mathrm{p}=0.0002$ ).

Testing individual medications revealed that Lithium was used by 33 patients at any given moment during the study (number of observations: 314). The use of lithium was not associated with significant effects on cognitive functioning. Lithium use at baseline displayed a significant positive association with motor speed (tapping rate; $\beta=0.6 ; p=0.013$ ), and longer duration of lithium use was also positively associ- 
ated with motor speed $(0.19<\beta<0.24 ; 0.003<\mathrm{p}<0.0001)$. Negative effects of lithium were found for use in the last two months before interview occasion on basic information processing (reaction time; $-0.32<ß<-0.37 ; 0.019<\mathrm{p}<0.005$ ). Anticonvulsants were used by 36 patients, with a total number of observations of 255 . The use of these medications was not associated with any significant effect on cognitive measures. Second generation antipsychotics were taken by 24 patients (number of observations: 93). Their use had a significant negative effect on motor speed $(-0.36<ß<-0.5$; $0.003<\mathrm{p}<0.0001$ ) and basic information processing (reaction time, congruent condition; $\beta=-0.35 ; \mathrm{p}=0.011$ ). Antidepressants were used by 21 bipolar patients in our study, with a total number of observations of 140 . No associations with cognitive measures were observed. Benzodiazepines were taken by only 16 patients (number of observations: 80). No associations with cognition were apparent. Polypharmacy was observed in 48 patients (number of observations: 250). It was negatively associated with motor speed $(-0.18<ß<-0.21 ; \mathrm{p}=0.0001)$.

\section{Associations with global functioning}

In the analyses testing effects of groups of variables, associations between cognitive measures and GAF score are shown in table 3 and concern verbal memory $(\mathrm{p}=0.0117)$ and basic information processing (number correct, congruent condition; $\mathrm{p}=0.0136)$. Tested as individual variable, higher $G A F$-scores were positively associated with verbal learning and memory $(\beta=0.16 ; \mathrm{p}=0.001)$, basic information processing (number correct; $0.15<\beta<0,25 ; 0.02<\mathrm{p}<0.0001$ ), and motor speed $(0.13<\beta<0.14$; $0.017<\mathrm{p}<0.011)$.

\section{Thyroid function}

For partly imputed TSH-values, effect sizes were small, but significant for basic information processing $(\beta=-0.2 ; p=0)$, selective attention $(-0.13<\beta<-0.17$; $0.004<\mathrm{p}<0.001)$, and motor speed $(-0.11<ß<-0.13 ; 0.011<\mathrm{p}<0.004)$.

\section{Life-charts}

A varying number of patients, between 17 and 29, had reliable life-chart data on subjective mood over the period 7 days before the interview, yielding a varying number of observations (between 215 and 261) for depressive mood, and between 62 and 78 for (hypo-)manic symptoms.

Life-chart depressive mood had a significant negative effect on motor speed $(-0.31<ß<-0.42 ; \mathrm{p}<0.0001)$. Life-chart manic symptoms negatively impacted on basic information processing (reaction time; $\beta=-0.27 ; \mathrm{p}=0.001$ ) and selective attention (number correct; $ß=-0.24 ; \mathrm{p}=0.003$ ).

\section{Interactions with interview occasion}

For the above reported effects, there were no significant interactions with interview occasion, except for symptomatology (HDRS) in the motor speed task (tapping rate; $ß=0.13 ; p=0.01$ ). This interaction indicated decreased effects of HDRS on cognition 
at later interview occasions. Of note was the fact that associations between CFQ and neurocognition were constant over time, as indicated by non-significant interactions with interview occasion.

\section{Variability of cognitive measures over time and new learning}

Analysis of variability over time, testing that the parameters of all dummies of time equalled zero, revealed effects of time that were large and highly significant for most of the cognitive domains (5 out of 7), with the exception of sustained attention and motor performance (Table 4). Inspection of the parameters for the dummy variables indicated increasingly better cognitive performance over time from baseline to the end of the study for most of the variables, suggestive of new learning. Follow-up modelling of time as a linear variable quantified new learning effects in 5 out of 7 cognitive domains (verbal learning and memory, basic information processing, selective attention, attentional span, and working memory). Sustained attention and tapping showed no improvement over time; selective attention displayed the largest increases $(\beta=0.37)$.

\section{Can variability of cognitive measures over time can be reduced to other factors?}

Introducing groups of independent variables (demographics, psychopathology, medication, GAF, illness-related factors), in the model generally did not or only minimally impact on the effect of time (testing that the parameters of all dummies of time equalled zero) (Table 4), indicating that most of the variance over time was related to other factors.

\section{Directional changes over time}

The rate of cognitive improvement and cognitive deterioration was high for all cognitive domains. The mean monthly rate of cognitive improvement was around $5 \%$ and around 3\% for cognitive deterioration. The 2-year cumulative incidence rate of cognitive improvement was $48 \%$ and around $31 \%$ for cognitive deterioration, i.e. a net improvement over time for all cognitive domains, with the exception of sustained attention (net decrement of 5\%).

Of the variables signalling associations in the multiple time point analyses, lithium use positively predicted cognitive improvement in verbal learning $(\mathrm{HR}=2.3$; $\mathrm{p}=0.009$ ) and negatively predicted cognitive deterioration in verbal memory ( $\mathrm{HR}=0.4 ; \mathrm{p}=0.036)$, although the latter was just below the set significance level. The first effect is illustrated in Figure 1.

Higher CFQ scores negatively impacted on cognitive improvement in the area of basic information processing $(\mathrm{HR}=0.37, \mathrm{p}=0.005)$ and in the area of selective attention $(\mathrm{HR}=0.47, \mathrm{p}=0.003)$. Higher BPRS-scores predicted cognitive deterioration in verbal learning $(\mathrm{HR}=5.9$ : $\mathrm{p}=0.008)$. 
Table 4. Variability of cognitive measures over time

\begin{tabular}{|c|c|c|c|c|c|}
\hline & \multirow[b]{2}{*}{$\mathrm{N}$ obs. } & \multicolumn{2}{|l|}{ Time } & \multicolumn{2}{|l|}{ Time $^{*}$} \\
\hline & & Chi2 (df) & $\mathrm{p}$ & Chi2 (df) & $\mathrm{p}$ \\
\hline \multicolumn{6}{|c|}{ Verbal learning and memory } \\
\hline Immediate recall & 545 & $161.4(11)$ & 0.0000 & $130.4(11)$ & 0.0000 \\
\hline Delayed recall & 545 & $140.1(11)$ & 0.0000 & $119.8(11)$ & 0.0000 \\
\hline \multicolumn{6}{|l|}{ Sustained attention } \\
\hline$\%$ correct detections & 548 & $18.2(11)$ & 0.0767 & $19.7(11)$ & 0.0502 \\
\hline RT correct detections & 548 & $9.7(11)$ & 0.5564 & $10.6(11)$ & 0.4805 \\
\hline \multicolumn{6}{|l|}{ Information processing } \\
\hline Correct-neutral & 500 & $78.9(11)$ & 0.0000 & $61.0(11)$ & 0.0000 \\
\hline Correct-congruent & 500 & $100.3(11)$ & 0.0000 & $64.6(11)$ & 0.0000 \\
\hline RT-neutral & 500 & $155.8(11)$ & 0.0000 & $140.5(11)$ & 0.0000 \\
\hline RT-congruent & 500 & $140.7(11)$ & 0.0000 & $129.4(11)$ & 0.0000 \\
\hline \multicolumn{6}{|l|}{ Selective attention } \\
\hline Correct-incongruent & 500 & $72.9(11)$ & 0.0000 & $58.9(11)$ & 0.0000 \\
\hline RT-incongruent & 500 & $175.9(11)$ & 0.0000 & $164.8(11)$ & 0.0000 \\
\hline \multicolumn{6}{|l|}{ Motor speed } \\
\hline Rate & 485 & $14.4(11)$ & 0.2100 & $12.7(11)$ & 0.3162 \\
\hline Hits & 485 & $16.4(11)$ & 0.1267 & $14.6(11)$ & 0.2021 \\
\hline \multicolumn{6}{|l|}{ Attentional span } \\
\hline Forward condition & 544 & $45.4(11)$ & 0.0000 & $33.7(11)$ & 0.0004 \\
\hline \multicolumn{6}{|l|}{ Working memory } \\
\hline Backward condition & 544 & $120.7(11)$ & 0.0000 & $106.1(11)$ & 0.0000 \\
\hline
\end{tabular}

Time: Effect of time without any of the other groups of independent variables included in the model Time $^{*}$ : Effect of time with all of the other groups of independent variables included in the model

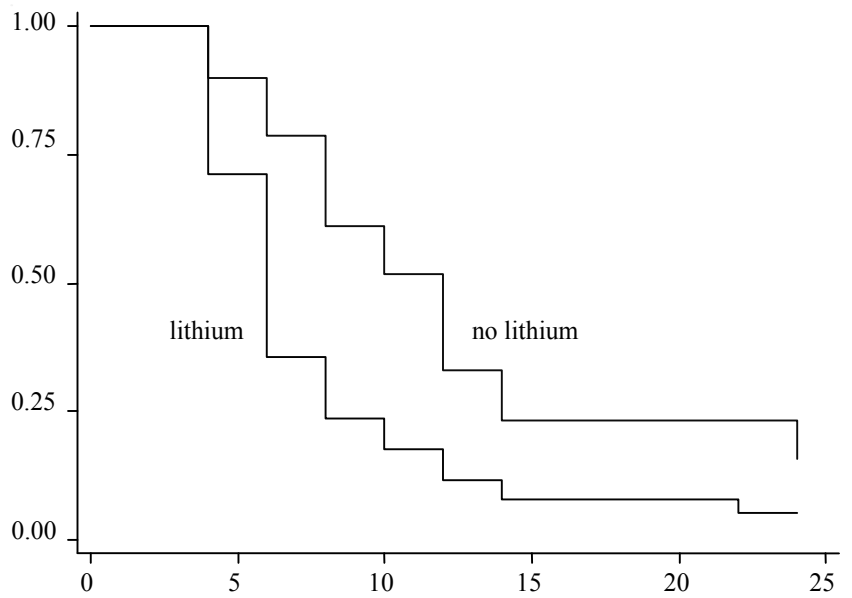

Figure 1. Kaplan - Meier survival estimates of the effect of lithium time to cognitive improvement in verbal learning (x-axis: analysis time in months) 


\section{Prediction of functioning}

Cox proportional hazard models of deterioration of functioning, corrected for age, sex and education, revealed protective effects for 11 out of 14 cognitive variables, which were statistically significant for higher verbal learning $(H R=0.42, p=0.009)$, higher verbal memory $(\mathrm{HR}=0.38, \mathrm{p}=0.010)$ and higher sustained attention $(\mathrm{HR}=0.42, \mathrm{p}=0.001)$. A similar protective effect size was apparent for better subjective cognition measured with the CFQ, albeit below the corrected significance level $(\mathrm{HR}=0.42, \mathrm{p}=0.036)$.

\section{Discussion}

\section{Summary of findings}

Bipolar patients displayed small impairments in the cognitive domains studied, with the largest significant effect size for sustained attention. Smaller effect sizes were found for verbal learning and memory, basic information processing, selective attention and working memory, with no significant differences for motor speed and attentional span. Cognitive impairment co-varied with subjective cognitive complaints and both predicted deterioration in functioning. The effects of the groups of independent variables studied (demographic and disease characteristics, psychopathology, medication, global function) were generally small and discrete, influencing different cognitive domains in different ways. The largest, but still small, significant effect sizes were found for age on selective attention, for number of episodes on working memory, for age of onset on verbal learning and memory, for subjective depressive mood (life-charts) on motor speed, and, finally, for antipsychotic medication on basic information processing and motor speed.

Cognitive functioning improved over time, particularly selective attention. Most likely, this improvement through practice reflected non-declarative learning (i.e., via implicit processes), although performance on some other tasks may also have benefitted from explicit formulating of more efficient strategies (i.e., declarative learning). ${ }^{43}$ Sustained attention and motor speed showed no improvement, and cognitive performance also deteriorated at some stage during the follow-up in more than a third of the sample. Time explained most of the variance in the observed cognitive areas, with the exception of sustained attention and motor speed.

Directional changes of improvement and deterioration over time was considerable for verbal learning and memory and attentional span. Lithium use, symptoms and subjective cognitive complaints influenced this variability in several ways, especially in the case of verbal learning and memory as well as basic information processing. 


\section{Effects of time}

Given observed practice-effects for most of the cognitive domains studied, nondeclarative learning may, at least in part, be intact in bipolar patients, in line with a number of previous studies. ${ }^{44,45}$ A dissociation between declarative and nondeclarative learning has been described for other disorders as well, and is in accordance with different brain networks underlying both forms of memory. ${ }^{43}$ However, we did not formally test whether the practice effects were based on non-declarative processes, and, in addition, high rates of cognitive deterioration and other sources of variation over time were apparent. The true rate of non-declarative learning, therefore, may be approximated by considering the difference between the $50 \%$ cumulative rate of 2 -year cognitive improvement versus the $30 \%$ cumulative rate of cognitive deterioration. The difference between these two percentages reflects the bias towards cognitive improvement induced by repeated exposure to cognitive tasks. Regardless of whether non-declarative or declarative processes form the basis for this effect, the results clearly show that there is room for cognitive improvement in bipolar disorder, a finding which has hitherto not been exploited. ${ }^{44,45}$

The findings of widespread variability are in contrast with the sparse literature on the longitudinal course of cognitive functioning in bipolar disorder in 3 studies with repeated measurement after 2, 3, and 6 years, respectively, which revealed stability over time for, respectively, executive functioning and processing speed, ${ }^{46} \mathrm{flu}$ ency, verbal memory, Stroop-interference tasks, ${ }^{5}$ and verbal memory. ${ }^{47}$ The current study, with more frequent assessments, yielded a much more detailed and heterogeneous picture. Of note was the fact that a range of disease and treatment variables failed to have a large impact on variation of cognition over time, suggesting that unknown person-specific factors explain such longitudinal variation.

\section{Subjective and objective measures of cognition}

The CFQ reliably assesses multiple dimensions of cognitive failures, ${ }^{48}$ is weakly associated with neuroticism, but more strongly with psychopathology. ${ }^{29}$ In the current study, CFQ was associated, in a stable fashion, with cognitive functioning in all domains in the multiple time point analyses, in contrast to earlier work. ${ }^{19}$ An association between subjective complaints and cognitive dysfunctions was reported, however, in another study. ${ }^{20}$ Number of episodes and mood symptoms influenced subjective cognitive complaints negatively and subjective cognitive complaints predicted deterioration in functioning with a similar effect size as measures of neurocognition. Medication did not impact on cognitive complaints in their study. ${ }^{20}$ However, posthoc analysis in our sample yielded significant negative associations between medication (lithium and anticonvulsants) and subjective cognitive complaints.

The results therefore suggest that in bipolar disorder, subjective cognitive complaints correspond, in part, to objective measures of neurocognition. This observation may be important, as it would allow for a sensitive clinical assessment of varia- 
tion over time and the impact of changes in medication, mood and other timevarying variables. The findings also suggest that subjective cognitive complaints may be relevant predicting the outcome of rehabilitation efforts, particularly in the area of work.

Also of note was the fact that CFQ not only was associated with current cognitive assessment in the multiple time point analyses, but also that CFQ negatively predicted future cognitive improvement in the areas of basic information processing and selective attention. This suggests that the apparent negative interference with current cognition of CFQ also indexes a longer term vulnerability interfering with new learning.

\section{Intermediary cognition phenotypes in bipolar disorder}

In the current sample of bipolar patients, sustained attention was the most stable cognitive function over the two-year period. Thus, sustained attention may be a candidate intermediary phenotype for bipolar disorder. In a recent meta-analysis on cognitive intermediary phenotypes in bipolar disorder, it was concluded that response inhibition deficit is the most prominent intermediary phenotype, as well as sustained attention. ${ }^{8}$ This corresponds to the finding that attention (in general), as an early cognitive process, represent the most stable deficit in bipolar patients over time, while later cognitive processes, such as verbal learning and memory, may be subject to greater levels of variation. ${ }^{49}$ A similar tendency for greater level of variation over time was found in the current study for verbal learning and attentional span; these cognitive domains may thus be more related to the clinical expression of bipolar disorder. ${ }^{8,46}$ A recent study challenges the position of response inhibition deficit as a candidate intermediary phenotype by finding intact inhibitory control in first-degree relatives of bipolar patients. ${ }^{50}$ Furthermore, sustained attention deficits, independent of working memory, have been reported in euthymic bipolar patients and described as a reduced inherent capacity, which remained apparent in a study of patients not taking medication. ${ }^{51}$ Another study found that only sustained attention deficit survived controlling for mild affective symptoms, suggesting that sustained attention indeed represents a vulnerability marker for bipolar disorder. ${ }^{52}$ Finally, sustained attention may be considered as an endophenotype of the illness. ${ }^{53}$

\section{Factors impacting on cognition}

\section{Disease characteristics}

In our study, number of episodes had a negative effect on all cognitive domains, but only significantly influenced working memory. This is in line with the literature on its negative effects on various cognitive domains, like verbal memory and response inhibition. ${ }^{13,54}$ 
Later age of onset had a significant negative effect on verbal learning and memory. Cognitive dysfunction in bipolar patients with late onset has been described earlier; ${ }^{55,56}$ however, both positive and negative associations between (early) age of onset and cognitive functions have also been reported. ${ }^{57}$

Post-hoc analysis did not reveal any significant effects of length of illness and number of hospitalisations, which corresponds to equivocal findings in the literature. ${ }^{13,58}$ In general, the direction of causality of these associations cannot be determined. In this respect, there is an interesting possibility that bipolar patients with neurocognitive impairments are more prone to a severe and recurrent form of illness. ${ }^{57}$

Alcohol use during the last two months did not significantly influence cognitive functioning, in contrast to the finding of worse executive functioning in bipolar patients with alcohol dependence in the past. ${ }^{58}$ A likely factor explaining the difference was that use of alcohol was moderate in the current sample.

\section{Psychopathology}

Overall, the effects of symptoms were rather small, perhaps due to the subclinical level of psychopathology in our study. Post-hoc analysis revealed no evidence for a nonlinear relationship between mood symptoms and cognition.

Furthermore, the tasks used in our study may not be specific or 'warm' enough to find effects of (subclinical) symptoms on cognitive dysfunction. ${ }^{59}$ This is illustrated by a study, finding only differences between unmedicated depressed bipolar patients and controls on specific tasks regarding reward processing and sensitivity to negative feedback, and no differences on conventional, 'cold' tests. ${ }^{60}$

A remarkable finding, however, are the relatively large effects of subjective mood, as measured by the life-chart, on motor speed and selective attention. The importance of (residual) mood symptoms on cognitive functioning in bipolar patients is emphasized by others. ${ }^{52}$ Finally, psychotic symptoms did not impact on cognitive functions, with the remarkable exception of a near significant positive effect on verbal memory $(\Omega=0.4 ; \mathrm{p}=0.024)$. Interestingly, another study found a positive association between schizotypal personality scores and visual memory performance in bipolar patients. ${ }^{61}$ Negative effects of psychotic symptoms on cognition are described in the literature, ${ }^{61,62}$ as well as absence of any effect. ${ }^{63}$ Others, however, found better cognitive performance in first-degree relatives of bipolar patients with (positive) psychotic symptoms, indicative of a relative protective effect of the absence of liability to neurodevelopmental impairment. ${ }^{11}$

\section{Medication}

Overall, the effects of medication were small and different for the various cognitive domains studied. This is in accordance with the equivocal, sparse literature in this area, ${ }^{64}$ showing deficits in affective processing, ${ }^{65}$ attention, ${ }^{51,66}$ and memory ${ }^{56,67}$ in medicated bipolar patients. Neurocognitive performance in drug-free and medicated euthymic bipolar patients was studied. ${ }^{67}$ The only significant difference was on de- 
layed verbal recall, drug-free patients performing better. This difference became non-significant, however, after controlling for residual mood symptoms, and effect sizes were modest. ${ }^{67,68}$

Lithium had positive and negative effects on cognitive functioning, which corresponds to the ongoing discussion in the literature on the neuroprotective versus neurotoxic effects of this drug. ${ }^{69}$ Negative (short-term) effects of lithium, in the current study on processing speed, are described in the literature regarding verbal memory, speed of processing and executive functioning. ${ }^{14,70,71}$ Long-term use of lithium, in the current study, was positively associated with motor speed. Long-term positive effects of lithium are illustrated by several studies. ${ }^{46,47,72}$ Furthermore, lithium may induce neuroplastic changes in amygdala and hippocampus, by increasing gray matter volume of these core regions of emotional and cognitive processing. ${ }^{73}$

Anticonvulsants were not associated with any significant effect on cognitive functioning. This is in accordance with the literature, showing none, or only modestly negative, effects of valproic acid, ${ }^{65,74,75}$ and none, or only positive, effects on cognition of lamotrigine..$^{76,77}$

Antipsychotics had the most prominent negative effects on cognition. In several studies, this negative association is described in bipolar patients. ${ }^{14,71,78}$ Euthymic bipolar patients with and without use of antipsychotics were studied, finding no differences between patients without antipsychotics and healthy controls on any neuropsychological measure, whereas a significant underperformance was apparent in the domains of verbal learning and executive functioning in the group using antipsychotics. $^{71}$

It has been suggested that second generation antipsychotics may improve cognitive functioning in the treatment of schizophrenia. ${ }^{79,80}$ These cognitive improvements may be (partly) due to non-declarative learning in the sense of practice effects. ${ }^{81}$ Another interesting hypothesis, however, is that the effect of antipsychotics depends on hyperdopaminergia in selected brain areas, causing beneficial effects in hyperdopaminergic states, as in schizophrenia, and inducing suboptimal cognitive functioning in bipolar patients without such increased dopaminergic alterations. ${ }^{71}$

Polypharmacy was negatively associated with motor speed in our study, comparable to another study. ${ }^{20}$ On the other hand, better working memory performance has been observed in bipolar patients on combination treatment, compared to monotherapy. ${ }^{82}$

\section{Thyroid function}

Elevated TSH-values, possibly indicating (sub-)clinical hypothyroidism, had only very small negative effects on some of the investigated cognitive domains. This could be due in part to a threshold-effect, the levels of TSH in our sample being too low to influence cognition in a significant way. The hypothesis that the anti-thyroid effects of lithium may contribute to the cognitive deficits of lithium-treated bipolar patients could not be confirmed. ${ }^{18}$ 


\section{Associations with global functioning}

Cognitive measures were positively associated with $G A F$-scores and survival analyses indicated better neurocognition, and indeed less subjective cognitive complaints, protected against deterioration in functioning, particularly verbal learning and memory and sustained attention. Several studies are in agreement with these results, describing negative effects on functional outcome of deficits in verbal memory, attention and executive functioning in bipolar patients. ${ }^{83,84}$ Negative effects of (subclinical) mood symptoms on daily functioning are illustrated in another study. ${ }^{85}$ In the current study, post-hoc analysis revealed negative associations between functional outcome on the one hand and psychopathology and use of antipsychotic medication on the other. Finally, impairment in theory of mind, ${ }^{86}$ may be important as well in daily functioning.

\section{Methodological considerations}

The prospective repeated measures design, increasing power and making it possible to disentangle the differential effects of various independent variables on (change in) cognitive functioning, is a strong point of this naturalistic study. The large number of observations in the repeated measures design increases reliability of significant, albeit small, effects, decreasing the risk of type I errors. In our opinion, we adequately controlled for confounding variables and for multiple tests of significance. Furthermore, the naturalistic character of our study in a heterogeneous group of patients increases the external validity of our findings.

A drawback of our study is the loss of almost half of the patients over the 2 year follow-up for unknown reasons; selective attrition, however, was shown to be unlikely. Furthermore, partly due to the naturalistic character of our study, we did not control for other factors possibly influencing cognitive functioning, like medical and psychiatric comorbidity, somatic (anticholinergic) medication, past drug use, traumatic events in the past, motivational factors and intrusive thoughts. Our sample of bipolar spectrum patients was moderately ill, which, perhaps, plays a role in the small effect sizes found. Finally, the tests we used may be too 'cold' to detect effects of (subclinical) mood and medication on cognitive functioning. ${ }^{57,59,60,87}$ The proportion of bipolar patients with cognitive impairments can vary substantially dependent on the particular task employed. ${ }^{57}$

\section{Concluding remarks}

Cognitive functioning in bipolar patients is likely the result of the dynamic interplay of multiple factors, in which a variable genetic vulnerability is influenced by various external, possibly interacting, unknown factors, with a modest role for mood and medication. Several cognitive domains are influenced differently by these factors, with sustained attention as a possible candidate intermediary phenotype, and verbal 
memory and selective attention being more related to the clinical expression of bipolar disorder. Multiple time point measures of subjective mood symptoms and subjective cognitive complaints predict cognitive performance in a stable fashion over time. As cognitive performance in turn is associated with functioning in daily life, these data suggest that subjective complaints have relevance for the potential of societal participation in patients with bipolar illness. Cognitive functioning changes, and, sometimes, improves over time, which gives opportunities for cognitive rehabilitation. ${ }^{88}$

The results of our study agree with a model of neuropsychological dysfunction in bipolar patients that describes the emotional and cognitive abnormalities of the disorder as the product of durable functional alterations of dynamic neural, frontostriatal networks involved in mood and cognition, with a potential role for residual symptomatology and long-term medication. ${ }^{89}$

This model indicates the importance of gene $\mathrm{x}$ environment interactions in the causation of cognitive dysfunctions in bipolar patients. An illustrative example of this interaction is the positive effect of antipsychotics on working memory only in patients with schizophrenia homozygous for the COMT (108/158) met allele. ${ }^{90}$ Similar interactions between medication and gene polymorphisms may apply to bipolar patients. ${ }^{91}$ Candidate genes, in this respect, are LIS $1,{ }^{92}$ DISC $1,{ }^{93}$ DAOA,${ }^{94}$ AKT $1,{ }^{95}$ GSK3b, ${ }^{96}$ BCL-2 / BAG-1, ${ }^{97}$ COMT, ${ }^{98}$ and BDNF. ${ }^{99}$ In our view, further research in this direction may be interesting and relevant, as illustrated by studies of the effects of lithium and valproic acid on BDNF. ${ }^{100}$ 


\section{References}

1. Gottesman, II, Gould TD. The endophenotype concept in psychiatry: etymology and strategic intentions. Am J Psychiatry 2003; 160(4): 636-645.

2. Christensen MV, Kyvik KO, Kessing LV. Cognitive function in unaffected twins discordant for affective disorder. Psychol Med 2006; 36(8): 1119-1129.

3. Meyer SE, Carlson GA, Wiggs EA, Martinez PE, Ronsaville DS, Klimes-Dougan B et al. A prospective study of the association among impaired executive functioning, childhood attentional problems, and the development of bipolar disorder. Dev Psychopathol 2004; 16(2): 461-476.

4. Pavuluri MN, Schenkel LS, Aryal S, Harral EM, Hill SK, Herbener ES et al. Neurocognitive function in unmedicated manic and medicated euthymic pediatric bipolar patients. Am J Psychiatry 2006; 163(2): 286-293.

5. Balanza-Martinez V, Tabares-Seisdebos, R., Selva-Vera, G., Martinez-Aran, A., Torrent, C., SalazarFraile, J., Leal-Cerbos, C., Vieta, E., Gomez-Beneyto, M. Persistent Cognitive Dysfunctions in Bipolar I Disorder and Schizophrenic Patients: A 3-Year Follow-Up Study. Psychotherapy and Psychosomatics 2005; 74: 113-119.

6. Mur M, Portella MJ, Martinez-Aran A, Pifarre J, Vieta E. Long-term stability of cognitive impairment in bipolar disorder: a 2-year follow-up study of lithium-treated euthymic bipolar patients. $J$ Clin Psychiatry 2008; 69(5): 712-719.

7. Arts B, Jabben N, Krabbendam L, van Os J. Meta-analyses of cognitive functioning in euthymic bipolar patients and their first-degree relatives. Psychol Med 2008; 38(6): 771-785.

8. Bora E, Yucel M, Pantelis C. Cognitive endophenotypes of bipolar disorder: A meta-analysis of neuropsychological deficits in euthymic patients and their first-degree relatives. J Affect Disord 2009; 113: 1-20.

9. Balanza-Martinez V, Rubio C, Selva-Vera G, Martinez-Aran A, Sanchez-Moreno J, Salazar-Fraile J et al. Neurocognitive endophenotypes (endophenocognitypes) from studies of relatives of bipolar disorder subjects: a systematic review. Neurosci Biobehav Rev 2008; 32(8): 1426-1438.

10. Krabbendam L, Marcelis M, Delespaul P, Jolles J, van Os J. Single or multiple familial cognitive risk factors in schizophrenia? Am J Med Genet 2001; 105(2): 183-188.

11. Jabben N, Arts B, Krabbendam L, van Os J. Investigating the association between neurocognition and psychosis in bipolar disorder: further evidence for the overlap with schizophrenia. Bipolar Disord 2009; 11(2): 166-177.

12. Quraishi S, Walshe M, McDonald C, Schulze K, Kravariti E, Bramon E et al. Memory functioning in familial bipolar I disorder patients and their relatives. Bipolar Disord 2009; 11(2): 209-214.

13. Robinson LJ, Ferrier IN. Evolution of cognitive impairment in bipolar disorder: a systematic review of cross-sectional evidence. Bipolar Disord 2006; 8(2): 103-116.

14. Savitz JB, van der Merwe L, Stein DJ, Solms M, Ramesar RS. Neuropsychological task performance in bipolar spectrum illness: genetics, alcohol abuse, medication and childhood trauma. Bipolar Disord 2008; 10(4): 479-494.

15. Vonk R, van der Schot AC, Kahn RS, Nolen WA, Drexhage HA. Is autoimmune thyroiditis part of the genetic vulnerability (or an endophenotype) for bipolar disorder? Biol Psychiatry 2007; 62(2): $135-140$.

16. Davis JD, Tremont G. Neuropsychiatric aspects of hypothyroidism and treatment reversibility. Minerva Endocrinol 2007; 32(1): 49-65.

17. Bocchetta A, Cocco F, Velluzzi F, Del Zompo M, Mariotti S, Loviselli A. Fifteen-year follow-up of thyroid function in lithium patients. J Endocrinol Invest 2007; 30(5): 363-366.

18. Prohaska ML, Stern, R.A., Steketee, M.C. Lithium-thyroid interactive hypothesis of neuropsychological deficits: a review and proposal. Depression 1995; 2: 241-251.

19. Burdick KE, Endick CJ, Goldberg JF. Assessing cognitive deficits in bipolar disorder: Are selfreports valid? Psychiatry Res 2005; 136(1): 43-50.

20. Martinez-Aran A, Vieta E, Colom F, Torrent C, Reinares M, Goikolea JM et al. Do Cognitive Complaints in Euthymic Bipolar Patients Reflect Objective Cognitive Impairment? Psychother Psychosom 2005; 74(5): 295-302. 
21. APA. Diagnostic and Statistical Manual of Mental Disorders, Fourth Edition: Washington, DC, 1994.

22. McGuffin P, Farmer A, Harvey I. A polydiagnostic application of operational criteria in studies of psychotic illness. Development and reliability of the OPCRIT system. Arch Gen Psychiatry 1991; 48(8): 764-770.

23. Andreasen NC, Flaum M, Arndt S. The Comprehensive Assessment of Symptoms and History (CASH). An instrument for assessing diagnosis and psychopathology. Arch Gen Psychiatry 1992; 49(8): 615-623.

24. Maxwell ME. Manual for the family interview for genetic studies (FIGS). National Institute of Mental Health: Bethesda, Maryland, 1992.

25. Hamilton M. A rating scale for depression. J Neurol Neurosurg Psychiatry 1960; 23: 56-62.

26. Young RC, Biggs JT, Ziegler VE, Meyer DA. A rating scale for mania: reliability, validity and sensitivity. Br J Psychiatry 1978; 133: 429-435.

27. Lukoff D, Nuechterlein, K.H., Ventura, J. Manual for the Expanded BPRS. Schizophr Bull 1986; 12: 594-602.

28. Leverich GS, Nolen WA, Rush AJ, McElroy SL, Keck PE, Denicoff KD et al. The Stanley Foundation Bipolar Treatment Outcome Network. I. Longitudinal methodology. J Affect Disord 2001; 67(1-3): 33-44.

29. Broadbent DE, Cooper, P.F., FitzGerald, P., Parkes, K.R. The Cognitive Failure Questionnaire (CFQ) and its correlates. British Journal of Clinical Psychology 1982; 21: 1-16.

30. Luteijn F, van der Ploeg, F.A.E. Handleiding Groninger Intelligentietest (GIT). Lisse, The Netherlands; 1983.

31. Wechsler D. Wechsler Adult Intelligence Scale-Revised. Psychological Corporation: New York, 1981.

32. Rey A. L'examen psychologique dans les cas d'encephalopathie traumatique. Presses Universitaires de France: Paris, 1964.

33. Nestor PG, Faux SF, McCarley RW, Shenton ME, Sands SF. Measurement of visual sustained attention in schizophrenia using signal detection analysis and a newly developed computerized CPT task. Schizophr Res 1990; 3(5-6): 329-332.

34. Smid HG, de Witte MR, Homminga I, van den Bosch RJ. Sustained and transient attention in the continuous performance task. J Clin Exp Neuropsychol 2006; 28(6): 859-883.

35. Eriksen CW, Schultz DW. Information processing in visual search: a continuous flow conception and experimental results. Percept Psychophys 1979; 25(4): 249-263.

36. Reitan RM, Wolfson, D. The Halstead-Reitan Neuropsychological Test Battery: Theory and clinical interpretation.: Tucson: Neuropsychology, 1985.

37. Wechsler D. WAIS-III: Wechsler Adult Intelligence Scale. San Antonio: Psychological Corporation; 1997.

38. StataCorp. STATA Statistical Software. Release 8.0 edn. College Station: Texas, 2002.

39. Simes RJ. An improved Bonferroni procedure for multiple tests of significance. Biometrika 1986; 73 : 751-754.

40. Rubin DB. Inference and missing data. Biometrika 1976; 63(3): 581-592.

41. Schafer JL, Graham JW. Missing data: our view of the state of the art. Psychol Methods 2002; 7(2): 147-177.

42. Royston P. Multiple imputation of missing values: update of ice. Stata Journal 2005; 5: 527-536.

43. Squire LR, Zola SM. Structure and function of declarative and nondeclarative memory systems. Proc Natl Acad Sci U S A 1996; 93(24): 13515-13522.

44. van Gorp WG, Altshuler L, Theberge DC, Mintz J. Declarative and procedural memory in bipolar disorder. Biol Psychiatry 1999; 46(4): 525-531.

45. Altshuler LL, Ventura J, van Gorp WG, Green MF, Theberge DC, Mintz J. Neurocognitive function in clinically stable men with bipolar I disorder or schizophrenia and normal control subjects. Biol Psychiatry 2004; 56(8): 560-569.

46. Abel T, Zukin RS. Epigenetic targets of HDAC inhibition in neurodegenerative and psychiatric disorders. Curr Opin Pharmacol 2008; 8(1): 57-64.

47. Engelsmann F, Katz J, Ghadirian AM, Schachter D. Lithium and memory: a long-term follow-up study. J Clin Psychopharmacol 1988; 8(3): 207-212. 
48. Rast P, Zimprich D, Van Boxtel M, Jolles J. Factor structure and measurement invariance of the cognitive failures questionnaire across the adult life span. Assessment 2009; 16(2): 145-158.

49. Burdick KE, Goldberg JF, Harrow M, Faull RN, Malhotra AK. Neurocognition as a stable endophenotype in bipolar disorder and schizophrenia. J Nerv Ment Dis 2006; 194(4): 255-260.

50. Kravariti E, Schulze K, Kane F, Kalidindi S, Bramon E, Walshe M et al. Stroop-test interference in bipolar disorder. Br J Psychiatry 2009; 194(3): 285-286.

51. Harmer CJ, Clark L, Grayson L, Goodwin GM. Sustained attention deficit in bipolar disorder is not a working memory impairment in disguise. Neuropsychologia 2002; 40(9): 1586-1590.

52. Clark L, Iversen SD, Goodwin GM. Sustained attention deficit in bipolar disorder. Br J Psychiatry 2002; 180: 313-319.

53. Ancin I, Santos JL, Teijeira C, Sanchez-Morla EM, Bescos MJ, Argudo I et al. Sustained attention as a potential endophenotype for bipolar disorder. Acta Psychiatr Scand 2010.

54. Swann AC, Lijffijt M, Lane SD, Steinberg JL, Moeller FG. Severity of bipolar disorder is associated with impairment of response inhibition. J Affect Disord 2009; 116(1-2): 30-36.

55. Schouws SN, Comijs HC, Stek ML, Dekker J, Oostervink F, Naarding P et al. Cognitive impairment in early and late bipolar disorder. Am J Geriatr Psychiatry 2009; 17(6): 508-515.

56. Martinez-Aran A, Vieta E, Colom F, Torrent C, Sanchez-Moreno J, Reinares M et al. Cognitive impairment in euthymic bipolar patients: implications for clinical and functional outcome. Bipolar Disord 2004; 6(3): 224-232.

57. Thompson JM, Gallagher P, Hughes JH, Watson S, Gray JM, Ferrier IN et al. Neurocognitive impairment in euthymic patients with bipolar affective disorder. Br J Psychiatry 2005; 186: 32-40.

58. van Gorp WG, Altshuler L, Theberge DC, Wilkins J, Dixon W. Cognitive impairment in euthymic bipolar patients with and without prior alcohol dependence. A preliminary study. Arch Gen Psychiatry 1998; 55(1): 41-46.

59. Strakowski SM, Fleck DE, DelBello MP, Adler CM, Shear PK, McElroy SL et al. Characterizing impulsivity in mania. Bipolar Disord 2009; 11(1): 41-51.

60. Roiser JP, Cannon DM, Gandhi SK, Taylor Tavares J, Erickson K, Wood S et al. Hot and cold cognition in unmedicated depressed subjects with bipolar disorder. Bipolar Disord 2009; 11(2): 178-189.

61. Savitz J, van der Merwe L, Stein DJ, Solms M, Ramesar R. Neuropsychological status of bipolar I disorder: impact of psychosis. Br J Psychiatry 2009; 194(3): 243-251.

62. Martinez-Aran A, Torrent C, Tabares-Seisdedos R, Salamero M, Daban C, Balanza-Martinez V et al. Neurocognitive impairment in bipolar patients with and without history of psychosis. J Clin Psychiatry 2008; 69(2): 233-239.

63. Selva G, Salazar J, Balanza-Martinez V, Martinez-Aran A, Rubio C, Daban C et al. Bipolar I patients with and without a history of psychotic symptoms: do they differ in their cognitive functioning? $J$ Psychiatr Res 2007; 41(3-4): 265-272.

64. Goldberg JF, Chengappa KN. Identifying and treating cognitive impairment in bipolar disorder. Bipolar Disord 2009; 11 Suppl 2: 123-137.

65. Holmes MK, Erickson K, Luckenbaugh DA, Drevets WC, Bain EE, Cannon DM et al. A comparison of cognitive functioning in medicated and unmedicated subjects with bipolar depression. Bipolar Disord 2008; 10(7): 806-815.

66. Clark L, Kempton MJ, Scarna A, Grasby PM, Goodwin GM. Sustained attention-deficit confirmed in euthymic bipolar disorder but not in first-degree relatives of bipolar patients or euthymic unipolar depression. Biol Psychiatry 2005; 57(2): 183-187.

67. Goswami U, Sharma A, Varma A, Gulrajani C, Ferrier IN, Young AH et al. The neurocognitive performance of drug-free and medicated euthymic bipolar patients do not differ. Acta Psychiatr Scand 2009; 120(6): 456-463.

68. Strakowski SM, Adler CM, Holland SK, Mills N, DelBello MP. A preliminary FMRI study of sustained attention in euthymic, unmedicated bipolar disorder. Neuropsychopharmacology 2004; 29(9): 1734-1740.

69. Fountoulakis KN, Vieta E, Bouras C, Notaridis G, Giannakopoulos P, Kaprinis G et al. A systematic review of existing data on long-term lithium therapy: neuroprotective or neurotoxic? Int J Neuropsychopharmacol 2008; 11(2): 269-287. 
70. Pachet AK, Wisniewski AM. The effects of lithium on cognition: an updated review. Psychopharmacology (Berl) 2003; 170(3): 225-234.

71. Jamrozinski K, Gruber O, Kemmer C, Falkai P, Scherk H. Neurocognitive functions in euthymic bipolar patients. Acta Psychiatr Scand 2009; 119(5): 365-374.

72. Machado-Vieira R, Manji HK, Zarate CA, Jr. The role of lithium in the treatment of bipolar disorder: convergent evidence for neurotrophic effects as a unifying hypothesis. Bipolar Disord 2009; 11 Suppl 2: 92-109.

73. Savitz J, Nugent AC, Bogers W, Liu A, Sills R, Luckenbaugh DA et al. Amygdala volume in depressed patients with bipolar disorder assessed using high resolution 3T MRI: the impact of medication. Neuroimage 2010; 49(4): 2966-2976.

74. Goldberg JF, Burdick KE. Cognitive side effects of anticonvulsants. J Clin Psychiatry 2001; 62 Suppl 14: $27-33$.

75. Senturk V, Goker, C., Bigic, A., Olmez, S., Tugcu, H., Oncu, B., Atbasoglu, E.C. Impaired verbal memory and otherwise spared cognition in remitted bipolar patients on monotherapy with lithium or valproate. Bipolar Disord 2007; 9 (Suppl 1): 136-144.

76. Daban C, Martinez-Aran A, Torrent C, Sanchez-Moreno J, Goikolea JM, Benabarre A et al. Cognitive functioning in bipolar patients receiving lamotrigine: preliminary results. J Clin Psychopharmacol 2006; 26(2): 178-181.

77. Haldane M, Jogia J, Cobb A, Kozuch E, Kumari V, Frangou S. Changes in brain activation during working memory and facial recognition tasks in patients with bipolar disorder with Lamotrigine monotherapy. Eur Neuropsychopharmacol 2008; 18(1): 48-54.

78. Donaldson S, Goldstein LH, Landau S, Raymont V, Frangou S. The Maudsley Bipolar Disorder Project: the effect of medication, family history, and duration of illness on IQ and memory in bipolar I disorder. J Clin Psychiatry 2003; 64(1): 86-93.

79. Keefe RS, Bilder RM, Davis SM, Harvey PD, Palmer BW, Gold JM et al. Neurocognitive effects of antipsychotic medications in patients with chronic schizophrenia in the CATIE Trial. Arch Gen Psychiatry 2007; 64(6): 633-647.

80. Houthoofd SA, Morrens M, Sabbe BG. Cognitive and psychomotor effects of risperidone in schizophrenia and schizoaffective disorder. Clin Ther 2008; 30(9): 1565-1589.

81. Goldberg TE, Goldman RS, Burdick KE, Malhotra AK, Lencz T, Patel RC et al. Cognitive improvement after treatment with second-generation antipsychotic medications in first-episode schizophrenia: is it a practice effect? Arch Gen Psychiatry 2007; 64(10): 1115-1122.

82. Bilik E, Akdede, B.B., Hidiroglu, C., Oguz, M., Tunca, Z., Oral, T., Hariri, A., Erten, E., Ozerdem, A. Neurocognitive functions in euthymic bipolar patients on mono versus polypharmacy in comparison to healthy controls. Bipolar Disord 2009; 11 (Suppl.1): 21.

83. Martino DJ, Marengo E, Igoa A, Scapola M, Ais ED, Perinot L et al. Neurocognitive and symptomatic predictors of functional outcome in bipolar disorders: A prospective 1 year follow-up study. $J$ Affect Disord 2009; 116(1-2): 37-42.

84. Wingo AP, Harvey PD, Baldessarini RJ. Neurocognitive impairment in bipolar disorder patients: functional implications. Bipolar Disord 2009; 11(2): 113-125.

85. Marangell LB, Dennehy EB, Miyahara S, Wisniewski SR, Bauer MS, Rapaport MH et al. The functional impact of subsyndromal depressive symptoms in bipolar disorder: data from STEP-BD. J Affect Disord 2009; 114(1-3): 58-67.

86. Baldini M, Colasanti A, Orsatti A, Airaghi L, Mauri MC, Cappellini MD. Neuropsychological functions and metabolic aspects in subclinical hypothyroidism: the effects of l-thyroxine. Prog Neuropsychopharmacol Biol Psychiatry 2009; 33(5): 854-859.

87. Mur M, Portella MJ, Martinez-Aran A, Pifarre J, Vieta E. Neuropsychological profile in bipolar disorder: a preliminary study of monotherapy lithium-treated euthymic bipolar patients evaluated at a 2-year interval. Acta Psychiatr Scand 2008; 118(5): 373-381.

88. Deckersbach T, Ametrano, R.M., Carlson, L.E., Lund, H.G., Sachs, G.S., Nierenberg, A.A. Cognitive rehabilitation for bipolar disorder: preliminary results and predictors of treatment response. Bipolar Disord 2009; 11 (Suppl. 1): 32-33. 
89. Savitz J, Solms M, Ramesar R. Neuropsychological dysfunction in bipolar affective disorder: a critical opinion. Bipolar Disord 2005; 7(3): 216-235.

90. Weickert TW, Goldberg TE, Mishara A, Apud JA, Kolachana BS, Egan MF et al. Catechol-Omethyltransferase val108/158met genotype predicts working memory response to antipsychotic medications. Biol Psychiatry 2004; 56(9): 677-682.

91. Rybakowski JK, Suwalska A, Skibinska M, Szczepankiewicz A, Leszczynska-Rodziewicz A, Permoda A et al. Prophylactic lithium response and polymorphism of the brain-derived neurotrophic factor gene. Pharmacopsychiatry 2005; 38(4): 166-170.

92. Tabares-Seisdedos R, Escamez T, Martinez-Gimenez JA, Balanza V, Salazar J, Selva G et al. Variations in genes regulating neuronal migration predict reduced prefrontal cognition in schizophrenia and bipolar subjects from mediterranean Spain: a preliminary study. Neuroscience 2006; 139(4): 1289-1300.

93. Antila M, Tuulio-Henriksson A, Kieseppa T, Soronen P, Palo OM, Paunio T et al. Heritability of cognitive functions in families with bipolar disorder. Am J Med Genet B Neuropsychiatr Genet 2007; 144B(6): 802-808.

94. Soronen P, Silander K, Antila M, Palo OM, Tuulio-Henriksson A, Kieseppa T et al. Association of a nonsynonymous variant of DAOA with visuospatial ability in a bipolar family sample. Biol Psychiatry 2008; 64(5): 438-442.

95. Pietilainen OP, Paunio T, Loukola A, Tuulio-Henriksson A, Kieseppa T, Thompson P et al. Association of AKT1 with verbal learning, verbal memory, and regional cortical gray matter density in twins. Am J Med Genet B Neuropsychiatr Genet 2009; 150B(5): 683-692.

96. Dewachter I, Ris L, Jaworski T, Seymour CM, Kremer A, Borghgraef P et al. GSK3beta, a centrestaged kinase in neuropsychiatric disorders, modulates long term memory by inhibitory phosphorylation at serine-9. Neurobiol Dis 2009; 35(2): 193-200.

97. Zhou R, Gray NA, Yuan P, Li X, Chen J, Chen G et al. The anti-apoptotic, glucocorticoid receptor cochaperone protein BAG-1 is a long-term target for the actions of mood stabilizers. $J$ Neurosci 2005; 25(18): 4493-4502.

98. Burdick KE, Funke B, Goldberg JF, Bates JA, Jaeger J, Kucherlapati R et al. COMT genotype increases risk for bipolar I disorder and influences neurocognitive performance. Bipolar Disord 2007; 9(4): 370-376.

99. Rybakowski JK, Borkowska A, Skibinska M, Hauser J. Illness-specific association of val66met BDNF polymorphism with performance on Wisconsin Card Sorting Test in bipolar mood disorder. Mol Psychiatry 2006; 11(2): 122-124.

100. Frey BN, Andreazza AC, Cereser KM, Martins MR, Valvassori SS, Reus GZ et al. Effects of mood stabilizers on hippocampus BDNF levels in an animal model of mania. Life Sci 2006; 79(3): 281-286. 


\section{Chapter 6}

\section{Evidence for impact of CACNA1C risk allele rs1006737 on two-year cognitive functioning in bipolar disorder}

Baer Arts ${ }^{1} \mathrm{MD}$, Claudia J.P. Simons ${ }^{1,2} \mathrm{PhD}$, Jim van $\mathrm{Os}^{1,3} \mathrm{PhD}$

${ }^{1}$ Department of Psychiatry and Psychology, School for Mental Health and Neuroscience, European Graduate School of Neuroscience (EURON), South Limburg Mental Health Research and Teaching Network (SEARCH), Maastricht University Medical Centre, P.O. Box 5800, 6202 AZ Maastricht, The Netherlands

${ }^{2}$ GGzE, Institute for Mental Health Care Eindhoven en de Kempen, P.O. Box 909, 5600 AX Eindhoven, The Netherlands

${ }^{3}$ King's College London, King's Health Partners, Department of Psychosis Studies, Institute of Psychiatry, London, United Kingdom

Submitted for publication 


\begin{abstract}
Objective: The CACNA1C (alpha 1C subunit of the L-type voltage-gated calcium channel) risk allele (rs1006737) is highly consistently associated with risk for bipolar disorder. Cognitive alterations in bipolar disorder vary over time, mostly independent of clinical factors, possibly reflecting genetic influence. The aim of the present study was to investigate whether the CACNA1C risk allele is associated with longitudinal assessment of cognitive functioning in bipolar patients.
\end{abstract}

Methods: The association between the risk allele and a composite measure of neurocognitive functioning was examined in 51 bipolar patients who were assessed 12 times at two-monthly intervals over a period of two years (392 observations). In addition, neuropsychological assessments pertaining to 34 first-degree relatives, and 50 healthy controls, tested twice at two-monthly intervals (62 and 91 observations respectively) were also examined.

Results: There was a significant association in bipolar patients between the risk allele and the composite cognitive measure (effect size: $-0.26 ; \mathrm{p}=0.003$ ). No large or significant associations were found in either relatives (effect size: $0.06 ; \mathrm{p}=0.647$ ) or controls (effect size: $-0.03 ; \mathrm{p}=0.82$ ).

Conclusions: Cognitive functioning, assessed repeatedly over an extended period of time, is associated with the CACNA1C risk allele in bipolar patients, suggesting impact of CACNA1 on course of cognition in patients, contingent on other, diseasedependent factors. Longitudinal rather than cross-sectional measures of cognition may be sensitive to genetic effects. 


\section{Introduction}

A recent meta-analysis of neuropsychological functioning in euthymic bipolar patients suggests that generalized, rather than specific, cognitive impairment exists in patients. ${ }^{1}$ Cognitive impairments may be contingent on expression of disease, as only very minor alterations are detectable in first-degree relatives of patients with bipolar disorder. ${ }^{2-4}$ Several meta-analyses reveal a broad pattern of impairment in patients, emphasizing executive functioning and verbal memory, reporting medium effects sizes with extensive heterogeneity, not fully explained by demographic, illness and medication variables. ${ }^{2,35}$ A recent 2-year naturalistic study on cognitive functioning in bipolar patients showed significant variation of cognitive functioning over time, largely independent of clinical factors, such as demographics, disease characteristics, psychopathology and medication. ${ }^{6}$ Cognitive functioning in bipolar patients thus likely reflects the dynamic interplay of multiple factors, including background genetic vulnerability, the expression of which may be contingent on disease-specific factors, which would explain the lack of cognitive alterations in relatives. Extensive variation of cognitive functioning in patients over time also suggests that a single cross-sectional measure of cognition will not be sensitive in detecting underlying genetic and non-genetic influences.

The CACNA1C (alpha 1C subunit of the L-type voltage-gated calcium channel) risk allele (rs1006737) is associated with the risk of bipolar disorder across samples, ${ }^{7-9}$ with highly consistent replications in recent GWAS studies. ${ }^{10,11}$ The risk allele may be associated with structural brain morphology in healthy controls ${ }^{12,13}$ and bipolar patients. ${ }^{14}$ Furthermore, functional changes in brain activity have been described in healthy controls ${ }^{15-17}$ and in patients with bipolar disorder. ${ }^{18}$ Finally, there is some preliminary evidence for a role of CACNA1C in cognitive functioning in healthy subjects. ${ }^{19,20}$ A recent publication by Zhang and colleagues (2011) described effects of CACNA1C on spatial working memory in both healthy controls and patients with schizophrenia and bipolar disorder. ${ }^{21}$ The authors reported an association between the risk allele and impaired working memory in Han Chinese healthy controls and patients with schizophrenia; in manic bipolar patients, however, associations were either in the opposite direction or non-significant one. ${ }^{21}$

The aim of the present study, therefore, was to examine the association of the CACNA1C risk allele (rs1006737) with general cognitive functioning in a white European sample of patients with bipolar disorder and in two groups at high and average genetic risk for bipolar disorder: first-degree relatives and healthy controls. 


\section{Materials and Methods}

\section{Subjects}

Individuals were participants in the BIPOLCOG (BIPOLar and COGnition) study, ${ }^{4}$ a study on cognitive functioning in bipolar disorder (BD) in which three groups were investigated: (i) patients with bipolar disorder, (ii) healthy first-degree relatives of patients with bipolar disorder, and (iii) healthy control participants. All subjects were between the ages of 18 and 60 years, fluent in Dutch, had an IQ > 70 and were without a history of neurological disorders such as epilepsy and concussion with loss of consciousness.

A representative cohort of successively attending patients with a diagnosis of bipolar spectrum disorder according to DSM-IV ${ }^{22}$ were recruited through the inpatient and out-patient mental health facilities in the geographically defined catchment area of South Limburg. In addition, patients were recruited through the local association of bipolar patients and their families, in order to also include patients not currently in contact with services. The computer program OPCRIT was used to confirm DSM-IV diagnosis on the basis of current and lifetime recorded symptomatology listed in the Operational Criteria Checklist for Psychotic Illness, scored by the clinical researcher on the basis of all interview and historical case note data (OC$\mathrm{CPI})^{23}$

First-degree relatives, free from a lifetime history of BD or psychosis, were sampled through participating patients and had at least one first-degree relative with a diagnosis of BD. Control subjects were recruited from the general population using a random mailing sampling procedure. First-degree relatives and controls were clinically and diagnostically interviewed with The Comprehensive Assessment of Symptoms and History (CASH) ${ }^{24}$ and OPCRIT criteria to exclude those with a past or current diagnosis of $\mathrm{BD}$ or psychotic disorder. Healthy controls were additionally interviewed with the Family Interview for Genetic Studies (FIGS) ${ }^{25}$ in order to confirm the absence of a family history of psychotic or bipolar disorder.

The initial sample consisted of 81 patients, 39 relatives and 61 healthy control subjects. Three patients were excluded because data on diagnosis were missing. Neuropsychological testing data were missing for two patients. The last filter concerned incomplete or missing genetic data, leaving a final risk set for analysis of 51 patients, 34 first-degree relatives and 50 healthy controls.

\section{Procedure}

As cognitive alterations in bipolar disorder largely develop after onset of illness, ${ }^{26}$ longitudinal assessment is necessary to adequately capture the phenotype. Thus, patients were examined at 2-monthly intervals over a period of 2 years, yielding a maximum of 12 assessments. At all time points, neuropsychological testing and psychiatric interviewing took place and questionnaires were completed (regarding 
social functioning, medication, use of drugs etc.). Genetic material was collected at the first visit. During the baseline interview, basic demographic information was collected and as was information on illness characteristics. Written informed consent, conforming to the local ethics committee guidelines, was obtained from all subjects. Neuropsychological tests and psychiatric interviews were conducted by trained psychologists, each interview occasion taking approximately 2 hours to complete.

First-degree relatives and healthy controls, in whom cognition is more stable than in patients, were tested twice at two monthly intervals. Data on relatives and controls were used to test the hypothesis that any effect of the CACNA1C risk allele on the composite cognitive measure would be contingent on disease expression.

\section{Neurocognitive assessment}

Neurocognitive tests were administered by computer, using E-prime for Windows on a 15-inch monitor Toshiba Tecra laptop. The test battery included tasks measuring various neurocognitive domains, guided by previous meta-analytic evidence of impaired performance in these domains in bipolar patients. ${ }^{2,3}$

Overall intellectual functioning was estimated at baseline using three Groningen Intelligence Test (GIT) subtests (Mental Rotation, Word Analogies and Mental Arithmetic), ${ }^{27}$ yielding results that are comparable to those of the Wechsler Adult Intelligence Scale III. ${ }^{28}$

Verbal learning and memory was assessed with the standardized Dutch version of the visually-presented Verbal Learning Test. ${ }^{29,30}$ Sustained attention was measured with a continuous performance test, the CPT-HQ version, a variant of the CPT$\mathrm{AX}^{31,32,33}$

The Flanker CPT (Cogtest plc, London) ${ }^{34}$ was used as a measure of selective visual control of attention. Finally, Digit Span Forward and Digit Span Backward of the Wechsler intelligence Scale III $^{35}$ were used as measures of attentional span and working memory, respectively. Details of these cognitive tests were published elsewhere. ${ }^{6}$

All 12 cognitive measures were standardised, higher scores reflecting better performance. In order to calculate a measure of global cognitive functioning, raw test scores were converted into standardized z-scores against the means and standard deviations of the healthy control group. For verbal learning and memory, the z-score was based on the mean value of the $z$-scores for immediate recall and retention rate. For sustained attention, the $\mathrm{z}$-score was based on the mean value of $\mathrm{z}$-scores for reaction time and number of correct detections. For selective attention, the $\mathrm{z}$-score was based on the mean value of the mean of the $\mathrm{z}$-scores for the sum of correct trials in both the congruent and incongruent condition, and the mean of the z-scores for the reaction times in both the congruent and incongruent condition. The final composite measure of neurocognition was based on the means of the five domain scores (verbal memory, sustained attention, selective attention, attentional span and working memory). 


\section{Genotyping}

Buccal swab samples were obtained followed by SNP analysis. For the current analysis, the CACNA1C rs1006737 was selected a priori because this is the only SNP that is truly consistently associated with the risk of bipolar disorder across GWASstudies, making it the only credible candidate. Although more SNPs had been determined $(n=184)$, these formed part of a standard set for the study of geneenvironment interactions ( $\mathrm{GxE}$ ), based on published findings up to April 2009 (for the rational underlying this selection process and an overview of selected SNPs see). ${ }^{36}$ The 184 SNPs had been chosen a priori (i.e were not selected from a larger set of genome-wide markers) and selectively determined by Sequenom (Hamburg, Germany) using the Sequenom MassARRAY iPLEX platform at the facilities of the manufacturer. In accordance with a priori quality control criteria of the GROUP study, SNPs with more than 10\% genotyping errors were excluded, as were SNPs in marked Hardy-Weinberg disequilibrium $(\mathrm{p}<0.001)$.

\section{Statistical analysis}

Regression analyses were carried out using the statistical software program STATA (version 11.2). ${ }^{37}$ In the bipolar patient group, the effect of the risk allele on the 10 separate cognitive tasks was analysed, as well as on the composite cognitive measure. The Bonferroni correction for multiple testing was applied, yielding a corrected pvalue for significance of $\mathrm{p}<0.0045(0.05 / 11)$.

Data were hierarchical with multiple observations (interview occasion or time; level 1) clustered within subjects (level 2). Data were analysed using the STATA XTREG multilevel random regression routine with time as a random factor. The analyses of the effects of the risk allele on cognitive functioning were a priori adjusted for the confounding effects of demographic characteristics (age, sex, education). Standardized beta-scores ( $(3)$ are reported.

Dummies were constructed for the different genotypes with value 0 for GG, 1 for AG, and 2 for AA. Genotype-effects under a -statistically most conservativerecessive genetic model were estimated by comparing the differences between GG vs AG and $G G$ vs $A A$.

\section{Results}

\section{Subjects}

Demographic data, neurocognitive test results and genotype frequency are presented in Table 1. First-degree relatives were younger $(\mathrm{p}=0.003)$ and of higher educational level $(\mathrm{p}=0.024)$ than the controls, but nevertheless performed slower on a sustained attention and information processing task compared to controls (respectively, effect 
size: $-0.27 ; \mathrm{p}=0.035$ and effect size: $-0.26 ; \mathrm{p}=0.048)$. Bipolar patients performed worse than the controls on verbal memory (immediate recall; effect size: $-0.27 ; p=0.007$ ), sustained attention (\% correct; effect size: -0.3 ; $\mathrm{p}=0.006$ ), information processing (effect size: $-0.36<$ beta $<-0.24 ; 0.023<\mathrm{p}<0.002$ ) and on the composite cognitive measure (effect size: $-0.36 ; \mathrm{p}<0.0001$ ) (Table 1 ).

Table 1. Demographics, neurocognitive test results and genotype frequency

\begin{tabular}{|c|c|c|c|c|c|c|c|c|}
\hline & \multicolumn{2}{|c|}{$\begin{array}{l}\text { Bipolar patients } \\
\qquad(\mathrm{n}=51)\end{array}$} & \multicolumn{2}{|c|}{ Relatives $(n=34)$} & \multicolumn{2}{|c|}{$\begin{array}{l}\text { Controls } \\
(\mathrm{n}=50)\end{array}$} & \multicolumn{2}{|c|}{$\begin{array}{l}\text { Between group } \\
\text { comparisons }\end{array}$} \\
\hline & Mean & SD & Mean & $\mathrm{SD}$ & Mean & SD & & $\overline{p \text {-value }}$ \\
\hline Gender M/F & $26 / 25$ & & $16 / 18$ & & $18 / 32$ & & $\mathrm{~B}>\mathrm{R}>\mathrm{C}$ & $\overline{\mathrm{ns}}$ \\
\hline Age & 45.4 & 7.9 & 40.7 & 12.1 & 45.8 & 8.4 & $\mathrm{R}<\mathrm{B}<\mathrm{C}$ & 0.003 \\
\hline Educational level & 5.4 & 2.2 & 6.1 & 2.1 & 5.7 & 1.7 & $\mathrm{R}>\mathrm{B}>\mathrm{C}$ & 0.024 \\
\hline GIT-IQ & 114.3 & 12 & 116.4 & 14.3 & 119.7 & 9.5 & $\mathrm{~B}<\mathrm{R}<\mathrm{C}$ & ns \\
\hline Verbal memory; immediate recall & 22.5 & 5.5 & 26.4 & 6.3 & 26.3 & 4.3 & $\mathrm{~B}<\mathrm{R}<\mathrm{C}$ & 0.007 \\
\hline Verbal memory; delayed recall & 7 & 3.1 & 9 & 3 & 8.7 & 2.2 & $\mathrm{~B}<\mathrm{C}<\mathrm{R}$ & ns \\
\hline Sustained attention; \% correct & 96 & 5 & 98 & 4 & 99 & 3 & $\mathrm{~B}<\mathrm{R}<\mathrm{C}$ & 0.006 \\
\hline Sustained attention; RT correct & 472.8 & 99 & 490.3 & 87.4 & 471 & 75 & $\mathrm{R}<\mathrm{B}<\mathrm{C}$ & 0.035 \\
\hline Selective attention; correct-congruent & 43.2 & 6.4 & 45.6 & 2.7 & 45.9 & 3.5 & $\mathrm{~B}<\mathrm{R}<\mathrm{C}$ & 0.009 \\
\hline Selective attention; correct-incongruent & 38.2 & 9.2 & 43.5 & 3.5 & 42.3 & 5.2 & $\mathrm{~B}<\mathrm{R}<\mathrm{C}$ & 0.023 \\
\hline Selective attention; RT-congruent & 671 & 85.5 & 649.3 & 53.6 & 643.9 & 60 & $\mathrm{~B}<\mathrm{R}<\mathrm{C}$ & 0.002 \\
\hline Selective attention; RT-incongruent & 722.8 & 82.7 & 716 & 66.7 & 707.4 & 69.1 & $\mathrm{R}<\mathrm{B}<\mathrm{C}$ & 0.048 \\
\hline Attentional span & 8.5 & 1.9 & 8.9 & 2.1 & 9.1 & 2 & $\mathrm{~B}<\mathrm{R}<\mathrm{C}$ & ns \\
\hline Working memory & 5.7 & 1.9 & 7 & 2.5 & 6.6 & 1.8 & $\mathrm{~B}<\mathrm{C}<\mathrm{R}$ & ns \\
\hline Composite cognitive measure & -0.6 & 0.73 & 0.006 & 0.66 & -0.09 & 0.54 & $\mathrm{~B}<\mathrm{R}<\mathrm{C}$ & $<0.0001$ \\
\hline \multicolumn{9}{|l|}{ Genotype frequency; \% } \\
\hline AA & 12 & & 3 & & 4 & & & \\
\hline AG & 41 & & 44 & & 48 & & & \\
\hline GG & 47 & & 53 & & 48 & & & \\
\hline
\end{tabular}

\section{Genotype}

Analysis of SNP rs1006737 showed the following distribution in bipolar patients: 6 subjects were homozygous for the risk allele (A/A), 21 patients were heterozygous $(A / G)$ and 24 subjects belonged to the non-risk group $(G / G)$. Carriers of the $A G$ genotype were older and had lower educational level than carriers of the AA genotype (respectively, $\mathrm{p}=0.015$ and $\mathrm{p}=0.016$ ), with no significant differences in sex and IQ.

In the group of first-degree relatives, only 1 subject was homozygous for the risk allele; 15 relatives were heterozygous and 18 belonged to the non-risk group. There were no large or significant differences between the various carriers regarding age, sex, education or intelligence.

Finally, 2 healthy controls were homozygous for the risk allele, 24 were heterozygous and 24 carried the non-risk allele. The latter group more often were fe- 
male compared to the A/A carriers $(\mathrm{p}=0.025)$. Genotypes in all groups were in the Hardy-Weinberg equilibrium ( $\mathrm{P}>0.1$ for all).

\section{Cognitive data in bipolar sample}

The association between the CACNA1C risk allele rs1006737 and two-year cognitive functioning in the bipolar patients is presented in Table 2. The AG genotype was not significantly associated with any of the cognitive measures. The AA genotype, however, was associated with poorer cognitive performance on several tasks, particularly in the area of speed of processing $(-0.27<$ beta $<-0.18 ; 0.048<\mathrm{p}<0.011)$. However, none of the individual cognitive tests survived Bonferroni correction. The composite cognitive measure, however, survived correction with a moderate effect size of -0.26 $(\mathrm{p}=0.003)$.

Table 2. Association between the CACNA1C risk allele rs1006737 and cognitive functioning in bipolar patients (reference genotype: GG)

\begin{tabular}{lccccc}
\hline Cognitive variable & & \multicolumn{3}{c}{ Genotype } \\
& & \multicolumn{2}{c}{ AG } & \multicolumn{2}{c}{ AA } \\
\cline { 2 - 6 } & N obs. & Beta & p-value & Beta & p-value \\
\hline Verbal memory; immediate recall & 440 & -0.08 & 0.437 & -0.18 & 0.048 \\
Verbal memory; delayed recall & 439 & -0.07 & 0.517 & -0.12 & 0.231 \\
Sustained attention; \% correct & 440 & -0.008 & 0.931 & -0.09 & 0.275 \\
Sustained attention; RT correct & 440 & 0.004 & 0.978 & -0.27 & 0.021 \\
Selective attention; correct-congruent & 405 & -0.05 & 0.639 & -0.08 & 0.468 \\
Selective attention: correct-incongruent & 405 & -0.11 & 0.296 & -0.12 & 0.243 \\
Selective attention; RT-congruent & 405 & -0.07 & 0.513 & -0.24 & 0.016 \\
Selective attention; RT-incongruent & 405 & -0.03 & 0.774 & -0.24 & 0.011 \\
Attentional span & 436 & 0.13 & 0.245 & -0.14 & 0.144 \\
Working memory & 438 & 0.12 & 0.29 & -0.12 & 0.233 \\
Composite cognitive measure & 392 & -0.02 & 0.861 & -0.26 & 0.003 \\
\hline
\end{tabular}

Beta: standardized regression coefficient

The association between CACNA1C genotype and the global cognitive measure in patients with bipolar disorder is illustrated in the boxplot (Figure 1). Post-hoc analysis, removing the outliers identified in the boxplot, did not affect the significant difference in cognitive functioning between the GG and AA genotypes in bipolar patients (number of observations: 356 ; effect size: -0.27 ; $=0.005$ ). 


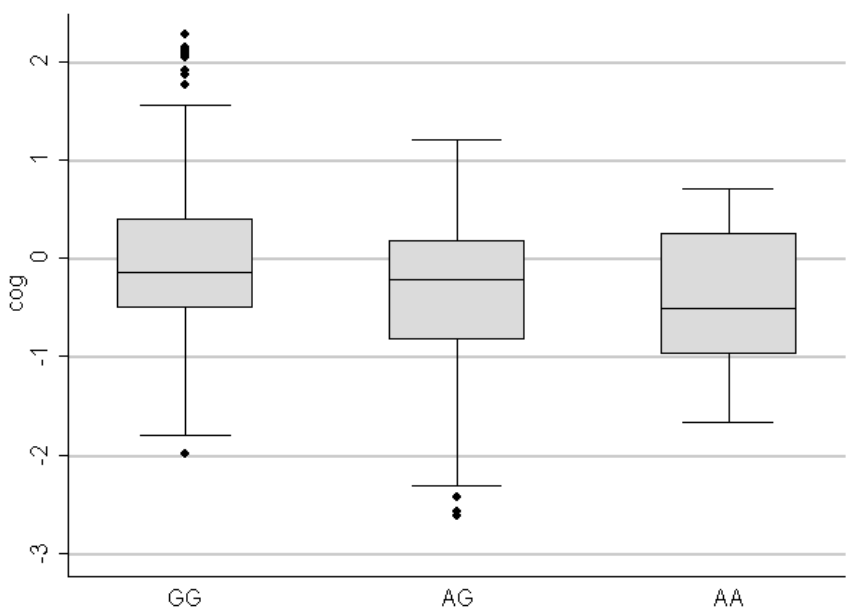

Figure 1. Box-plot of association between CACNA1C genotype (x-axis) and global cognitive measure, cog (Y-axis)

Horizontal line in box=median; upper hinge $=75$ th percentile; lower hinge $=25$ th percentile; horizontal lines above and under box= upper adjacent value (1.67 SD) resp. lower adjacent value (1.67 SD); black dots=outlier values

\section{Replication in first-degree relatives and healthy controls}

The finding of a negative association between the AA genotype and the composite cognitive measure could be replicated in neither relatives $(\mathrm{N}$ obs $=62$; beta:0.06; $\mathrm{p}=0.647$ ), nor controls ( $\mathrm{N}$ obs=91; beta: $-0.03 ; \mathrm{p}=0.82$ ).

\section{Discussion}

\section{Summary of findings}

Patients with bipolar disorder displayed a negative effect of the CACNA1C risk allele rs1006737 on a composite cognitive measure, only apparent in the group homozygous for this risk allele, thus fitting a recessive model. This finding could not be replicated in a group of first-degree relatives or in healthy controls. Thus, cognitive impairment associated with the CACNA1C risk allele may be contingent on expression of disease and may become only visible over time, given the large extent of variability of cognitive functioning in bipolar patients over time. ${ }^{6}$ In this respect, crosssectional measures may not be sensitive enough to detect genetic effects on cognitive functioning in bipolar disorder.

Post-hoc analyses displayed only one significant finding in healthy controls on the Flanker test sum of correct responses in the incongruent condition (beta:-0.26; $\mathrm{p}=0.044$ ). Given the small number of relatives and controls homozygous for the risk 
allele and therefore the small number of observations, lack of power to find statistical differences is likely to have played a major role in making these comparisons noninformative. Increasing power by combining the risk allele carriers (A/A and A/G) in the relatives and control groups, testing an additive, co-dominant genetic model, however, revealed no large or significant effects of the risk allele on our composite cognitive measure (respectively; beta:-0.12; $\mathrm{p}=0.391$, and beta: $-0.07 ; \mathrm{p}=0.615$ ).

\section{CACNA1C and cognition in bipolar disorder and other psychiatric disorders}

The finding of a negative association between the CACNA1C risk allele and a composite cognitive measure, only apparent in homozygous risk allele carriers, may be in line with the findings reported by Zhang et al. ${ }^{21}$ These authors combined, in a crosssectional study, the A/A and A/G carriers in the analyses, given very small numbers of A/A carriers. Their finding of associations, in bipolar patients, between the A/G genotype and cognitive functioning that were either non-significant or opposite to those observed in schizophrenia is concordant with our findings, presented in Table 2 , that fit a recessive model. Furthermore, it may be argued that a cross-sectional design, as opposed to our longitudinal repeated measure design, is not sufficiently sensitive to detect subtle genetic associations in bipolar patients, whereas in schizophrenia associations may be more readily detectable because of the stable nature of the cognitive alterations. ${ }^{38}$ Finally, the finding by Zhang and colleagues suggesting an association in healthy controls may be due to the large number of subjects in their study and the lack of power in our study, as discussed earlier. It should be noted, however, that the literature on the cognitive effects of the CACNA1C risk allele in healthy controls is equivocal in this respect. On the one hand, testing a recessive model, Thimm et al. (2011) described a negative effect of the AA genotype on attention in healthy controls, ${ }^{20}$ whereas Bigos et al. (2010) and Roussos et al. (2011) did not find any effect of this genotype on several cognitive measures. ${ }^{17,39}$ On the other hand, testing an additive model, Krug and colleagues (2010) reported decreased semantic fluency in the risk allele groups, ${ }^{19}$ whereas Erk et al. (2011) found no effects on memory or intelligence. ${ }^{16}$ Neuroimaging (f-)MRI changes in cognitive paradigms have also been described, the results of which depends, amongst others, on the genetic model used. For instance, when using an additive model, different changes in hippocampal and amygdala activity may be apparent during various cognitive tasks in healthy controls, ${ }^{15,16}$ relatives and bipolar patients, with possible diagnosis-specific prefrontal changes in the latter. ${ }^{18}$ Bigos et al (2010), however, found non-significant results testing an additive model, only the recessive genetic model showing a significant effect of genotype on hippocampal and prefrontal cortex activity in healthy controls. ${ }^{17}$ Furthermore, these authors described a significant effect of the risk genotype (AA) on CACNA1C expression, heterozygotes (AG) having intermediate expression and the common allele carriers (GG) having the lowest expression. ${ }^{17}$

The fact that only the composite cognitive measure survived Bonferroni correction in our group of bipolar patients may be in line with the finding in the literature 
that genetic effects on cognitive abilities are general, rather than specific, with highest heritability for general cognitive ability. ${ }^{40}$ The finding of a negative effect on cognition of the CACNA1C risk allele in bipolar patients only may further be related to an increased expression of this recessive allele in bipolar disorder, as well as to epistatic and epigenetic effects, disease characteristics, comorbidity and (co-)medication, and specific and/or more serious structural and/or functional brain changes in patients. Furthermore, one could speculate that relatives and healthy controls, showing none or inconsistent cognitive effects of the risk allele, make use of compensatory mechanisms. This would explain the fact that one report found an association between the risk allele and functional brain changes, representing biologically proximal measures with high penetrance, but not with changes in cognitive functioning, representing behavioural measures further removed from the genetic substrate. ${ }^{16}$

Finally, the recent finding of Lett et al. (2011) that the strongest associations between the CACNA1C and ZNF804A risk alleles was apparent in a psychotic subgroup of bipolar patients, may suggest the existence of a clinical manifestation of the shared genetic liability between bipolar disorder and schizophrenia, ${ }^{10}$ given the trans-disorder effects of these, and other, genes. ${ }^{41-43}$ The CACNA1C risk allele is not only associated with bipolar disorder and schizophrenia, ${ }^{42,44}$ but also with depression, ${ }^{43,45-47}$ and thus represents a pleiomorphic risk factor with possibly a key role for voltage-dependent calcium channels across disorders. ${ }^{41,48}$

\section{CACNA1C and calcium channels}

CACNA1C encodes the alpha-1C subunit of voltage-dependent L-type calcium channels, which play a critical role in calcium influx in response to synaptic activity, thus mediating synaptic plasticity and long-term potentiation in an N-methyl-Daspartate receptor-independent way, relevant for learning and hippocampal memory formation. ${ }^{49-51}$ Genetic variation in voltage-gated calcium channel genes has been associated with several other multigenic neuropsychiatric disorders, including autism, epilepsy, migraine and Timothy syndrome, the latter characterized by autism, cardiac arrhythmias and cognitive abnormalities. ${ }^{52,53}$ Bipolar disorder shares salient features with these CNS ion channel disorders, as evidenced by efficacy of antiepileptic drugs in the treatment of bipolar disorder and the downregulation of subunits of the calcium channel by lithium carbonate..$^{54,55}$

Furthermore, calcium channel blockers have been studied in bipolar disorder, yielding conflicting results and limited support for their efficacy, due to underpowered, heterogeneous trial designs. ${ }^{48,56}$ The dihydropyridine-based calcium channel blockers, such as nimodipine, and flunarizine, an agent used in the treatment of migraine and structurally related to antipsychotics, could be promising in the treatment of bipolar disorder according to some. ${ }^{57}$ 


\section{Strengths and limitations}

The results should be interpreted in the light of several limitations. First, power was low to test recessive models, given low frequency of the risk genotype. Although power was increased due to higher precision and greater phenotypic accuracy associated with multiple assessments, particularly comparisons involving relatives and controls suffered due to lack of power. Second, although attempts were made to include a representative sample of patients, including patients not currently in contact with services, the sample was not strictly epidemiologically defined and suffered from a degree of attrition. Therefore the sample may not be representative. However, it is highly unlikely that selection and attrition was differential with regard to cognition and rs1006737 genotype in such a way that a spurious association would have arisen.

\section{Conclusion}

In conclusion, the CACNA1C risk allele rs1006737 was negatively associated with global cognitive functioning in a sample of patients with bipolar disorder, impacting more specifically on attentional measures and verbal memory. This finding could not be replicated in underpowered comparisons involving first-degree relatives and healthy controls, except for an association with a single attentional measure in the latter. Of course, it remains unclear whether the observed effects are due to rs1006737 or another genetic variant in linkage disequilibrium with $\mathrm{rs} 1006737,{ }^{16}$ and the finding needs replication in other samples.

The results of our study agree with a recessive genetic model with pleiotrophic effects of CACNA1C on relevant brain structures and functions in bipolar disorder, such as brainstem associated disturbances of sleep, cardiovascular regulation and vigilance, ${ }^{13,20,48}$ reduced prefrontal efficiency, ${ }^{17,18}$ and altered modulation of hippocampal and amygdala activity during cognitive and emotional processing. ${ }^{15,17}$ Finally, an interesting hypothesis, proposed by Roussos and colleagues (2011), amongst others, is the possibility that the CACNA1C alleles also affect personality (neuroticism) and psychosocial functioning through their effects on hippocampal-amygdala threat processing, thus increasing vulnerability to stress, leading to hippocampal damage and/or associated amygdala overactivity through gene-environment and gene-gene interactions. ${ }^{16,39}$ 


\section{References}

1. Mann-Wrobel MC, Carreno JT, Dickinson D. Meta-analysis of neuropsychological functioning in euthymic bipolar disorder: an update and investigation of moderator variables. Bipolar Disord 2011; 13(4): 334-342.

2. Arts B, Jabben N, Krabbendam L, van Os J. Meta-analyses of cognitive functioning in euthymic bipolar patients and their first-degree relatives. Psychol Med 2008; 38(6): 771-785.

3. Bora E, Yucel M, Pantelis C. Cognitive endophenotypes of bipolar disorder: A meta-analysis of neuropsychological deficits in euthymic patients and their first-degree relatives. J Affect Disord 2009; 113: 1-20.

4. Jabben N, Arts B, Krabbendam L, van Os J. Investigating the association between neurocognition and psychosis in bipolar disorder: further evidence for the overlap with schizophrenia. Bipolar Disord 2009; 11(2): 166-177.

5. Kurtz MM, Gerraty RT. A meta-analytic investigation of neurocognitive deficits in bipolar illness: profile and effects of clinical state. Neuropsychology 2009; 23(5): 551-562.

6. Arts B, Jabben N, Krabbendam L, van Os J. A 2-year naturalistic study on cognitive functioning in bipolar disorder. Acta Psychiatr Scand 2011; 123(3): 190-205.

7. Genome-wide association study of 14,000 cases of seven common diseases and 3,000 shared controls. Nature 2007; 447(7145): 661-678.

8. Sklar P, Smoller JW, Fan J, Ferreira MA, Perlis RH, Chambert K et al. Whole-genome association study of bipolar disorder. Mol Psychiatry 2008; 13(6): 558-569.

9. Ferreira MA, O’Donovan MC, Meng YA, Jones IR, Ruderfer DM, Jones L et al. Collaborative genome-wide association analysis supports a role for ANK3 and CACNA1C in bipolar disorder. Nat Genet 2008; 40(9): 1056-1058.

10. Lett TA, Zai CC, Tiwari AK, Shaikh SA, Likhodi O, Kennedy JL et al. ANK3, CACNA1C and ZNF804A gene variants in bipolar disorders and psychosis subphenotype. World J Biol Psychiatry 2011; 12(5): 392-397.

11. Ripke S, Sanders AR, Kendler KS, Levinson DF, Sklar P, Holmans PA et al. Genome-wide association study identifies five new schizophrenia loci. Nat Genet 2011; 43(10): 969-976.

12. Kempton MJ, Ruberto G, Vassos E, Tatarelli R, Girardi P, Collier D et al. Effects of the CACNA1C risk allele for bipolar disorder on cerebral gray matter volume in healthy individuals. Am J Psychiatry 2009; 166(12): 1413-1414.

13. Franke B, Vasquez AA, Veltman JA, Brunner HG, Rijpkema M, Fernandez G. Genetic variation in CACNA1C, a gene associated with bipolar disorder, influences brainstem rather than gray matter volume in healthy individuals. Biol Psychiatry 2010; 68(6): 586-588.

14. Perrier E, Pompei F, Ruberto G, Vassos E, Collier D, Frangou S. Initial evidence for the role of CACNA1C on subcortical brain morphology in patients with bipolar disorder. Eur Psychiatry 2011; 26(3): 135-137.

15. Wessa M, Linke J, Witt SH, Nieratschker V, Esslinger C, Kirsch P et al. The CACNA1C risk variant for bipolar disorder influences limbic activity. Mol Psychiatry 2010; 15(12): 1126-1127.

16. Erk S, Meyer-Lindenberg A, Schnell K, Opitz von Boberfeld C, Esslinger C, Kirsch P et al. Brain function in carriers of a genome-wide supported bipolar disorder variant. Arch Gen Psychiatry 2010; 67(8): 803-811.

17. Bigos KL, Mattay VS, Callicott JH, Straub RE, Vakkalanka R, Kolachana B et al. Genetic variation in CACNA1C affects brain circuitries related to mental illness. Arch Gen Psychiatry 2010; 67(9): 939945.

18. Jogia J, Ruberto G, Lelli-Chiesa G, Vassos E, Maieru M, Tatarelli R et al. The impact of the CACNA1C gene polymorphism on frontolimbic function in bipolar disorder. Mol Psychiatry 2011; 16(11): 1070-1071.

19. Krug A, Nieratschker V, Markov V, Krach S, Jansen A, Zerres K et al. Effect of CACNA1C rs1006737 on neural correlates of verbal fluency in healthy individuals. Neuroimage 2010; 49(2): 1831-1836. 
20. Thimm M, Kircher T, Kellermann T, Markov V, Krach S, Jansen A et al. Effects of a CACNA1C genotype on attention networks in healthy individuals. Psychol Med 2011; 41(7): 1551-1561.

21. Zhang Q, Shen Q, Xu Z, Chen M, Cheng L, Zhai J et al. The Effects of CACNA1C Gene Polymorphism on Spatial Working Memory in Both Healthy Controls and Patients with Schizophrenia or Bipolar Disorder. Neuropsychopharmacology 2011.

22. APA. Diagnostic and Statistical Manual of Mental Disorders, Fourth Edition: Washington, DC, 1994.

23. McGuffin P, Farmer A, Harvey I. A polydiagnostic application of operational criteria in studies of psychotic illness. Development and reliability of the OPCRIT system. Arch Gen Psychiatry 1991; 48(8): 764-770.

24. Andreasen NC, Flaum M, Arndt S. The Comprehensive Assessment of Symptoms and History (CASH). An instrument for assessing diagnosis and psychopathology. Arch Gen Psychiatry 1992; 49(8): 615-623.

25. Maxwell ME. Manual for the family interview for genetic studies (FIGS): Bethesda, Maryland: National Institute of Mental Health, 1992.

26. Goodwin GM, Anderson I, Arango C, Bowden CL, Henry C, Mitchell PB et al. ECNP consensus meeting. Bipolar depression. Nice, March 2007. Eur Neuropsychopharmacol 2008; 18(7): 535-549.

27. Luteijn F, van der Ploeg, F.A.E. Handleiding Groninger Intelligentietest (GIT). Lisse, The Netherlands; 1983.

28. Wechsler D. Wechsler Adult Intelligence Scale-Revised. Psychological Corporation: New York, 1981.

29. Brand N, Jolles J. Learning and retrieval rate of words presented auditorily and visually. J Gen Psychol 1985; 112(2): 201-210.

30. Van der Elst W, van Boxtel MP, van Breukelen GJ, Jolles J. Rey's verbal learning test: normative data for 1855 healthy participants aged 24-81 years and the influence of age, sex, education, and mode of presentation. J Int Neuropsychol Soc 2005; 11(3): 290-302.

31. Nuechterlein KH, Dawson ME. Information processing and attentional functioning in the developmental course of schizophrenic disorders. Schizophr Bull 1984; 10(2): 160-203.

32. Nestor PG, Faux SF, McCarley RW, Shenton ME, Sands SF. Measurement of visual sustained attention in schizophrenia using signal detection analysis and a newly developed computerized CPT task. Schizophr Res 1990; 3(5-6): 329-332.

33. Smid HG, de Witte MR, Homminga I, van den Bosch RJ. Sustained and transient attention in the continuous performance task. J Clin Exp Neuropsychol 2006; 28(6): 859-883.

34. Eriksen CW, Schultz DW. Information processing in visual search: a continuous flow conception and experimental results. Percept Psychophys 1979; 25(4): 249-263.

35. Wechsler D. WAIS-III: Wechsler Adult Intelligence Scale. San Antonio: Psychological Corporation; 1997.

36. van Winkel R. Family-based analysis of genetic variation underlying psychosis-inducing effects of cannabis: sibling analysis and proband follow-up. Arch Gen Psychiatry 2011; 68(2): 148-157.

37. StataCorp. STATA Statistical Software. Release 8.0 edn. College Station: Texas, 2002.

38. Bozikas VP, Andreou C. Longitudinal studies of cognition in first episode psychosis: a systematic review of the literature. Aust N Z J Psychiatry 2011; 45(2): 93-108.

39. Roussos P, Giakoumaki SG, Georgakopoulos A, Robakis NK, Bitsios P. The CACNA1C and ANK3 risk alleles impact on affective personality traits and startle reactivity but not on cognition or gating in healthy males. Bipolar Disord 2011; 13(3): 250-259.

40. Plomin R, Craig I. Genetics, environment and cognitive abilities: review and work in progress towards a genome scan for quantitative trait locus associations using DNA pooling. Br J Psychiatry Suppl 2001; 40: s41-48.

41. Curtis D, Vine AE, McQuillin A, Bass NJ, Pereira A, Kandaswamy R et al. Case-case genome-wide association analysis shows markers differentially associated with schizophrenia and bipolar disorder and implicates calcium channel genes. Psychiatr Genet 2011; 21(1): 1-4.

42. Nyegaard M, Demontis D, Foldager L, Hedemand A, Flint TJ, Sorensen KM et al. CACNA1C (rs1006737) is associated with schizophrenia. Mol Psychiatry 2010; 15(2): 119-121. 
43. Green EK, Grozeva D, Jones I, Jones L, Kirov G, Caesar S et al. The bipolar disorder risk allele at CACNA1C also confers risk of recurrent major depression and of schizophrenia. Mol Psychiatry 2010; 15(10): 1016-1022.

44. Ripke S, Sanders AR, Kendler KS, Levinson DF, Sklar P, Holmans PA et al. Genome-wide association study identifies five new schizophrenia loci. Nat Genet 2011.

45. Sullivan PF, de Geus EJ, Willemsen G, James MR, Smit JH, Zandbelt T et al. Genome-wide association for major depressive disorder: a possible role for the presynaptic protein piccolo. Mol Psychiatry 2009; 14(4): 359-375.

46. Casamassima F, Huang J, Fava M, Sachs GS, Smoller JW, Cassano GB et al. Phenotypic effects of a bipolar liability gene among individuals with major depressive disorder. Am J Med Genet B Neuropsychiatr Genet 2010; 153B(1): 303-309.

47. Liu Y, Blackwood DH, Caesar S, de Geus EJ, Farmer A, Ferreira MA et al. Meta-analysis of genomewide association data of bipolar disorder and major depressive disorder. Mol Psychiatry 2011; 16(1): $2-4$.

48. Casamassima F, Hay AC, Benedetti A, Lattanzi L, Cassano GB, Perlis RH. L-type calcium channels and psychiatric disorders: A brief review. Am J Med Genet B Neuropsychiatr Genet 2010; 153B(8): 1373-1390.

49. Moosmang S, Haider N, Klugbauer N, Adelsberger H, Langwieser N, Muller J et al. Role of hippocampal Cav1.2 Ca2+ channels in NMDA receptor-independent synaptic plasticity and spatial memory. J Neurosci 2005; 25(43): 9883-9892.

50. Vacher H, Mohapatra DP, Trimmer JS. Localization and targeting of voltage-dependent ion channels in mammalian central neurons. Physiological reviews 2008; 88(4): 1407-1447.

51. Woodside BL, Borroni AM, Hammonds MD, Teyler TJ. NMDA receptors and voltage-dependent calcium channels mediate different aspects of acquisition and retention of a spatial memory task. Neurobiol Learn Mem 2004; 81(2): 105-114.

52. Gargus JJ. Ion channel functional candidate genes in multigenic neuropsychiatric disease. Biol Psychiatry 2006; 60(2): 177-185.

53. Gargus JJ. Genetic calcium signaling abnormalities in the central nervous system: seizures, migraine, and autism. Ann N Y Acad Sci 2009; 1151: 133-156.

54. Schlecker C, Boehmerle W, Jeromin A, DeGray B, Varshney A, Sharma Y et al. Neuronal calcium sensor-1 enhancement of InsP3 receptor activity is inhibited by therapeutic levels of lithium. J Clin Invest 2006; 116(6): 1668-1674.

55. McQuillin A, Rizig M, Gurling HM. A microarray gene expression study of the molecular pharmacology of lithium carbonate on mouse brain mRNA to understand the neurobiology of mood stabilization and treatment of bipolar affective disorder. Pharmacogenet Genomics 2007; 17(8): 605-617.

56. Levy NA, Janicak PG. Calcium channel antagonists for the treatment of bipolar disorder. Bipolar Disord 2000; 2(2): 108-119.

57. Keers R, Farmer AE, Aitchison KJ. Extracting a needle from a haystack: reanalysis of whole genome data reveals a readily translatable finding. Psychol Med 2009; 39(8): 1231-1235. 



\section{Chapter 7}

\section{Antipsychotic medications and two-year cognitive functioning in bipolar disorder: evidence for moderating effects of COMT Val $^{108 / 158}$ Met genotype}

Baer Arts ${ }^{\mathrm{a}}$, Claudia J.P. Simons ${ }^{\mathrm{a}, \mathrm{b}}$, Jim van Os ${ }^{\mathrm{a}, \mathrm{c}}$

a Department of Psychiatry and Psychology, School for Mental Health and Neuroscience, European Graduate School of Neuroscience (EURON), South Limburg Mental Health Research and Teaching Network (SEARCH), Maastricht University Medical Centre, P.O. Box 616 (DRT 12), 6200 MD Maastricht, The Netherlands

${ }^{b}$ GGZE, Institute for Mental Health Care Eindhoven en de Kempen, P.O. Box 909. 5600 AX Eindhoven, The Netherlands

${ }^{c}$ King's College London, King's Health Partners, Department of Psychosis Studies, Institute of Psychiatry, London, United Kingdom

Submitted for publication 


\section{Abstract}

Objective: There is a negative association between the use of antipsychotics and cognitive functioning in bipolar patients, which may be mediated by altered dopamine signaling in selected brain areas, and moderation thereof by genetic sequence variation such as COMT Val ${ }^{108 / 158}$ Met. The interaction between antipsychotic drug use and the COMT $\mathrm{Val}^{108 / 158}$ Met genotype on two-year cognitive functioning in bipolar patients was examined.

Method: Interaction between the COMT Val ${ }^{108 / 158}$ Met and antipsychotics on a composite cognitive measure was examined in 51 bipolar patients who were assessed 12 times at two-monthly intervals over a period of two years (394 observations).

Results: There was a significant negative effect of the interaction between antipsychotic medications and Val allele load on the composite cognitive measure in bipolar patients $(\mathrm{p}=0.001)$.

Conclusion: The negative effects of antipsychotics on cognitive functioning in bipolar disorder may be moderated by the COMT Val ${ }^{108 / 158}$ Met genotype, with a doseresponse effect of $\mathrm{Val}$ allele load. If replicated, the results may be indicative of pharmacogenetic interactions in bipolar disorder. 


\section{Introduction}

Meta-analyses of neuropsychological functioning in euthymic bipolar patients suggest that generalized, rather than specific, cognitive impairments may exist, characterized by substantial heterogeneity that is not fully explained by demographic, illness and medication variables. ${ }^{1-4}$ Nevertheless, reviews point to a possible role for antipsychotics, indicating that antipsychotics may have detrimental impact on cognitive functioning in bipolar patients. ${ }^{5}$ For example, Jamrozinski and colleagues (2008) reported no differences between euthymic bipolar patients not exposed to antipsychotic treatment and healthy controls on any neuropsychological measure, whereas a significant underperformance was apparent in the bipolar group treated with antipsychotics. ${ }^{6}$ A more recent study showed dose-independent deficits in several cognitive tasks in euthymic bipolar patients treated with quetiapine, olanzapine or risperidone, with worse performance in patients on second generation antipsychotics compared to untreated euthymic patients. ${ }^{7}$ A recent 2-year naturalistic study on cognitive functioning in bipolar patients showed significant variation of cognitive functioning over time, largely independent of clinical factors, with the exception of antipsychotic drug use impacting negatively on tasks indexing speed of information processing. ${ }^{8}$ The suggested negative effects of antipsychotics on cognition in bipolar patients contrast with the apparently positive, cognition-enhancing effects of these drugs in the treatment of schizophrenia. ${ }^{9-12}$ However, cognition-enhancing effects in schizophrenia may at least in part be attributable to practice effects. ${ }^{13,14}$ Cognitive effects of antipsychotics may be mediated by alterations in dopamine signaling in selected brain areas. It may be hypothesized that in altered and/or hyperdopaminergic states, which may underlie schizophrenia symptoms, ${ }^{15}$ antipsychotic drugs improve cognition, whereas in bipolar patients without hyperdopaminergia, antipsychotic treatment may induce suboptimal cognitive functioning. ${ }^{6}$

Antipsychotic effects impacting on dopamine signaling may be moderated by genetic sequence variation. The COMT (catechol-O-methyltransferase) gene $\mathrm{Val}^{108 / 158}$ Met polymorphism modulates dopaminergic function in frontostriatal circuitry, and may impact information processing efficiency, due to its critical role in the enzymatic degradation of dopamine. The Val/Val genotype is associated with greater activity of the enzyme and hence with lower concentrations of dopamine in the prefrontal cortex. ${ }^{16,17}$ Furthermore, in patients with schizophrenia, an interaction of the COMT Val ${ }^{108 / 158}$ Met genotype and antipsychotic treatment on cognitive functioning has been reported, Met allele load predicting better cognitive performance, ${ }^{18-21}$ especially in tasks requiring effortful cognitive control. ${ }^{22}$

The aim of the present study was to examine whether COMT Val ${ }^{108 / 158}$ Met genotype moderates the effect of antipsychotics on a composite cognitive measure, indexing effortful cognitive control, in a sample of bipolar patients, hypothesizing a detrimental, dose-response effect of Val allele load. 


\section{Method and materials}

\section{Subjects}

Individuals were participants in the BIPOLCOG (BIPOLar and COGnition) study, ${ }^{23}$ a study on cognitive functioning in bipolar disorder (BD) in which three groups were investigated: (i) patients with bipolar disorder, (ii) healthy first-degree relatives of patients with bipolar disorder, and (iii) healthy control participants. All subjects were between the ages of 18 and 60 years, fluent in Dutch, had an IQ > 70 and were without a history of neurological disorders such as epilepsy and concussion with loss of consciousness. For the purpose of the current report, only the bipolar patient group was studied, with the healthy control group as reference.

A representative cohort of successively attending patients with a diagnosis of bipolar spectrum disorder according to DSM-IV ${ }^{24}$ were recruited through the inpatient and out-patient mental health facilities in the geographically defined catchment area of South Limburg. In addition, patients were recruited through the local association of bipolar patients and their families, in order to also include patients not currently in contact with services. The computer program OPCRIT was used to confirm DSM-IV diagnosis on the basis of current and lifetime recorded symptomatology listed in the Operational Criteria Checklist for Psychotic Illness, scored by the clinical researcher on the basis of all interview and historical case note data (OCCPI). ${ }^{25}$

Control subjects were recruited from the general population using a random mailing sampling procedure and were clinically and diagnostically interviewed with The Comprehensive Assessment of Symptoms and History (CASH) ${ }^{26}$ and OPCRIT criteria to exclude those with a past or current diagnosis of $\mathrm{BD}$ or psychotic disorder. Healthy controls were additionally interviewed with the Family Interview for Genetic Studies (FIGS) ${ }^{27}$ in order to confirm the absence of a family history of psychotic or bipolar disorder.

The initial sample consisted of 81 patients and 61 healthy control subjects. Three patients were excluded because data on diagnosis were missing. Neuropsychological testing data were missing for two patients. The last filter concerned incomplete or missing genetic data, leaving a final risk set for analysis of 51 patients and 50 healthy controls.

\section{Procedure}

As cognitive alterations in bipolar disorder largely develop after onset of illness, ${ }^{28}$ longitudinal assessment is necessary to adequately capture the phenotype. Thus, patients were examined at 2-monthly intervals over a period of 2 years, yielding a maximum of 12 assessments. At all time points, neuropsychological testing and psychiatric interviewing took place and questionnaires were completed (regarding social functioning, medication, use of drugs etc.). Genetic material was collected at 
the first visit. During the baseline interview, basic demographic information was collected as was information on illness characteristics. Written informed consent, conforming to the local ethics committee guidelines, was obtained from all subjects. Neuropsychological tests and psychiatric interviews were conducted by trained psychologists, each interview occasion taking approximately 2 hours to complete.

Healthy controls, in whom cognition is more stable than in patients, were tested twice at two monthly intervals. Data on healthy controls were used as reference to calculate standardized $\mathrm{z}$-scores.

\section{Neurocognitive assessment}

Neurocognitive tests were administered by computer, using E-prime for Windows on a 15-inch monitor Toshiba Tecra laptop. The test battery included tasks measuring various neurocognitive domains, guided by previous evidence of impaired performance in these domains in bipolar patients. ${ }^{1,2}$ Three subtests were selected a priori from the original test battery, described elsewhere, ${ }^{8}$ representing tasks with high cognitive load that previous work suggests are most sensitive to moderation by sequence variation in $\mathrm{COMT}^{29-31}$

Overall intellectual functioning was estimated at baseline using three Groningen Intelligence Test (GIT) subtests (Mental Rotation, Word Analogies and Mental Arithmetic), ${ }^{32}$ yielding results that are comparable to those of the Wechsler Adult Intelligence Scale III. ${ }^{33}$

Verbal learning and memory was assessed with the standardized Dutch version of the visually-presented Verbal Learning Test. ${ }^{34,35}$ In three consecutive trials, 15 monosyllabic non-related words had to be memorized and reproduced. Delayed recall was measured after a 20-minute delay. Parallel versions of this test were used, in order to avoid test-retest-effects.

The Flanker CPT (Cogtest plc, London) ${ }^{36}$ is a measure of selective visual control of attention. Subjects are instructed to respond by pressing the right or left mouse button depending on whether the middle element in a display of five lines has an arrowhead pointing to the right or left. There are three trial types: (i) neutral trials in which the flankers are just horizontal lines without arrowheads, (ii) congruent trials in which all flankers have an arrowhead pointing in the same direction as the target, and (iii) incongruent trials, in which flankers are pointing in the opposite direction from the target. The incongruent condition involves more cognitive effort, because the flankers are associated with a response that needs to be suppressed (measure of response inhibition). One-half of the trials was presented with the stimuli above the fixation cross and the other half were presented below fixation, in order to prevent the subjects from keeping their gaze fixed in one position. The test consisted of 144 trials of neutral, congruent and incongruent flankers, which were presented randomly. Outcome measure was the mean reaction time for correct responses (RT) in the incongruent condition. 
Finally, Digit Span Backward of the Wechsler Intelligence Scale III $^{37}$ was used as measure of working memory.

All 3 cognitive measures were standardised, higher scores reflecting better performance. In order to calculate a measure of global cognitive functioning, raw test scores were converted into standardized z-scores against the means and standard deviations of the healthy control group. The final composite measure of neurocognition was based on the means of the three domain scores, representing effortful information processing (verbal memory, selective attention/response inhibition and working memory).

\section{Genotyping}

Buccal swab samples were obtained followed by SNP analysis. For the current analysis, the COMTVal ${ }^{108 / 158}$ Met rs4680 was selected a priori because this is the only SNP that is consistently associated with antipsychotics in pharmacogenetic models, ${ }^{18,19}$ making it the only credible candidate. Although more SNPs had been determined $(n=184)$, these formed part of a standard set for the study of gene-environment interactions $(\mathrm{GxE})$, based on published findings up to April 2009 (for the rational underlying this selection process and an overview of selected SNPs see). ${ }^{38}$ The 184 SNPs had been chosen a priori (i.e were not selected from a larger set of genomewide markers) and selectively determined by Sequenom (Hamburg, Germany) using the Sequenom Mass ARRAY iPLEX platform at the facilities of the manufacturer. In accordance with a priori quality control criteria of the GROUP study, SNPs with more than $10 \%$ genotyping errors were excluded, as were SNPs in marked HardyWeinberg disequilibrium $(\mathrm{p}<0.001)$.

\section{Statistical analysis}

Regression analyses were carried out using the statistical software program STATA (version 11.2).$^{39}$ In the bipolar patient group, the moderating effect of Val allele load on the cognitive effects of antipsychotic medications was analysed on the 3 separate cognitive tasks, as well as on the composite cognitive measure. The Bonferroni correction for multiple testing was applied, yielding a corrected $\mathrm{p}$-value for significance of $\mathrm{p}<0.0042(0.05 / 12)$.

Data were hierarchical with multiple observations (interview occasion or time; level 1) clustered within subjects (level 2). Data were analysed using the STATA XTREG multilevel random regression routine with time as a random factor. The analyses of the interaction between the COMT Val allele load and antipsychotics on cognitive functioning were a priori adjusted for the confounding effects of demographic characteristics (age, sex, education).

Dummies were constructed for Val allele load with value 0 for the Met/Met genotype, value 1 for the $\mathrm{Val} / \mathrm{Met}$ genotype and value 2 for the $\mathrm{Val} / \mathrm{Val}$ genotype, with $\mathrm{Val}$ allele load as a continuous variable in a linear interaction model. Finally, dum- 
mies were constructed for the medication variable with value 1 for using antipsychotics and value 0 for not using this type of medication. Stratified effects were calculated from the model containing the interaction, using the STATA MARGINS command.

\section{Results}

\section{Subjects}

Demographic data, neurocognitive test results and allele frequencies are presented in Table 1. There were no significant differences between the three groups (Met/Met; $\mathrm{Val} / \mathrm{Met}$; Val/Val) after Bonferroni correction ( $\mathrm{p}<0.0042)$. The Val/Met group had a higher GIT-IQ than the Met/Met group (effect size: 0.29; $\mathrm{p}=0.026$ ) and performed better on the working memory task than the Met/Met group (effect size: 0.29; $\mathrm{p}=0.023$ ). Twelve of the 51 patients used antipsychotic medications during the twoyear period of our study; these patients contributed 38 observations.

Table 1. Demographics, neurocognitive testresults and allele frequency of COMT Val/Met rs4680 in bipolar patients

\begin{tabular}{|c|c|c|c|c|c|c|}
\hline & \multicolumn{2}{|c|}{$\begin{array}{c}\text { Met/Met } \\
(\mathrm{n}=12)\end{array}$} & \multicolumn{2}{|c|}{$\begin{array}{c}\text { Val/Met } \\
(\mathrm{n}=32)\end{array}$} & \multicolumn{2}{|c|}{$\begin{array}{c}\mathrm{Val} / \mathrm{Val} \\
(\mathrm{n}=7)\end{array}$} \\
\hline & Mean & SD & Mean & SD & Mean & $\overline{\mathrm{SD}}$ \\
\hline Gender M/F & $7 \mathrm{M} / 5 \mathrm{~F}$ & & $17 \mathrm{M} / 15 \mathrm{~F}$ & & $4 \mathrm{M} / 3 \mathrm{~F}$ & \\
\hline Age & 45.5 & 8.7 & 47 & 6.7 & 44.2 & 6.6 \\
\hline Educational level & 4.6 & 2.4 & 5.2 & 2.3 & 6.9 & 0.4 \\
\hline GIT-IQ & 101.7 & 9.7 & 111.2 & 13.9 & 105.8 & 7.5 \\
\hline Verbal memory; delayed recall & 7.2 & 2.4 & 8.2 & 3.8 & 8 & 3.1 \\
\hline Response inhibition; RT incongruent & 72.9 .5 & 77.4 & 685 & 83.7 & 699.4 & 72.4 \\
\hline Working memory & 5.7 & 1.6 & 7.1 & 2.1 & 6.4 & 1.9 \\
\hline \multicolumn{7}{|l|}{ Allele frequency; \% } \\
\hline Met & 55 & & & & & \\
\hline Val & 45 & & & & & \\
\hline
\end{tabular}

\section{Genotype}

Twelve patients were homozygous for the Met allele, 32 patients were heterozygous and 7 patients were homozygous for the Val allele. Genotypes in the bipolar group were in Hardy-Weinberg equilibrium $(\mathrm{P}>0.09)$. 


\section{Cognitive data}

The interaction between COMTVal ${ }^{108 / 158}$ Met Val allele load and antipsychotics on two-year cognitive functioning in bipolar patients is presented in Table 2. As evidenced in this table, there exists a dose-response effect of Val allele load on the cognitive effects of antipsychotic medications, with higher Val allele load yielding larger negative effects. The composite cognitive measure and the verbal memory test survived Bonferroni correction.

Table 2. Interaction between antipsychotic medications and COMT Val allele load (VAL) on cognitive functioning in bipolar patients

\begin{tabular}{|c|c|c|c|c|c|c|c|c|c|}
\hline & \multirow[t]{2}{*}{ N obs. } & \multicolumn{2}{|c|}{ Main effect } & \multicolumn{2}{|c|}{$\begin{array}{l}\text { Met/Met } \\
(\mathrm{VAL}=0)\end{array}$} & \multicolumn{2}{|c|}{$\begin{array}{l}\mathrm{Val} / \mathrm{Met} \\
(\mathrm{VAL}=1)\end{array}$} & \multicolumn{2}{|c|}{$\begin{array}{l}\mathrm{Val} / \mathrm{Val} \\
(\mathrm{VAL}=2)\end{array}$} \\
\hline & & coefficient & $\mathrm{p}$-value & coefficient & $\mathrm{p}$-value & coefficient & p-value & coefficient & p-value \\
\hline \multicolumn{10}{|l|}{ Cognitive function } \\
\hline $\begin{array}{l}\text { Verbal memory; } \\
\text { delayed recall }\end{array}$ & 437 & -0.9 & 0.038 & -0.1 & 0.766 & -1 & $<0.0001$ & -1.9 & 0.002 \\
\hline $\begin{array}{l}\text { Response inhibition; } \\
\text { RT incongruent }\end{array}$ & 399 & -1.2 & 0.017 & 0.5 & 0.271 & -0.7 & 0.024 & -1.9 & 0.008 \\
\hline Working memory & 434 & -0.8 & 0.027 & 0.1 & 0.615 & -0.6 & 0.006 & -1.4 & 0.006 \\
\hline $\begin{array}{l}\text { Composit cognitive } \\
\text { measure }\end{array}$ & 394 & -0.9 & 0.001 & 0.1 & 0.723 & -0.9 & $<0.0001$ & -1.8 & $<0.0001$ \\
\hline
\end{tabular}

\section{Discussion}

\section{Summary of findings}

Patients with bipolar disorder displayed a negative moderating, dose-response effect of COMT Val ${ }^{108 / 158} \mathrm{Met} \mathrm{Val}$ allele load on the effects of antipsychotics on two-year cognitive functioning. Given the small number of patients, this finding must be considered preliminary. Nevertheless, the results, if replicated, suggest a gene-byenvironment interaction between antipsychotic medications and COMT $\mathrm{Val}^{108 / 158} \mathrm{Met}$ rs 4680 . Patients with a more severe course of illness may be more likely to receive antipsychotic medications; however, post-hoc analyses revealed no significant effects of number of episodes and / or psychotic symptoms in the past on the interaction between antipsychotics and Val allele load. Furthermore, post-hoc analyses yielded no significant interactive effects of Val allele load on tasks requiring less cognitive effort, such as sustained attention and motor speed. This may explain our remarkable finding of an interaction between Val allele load and antipsychotics on delayed recall in a verbal memory test; a task requiring much cognitive effort. 


\section{Interaction between antipsychotics and COMT Val ${ }^{108 / 158}$ Met on cognitive functioning}

Our finding of a negative effect on cognition of antipsychotics in Val allele carriers is in line with the sparse literature in patients with schizophrenia. Rebollo-Mesa et al (2011), for instance, report a negative effect on cognition in $\mathrm{Val} / \mathrm{Val}$ homozygotes using antipsychotics in contrast with a reversed association in Met/Met carriers. ${ }^{21}$ Furthermore, a positive effect of antipsychotics on cognitive functioning in Met allele carriers with schizophrenia is described in the literature, with no evidence of improvement of cognition in Val allele carriers using antipsychotics, thus indicating interactive effects. ${ }^{18-20}$ These findings support the hypothesis of Jamrozinski et al (2009) of differential effects of antipsychotics on cognitive functioning depending on basal dopamine levels, antipsychotics lowering dopamine functioning and inducing suboptimal cognitive status in bipolar patients with already lower basal dopamine levels, as is the case in Val allele carriers. ${ }^{6}$

\section{COMTVal ${ }^{108 / 158}$ Met rs4680 and cognitive functioning}

In general, the COMT Val ${ }^{108 / 158}$ Met polymorphism appears to have little if any direct association with cognitive functioning, ${ }^{40}$ with mixed results in patients with schizophrenia ${ }^{41,42}$ and bipolar disorder, ${ }^{29,31}$ as well as in healthy controls. ${ }^{43,44}$ Krabbendam et al. (2006) suggest indirect (positive) effects of Met allele loading on cognitive functioning, independent of schizophrenia liability, through gene-gene interactions or the influence of a functional polymorphism near COMT Val ${ }^{108 / 158} \mathrm{Met}^{45}$ The latter is illustrated by the study of Burdick et al. (2007), finding no association between COMTrs4680 and cognitive functioning, but an association between cognitive functioning and COMTrs165599 in bipolar patients and healthy controls. ${ }^{46}$ Furthermore, Diaz-Asper and colleagues (2008) report a negative effect of the Val allele on cognitive functioning, irrespective of diagnosis, and significant effects on cognition of other COMT haplotypes, for instance COMTrs737865. ${ }^{30}$ Finally, the literature supports the possible role of gene-gene interactions on cognitive functioning due to epistatis between COMT and several other gene polymorphisms, impacting dopamine signalling, ${ }^{47-49}$ GABAergic functioning ${ }^{50,51}$ and glutamatergic systems, ${ }^{52,53}$ amongst others.

In conclusion, COMT most likely has indirect effects on cognitive functioning by modulating dopaminergic neurotransmission, influencing attentional network efficiency, ${ }^{54}$ amongst others, with a possible advantage of the Met allele on effortful cognitive control or conflict processing, not supporting a simple stability/flexibility model of dopamine COMT Val/Met effects, according to Rosa et al. ${ }^{22}$

\section{COMTrs4680 and dopamine function}

The dual state, or tonic-phasic dopamine theory hypothesizes that the COMT Met allele results in increased levels of dopamine and a tonic D1-dominated state in the 
prefrontal cortex, thus increasing signal-to-noise ratio in prefrontal attractor states that may improve performance in some measures, such as working memory, but not others. ${ }^{16,55,56}$ The latter is illustrated by the meta-analysis of neuroimaging studies of COMTrs4680 by Mier et al. (2010), reporting a significant association between the COMT genotype and prefrontal activation (effect size: 0.73 ), with opposing effects for executive cognition paradigms, favouring Met allele carriers, and emotional paradigms, favouring Val allele carriers. ${ }^{57}$ These pleiotropic effects of COMTrs 4680 on neural mechanisms underlying cognitive functioning are further illustrated by recent (f-)MRI-studies, showing evidence for COMT-genotype-dependent differences in amygdala responsivity and connectivity ${ }^{58-60}$ and prefrontal cortex activation and connectivity patterns, including default network. ${ }^{61-63}$ Finally, COMT haplotypes, other than Val/Met, can nonlinearly modulate intelligence-related white matter integrity of the prefrontal lobes by significantly influencing prefrontal dopamine variations, fitting an inverted U-model..$^{64}$

\section{Dopamine and cognitive functioning}

The evidence for the inverted U-model of the dopamine actions on cognitive functioning, especially working memory and cognitive control, is reviewed by Cools et al. (2011). These authors conclude that there exists an optimum dopamine level for different cognitive functions, implicating the importance of baseline levels of dopamine, where both too little and too much dopamine may impair performance, depending on a dynamic balance between cognitive stability (prefrontal cortex) and cognitive flexibility (striatum). ${ }^{65,66}$ Prefrontal dopamine D1 receptor activation, in this respect, may improve sustained attention, ${ }^{67}$ whereas striatal dopamine D2 receptor signalling may be associated with cognitive flexibility, ${ }^{68}$ with a central role for dopamine in effort-based decision making ${ }^{69}$ and the interaction between appetitive motivation and cognition, ${ }^{70}$ amongst others. The inverted U-shaped curve of dopamine's action is influenced by (uncontrollable) stress, weakening prefrontal cortex functioning, ${ }^{71}$ as well as influencing stress-related methylation of the gene, partially compensating the role of the high-activity Val allele in prefrontal cognition. ${ }^{72}$ Furthermore, estradiol status and working memory load, which may potentiate dopamine and thus have beneficial effects for Val homozygotes and unfavourable effects for Met homozygotes, may play a role as well. ${ }^{73}$ In contrast, Karlsson et al. (2011), found no linear or curvilinear relationships between dopamine D1 receptor binding in dorsolateral prefrontal cortex and performance in any cognitive task, providing support for the notion that D1 receptors in separate brain regions are differentially related to performance in various cognitive tasks. ${ }^{74}$

\section{Strengths and limitations}

The results should be interpreted in the light of several limitations. First, the small number of patients and observations regarding exposure to antipsychotic medica- 
tions, makes our results preliminary, needing replication in larger samples. Results therefore can be considered as hypothesis-generating. Second, the effects of possible confounders such as gene-gene interactions, the influence of functional polymorphisms near COMT Val ${ }^{108 / 158}$ Met, epigenetic changes due to stress and/or medication, task demands, and the possible interaction between COMT Val ${ }^{108 / 158} \mathrm{Met}$ and herpes simplex virus type 1 infection, ${ }^{29}$ amongst others, were not adequately controlled for in our study.

The longitudinal character of our study, however, may have been more sensitive to genetic effects, in this case the interaction between COMT Val ${ }^{108 / 158}$ Met Val allele load and antipsychotic medication, given the significant variation of cognitive functioning over time in bipolar patients. ${ }^{8}$

\section{Conclusion}

In conclusion, the negative effects of antipsychotic medication on cognitive functioning in patients with bipolar disorder, may be partly moderated by COMT $\mathrm{Val}^{108 / 158} \mathrm{Met} \mathrm{Val}$ allele load. This finding agrees with an indirect, modulatory role for COMT on (basal) dopamine levels in different brain areas, relevant for (effortful) cognitive functioning, thus influencing the cognitive side-effects of antipsychotics in patients with bipolar disorder. This finding needs replication in other, larger samples. 


\section{References}

1. Arts B, Jabben N, Krabbendam L, van Os J. Meta-analyses of cognitive functioning in euthymic bipolar patients and their first-degree relatives. Psychol Med 2008; 38(6): 771-785.

2. Bora E, Yucel M, Pantelis C. Cognitive endophenotypes of bipolar disorder: A meta-analysis of neuropsychological deficits in euthymic patients and their first-degree relatives. J Affect Disord 2009; 113: 1-20.

3. Kurtz MM, Gerraty RT. A meta-analytic investigation of neurocognitive deficits in bipolar illness: profile and effects of clinical state. Neuropsychology 2009; 23(5): 551-562.

4. Mann-Wrobel MC, Carreno JT, Dickinson D. Meta-analysis of neuropsychological functioning in euthymic bipolar disorder: an update and investigation of moderator variables. Bipolar Disord 2011; 13(4): 334-342.

5. Balanza-Martinez V, Selva G, Martinez-Aran A, Prickaerts J, Salazar J, Gonzalez-Pinto A et al. Neurocognition in bipolar disorders--a closer look at comorbidities and medications. Eur J Pharmacol 2010; 626(1): 87-96.

6. Jamrozinski K, Gruber O, Kemmer C, Falkai P, Scherk H. Neurocognitive functions in euthymic bipolar patients. Acta Psychiatr Scand 2009; 119(5): 365-374.

7. Torrent C, Martinez-Aran A, Daban C, Amann B, Balanza-Martinez V, Del Mar Bonnin C et al. Effects of atypical antipsychotics on neurocognition in euthymic bipolar patients. Compr Psychiatry 2011; 52(6): 613-622.

8. Arts B, Jabben N, Krabbendam L, van Os J. A 2-year naturalistic study on cognitive functioning in bipolar disorder. Acta Psychiatr Scand 2011; 123(3): 190-205.

9. Keefe RS, Bilder RM, Davis SM, Harvey PD, Palmer BW, Gold JM et al. Neurocognitive effects of antipsychotic medications in patients with chronic schizophrenia in the CATIE Trial. Arch Gen Psychiatry 2007; 64(6): 633-647.

10. Keefe RS, Sweeney JA, Gu H, Hamer RM, Perkins DO, McEvoy JP et al. Effects of olanzapine, quetiapine, and risperidone on neurocognitive function in early psychosis: a randomized, doubleblind 52-week comparison. Am J Psychiatry 2007; 164(7): 1061-1071.

11. Woodward ND, Purdon SE, Meltzer HY, Zald DH. A meta-analysis of cognitive change with haloperidol in clinical trials of atypical antipsychotics: dose effects and comparison to practice effects. Schizophr Res 2007; 89(1-3): 211-224.

12. Davidson M, Galderisi S, Weiser M, Werbeloff N, Fleischhacker WW, Keefe RS et al. Cognitive effects of antipsychotic drugs in first-episode schizophrenia and schizophreniform disorder: a randomized, open-label clinical trial (EUFEST). Am J Psychiatry 2009; 166(6): 675-682.

13. Goldberg TE, Goldman RS, Burdick KE, Malhotra AK, Lencz T, Patel RC et al. Cognitive improvement after treatment with second-generation antipsychotic medications in first-episode schizophrenia: is it a practice effect? Arch Gen Psychiatry 2007; 64(10): 1115-1122.

14. Guo X, Zhai J, Wei Q, Twamley EW, Jin H, Fang M et al. Neurocognitive effects of first- and second-generation antipsychotic drugs in early-stage schizophrenia: a naturalistic 12-month follow-up study. Neurosci Lett 2011; 503(2): 141-146.

15. Howes OD, Kapur S. The dopamine hypothesis of schizophrenia: version III--the final common pathway. Schizophr Bull 2009; 35(3): 549-562.

16. Frank MJ, Fossella JA. Neurogenetics and pharmacology of learning, motivation, and cognition. Neuropsychopharmacology 2011; 36(1): 133-152.

17. Hariri AR. The what, where, and when of catechol-o-methyltransferase. Biol Psychiatry 2011; 70(3): 214-215.

18. Weickert TW, Goldberg TE, Mishara A, Apud JA, Kolachana BS, Egan MF et al. Catechol-Omethyltransferase val108/158met genotype predicts working memory response to antipsychotic medications. Biol Psychiatry 2004; 56(9): 677-682.

19. Bertolino A, Caforio G, Blasi G, De Candia M, Latorre V, Petruzzella V et al. Interaction of COMT (Val(108/158)Met) genotype and olanzapine treatment on prefrontal cortical function in patients with schizophrenia. Am J Psychiatry 2004; 161(10): 1798-1805. 
20. Woodward ND, Jayathilake K, Meltzer HY. COMT val108/158met genotype, cognitive function, and cognitive improvement with clozapine in schizophrenia. Schizophr Res 2007; 90(1-3): 86-96.

21. Rebollo-Mesa I, Picchioni M, Shaikh M, Bramon E, Murray R, Toulopoulou T. COMT (Val(158/108)Met) genotype moderates the impact of antipsychotic medication on verbal IQ in twins with schizophrenia. Psychiatr Genet 2011;21(2): 98-105.

22. Rosa EC, Dickinson D, Apud J, Weinberger DR, Elvevag B. COMT Val158Met polymorphism, cognitive stability and cognitive flexibility: an experimental examination. Behav Brain Funct 2010; 6 : 53.

23. Jabben N, Arts B, Krabbendam L, van Os J. Investigating the association between neurocognition and psychosis in bipolar disorder: further evidence for the overlap with schizophrenia. Bipolar Disord 2009; 11(2): 166-177.

24. APA. Diagnostic and Statistical Manual of Mental Disorders, Fourth Edition: Washington, DC, 1994.

25. McGuffin P, Farmer A, Harvey I. A polydiagnostic application of operational criteria in studies of psychotic illness. Development and reliability of the OPCRIT system. Arch Gen Psychiatry 1991; 48(8): 764-770.

26. Andreasen NC, Flaum M, Arndt S. The Comprehensive Assessment of Symptoms and History (CASH). An instrument for assessing diagnosis and psychopathology. Arch Gen Psychiatry 1992; 49(8): 615-623.

27. Maxwell ME. Manual for the family interview for genetic studies (FIGS): Bethesda, Maryland: National Institute of Mental Health, 1992.

28. Goodwin GM, Anderson I, Arango C, Bowden CL, Henry C, Mitchell PB et al. ECNP consensus meeting. Bipolar depression. Nice, March 2007. Eur Neuropsychopharmacol 2008; 18(7): 535-549.

29. Dickerson FB, Boronow JJ, Stallings C, Origoni AE, Cole S, Leister F et al. The catechol Omethyltransferase Val158Met polymorphism and herpes simplex virus type 1 infection are risk factors for cognitive impairment in bipolar disorder: additive gene-environmental effects in a complex human psychiatric disorder. Bipolar Disord 2006; 8(2): 124-132.

30. Diaz-Asper CM, Goldberg TE, Kolachana BS, Straub RE, Egan MF, Weinberger DR. Genetic variation in catechol-O-methyltransferase: effects on working memory in schizophrenic patients, their siblings, and healthy controls. Biol Psychiatry 2008; 63(1): 72-79.

31. Wirgenes KV, Djurovic S, Sundet K, Agartz I, Mattingsdal M, Athanasiu L et al. Catechol Omethyltransferase variants and cognitive performance in schizophrenia and bipolar disorder versus controls. Schizophr Res 2010; 122(1-3): 31-37.

32. Luteijn F, van der Ploeg, F.A.E. Handleiding Groninger Intelligentietest (GIT). Lisse, The Netherlands; 1983.

33. Wechsler D. Wechsler Adult Intelligence Scale-Revised. Psychological Corporation: New York, 1981.

34. Brand N, Jolles J. Learning and retrieval rate of words presented auditorily and visually. J Gen Psychol 1985; 112(2): 201-210.

35. Van der Elst W, van Boxtel MP, van Breukelen GJ, Jolles J. Rey's verbal learning test: normative data for 1855 healthy participants aged 24-81 years and the influence of age, sex, education, and mode of presentation. J Int Neuropsychol Soc 2005; 11(3): 290-302.

36. Eriksen CW, Schultz DW. Information processing in visual search: a continuous flow conception and experimental results. Percept Psychophys 1979; 25(4): 249-263.

37. Wechsler D. WAIS-III: Wechsler Adult Intelligence Scale. San Antonio: Psychological Corporation; 1997.

38. van Winkel R. Family-based analysis of genetic variation underlying psychosis-inducing effects of cannabis: sibling analysis and proband follow-up. Arch Gen Psychiatry 2011; 68(2): 148-157.

39. StataCorp. STATA Statistical Software. Release 8.0 edn. College Station: Texas, 2002.

40. Barnett JH, Scoriels L, Munafo MR. Meta-analysis of the cognitive effects of the catechol-Omethyltransferase gene Val158/108Met polymorphism. Biol Psychiatry 2008; 64(2): 137-144.

41. Tunbridge EM, Harrison PJ, Weinberger DR. Catechol-o-methyltransferase, cognition, and psychosis: Val158Met and beyond. Biol Psychiatry 2006; 60(2): 141-151. 
42. Mata I, Perez-Iglesias R, Pelayo-Teran JM, Rodriguez-Sanchez JM, Gonzalez-Blanch C, CarrascoMarin E et al. Lack of influence of COMT Val158Met genotype on cognition in first-episode nonaffective psychosis. Schizophr Res 2008; 102(1-3): 206-209.

43. Barnett JH, Jones PB, Robbins TW, Muller U. Effects of the catechol-O-methyltransferase Val158Met polymorphism on executive function: a meta-analysis of the Wisconsin Card Sort Test in schizophrenia and healthy controls. Mol Psychiatry 2007; 12(5): 502-509.

44. Blanchard MM, Chamberlain SR, Roiser J, Robbins TW, Muller U. Effects of two dopaminemodulating genes (DAT1 9/10 and COMT Val/Met) on n-back working memory performance in healthy volunteers. Psychol Med 2011; 41(3): 611-618.

45. Krabbendam L, Isusi P, Galdos P, Echevarria E, Bilbao JR, Martin-Pagola A et al. Associations between COMTVal158Met polymorphism and cognition: direct or indirect effects? Eur Psychiatry 2006; 21(5): 338-342.

46. Burdick KE, Funke B, Goldberg JF, Bates JA, Jaeger J, Kucherlapati R et al. COMT genotype increases risk for bipolar I disorder and influences neurocognitive performance. Bipolar Disord 2007; 9(4): 370-376.

47. Buckholtz JW, Sust S, Tan HY, Mattay VS, Straub RE, Meyer-Lindenberg A et al. fMRI evidence for functional epistasis between COMT and RGS4. Mol Psychiatry 2007; 12(10): 893-895, 885.

48. Prata DP, Mechelli A, Fu CH, Picchioni M, Toulopoulou T, Bramon E et al. Epistasis between the DAT 3' UTR VNTR and the COMT Val158Met SNP on cortical function in healthy subjects and patients with schizophrenia. Proc Natl Acad Sci U S A 2009; 106(32): 13600-13605.

49. Wishart HA, Roth RM, Saykin AJ, Rhodes CH, Tsongalis GJ, Pattin KA et al. COMT Val158Met Genotype and Individual Differences in Executive Function in Healthy Adults. J Int Neuropsychol Soc 2011; 17(1): 174-180.

50. Straub RE, Lipska BK, Egan MF, Goldberg TE, Callicott JH, Mayhew MB et al. Allelic variation in GAD1 (GAD67) is associated with schizophrenia and influences cortical function and gene expression. Mol Psychiatry 2007; 12(9): 854-869.

51. Marenco S, Savostyanova AA, van der Veen JW, Geramita M, Stern A, Barnett AS et al. Genetic modulation of GABA levels in the anterior cingulate cortex by GAD1 and COMT. Neuropsychopharmacology 2010; 35(8): 1708-1717.

52. Tan HY, Chen Q, Sust S, Buckholtz JW, Meyers JD, Egan MF et al. Epistasis between catechol-Omethyltransferase and type II metabotropic glutamate receptor 3 genes on working memory brain function. Proc Natl Acad Sci U S A 2007; 104(30): 12536-12541.

53. Nixon DC, Prust MJ, Sambataro F, Tan HY, Mattay VS, Weinberger DR et al. Interactive effects of DAOA (G72) and catechol-O-methyltransferase on neurophysiology in prefrontal cortex. Biol Psychiatry 2011; 69(10): 1006-1008.

54. Opgen-Rhein C, Neuhaus AH, Urbanek C, Hahn E, Sander T, Dettling M. Executive attention in schizophrenic males and the impact of COMT Val108/158Met genotype on performance on the attention network test. Schizophr Bull 2008; 34(6): 1231-1239.

55. Bilder RM, Volavka J, Lachman HM, Grace AA. The catechol-O-methyltransferase polymorphism: relations to the tonic-phasic dopamine hypothesis and neuropsychiatric phenotypes. Neuropsychopharmacology 2004; 29(11): 1943-1961.

56. Durstewitz D, Seamans JK. The dual-state theory of prefrontal cortex dopamine function with relevance to catechol-o-methyltransferase genotypes and schizophrenia. Biol Psychiatry 2008; 64(9): 739-749.

57. Mier D, Kirsch P, Meyer-Lindenberg A. Neural substrates of pleiotropic action of genetic variation in COMT: a meta-analysis. Mol Psychiatry 2010; 15(9): 918-927.

58. Rasch B, Spalek K, Buholzer S, Luechinger R, Boesiger P, de Quervain DJ et al. Aversive stimuli lead to differential amygdala activation and connectivity patterns depending on catechol-Omethyltransferase Val158Met genotype. Neuroimage 2010; 52(4): 1712-1719.

59. Williams LM, Gatt JM, Grieve SM, Dobson-Stone C, Paul RH, Gordon E et al. COMT Val(108/158)Met polymorphism effects on emotional brain function and negativity bias. Neuroimage 2010; 53(3): 918-925. 
60. Lelli-Chiesa G, Kempton MJ, Jogia J, Tatarelli R, Girardi P, Powell J et al. The impact of the Val158Met catechol- O-methyltransferase genotype on neural correlates of sad facial affect processing in patients with bipolar disorder and their relatives. Psychol Med 2011; 41(4): 779-788.

61. Dennis NA, Need AC, LaBar KS, Waters-Metenier S, Cirulli ET, Kragel J et al. COMT val108/158 met genotype affects neural but not cognitive processing in healthy individuals. Cereb Cortex 2010; 20(3): 672-683.

62. Liu B, Song M, Li J, Liu Y, Li K, Yu C et al. Prefrontal-related functional connectivities within the default network are modulated by COMT val158met in healthy young adults. J Neurosci 2010; 30(1): 64-69.

63. Stokes PR, Rhodes RA, Grasby PM, Mehta MA. The Effects of The COMT val(108/158)met Polymorphism on BOLD Activation During Working Memory, Planning, and Response Inhibition: A Role for The Posterior Cingulate Cortex? Neuropsychopharmacology 2011; 36(4): 763-771.

64. Liu B, Li J, Yu C, Li Y, Liu Y, Song M et al. Haplotypes of catechol-O-methyltransferase modulate intelligence-related brain white matter integrity. Neuroimage 2010; 50(1): 243-249.

65. Cools R, D'Esposito M. Inverted-U-shaped dopamine actions on human working memory and cognitive control. Biol Psychiatry 2011; 69(12): e113-125.

66. Cools R. Dopaminergic control of the striatum for high-level cognition. Curr Opin Neurobiol 2011; 21(3): 402-407.

67. Barnes SA, Young JW, Neill JC. D(1) receptor activation improves vigilance in rats as measured by the 5-choice continuous performance test. Psychopharmacology (Berl) 2011.

68. van Holstein M, Aarts E, van der Schaaf ME, Geurts DE, Verkes RJ, Franke B et al. Human cognitive flexibility depends on dopamine D2 receptor signaling. Psychopharmacology (Berl) 2011.

69. Kurniawan IT, Guitart-Masip M, Dolan RJ. Dopamine and effort-based decision making. Front Neurosci 2011; 5: 81.

70. Aarts E, van Holstein M, Cools R. Striatal Dopamine and the Interface between Motivation and Cognition. Front Psychol 2011; 2: 163.

71. Gamo NJ, Arnsten AF. Molecular modulation of prefrontal cortex: rational development of treatments for psychiatric disorders. Behav Neurosci 2011; 125(3): 282-296.

72. Ursini G, Bollati V, Fazio L, Porcelli A, Iacovelli L, Catalani A et al. Stress-related methylation of the catechol-O-methyltransferase Val 158 allele predicts human prefrontal cognition and activity. $J$ Neurosci 2011; 31(18): 6692-6698.

73. Jacobs E, D’Esposito M. Estrogen shapes dopamine-dependent cognitive processes: implications for women's health. J Neurosci 2011; 31(14): 5286-5293.

74. Karlsson S, Rieckmann A, Karlsson P, Farde L, Nyberg L, Backman L. Relationship of dopamine D1 receptor binding in striatal and extrastriatal regions to cognitive functioning in healthy humans. Neuroimage 2011; 57(2): 346-351. 

Chapter 8

Summary and Discussion 


\section{Summary}

In the first part of this thesis we compared cognitive functioning in schizophrenic and bipolar patients in a meta-analysis of studies finding only quantitative differences between the patient groups with better performance in bipolar patients (Chapter 2). This is in line with the idea of a continuum between these disorders. The hypothesis of cognitive functioning as a possible genetic vulnerability marker for bipolar disorder was further explored in meta-analyses of studies on cognition in euthymic bipolar patients and their first-degree relatives (Chapter 3). In first-degree relatives effect sizes were small and only significantly different from healthy controls for executive function, giving some, but weak support to this hypothesis. Finally, in Chapter 4, we studied the role of psychosis in neurocognition in bipolar patients and their unaffected relatives, finding better cognitive performance in relatives with subclinical psychotic symptoms and in relatives of bipolar patients with a history of psychotic symptoms. This finding is in line with the partially overlapping vulnerability to bipolar disorder and schizophrenia.

In the second part, the differential effects of mood and medication on cognitive functioning were further explored in a longitudinal, 2-year study of a cohort of bipolar patients, revealing substantial variation in cognitive performance over the 2-year follow-up with limited explanatory power of predictors like medication on this temporal variation (Chapter 5). Use of second-generation antipsychotics was associated with the largest negative effects on cognition in the areas of motor speed and basic information processing. Sustained attention, showing the largest effect size and being invariant over time, may be a possible candidate intermediary phenotype. Given the small effects of factors like mood and medication, with the possible exception of second-generation antipsychotics, we finally studied the possible effects of candidate genes on cognitive vulnerability in bipolar patients (Chapters 6 and 7). We described a significant association between the CACNA1C risk allele and cognitive functioning in bipolar patients, contingent on expression of disease, as well as an interaction between the COMT Val ${ }^{108 / 158}$ Met polymorphism and antipsychotics causing negative effects on a composite cognitive measure.

\section{Discussion}

'...slowness of movement... may reflect slowing in any of a variety of cognitive or motor processes... Similarly, disturbances in attention are rife in mood disorders, yet they can pertain to distinct cognitive processes such as vigilance or sustained attention, freedom from distraction, divided attention, and capacity to shift set (p.273)1. .Attention compromises several distinct processes, and its overall integrity is central to the normal functioning of higher cognitive processes such as learning and memory...' (p.321). ${ }^{1}$ 
Goodwin and Jameson (2007), as quoted above, underline the central role of speed and attention as 'basic' cognitive functions, underlying higher processes in a complex way, partially explaining the heterogeneity in the literature on cognitive functioning in bipolar patients. We will discuss some of these complex underlying mechanisms and propose a model to explain the cognitive deficits found in bipolar patients and their first-degree relatives.

\section{Cognitive functioning in bipolar disorder and schizophrenia}

\section{Neurocognitive deficits associated with bipolar disorder}

In Chapter 3 the largest effect sizes were noted for working memory, mental speed and verbal memory, with medium effect sizes for aspects of executive function and sustained attention. Recent meta-analyses of the literature on cognitive function in euthymic bipolar patients give more or less the same global picture. Torres et al. (2007) describe trait-related deficits in attention, processing speed, memory and executive function in euthymic bipolar patients. ${ }^{2}$ In their excellent meta-analysis, Bora et al. (2009) find response inhibition deficit the most likely candidate intermediary phenotype in bipolar patients and their relatives, with verbal memory and sustained attention as other possible candidates; processing speed, in their view, may be partly related to the use of medication. ${ }^{3}$ Yatham et al. (2010) reviewing four recent meta-analyses, conclude that patients with bipolar disorder show moderate to large impairments on tests of attention, processing speed, explicit memory, and several aspects of executive function. ${ }^{4}$ Finally, Mann-Wrobel et al. (2011) suggest in their recent meta-analysis of neuropsychological functioning in euthymic bipolar disorder, that generalized, rather than specific cognitive impairment characterizes bipolar patients. $^{5}$

\section{Neurocognitive functioning in schizophrenia}

In patients with schizophrenia cognitive deficits are, in general, more prominent than in bipolar patients (Chapter 2) and more stable over time. ${ }^{6-8}$ Sustained attention, verbal memory, and working memory are, according to Gur et al. (2007), possible neurocognitive endophenotypes in schizophrenic patients. ${ }^{9}$ Associative learning, however, was intact in patients with schizophrenia in a recent study, showing only longer reaction times in patients in a Go/NoGo paradigm. ${ }^{10}$ In contrast, recent studies show evidence of deficits in speed of processing, ${ }^{11-14}$ working memory, ${ }^{15-17}$ (sustained) attention, ${ }^{18-20}$ and facial emotion processing ${ }^{21-23}$ in schizophrenic patients. The latter being important in emotional processing and social cognition. 


\section{Emotional processing and social cognition in bipolar disorder and schizophrenia}

Emotional processing, in contrast to schizophrenic patients, has not been sufficiently studied in bipolar patients to provide firm conclusions. ${ }^{4}$ The ability to evaluate the emotional state of others (facial affect recognition) plays a key role in social cognition, a well as the ability to mentalize (theory of mind; TOM). Misattribution of facial expressions of emotion ${ }^{24}$ and deficits in theory of mind are evident in patients with schizophrenia, possibly as a trait marker, ${ }^{25,26}$ but may be also relevant in euthymic bipolar patients, ${ }^{27,28}$ partly mediated by attention-executive functions deficits and exposure to psychotropic medications. ${ }^{29}$ In their review, Bora et al. (2009), describe mentalizing impairments in bipolar patients and high risk groups, partially mediated by cognitive dysfunctions. ${ }^{30}$ In a study of Lahera et al. (2008) bipolar patients underperformed in a theory of mind task, which was moderated by sustained attention. ${ }^{31}$ In contrast, two recent studies find evidence for theory of mind impairments in bipolar patients independent of other cognitive dysfunctions. ${ }^{32,33}$

In the process of adaptive social interaction (outcome) knowledge about the self plays an important role, as well as insight, motivation, subjective (cognitive) complaints and salience. Poor insight, impaired awareness of illness and cognitive problems (metacognition), is associated with, and possibly mediated by, cognitive deficits in schizophrenic and bipolar patients, ${ }^{34-37}$ with, possibly, an independent role for emotional processing and psychotic features. ${ }^{38}$ Furthermore, motivational factors and the perception of self-competence may play a mediating role in the relationship between neurocognition, social cognition and functional outcome. ${ }^{39,40}$ Subjective cognitive complaints are associated with cognitive functioning and outcome in our study (Chapter 5), which is also reported in the literature, ${ }^{41-44}$ although not by all. ${ }^{45}$ Finally, aberrant salience and reward processing may play a role in cognitive and psychotic symptoms, especially in schizophrenic patients. ${ }^{46,47}$

\section{Cognition and outcome}

Social cognition, especially theory of mind, is more strongly associated with community functioning than neurocognition in a recent meta-analysis in schizophrenia. ${ }^{48,49}$ Neurocognitive deficits, however, predicted worse functioning in everyday living skills, like academic achievement, community and household activities, work skills, and interpersonal relationships, in bipolar and schizophrenic patients. ${ }^{50-52}$ In general, neurocognition, amongst other fators, is associated with functional outcome in both patient groups, ${ }^{53-55}$ with a possible specific role for speed of processing, ${ }^{12,56-58}$ verbal memory, ${ }^{59-61}$ and sustained attention. ${ }^{59,62,63}$ Finally, observer-rated impaired social competence in bipolar patients worsen the impact of depression and cognitive impairment on social functioning. ${ }^{64}$ 


\section{Cognition as an intermediary phenotype}

Premorbid cognitive deficits and neurodevelopmental antecedents, which may be related to functional outcome ${ }^{65,66}$ are described in high risk groups for psychosis and in persons with subclinical psychotic symptoms, both for bipolar disorder and schizophrenia, but predominantly for the non-affective psychoses. ${ }^{67-71}$ In a prospective study on premorbid cognitive functioning Meyer et al. (2004), however, report executive deficits in $67 \%$ of adolescents that met criteria for bipolar disorder in adulthood. ${ }^{72}$ In a more recent study of MacCabe et al. (2010), both individuals with excellent school performance and those with the poorest grades had an increased risk of later bipolar disorder. ${ }^{73}$ Furthermore, Olvet et al. (2010) describe a bipolar prodrome that is indistinguishable from the schizophrenia prodrome based on clinical and neurocognitive measures. ${ }^{74}$ There are indications for a dose-response relationship between cognitive dysfunction and increasing risk for psychosis, ${ }^{75-77}$ on the one hand, and for a role of premorbid deficits in attention, ${ }^{78}$ speed of processing, ${ }^{79-82}$ executive functions, ${ }^{83,84}$ and facial emotion processing ${ }^{85}$ and social cognition, ${ }^{86}$ on the other hand.

Cognitive alterations in bipolar children and early in the course of bipolar or schizophrenic patients are further evidence for an association between cognitive dysfunction and genetic liability in these disorders. Children and adolescents with bipolar disorder show cognitive deficits comparable to adult bipolar patients in kind and magnitude, ${ }^{87,88}$ that show a developmental delay, ${ }^{89}$ comparable to schizophrenia, ${ }^{68}$ and are persistent into adulthood. ${ }^{90}$ The severity and profile of cognitive dysfunction in first episode schizophrenia and psychotic affective disorders (bipolar with psychosis and psychotic depression) were compared in a study by Hill et al. (2009) revealing no profile differences and intermediate cognitive performance in the affective groups between the schizophrenia and healthy comparison group. ${ }^{91}$ The same picture emerges from a study of Barrett et al. (2009) finding only quantitative differences in cognition between first episode psychotic bipolar and schizophrenic patients, the latter performing worse. ${ }^{22}$ After their first manic episode bipolar I patients showed deficits on tests assessing sustained attention, set shifting, working memory and verbal memory; cognitive dysfunction may thus be present at illness onset. ${ }^{93}$ First episode psychosis in the course of schizophrenia is characterized by cognitive deficits concerning speed of processing, verbal memory and executive functioning most of the time. ${ }^{94-97}$ Becker et al. (2010), however, report no cognitive deterioration during the first psychotic episode compared to premorbid, impaired functioning. ${ }^{98}$ Deterioration in speed of processing in first episode schizophrenia patients was seen in a study by Gonzalez-Blanch and colleagues (2010), despite the fact that $23 \%$ of their sample performed similarly to controls; this subgroup having better social premorbid adjustment and higher premorbid IQ than the cognitive impaired subgroup. ${ }^{99}$ Follow-up studies report mostly a stabile pattern of cognitive deficits over time, indicative of a 'neurodevelopmental arrest'. ${ }^{100-102}$ Recent longitudinal studies in first episode schizophrenic patients with early-onset, however, reveal 
a somewhat different picture with deterioration of some cognitive functions, like speed of processing, over time. ${ }^{103-105}$

In Chapter 3 we describe only small effects for executive control in first-degree relatives of bipolar patients and in Chapter 4 performance of relatives was comparable to that of controls. In their recent meta-analysis of the literature, BalanzaMartinez et al. (2008), address to the point that the evidence is 'sparse and unclear' regarding the cognitive deficits in relatives of bipolar patients, with likely 'less cognitive efficiency' in relatives and verbal memory and working memory as possible 'endophenocognitypes'. ${ }^{106}$ Heterogeneity of findings in relatives is further illustrated by the meta-analyses of Bora and colleagues (2009) finding response inhibition deficit the most prominent endophenotype of bipolar disorder, with verbal memory and sustained attention as potential endophenotypes. ${ }^{3,107}$ Basic information processing, however, may be impaired in first-degree relatives of bipolar patients, given preliminary data on disrupted prepulse inhibition in unaffected siblings, ${ }^{108}$ diminished P50 suppression in relatives of psychotic bipolar patients, ${ }^{109,110}$ increased intrasubject variability in response time and reduced sensitivity during attention in at-risk family members, ${ }^{111,112}$ and impaired psychomotor processing in relatives of bipolar I patients. ${ }^{113}$ In relatives of schizophrenic patients the same picture emerges of deficits with small effect sizes in verbal memory, executive function and attention. ${ }^{12,114-116}$ Early information processing may be disturbed in relatives, ${ }^{117}$ as well as emotion recognition and social cognition. ${ }^{118,119}$ Heydebrand (2006) concludes that the most consistent deficit shown by relatives is impaired performance on 'maintenance plus' frontal lobe tasks requiring increased effort. ${ }^{120}$ This is illustrated by a study of Bove (2008) finding only worse performance in relatives of schizophrenic patients in tasks with greater cognitive processing load. ${ }^{121}$ Higher intra-individual variability and reduced sensitivity in healthy first-degree relatives of schizophrenia patients, as reported by Hilti et al. (2010), ${ }^{122}$ may be related to different cognitive strategies, used by relatives, affecting the speed-accuracy tradeoff. ${ }^{123}$ Relatives showed considerable variability in speed for different cognitive domains with, for example, impaired performance accuracy, but normal speed on mental flexibility, and, by contrast, normal accuracy, but slowed response time on the attention domain with significant heritability estimates for speed. ${ }^{123,124}$

Finally, measures of attention regulation, (working) memory, and emotion processing, according to Hill et al. (2008), offer potential for shared neurocognitive phenotypes for schizophrenia and bipolar disorder. ${ }^{125}$

\section{Overlap between schizophrenia and bipolar disorder; the role of psychosis}

In Chapter 2 of this thesis we describe only moderate quantitative differences in cognitive functioning between schizophrenia and bipolar patients, with better performance in the bipolar patient group. This finding is replicated in more recent studies and meta-analytical reviews, ${ }^{92,126-130}$ with possibly a distinct pattern of the evolution of neurocognitive deficits in schizophrenia and bipolar disorder, ${ }^{131}$ that fits 
in with current models of the relationship between both disorders. Murray et al. (2004) hypothesize that shared susceptibility genes may predispose individuals to psychosis in general ${ }^{132}$ as illustrated by more recent reviews showing evidence of genetic overlap between schizophrenia and bipolar disorder, ${ }^{133-135}$ with a polygenic dissection of the bipolar phenotype depending on the nature of psychotic symptoms. ${ }^{136}$

The role of psychosis was further explored in Chapter 4 suggesting that a history of psychosis in bipolar patients and the presence of subclinical psychotic symptoms within the group of relatives predicted better cognitive performance in the latter. This is in line with the partially overlapping vulnerability to bipolar disorder and schizophrenia, given the similar psychosis-cognition association in both diseases, hypothesizing a distinction in schizophrenia between good-outcome psychosis without developmental impairment (with positive and affective symptoms) and pooroutcome psychosis with developmental impairment (with negative and cognitive symptoms). ${ }^{137}$ Recent studies show evidence for this distinction, showing a modest association between negative symptoms and disorganization and neurocognition, ${ }^{138-140}$ but a not entirely orthogonal association between positive psychotic symptoms and cognitive functioning. ${ }^{141}$

In their meta-analysis on the role of psychosis on cognition in bipolar disorder, Bora et al. (2010) conclude that a history of psychosis is associated with greater, but modest, severity of cognitive deficits, amongst others in memory and processing speed, and that psychosis in bipolar disorder might reflect partly distinct neurobiological processes, such as more severe brain functional and structural abnormalities. ${ }^{142}$ Thus, psychotic symptoms in all their modalities, positive, negative and disorganised, may play a role in cognitive dysfunction in bipolar patients and may be an expression of a more 'neurodevelopmental' course of the illness, resembling developmental impairment in schizophrenia in an attenuated form.

The 'unifying' role of psychosis across diagnostic boundaries of different DSMIV disorders, like schizophrenia, schizoaffective disorder, bipolar disorder and depression, is illustrated by the study of Weiser et al. (2008), showing a gradient in cognitive performance (worst to best) from patients affected by psychotic illness, followed by individuals affected by nonpsychotic illness, unaffected siblings of patients affected by psychotic illness, and unaffected siblings of patients affected by nonpsychotic illness, concluding that cognitive impairment in psychiatric disorders is familial and cuts across diagnostic entities. ${ }^{143}$ This is further illustrated by recent studies and reviews finding comparable cognitive deficits in schizophrenia and psychotic affective disorders (bipolar and unipolar). ${ }^{144-147}$ Finally, Bora and colleagues (2010) conclude that inclusion of cognitive impairment criteria in DSM-V would not provide a major advancement in discriminating schizophrenia from bipolar disorder and affective psychoses, and they propose the use of cognitive impairment as a specifier or a dimension in a hybrid categorical-dimensional system. ${ }^{148}$ The latter is also propagated by van Os (2009), combining categorical and dimensional representations of psychosis to propose a 'salience dysregulation syndrome' with subcate- 
gories based on symptom dimensions, as depicted in Figure $1 .^{149,150}$ This is in line with recent literature on a dimensional-spectrum model of psychopathology and comorbidity among psychiatric disorders. ${ }^{151,152}$

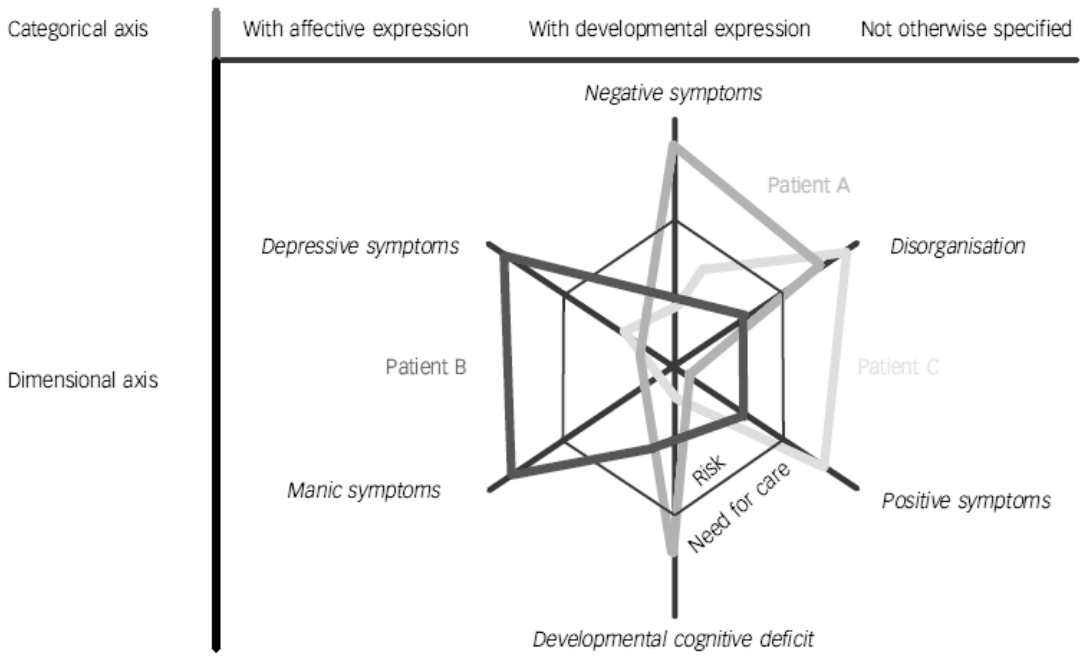

Figure 1. Salience dysregulation syndrome (van Os, 2009)

\section{Neurobiology of cognition in bipolar disorder}

The dimensional conceptualization of psychosis with different clinical phenotypes as a consequence of interactions between (hypothetically) specific genetic influences and environmental factors, makes the search for intermediate phenotypes as well as putative candidate genes worthwhile, trying to explain the pathophysiologic characteristics of bipolar disorder and schizophrenia. ${ }^{117} \mathrm{We}$ will discuss some of these characteristics, going from a macroscopic to a microscopic level.

\section{Electrophysiological intermediate phenotypes}

Information processing deficits underlying cognitive dysfunctions in bipolar and schizophrenia patients can be examined electrophysiologically using event-related potentials (ERPs). ${ }^{153}$ This topic is excellently reviewed by Ivleva and coworkers (2010); ${ }^{117}$ we will refer to their article discussing prepulse inhibition, P50 and P300 abnormalities.

Prepulse inhibition (PPI) measures inhibition of the startle reflex and is used as an index of sensorimotor gating. In bipolar disorder there are limited and controversial data, in contrast to schizophrenia. Most studies suggest a state dependent component in bipolar patients, linked to psychosis, but the study of Giakoumaki et al. 
(2007) reported lower PPI in euthymic bipolar patients and their unaffected relatives. ${ }^{108}$ In schizophrenia, PPI deficits are widely reported in patients and relatives, heritable, and associated with polymorphisms in NRG1, COMT and PRODH (genes discussed later on), suggesting a regulation by dopaminergic neurotransmission in the prefrontal cortex. ${ }^{117}$ Finally, in healthy males, reduced PPI was associated with NRG1 various polymorphisms. ${ }^{154}$

P50 event-related potential (P50) measures the largest EEG wave within $50 \mathrm{~ms}$ after two auditory clicks, with inhibition/suppression of the second P50 wave in healthy controls, reflecting normal sensory gating. Diminished suppression of P50 auditory stimuli has been reported in bipolar patients with a history of psychosis ${ }^{155,156}$ and in unaffected relatives of psychotic bipolar patients. ${ }^{109,110}$ A recent study by Lijffijt et al. (2010) reported impaired sensory gating in bipolar I disorder, suggesting impaired filtering at both pre-attentive and early attentive levels. ${ }^{157}$ In schizophrenia, P50 suppression is disturbed in patients and their relatives, ${ }^{158}$ heritable, possibly associated with polymorphisms at chromosomes $15 \mathrm{q}$ (alpha-7 nicotine receptor) and $22 \mathrm{q}$, and related to negative symptoms, disorganisation, and poor attention. ${ }^{117}$

P300 event-related potential (P300) is a positive EEG wave, occurring $300 \mathrm{~ms}$ after an infrequent or unexpected sensory stimulus, and is vulnerable to motivational factors and attentional capacity. Studies in bipolar patients consistently report prolonged P300 latency, but less consistently decreased P300 amplitude. ${ }^{159-161}$ The same picture emerges for unaffected relatives of bipolar patients. ${ }^{162-164}$ Ivleva and colleagues (2010) conclude that P300 in schizophrenia is a promising intermediate phenotype, that is consistently impaired in patients and their relatives with moderate heritability, possibly associated with polymorphisms in COMT and NRG1, and related to the presence of negative and positive symptoms and deficits in attention and working memory. ${ }^{117}$ Furthermore, clozapine may modulate P300 response in schizophrenia patients ${ }^{165}$ and treatment with quetiapine may normalize P300 amplitude and latency. ${ }^{166}$

Finally, Mismatch negativity (MMN), is an early evoked potential, elicited approximately 150-200 ms after the onset of physically deviant auditory stimuli in identical and repeated stimulus sequences, even elicited when attention is directed away from the auditory input, and thus reflecting preattentive information processing. ${ }^{167}$ This automatic mismatch process may have an important role in initiating an involuntary switching of attention to a stimulus outside the focus of attention. Takei et al. (2010) report preliminary evidence for delayed peak latency of MMN, measuring magnetic fields (MEG), with normal early sensory processing (P1/P50). ${ }^{167}$ Leitman and colleagues (2010), studied the relationship between the 'preattentive' MMN and the higher order, 'attentive' P300 in schizophrenia, finding impaired mismatch negativity contributing to impaired higher order processing in a hierarchical model of cognitive functioning. ${ }^{168}$ 


\section{Structural and functional imaging intermediate phenotypes}

Imaging studies in bipolar disorder have highly heterogeneous methodology and clinical populations, with small scale, low-powered, cross-sectional designs, inadequately controlling for confounding variables such as age, sex, disease characteristics, cognitive task demands and medication. ${ }^{169}$ Therefore, it is still unclear whether the reported structural and functional changes reflect abnormal development, the disease process or medication exposure, needing longitudinal designs in large homogeneous groups of patients and unaffected relatives to answer these questions. ${ }^{170}$ Furthermore, the large number of studies with statistical significant results suggests strong biases in the literature. ${ }^{171}$ Nevertheless, some of the relevant findings will be discussed here.

\section{Structural abnormalities}

Recent reviews on the structural neuroimaging (sMRI) of bipolar disorder reveal the picture of preservation of total cerebral volume with regional gray and white matter structural changes in prefrontal areas, striatum, amygdala and anterior cingulate cortex (ACC), amongst other brain regions. ${ }^{170,172-174}$ Bora et al. (2010) review the gray matter abnormalities in bipolar patients finding the most robust reductions in left rostral ACC and right fronto-insular cortex, anterior limbic regions supposed to be related to executive control and emotional processing, with an impact of clinical factors such as illness duration and lithium treatment. ${ }^{175}$ Preliminary evidence indicates progressive neurostructural changes in anterior limbic structures in patients with bipolar disorder. ${ }^{176}$ White matter abnormalities, especially deep white matter lesions in tracts connecting prefrontal regions and subcortical gray matter structures, ${ }^{177}$ may play a role too in the neurobiology of bipolar disorder, as reviewed by Mahon et al. (2010). ${ }^{178}$ These structural abnormalities in bipolar disorder may overlap substantially with those found in schizophrenia, ${ }^{179-182}$ especially in the psychotic bipolar subtype, ${ }^{117,183}$ with both similarities and differences in structural brain abnormalities. ${ }^{184,185}$

Premorbid structural abnormalities in ACC and adjacent paracingulate cortex are described in bipolar patients, with reduced cortical folding patterns indicating aberrant pre-or perinatal developmental processes. ${ }^{186}$ Furthermore, structural MRI studies in people at risk for psychosis show decreased prefrontal, cingulate, insular and cerebellar gray matter volume, amongst others. ${ }^{187-189}$

First-episode patients with bipolar disorder show already structural changes, ${ }^{190,191}$ for example in amygdala and ACC, ${ }^{192-194}$ with different patterns of changes in brain morphology over the time course of the disease. This is illustrated by studies in children and adolescents with bipolar disorder, showing smaller amygdala volumes in pediatric samples compared to adult patients, ${ }^{195}$ larger volumes of nucleus accumbens only in a prepubertal group, ${ }^{196}$ and the negative effect of life events on the volume of amygdala and nucleus accumbens in children with bipolar disorder. ${ }^{197}$ 
Finally, structural abnormalities in first-degree relatives of bipolar patients are not explored or absent, ${ }^{198,199}$ but may be present in relatives of psychotic bipolar patients, given the reduced inferior frontal gyrus volume in unaffected siblings of schizophrenia patients in the study by Harms and colleagues $(2010)^{200}$ and the reductions in white matter integrity in unaffected relatives at high risk of bipolar disorder. ${ }^{201}$

\section{Functional abnormalities}

Functional MRI (fMRI), PET/SPECT and DTI (diffusion tensor imaging) are ways to evaluate the functional organisation and activation of the brain in rest and during task performance, using blood oxygen level (BOLD fMRI), cerebral bloodflow (PET), or diffusion of water to measure white matter integrity (fractional anisotropy or FA in DTI).

The functional neuroanatomy of bipolar disorder (fMRI studies), reviewed by Cerullo et al. (2009), Chen and co-workers (2011) and Houenou et al. (2011), shows altered brain activation in cortico-limbic pathways, with overactivation of amygdala, striatum and thalamus as most consistent findings and, less consistently, increased activation in prefrontal cortical areas. ${ }^{202-204}$ Cerebral metabolic rate and blood flow, used as surrogate measures of neuronal activity, are increased in frontal areas in bipolar depression, but decreased in mania, reflecting its loss of modulatory control over limbic structures, such as dorsal cingulate cortex, striatum and nucleus accumbens, all showing an increase in metabolism in mania in PET and SPECT studies. ${ }^{205}$ Diffusion imaging studies (DTI), although preliminary, reveal reduced fractional anisotropy (FA) indicating white matter microstructural abnormalities and reduced white matter integrity in intra- and inter-hemisperic white matter tracts, mainly impairing fronto-limbic and callosal connectivity. ${ }^{206-208}$

In their review of the literature on studies using these techniques in bipolar patients, Mahon et al. (2010), conclude that abnormalities converge in prefrontal white matter and tracts that connect these regions with subcortical structures, supporting a model of bipolar disorder that involves disconnectivity in regions implicated in emotional processing and executive control. ${ }^{178}$

Dysfunction in emotional processing in bipolar disorder has been proposed to be related to an imbalance between an 'overactive' ventral-limbic network, including amygdala, insula, striatum, subgenual cingulate cortex, ventrolateral prefrontal cortex and orbitofrontal cortex, and a relative 'hypoactive' dorsal network, including dorsolateral prefrontal cortex, dorsal ACC and posterior cingulate cortex. ${ }^{209}$ This is illustrated in a study of Kim et al. (2009), showing reduced activation in mirror neuron system during a social cognition task in euthymic bipolar patients; patients having difficulties recruiting brain regions for the utilization of emotional cues. ${ }^{210} \mathrm{~A}$ recent PET study shows an association between resting prefrontal hypometabolism and paralimbic hypermetabolism and verbal memory deficits in euthmic bipolar patients. ${ }^{211}$ Finally, the same pattern of resting-state corticolimbic dysregulation was associated with sustained attention deficits. ${ }^{212,213}$ 
There is some overlap in functional imaging studies in schizophrenia and bipolar patients, as illustrated by the same activation deficits in the left superior frontal region during a Theory of Mind task ${ }^{214}$ and reduced FA, indicating white matter abnormalities, in the anterior limb of the internal capsule, anterior thalamic radiation and uncinate fasciculus in both patient groups using DTI. ${ }^{215}$ Other studies, however, show different activation patterns in bipolar and schizophrenia patients during cognitive tasks. ${ }^{216-218}$

Premorbid abnormalities in people at risk for psychosis show reduced brain activation in prefrontal cortex with less prefrontal-amygdala coupling and differences in white matter integrity, with lower FA values in frontal lobes, ${ }^{187,219,220}$ which are possibly associated with cognitive functioning and in line with the disconnectivity hypothesis of bipolar disorder and schizophrenia. ${ }^{221,222}$ Furthermore, children at risk for bipolar disorder show decreased FA in superior frontal tracts. ${ }^{223}$

DTI studies in first-episode psychosis and mania show white matter abnormalities in inferior longitudinal fasciculus and anterior thalamic radiation, associated with executive functioning. ${ }^{224-226}$ The same applies to bipolar children and adolescents, showing white matter abnormalities in different tracts, ${ }^{223}$ associated with cognitive functioning, ${ }^{227}$ a pattern of reduced activation of prefrontal cortex and greater amygdala activation, ${ }^{228}$ and altered neural function during emotional and cognitive processing. ${ }^{229-231}$

In unaffected siblings of bipolar patients reduced fractional anisotropy, indicating disturbed integrity within intra -and interhemispheric tracts, may be present, ${ }^{232}$ possibly associated with abnormal actvation patterns in emotional and cognitive processing. ${ }^{233-236}$

\section{Medication effects}

As mentioned earlier, variables such as age, ${ }^{195} \operatorname{sex}^{193,237}$ and disease characteristics like rapid cycling ${ }^{238}$ and number of manic episodes, ${ }^{239}$ may influence structural and functional imaging findings, as well as use of psychotropic medications. ${ }^{238}$ In their review of the literature on medication effects in neuroimaging studies of bipolar disorder, Phillips et al. (2008), conclude that there are either no or ameliorative effects of psychotropic medications, with the association between lithium and increased gray matter volume in key neural regions, such as ACC, amygdala and hippocampus, as most consistent finding. ${ }^{240}$ Furthermore, medicated more than unmedicated bipolar patients demonstrate levels of prefrontal cortical activity during cognitive control that are similar to those observed in healthy controls. ${ }^{240}$

Lithium may have neurotrophic effects as shown in more recent studies by increased amygdala volume in lithium-treated bipolar patients ${ }^{241,242}$ and lithiuminduced increases in gray matter volume of ACC and insula, amongst others. ${ }^{243,244}$ However, the possibility of an osmotic effect of lithium cannot be ruled out entirely in these studies. ${ }^{245}$ 
The evidence for the effects of anticonvulsants is less clear, ${ }^{240,244}$ although lamotrigine has been shown to normalize abnormal activation patterns in bipolar patients. ${ }^{246,247}$

Antipsychotics, finally, are possibly associated with decreased brain volume in schizophrenia patients, ${ }^{248-250}$ with regional specific effects, ${ }^{251}$ for instance increased volume of basal ganglia by the use of typical antipsychotic drugs. ${ }^{252}$ In bipolar patients, antipsychotic medication is possibly associated with larger white matter volumes in temporal lobes. ${ }^{253}$ Finally, atypical antipsychotics may change and normalize abnormal activation patterns during cognitive function, at least in schizophrenia patients. $^{254-256}$

\section{Genetic neuroimaging}

Structural and functional neuroimaging abnormalities in bipolar and schizophrenia patients largely meet the criteria for endophenotypes in psychotic disorders. ${ }^{257-260}$ Neuroimaging techniques can provide a sensitive means to bridge the neurobiology of genes and behaviour, for example cognitive functioning, using neuroimaginggenetic paradigms. ${ }^{261-263}$ This is illustrated by the study of Roffman and colleagues (2006), describing how this paradigm helped to clarify the contribution of candidate genes, such as COMT, DISC1 and BDNF, to cognitive deficits in schizophrenia. ${ }^{261}$ Furthermore, this line of investigation can be useful to validate risk genes for schizophrenia and bipolar disorder in healthy controls carrying risk genotypes, via functional magnetic resonance imaging, ${ }^{264}$ and testing hypotheses on the role of underlying neurobiological mechanisms, such as the role of striatal dopaminergic activity, using fMRI, in carriers of a common polymorphism in the DAT1 gene in the modulation of cognitive flexibility. ${ }^{265}$ Finally, this integrative approach can possibly provide an accurate algorithm for classification of psychiatric diseases, integrating neuroimaging data associated with multiple symptom-related neural processes in a dimensional model of disease. ${ }^{266,267}$

\section{Neurocircuitry and neurotransmitter systems in bipolar disorder}

\section{Neurocircuitry}

In general, the brain networks that underlie normal and adaptive behaviors on the interface of motivation, emotion and cognition, are important to understand the pathophysiology of bipolar disorder. Key structures in this neurocircuitry include the prefrontal cortex, the striatum, the hippocampus, the (extended) amygdala, and the ascending monoaminergic modulatory transmitter systems, particularly the midbrain dopamine system. ${ }^{268}$ Recent reviews emphasize the role of these networks in mood disorders, ${ }^{269,270}$ reward processing, ${ }^{271}$ executive control, ${ }^{272}$ and social judgement. ${ }^{273}$ The same networks likely play a role in schizophrenia. ${ }^{274,275}$

A network model of bipolar disorder emerges characterized by a disbalance between subcortical (striatal-thalamic) and prefrontal networks and associated limbic modulating regions (amygdala, cerebellum), with diminished prefrontal modulation 
and striatal hyperactivity. ${ }^{172,276,277}$ The latter, striatal hyperactivity, is considered to play a central role in the pathophysiology of bipolar disorder in the cortico-basal ganglia networks model of Marchand et al. (2010), integrating neuroimaging and neurochemistry studies in bipolar patients. ${ }^{277}$ The striatum is the primary input nucleus for the cortico-basal ganglia circuitry, as shown in this figure (Figure 2.) from their article, which will be briefly reviewed here.

The striatum receives extensive excitatory, glutamatergic input from cortex, thalamus, amygdala and hippocampus; striatal output is inhibitory by GABAergic interneurons, so called medium spiny neurons (MSNs). MSNs priming for firing needs sustained cortical input and their output is controlled by other GABA neurons, fastspiking striatal interneurons (FS), that function as input detectors and are sensitive to synchronized inputs from the cortex.

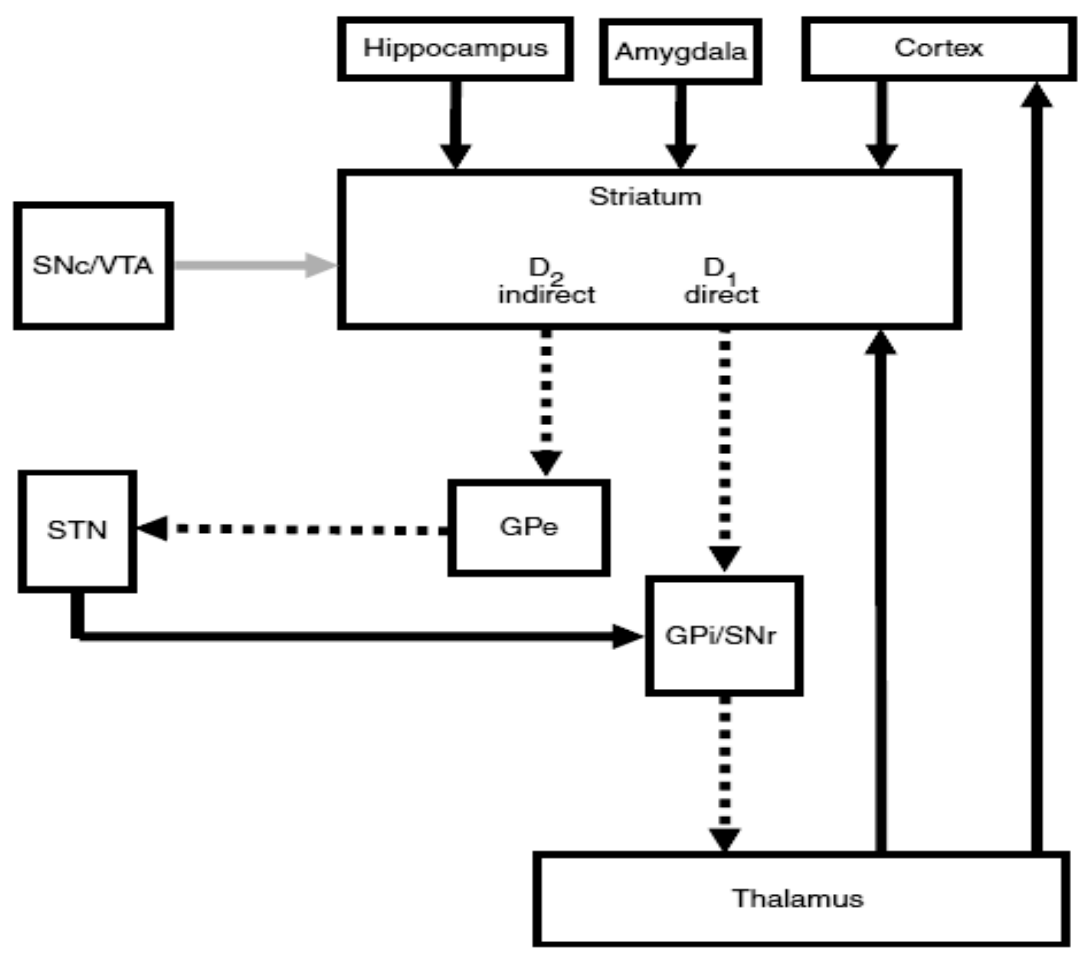

Figure 2. Simplified schematic of cortico-basal ganglia circuitry (Marchand et al., 2010) Direct pathway = striatum-GPi / SNr; indirect pathway = striatum-GPe-STN-GPi / SNr.

Solid arrows = excitatory pathways; dotted arrows = inhibitory pathways; gray arrow = dopamine. SNc / VTA = substantia nigra pars compacta / ventral tegmental area; STN = subthalamic nucleus; GPe = globus pallidus, external segment; GPi / SNr = globus pallidus, internal segment / substantia nigra, pars reticularis

Glutamate and GABA are fast-acting neurotransmitters for the striatum, with serotonin, acetylcholine and dopamine as primary modulatory neurotransmitters. Large 
striatal acetylcholine interneurons have spontaneous firing activity, referred to as tonically active neurons (TANs), and control MSNs and FS interneurons increasing GABAergic output. TANs modulate striatal information processing in this way and may play a role in reward learning. Serotonin modulates this network too, by exciting both FS and cholinergic interneurons, and modulating mesolimbic and mesocortical dopamine neurons. Dopamine (DA), finally, modulates striatal function by projections from the ventral tegmental area (VTA) and the substantia nigra (SN). Dopaminergic fibers terminate on the MSNs, thus modulating cortical input into the striatum. The D1 family of striatal DA receptors (D1 and D5), which stimulates adenylate cyclase activity, resulting in enhanced corticostriatal glutamatergic excitation, is expressed in the direct pathway in phasic DA signalling. In contrast, the D2 receptor family (D2, D3, D4) inhibits adenylate cyclase activity and attenuates glutamatergic activity, and expresses itself in the indirect pathway. MSNs predominately express either D1 or D2 receptors and in this two-pathway model phasic DA enhances direct pathway activity while at the same time decreasing indirect activity, with an increase of direct-pathway excitation and decrease of indirect-pathway inhibition. Phasic striatal DA release is modulated by GABAergic inputs and tonic DA release by glutamate fibres. Finally, phasic DA release may serve as rewardprediction error signal in response to novel stimuli, facilitating long-term changes in synaptic efficacy (long-term potentiation) in the striatum. Activation of the direct pathway inhibits the output nucleus (GPi/SNr in the figure) allowing greater cortical excitation, whereas the indirect pathway has a net excitatory effect on the output nucleus, increasing inhibition of the thalamus with subsequent decreased excitatory modulation of the cortex. This model is based on the hypothesis that the striatum may be generally hyperactive in bipolar disorder. ${ }^{277}$

\section{Neurotransmitter systems}

Aberrant excitatory glutamatergic neurotransmission may play a role in the neurobiology of mood disorders, ${ }^{278,279}$ as shown by increased glutamate levels in the basal ganglia of children with bipolar disorder, ${ }^{280}$ elevated glutamine/glutamate ratio in manic patients, ${ }^{281,282}$ increased glutamate neurotransmission in ACC in bipolar disorder, ${ }^{283}$ and altered glutamate receptor expression in GABA interneurons. ${ }^{284,285}$ Corticostriatal glutamate projections likely modulate tonic striatal DA release and therefore, abnormal glutamatergic neurotransmission has an impact on striatal function. $G A B A$, the main inhibitory neurotransmitter, most likely plays a role in the pathophysiology of bipolar disorder, given the GABAergic striatal projection neurons and the possible role of GABAergic genes in the aetiology of bipolar disorder and schizophrenia. ${ }^{286,287}$ Most studies find regional GABA abnormalities in bipolar patients, ${ }^{288-290}$ in contrast to a study looking at global brain GABA levels, finding no differences compared to controls. ${ }^{291}$ The role of acetylcholine in mood disorders remains incompletely characterized, given its modulatory role in the model of Marchand et al. (2010), but reduced type 2 acetylcholine muscarinic receptor binding possibly contributes to mood dysregulation in bipolar disorder. ${ }^{292}$ There is some 
evidence of abnormal serotonin transporter binding in bipolar patients in midbrain areas, ${ }^{293,294}$ likely to be relevant given the widespread modulatory effects of serotonin. Finally, the dopaminergic system likely plays a central role in the pathophysiology of bipolar disorder as reviewed by Cousins et al. (2009) 295 and Berk and colleagues (2007). ${ }^{296}$ This is in line with the model of striatal hyperactivity discussed earlier, ${ }^{277}$ and the multiple interactions of dopamine with other neurotransmitters, such as glutamate, ${ }^{297}$ serotonin $^{298}$ and acetylcholine. ${ }^{299}$ Dopamine also plays a central role in the neurobiology of schizophrenia, as reviewed by Howes et al. (2009); increased presynaptic striatal dopaminergic function is supposed to be the final common pathway, explaining frontotemporal abnormalities, cognitive impairments and aberrant salience and psychosis. ${ }^{300}$ Glutamatergic dysregulation, however, is critical too, given its excitatory and excitotoxic effects and key role in synaptic plasticity and cortical development ${ }^{301}$ and the literature on aberrant glutamatergic neurotransmission in schizophrenia patients. ${ }^{285,302-306}$ In general, the glutamatergic hypothesis states that hypofunction of the NMDA-receptor in cortico-striatal projections reduces the excitation of fast-spiking GABAergic interneurons, which in turn results in disinhibition of (cortical) pyramidal cells and an increase in dopaminergic input, because of the disinhibition of the ventral tegmental area. ${ }^{307,308}$ This cortical disinhibition, due to alterations in GABA interneurons essential for synchronized cortical network activation, ${ }^{309-311}$ decreases the signal-to-noise ratio and thus may give rise to cognitive dysfunctioning.

\section{Effects on cognitive functioning}

The interaction of dopamine and glutamate receptor signalling at critical nodes and networks in areas like the prefrontal cortex is essential for cognitive functioning and adaptation. ${ }^{312,313}$ Dopamine is a key regulator of cognitive functions, such as attention, and contributes to behavioural adaptation and anticipatory processes necessary for voluntary action. ${ }^{314,315}$ According to the 'dual-state' model of prefrontal cortex dopamine function, the balance between D1- and D2- class receptor functioning is important for normal cognitive functioning; imbalanced D1:D2 receptor activation possibly leading to cognitive, positive and negative symptoms in schizophrenia (and bipolar disorder). ${ }^{316}$ There may exist an optimum dopamine level for different cognitive functions, implicating the importance of baseline levels of dopamine, where both too little and too much dopamine may impair performance, evidencing an inverted U-model of dopamine actions on cognitive functioning. ${ }^{317}$ Striatal dopaminergic activity, particularly via D2 receptors, may be important for response inhibition, temporal organization and motor performance, whereas cortical dopaminergic transmission via D1 receptors may be important for maintaining and representing on-going information and behaviour. ${ }^{318}$ The regulation of the balance of D1versus D2-mediated cellular and synaptic effects influences adaptation to different cognitive requirements, favoring either working memory or cognitive flexibility. This adaptive process may be disturbed in psychosis, characterized by predominant D2 effects, resulting in an inability to hold and manipulate information, disorgan- 
ized thinking, and positive symptoms. A hypo-dopaminergic state in the prefrontal cortex, on the other hand, may produce an upregulation of D1 receptor activity, interfering with goal-directed behaviour, emotional processing, possibly resulting in negative symptoms. ${ }^{316}$ Finally, dopaminergic dysfunction influences aberrant salience coding of reward-predicting stimuli. ${ }^{46,47}$ Glutamatergic hypofunction, at least in schizophrenia, interferes with normal cognitive functioning, ${ }^{319-322}$ while activation of metabotropic glutamate receptors by allosteric modulators may improve cognitive function. ${ }^{323,324}$ Other neurotransmitters systems, such as the noradrenergic, ${ }^{325,326}$ cholinergic, ${ }^{327,328}$ GABAergic, ${ }^{329-332}$ and serotonergic system ${ }^{333-336}$ are associated too with cognitive functioning.

\section{Microcircuitry}

The described interactions between different neurotransmitter systems, such as dopamine, glutamate and GABA, emerges into an integrative microcircuitry model describing integration of synaptic activity, with a central role for GABAergic interneurons ${ }^{337,338}$ with altered glutamate NMDA-receptor functioning and dysregulation of dopaminergic modulation, ${ }^{339}$ possibly explaining dysfunctional synaptic plasticity underlying cognitive deficits in bipolar disorder and schizophrenia. ${ }^{340}$ Glial cells play an important role as regulators of synaptic connectivity and plasticity, modulating the properties of synapses by releasing neurologically active substances such as D-serine, expressing metabotropic glutamate receptors, and regulating glutamate reuptake, amongst others. ${ }^{31}$ The structural and functional association of perisynaptic glia with the synapse leading to the concept of 'tripartite synapse' particularly playing a role in fast synaptic transmission and synchronisation of neural activity, mediated by glutamate and GABA. ${ }^{341-343}$ Dysfunctions in these synaptic processes are described in bipolar and schizophrenia patients, ${ }^{344-347}$ as well as extracellular matrix-glial abnormalities. ${ }^{348}$

\section{Molecular biology of bipolar disorder}

Abnormalities in intracellular signal transduction pathways, linked to neurotransmitters, play a role in the pathophysiology of bipolar disorder and are discussed here, as well as other abnormalities in neuronal and glial cells, like mitochondrial dysfunction.

\section{Magnetic resonance spectroscopy (MRS)}

MRS allows in vivo study of brain chemistry in bipolar patients with proton $(\mathrm{H})$ MRS measuring chemical concentrations of substances such as $\mathrm{N}$-acetyl aspartate (NAA), a marker of neuronal integrity, and phosphorous (P) MRS measuring products of cellular metabolism like ATP. This topic is recently reviewed by Lyoo et al. in the textbook on bipolar disorder by Yatham et al. (2010), ${ }^{349}$ which is referred to here. Decreased levels of NAA, particularly in dorsolateral prefrontal cortex, is one of the most consistent findings in bipolar disorder, in this regard, suggesting decreased 
neuronal viability and dysfunction of mitochondria. Elevated choline concentrations in the striatum, a marker of cell membrane integrity, may be indicative for impaired phospholipid metabolism in bipolar patients, and elevated myo-inositol and glutamine/glutamate ratio possibly reflect disturbed neuronal-glial interactions in bipolar patients. Finally, phosphorous (P) MRS reveales alterations in membrane phospholipid metabolism, reflecting abnormalities in signal transduction pathways and mitochondrial functioning, ${ }^{349}$ with inconsistent findings possibly due to sample heterogeneity, different medications and mood states. ${ }^{172}$

\section{Signal transduction pathways}

Postmortem brain studies suggest that bipolar disorder is associated with neuronal and glial cell loss and/or alterations in specific areas, for instance in hippocampal interneurons, ${ }^{337}$ supporting the hypothesis of altered neuroplasticity in bipolar disorder. ${ }^{350}$ Signal transduction pathways or cellular plasticity cascades, for example the Wnt cascade, ${ }^{351}$ are molecular circuits, which detect, amplify and integrate diverse external stimuli to generate cellular response, controlling synaptic plasticity and cellular resilience, and thus allowing adaptations to alterations in internal and external environments. As reviewed by Schloesser et al. (2008) $)^{350}$ and Andreazza and colleagues (2010), ${ }^{349}$ some of the most relevant findings will be discussed here.

Extracellular signal-related kinases (ERKs) play an important role in synaptic plasticity and memory formation; ${ }^{352}$ reduced levels of proteins of this cascade are found in postmortem brains of bipolar and schizophrenia patients. ${ }^{353}$ Increased Gprotein coupled monoaminergic receptors play a critical role in bipolar disorder, as well as (reduced) tyrosine kinase receptors (TRKs), transmembrane proteins, that function as growth factor receptors such as brain-derived neurotrophic factor (BDNF), essential for cell growth and differentiation. After receptor binding, second messengers are activated, such as cAMP, which modulate the phosphorylation state of intracellular proteins regulating neuronal function. Altered activity in these second messenger systems in bipolar disorder concerns adenyl cyclase (AC), protein kinase A (PKA), phosphoinositide (PI), calcium, and glycogen synthase kinase-3 (GSK3). ${ }^{350}$ The latter, for instance, is increased in bipolar mania, inhibited by lithium, involved in dopaminergic neurotransmission, and possibly a central modulator of mood. ${ }^{354-356}$ The last step in signal transduction is the activation of transcription factors by second messengers. Transcription factors, such as CREB, modulate gene expression by binding to specific DNA sequences, and are, in their turn, modulated by mood stabilizers like lithium. ${ }^{357}$ The role of medication on various of these mechanisms will be discussed below.

\section{Mitochondrial dysfunction and oxidative stress}

Mitochondria play a central role in the process of oxidative phosphorylation, by converting the energy stored in sugars to high-energy phosphates, like ATP. Furthermore, they play a key role in calcium homeostasis, preventing high intracellular 
calcium levels and thereby oxidative stress, excitotoxicity and apoptosis. Thus playing a pivotal role in cellular resilience.

A disturbance of mitochondrial energy metabolism may be central to the pathophysiology of bipolar disorder and schizophrenia, as reviewed by Clay et al. (2010). ${ }^{358}$ Impairment of mitochondrial function in the prefrontal cortex of bipolar patients, ${ }^{359}$ morphological changes of mitochondria, ${ }^{360}$ and elevated cerebrospinal fluid lactate concentrations in bipolar and schizophrenia patients, indicating increased extra-mitochondrial and anaerobic glucose metabolism, ${ }^{361}$ support this hypothesis.

Reactive oxygen species (ROS) are oxygen-containing free radicals created as byproducts of electron transport, which are produced in larger amounts in case of mitochondrial dysfunction. ROS may damage proteins, lipids and nucleic acids, particularly mitochondrial DNA is vulnerable to oxidative stress. Oxidative stress markers are increased in bipolar disorder and schizophrenia ${ }^{362}$ with impairment of oxidative balance and compensatorily changed antioxidant levels. ${ }^{363,364}$

Oxidative stress is a final common pathway, linked to a variety of pathophysiological processes, such as DNA damage, endothelial dysfunction, telomere shortening, mitochondrial dysfunction, hypoactive NMDA receptors and impairment of fast-spiking GABAergic interneurons. ${ }^{349,365}$

An interesting hypothetical model, proposed by Kato (2008) and shown in the figure (Figure 3.), integrates the above mentioned molecular biological alterations in bipolar disorder, suggesting impairment of cellular resilience and progressive dysfunction of 'mood-stabilizing neurons', particularly GABAergic interneurons. ${ }^{366}$

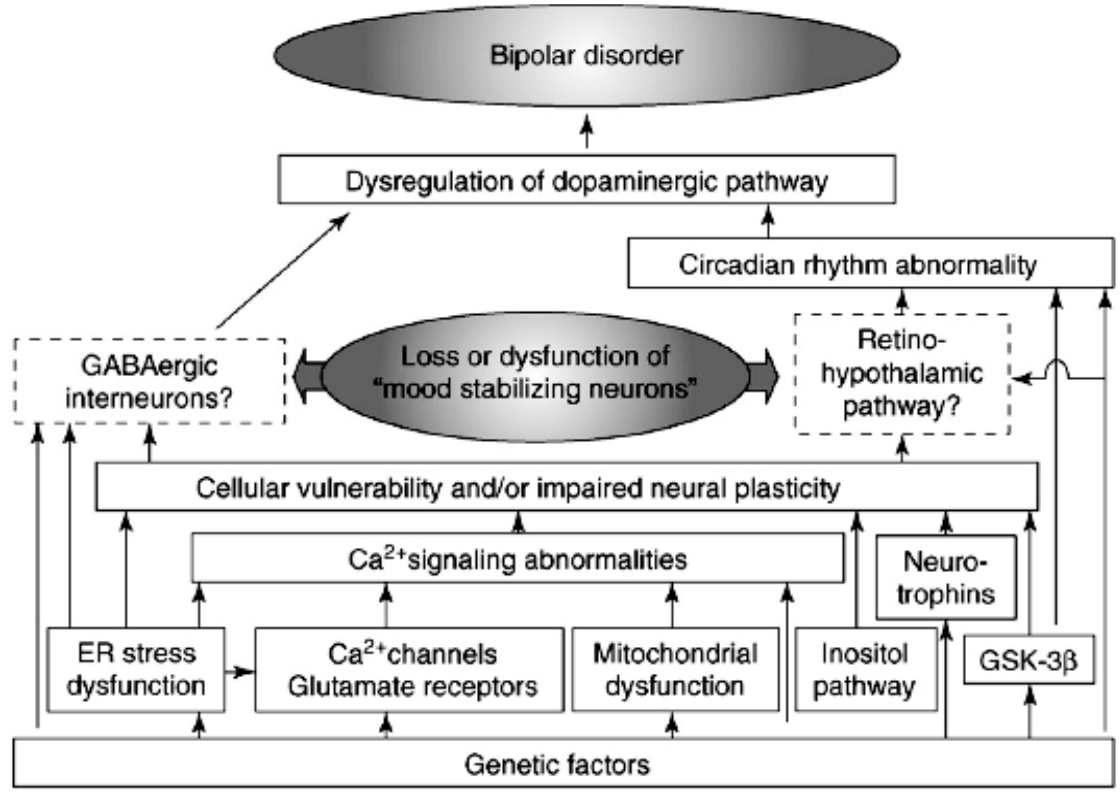

Figure 3. Pathophysiological mechanisms of bipolar disorder (Kato, 2008) 


\section{Epigenetics and molecular genetics of bipolar disorder}

The various pathophysiological changes, mentioned above, possibly play a role in the emotional and cognitive dysregulation in (psychotic) bipolar and schizophrenia patients, and can be seen as intermediate phenotypes. The major appeal of these 'endophenotypes' stems from the presumption that they are proximal and thus more tightly linked to genotypes. The usefulness of these endophenotypes is still under debate, given the fact that some of them are broad constructs, such as neurocognitive deficits, requiring operational definition, ${ }^{367}$ and the fact that endophenotype measures do not show simpler genetic architecture and/or larger genetic effect sizes than other phenotypes. ${ }^{368}$ Nevertheless, this hypothesis-driven approach of translational cascades linking genetic variation to behaviour is worthwhile. ${ }^{369}$ Candidate brain function endophenotypes in bipolar disorder, amongst others, include attention deficits, circadian rhythm instability and dysmodulation of motivation and reward, according to Hasler et al. (2006), with reduced anterior cingulated volume and white matter abnormalities as candidate brain structure endophenotypes. ${ }^{370}$ In more recent studies, processing speed and sustained attention, amongst others, are identified as strong intermediate cognitive phenotypes, ${ }^{371-373}$ with a possible common cellular phenotype for schizophrenia and bipolar disorder, in which dysfunctional GABAergic interneurons contribute to abnormal information processing. ${ }^{374}$

\section{Epigenetics}

The candidate-gene approach and genomewide association studies (GWAS), discussed below, have revealed small effect sizes awaiting replication, which makes it unlikely that common genetic variants account for most of the variance in risk for psychosis. ${ }^{375,376}$ Epigenetics refers to the study of reversible, mitotically heritable changes in gene expression, occurring without a change in DNA sequence, and mediated principally through alterations in DNA methylation and chromatine structure. $^{377}$ The lasting effects of environmental exposures on gene expression, such as the programming of stress responses through DNA methylation, is consistent with epigenetic mechanisms in psychiatric diseases. ${ }^{378,379}$ Epigenetic processes play a critical role in normal cell differentiation during embryogenesis, ${ }^{380}$ and dynamic epigenetic changes at key developmental periods can have a lasting influence on brain growth and development, ${ }^{381}$ cognitive functioning ${ }^{382-384}$ and psychotic susceptibility. ${ }^{385,386}$ In this respect, Lahiri et al. (2009) propose a 'Latent Early-life Associated Regulation' (LEARn) model, in which environmental agents epigenetically change gene regulation in a long-term manner, beginning at early developmental stages, but having pathological results later in life, combining genetic and environmental risk factors in an epigenetic pathway. ${ }^{387,388}$ The degree of promoter DNA methylation is inversely correlated with the level of gene expression; the same applies to condensed chromatin, in which DNA and histone proteins are tightly packed. ${ }^{389}$

In their recent review on epigenetic studies of psychosis (Pidsley et al., 2010), the authors conclude that there is evidence for associations between epigenetic modifi- 
cations and psychosis, with the potential of epigenetic alterations to integrate and mediate genetic and environmental factors. ${ }^{390}$ This is illustrated by 1) the possible role of epigenetic mechanisms in phenotypic discordance between monozygotic twins for psychosis, with differences in methylation of specific risk genes, such as DRD2 and COMT; 2) the role of methyl-donors and cofactors in diet, required for epigenetic methylation processes, with abnormal levels of homocysteine and folate in schiziophrenia patients and the interaction between functional polymorphisms in COMT and MTHFR (methylenetetrahydrofolate reductase) genes affecting plasma homocysteine levels in bipolar and schizophrenia patients, and; 3) overexpression of catalytic enzymes involved in DNA methylation in these patients. ${ }^{390}$ Furthermore, DNA methylation differences, using post-mortem brain samples of psychotic patients, have been described for various genes, such as COMT, RELN, and DRD2, amongst others, and preliminary, mixed findings show some evidence of the role of histone modifications in psychosis, especially downregulated GABAergic neurotransmission in GABAergic interneurons. ${ }^{390}$ According to Rutten et al. (2009), the boundary between 'environmental' and 'heritable' risks for schizophrenia and bipolar disorder is far less clear-cut than currently recognized, given the evidence that epigenetic marks may be transmitted meiotically across generations and the fact that the environment can alter epigenetic regulation of gene expression. ${ }^{389}$ In their view, important environmental risk factors for psychosis, such as paternal age, nutritional deficiency, rearing environment and childhood abuse, act, at least in part, via epigenomic alterations. ${ }^{389}$ Finally, HDAC (Histone deacetylases) inhibitors, influencing histone modifications leading to inhibition of chromatin condensation and thus improving gene expression, can ameliorate deficits in synaptic plasticity, cognition and stress-related behaviors. ${ }^{391,392}$ This is illustrated by the effects of valproate, a HDAC inhibitor, in combination with clozapine, increasing DNA demethylation causing a beneficial chromatin remodelling in the epigenetic GABAergic dysfunction typical of schizophrenia and bipolar patients. ${ }^{393}$

\section{Molecular genetics}

The genetic contribution to highly heritable psychiatric disorders, such as bipolar disorder and schizophrenia, is complex, with a small, often nonspecific impact of multiple genes embedded in complex pathophysiological pathways. ${ }^{394,395}$ A polygenic heterogeneity model is proposed by Rucker and McGuffin (2010), whereby phenotypically different syndromes, e.g. schizophrenia and bipolar disorder, result from overlapping liabilities with common variants of small effect and / or rare variants of large effect, which, however, explain only a small proportion of variance. ${ }^{396}$ Genomewide association studies (GWAS) investigate large numbers of common genetic variants in a cross-sectional case-control design, requiring large sample sizes given the number of polymorphisms studied and the small anticipated effect sizes. ${ }^{397,398}$ Replication of findings is a problem, as well as the possibility of 'synthetic associations' caused by rare genetic variants. ${ }^{399}$ Furthermore, copy number variants of DNA sequences (CNVs), spanning multiple genes, are important in explaining genetic 
diversity. ${ }^{400,401}$ The latter applies to schizophrenia in particular, ${ }^{402}$ and not or to a lesser degree to bipolar disorder, ${ }^{403}$ with the possibility that large, rare CNVs may modify the phenotype in those at risk of psychosis. ${ }^{404}$ Furthermore, there is genetic evidence for a selective influence of GABA A receptors on a specific component of the bipolar phenotype, namely schizophrenia-like psychotic symptoms in the case of schizoaffective disorder, bipolar type. ${ }^{405,406}$ This finding is in line with the possible central role of GABAergic neurotransmission in bipolar disorder (model Kato; see Figure 3).

The genetic heterogeneity is illustrated by GWA studies in bipolar patients, revealing a large number of candidate genes, ${ }^{407-409}$ with considerable genetic overlap between bipolar disorder and schizophrenia, ${ }^{117,135,376,410}$ particularly for the best supported loci ZNF804A (schizophrenia) and CACNA1C (bipolar disorder), ${ }^{133,411,412}$ and with neuregulin, dysbindin, DISC1 and neurexin 1 as possible strong candidate genes for psychosis. ${ }^{134}$

GWAS, using a general linear model method to determine the contribution of a given single nucleotide polymorphism (SNP), in combination with a quantitative trait approach, e.g. fMRI measures of cortical efficiency during a cognitive task, can increase statistical power and create a strategy for identification of genes modulating cognitive processes. ${ }^{413}$ This approach, as illustrated by genetic neuroimaging studies discussed earlier, ${ }^{414}$ shows a possible role of polymorphisms in several dopaminergic genes (COMT, DRD2, DRD4, DAT1) and BDNF, amongst others, in the molecular genetics of cognition, ${ }^{415-418}$ with robust heritability of cognitive functions in bipolar patients and their relatives for working memory and sustained attention. ${ }^{117,419}$

The study of the effects of SNPs and CNVs on the intermediate phenotypes relevant for psychosis and cognition is a sensible approach in translational research. ${ }^{420}$ This is illustrated by several studies, showing convergence of multiple genetic variants on stress activated kinase pathways, ${ }^{421}$ neuroplasticity signalling pathways, ${ }^{422}$ prefrontal cortical development, ${ }^{302}$ white matter abnormalities, ${ }^{178}$ mitochondrial dysfunction, ${ }^{358,423}$ oxidative pathways, ${ }^{424}$ calcium homeostasis, ${ }^{425,426}$ and ion channelopathy, ${ }^{427,428}$ amongst others, in bipolar disorder and schizophrenia.

The only SNP that is truly consistently associated with the risk of bipolar disorder, CACNA1Crs1006737, was studied in Chapter 6, yielding a significant association with cognitive functioning in bipolar patients, contingent on expression of disease and possibly becoming only visible over time, given the large extent of variability of cognitive functioning in bipolar patients over time (described in Chapter 5).

\section{Effects of medication}

The volumetric effects of medication on different brain structures were discussed before. At a microscopic level, different mood stabilizers may have differential effects on various cell types; lithium, for instance, increases the proliferation rate and decreases apoptosis of adult gyrus-derived neural precursor cells. ${ }^{429}$ The 'neuroprotective' effects of (atypical) antipsychotics, however, are questioned in a recent editorial 
by Moncrieff. ${ }^{430}$ The effects of mood stabilizers, such as lithium and valproate, on neurotransmitter systems are mainly indirect, readjusting the balance between excitatory and inhibitory activities. ${ }^{431,432}$ Atypical antipsychotics mostly block serotonergic 5-HT2A receptors, in the prefrontal cortex, with higher affinity than subcortical dopaminergic D2 receptors, thus modulating the prefrontal cortex output to basal ganglia circuits and normalizing the striatal input to ventral pallidum and the excitatory thalamic feedback to the cortex. ${ }^{433-435}$ Lithium possibly 'normalizes' the neurochemical abnormalities in bipolar patients, for example by increasing NAA, a marker of neuronal viability. ${ }^{172}$ The effects of medication on cellular plasticity cascades are diverse and complex, but with a net neuroprotective result. ${ }^{350,436,437}$ Inhibition of inositol monophosphatase ${ }^{438,439}$ and glycogen synthase kinase-3 (GSK-3), ${ }^{355,440-442}$ and activation of ERK and Wnt signalling pathways ${ }^{351,434,442}$ may all play a role in this respect, as well as activation of neuroprotective proteins, such as bcl-2. ${ }^{443,444}$ Finally, activation of cAMP response element binding (CREB) together with increased BDNF expression contributes to the neuroprotective effects of mood stabilizers, such as lithium. ${ }^{445-447}$ Lithium and valproate improve mitochondrial functioning, stabilize intracellular calcium dynamics, and reverse oxidative damage by increasing glutathione-S-transferase. ${ }^{358,448,449}$ Antipsychotics, in contrast, do not improve mitochondrial pathology and it is still unclear whether these medications increase or reduce oxidative cell stress, making claims of neuroprotective properties premature. ${ }^{358,433,450,451}$ Valproate is a histone deacetylase inhibitor (HDAC-inhibitor) and facilitates gene expression by increasing acetylation of histones. ${ }^{452,453}$ These epigenetic effects play a role in the neuroprotective effects of valproate, ${ }^{454}$ as well as the synergistic potentiation of valproate-induced GABAergic promoter demethylation by antipsychotics $^{455}$ and lithium ${ }^{456}$ in the treatment of bipolar disorder. In general, drugs may directly alter epigenetic homeostasis, for example valproate, or have indirect effects via signal transduction pathways leading to an alteration of transcription factor activity at gene promoters; a new approach to pharmacology termed 'pharmacoepigenomics'. ${ }^{457}$ Finally, regarding the effects of medication on gene expression, different genes, relevant for the pathophysiology of schizophrenia and bipolar disorder, are influenced by various medications, with differential modulation of postsynaptic genes expression by combinations of medication compared to the effects of these drugs when administered individually. ${ }^{458}$ Upregulation and/or modulation of BDNF expression, for example, by lithium, ${ }^{459-461}$ lamotrigine,${ }^{462,463}$ valproate,${ }^{464,465}$ and antipsychotics, ${ }^{466}$ such as clozapine, ${ }^{467}$ is described in the literature, as well as increased expression of DISC1 and neuregulin by atypical antipsychotics. ${ }^{468,469}$ The COMT $\mathrm{Val}^{108 / 158}$ Met polymorphism may mediate the effects of antipsychotic medication on cognitive functioning, with met allele load predicting cognitive improvement during treatment with antipsychotics in patients with schizophrenia. ${ }^{470-472}$ In Chapter 7, we presented evidence for an interaction between the COMT Val ${ }^{108 / 158} \mathrm{Met}$ rs4680 polymorphism and antipsychotics with a negative effect on cognitive functioning in Val allele carriers with bipolar disorder. A recent genome-wide pharmacogenomic study of neurocognition as an indicator of antipsychotic drug response, describes several 
other polymorphisms, for instance in DRD2 and SLC26A9, mediating the effects of atypical antipsychotics on vigilance, processing speed and working memory. ${ }^{473}$

\section{Environmental factors; allostatic load}

The (partially) overlapping clinical neurocognitive deficits in patients with (psychotic) bipolar disorder and schizophrenia may be caused by largely the same neurobiological mechanisms on the different spatial scales described above. Psychosis being conceptualized as a distinct clinical phenotype with its own neurophysiology and genetic background, with vulnerability to psychosis emerging from the interaction between sets of genes with environmental factors. ${ }^{117}$ In this respect, the debate on the neurodevelopmental versus the neurodegenerative nature of bipolar disorder and neurocognitive impairment is relevant, regarding the differential role of environmental factors. An expert meeting on this topic in 2008 reports inconsistent results pointing to a neurodegenerative model of cognitive impairment, rather than a neurodevelopmental one. ${ }^{474}$ A recent overview, in contrast, points in the direction of a combination of neurodegenerative and neurodevelopmental processes in the causation of cognitive deficits in (subgroups of) bipolar patients, ${ }^{475}$ with the possibility that these deficits are mediated by abnormal maturation of brain structures. ${ }^{476}$ Schizophrenia, and possibly psychosis in general, can be approached as a neurodevelopmental disorder with (early) environmental and epigenetic 'scars' on different pathways and regulatory processes leading to developmental allostasis and compensatory changes, leading to the different trajectories of schizophrenia or bipolar disorder if these changes no longer suffice. ${ }^{477,478}$

The study of gene-environment interactions, with the genetic control of sensitivity to the environment as its subject, is criticized by Zammit et al. (2010) as a method yielding statistical interactions, by testing additive or multiplicative models, between risk factors that are neither necessary nor sufficient to cause the multifactorial complex disorders, such as bipolar disorder or schizophrenia. ${ }^{479}$ Statistical interaction is model dependent and does not have any clear biological meaning, according to these authors, as evidenced by non-replicated GxE findings, such as the interaction between variation in the gene encoding the serotonin transporter and life stress in depression. ${ }^{40,481}$ Van Os et al. (2009), in contrast, plead for an integrative approach combining genome-wide association studies (GWAS), yielding candidate approach GxE analysis, with environmental information leading to gene-environment-wide interaction studies (GEWIS). ${ }^{482,483}$ The higher order genetic and environmental structure of psychopathology seems to be consistent with a 'generalist genes, specialist environments' etiological model, with a coherent underlying genetic structure, opposed to non-shared environmental influences. ${ }^{484,485}$ The relative importance of environmental influences on the developmental processes and pathways leading to different forms of psychopathology is, amongst others, ${ }^{486,487}$ stressed by van Os et al. (2010), regarding psychotic syndromes. ${ }^{488}$ These authors review the evidence linking 
environmental risk factors to psychotic syndrome, assuming that genetic factors operate by making individuals vulnerable for environmental risks, according to the 'stress-vulnerability' model. They describe a role for developmental trauma, amongst others, mediated by common cognitive and biological mechanisms, impacting on risk for psychosis in gene-environment interplay. ${ }^{488}$ Repeated exposure to environmental risk factors early in life may cause sensitization, making individuals more sensitive to the effects of stress ${ }^{489}$ and the recurrence of mood episodes (kindling). ${ }^{490}$ Furthermore, increased reactivity to stress is associated with positive psychotic symptoms ${ }^{491}$ and these non-specific alterations in reactivity can be seen as liability phenotypes, according to van Os et al. (2010). ${ }^{488}$ The balance between the detrimental effects of stress, for example on prefrontal cortex structure and function, ${ }^{492}$ dopaminergic circuits ${ }^{493}$ and cognitive functioning, ${ }^{494-496}$ and resilience to stress, for example by high reward experience, ${ }^{497}$ BDNF genotype, ${ }^{498,499}$ adaptive changes in neurocircuitry ${ }^{500}$ and cognitive reserve, ${ }^{501}$ determines the allostatic load on cognitive functioning. ${ }^{502}$ The allostatic load model proposes a temporal cascade of interacting multisystemic physiological dysregulations, for example neuroendocrine, immune and metabolic, as a reaction to chronic stress, contributing to disease trajectories, such as bipolar disorder with associated high mortality and comorbidity. ${ }^{503,504}$ Some of the most relevant contributing factors to the allostatic load within the scope of cognitive functioning in bipolar patients will be briefly discussed. First of all, episode recurrence may be a moderator of illness progression with higher number of episodes and earlier age of onset leading to accumulating allostatic load. ${ }^{505-507}$ Abnormalities in other mediators of allostasis concern the immune and inflammatory systems, indicating an activated inflammatory response system, with increased levels of cytokines such as Il-1, Il-6, and TNF, amongst others, ${ }^{508}$ linked to cognitive function $^{509}$ and medical comorbidities, including cardiovascular disease and obesity. ${ }^{510}$ Herpes simplex virus type 1 (HSV-1) infection, for example, is associated with cognitive impairment in bipolar disorder, with an additive gene-environmental effect with the COMT $158 \mathrm{Val} / \mathrm{Val}$ genotype. ${ }^{51,512}$ The increased prevalence of autoimmunity in bipolar disorder is illustrated by autoimmune thyroiditis, being a possible endophenotype for this disease. ${ }^{513}$ Metabolic dysregulation is also an important modulator, given the possible effects of cholesterol, ${ }^{514515}$ hypertension and body mass index $\mathrm{x}^{516,517}$ on cognitive functioning, and the negative impact of elevated homocysteine levels ${ }^{518-520}$ and changes in the arachidonic acid cascade, such as omega-3 fatty acid deficiency. ${ }^{521,522}$ Changes in the HPA axis are central in allostatic load, with dysfunctional glucocorticoid receptor signalling ${ }^{523,524}$ and dysregulation of cortisol secretion. ${ }^{525,526}$ Subclinical hypothyroidism, with its possible neurocognitive and metabolic effects, may play a role too. ${ }^{527}$ Medical comorbidity, highly prevalent in bipolar patients ${ }^{528-530}$ and associated with poor outcome and high mortality, ${ }^{531-533}$ concerns cardiovascular disease ${ }^{534,535}$ and risk factors, such as hypertension, diabetes, obesity and dyslipidema, amongst others, associated with increased allostatic load and possible cognitive impairment. ${ }^{536-538}$ Chronic stress, mediated by dysregulation in the HPA axis, is associated with obesity and the metabolic syndrome, ${ }^{539,540}$ which 
in turn is influenced, amongst others, by disruption of the circadian system, ${ }^{541}$ lifestyle features and pharmacotherapy. ${ }^{542,543}$ Somatic side-effects of medications can contribute to the allostatic load in bipolar patients, concerning weight gain and metabolic syndrome, ${ }^{544,545}$ endocrine effects, ${ }^{546,547}$ cardiac side effects, ${ }^{548}$ haematological toxicity, ${ }^{549}$ and neurological complications, ${ }^{550}$ with possibly associated effects on cognitive functioning. In this respect, the anticholinergic burden of medications plays an important role. ${ }^{551}$ The balance between these negative effects of psychopharmaca on allostatic load and their possible 'neuroprotective' effects, determines the net effect of medications on cognitive functioning in bipolar patients. This net effect being possibly neuroprotective for lithium ${ }^{552-555}$ and anticonvulsants, such as valproate ${ }^{556}$ and lamotrigine, ${ }^{557,558}$ with evidence for a detrimental impact of antipsychotics on cognitive functioning in bipolar patients. ${ }^{538}$ Finally, the roles of caffeine, ${ }^{559}$ smoking, ${ }^{560,561}$ alcohol, ${ }^{562,563}$ and drugs of abuse, ${ }^{564}$ with their possible effects on allostatic load and cognitive functioning, have to be taken into account.

\section{Cognition revised; a default mode network model}

\section{Speed and attention as core cognitive deficits}

Cognitive dysfunctioning in bipolar disorder is a relative problem, concerning not all patients all the time. ${ }^{565}$ For example, Martinez-Aran et al. (2000) describe persistent cognitive deficits in approximately one third of their patients ${ }^{566}$ and Thompson et al. (2005) report significant cognitive impairment in 3-42\% of euthymic patients, depending on the cognitive domain ${ }^{567}$ Finally, Reichenberg et al. (2009) found comparable cognitive performance profile patterns in schizophrenia and (psychotic) bipolar disorder, with impairments in memory, executive functions, attention and processing speed, and deficits present in 55-84\% of schizophrenia patients against $36-58 \%$ of bipolar patients. ${ }^{144}$ The latter, the finding of only quantitatively differences in cognitive performance between schizophrenia and bipolar patients, fits with the evidence discussed before and the earlier described dimensional model of psychotic disorders by van Os. ${ }^{150}$

Psychosis, in all its dimensions, is hypothesized to be an 'epiphenomenon' of a more neurodevelopmental trajectory of bipolar disorder, characterized by early neurobiological changes and developmental allostasis, as described above, leading to a more serious clinical expression of the disease, characterized, amongst others, by more cognitive deficits, higher sensitivity to stress, earlier age of onset, larger number of episodes, and longer exposure to antipsychotics. The underlying changes, such as the disbalance between subcortical and prefrontal networks, described in the model of Marchand et al. (2010), ${ }^{277}$ and the dysfunctioning of inhibiting GABAergic interneurons, as hypothesized by Kato (2008), ${ }^{366}$ both leading to cognitive control deficits, ${ }^{568}$ are probably not specific for bipolar disorder, but are thought to play a central role in the etiology of cognitive impairments in bipolar patients. 
Speed of processing and (sustained) attention are considered here to be the 'core deficits' in cognitive dysfunctioning in bipolar disorder, against the background of a hypothesized hierarchical model of cognition with a central role for these functions. As described in Chapter 5, sustained attention showed the largest effect size and smallest variability over time, making it a possible candidate intermediary phenotype ${ }^{371,569}$ with possible differences between schizophrenia and bipolar patients being partly due to compromised visual information processing in the former. ${ }^{570}$ Speed of processing and attention, despite significant changes in mood, showed consistent impairment over time in a recent longitudinal study on neurocognitive performance in bipolar disorder. ${ }^{571}$ Furthermore, impaired processing speed contributed to a range of cognitive dysfunctions in bipolar disorder in a recent study by Antila et al. (2011), ${ }^{572}$ and may be an independent predictor of quality of life in schizophrenia patients. ${ }^{573}$

Part of the heterogeneity in the literature on cognitive functioning in bipolar disorder, may be due to some basic cognitive mechanisms. Firstly, increased intraindividual variability, described in Chapter 5, possibly due to disrupted internal timing mechanisms related to abnormalities in cerebellar function ${ }^{574}$ and/or greater requirement for top-down executive control, ${ }^{575}$ may contribute to the neuropsychological heterogeneity in speed and sustained attention in bipolar disorder. Secondly, processing efficiency may be impaired in bipolar patients, as evidenced by more effortful control of sustained attention at the expense of processing efficiency in euthymic patients ${ }^{576}$ with overactivation of various cortical areas to maintain sustained attention performance. ${ }^{577}$ Both these mechanisms point in the direction of a compensation hypothesis; the so-called compensation-related utilization of neural circuits hypothesis (CRUNH), ${ }^{578}$ with insufficient processing when task demands increase and go beyond resource ceilings. Thirdly, different cognitive strategies affecting the speed-accuracy trade-off may play a role in this respect. ${ }^{124}$ People are capable of trading speed for accuracy when performing tasks; focussing on accuracy at the cost of being slow, or emphasizing speed at the cost of accuracy, possibly maximizing reward rate by selection of decision thresholds. ${ }^{579}$ Apart from explicit strategic control, motivational biases influence this trade-off, 580 which is regulated by cortical integrator neurons in cortico-basal ganglia circuits. ${ }^{581}$

\section{A network model}

The brain is a complex network with a topological organization characterized by modularity, 'small-worldness' and highly connected network hubs, changing during development, aging and various diseases under the influence of environmental and genetic factors, with an interdependence of network configuration and cognitive performance. ${ }^{582,583}$ According to this model, the brain has a complex hierarchical modular organization of functional networks with the medial occipital, lateral occipital, central parieto-frontal and fronto-temporal systems as largest modules with the highest level of hierarchy, and connector nodes or 'hubs', playing a key role in 
inter-modular connectivity, concentrated in association cortical areas. ${ }^{584}$ The 'smallworldness' refers to the organization of connectivity, combining highly clustered sub-networks with a high level of global connectivity, thus providing a highly efficient organization of the brain. ${ }^{585,586}$ Structures such as precuneus, posterior cingulate gyrus and thalamus are centrally connected regions in the human brain, which, in its turn, develops from a 'local' organization of networks in children to a more 'distributed' architecture in adults, with possibly a greater overall connectivity of cortical networks in women, both locally and globally. ${ }^{587,588}$ Connectivity is more 'random' at adolescence and old age, and more structured in adulthood, with heritability of connectivity parameters such as synchronization likelihood between 40$80 \%{ }^{589}$ The small world structure of neural networks possibly reflects an optimal configuration associated with rapid synchronization and information processing, minimal wiring costs, and resilience to certain types of damage. ${ }^{590,591}$ Furthermore, intellectual performance, in general, is associated with certain network properties, such as shorter path length and higher global efficiency, indicating a more efficient parallel information transfer in the brain ${ }^{592,593}$ Interestingly, dopamine receptor antagonists may impair local and global efficiency of cortical and subcortical networks, ${ }^{594}$ and connectivity measures, especially in the subcallosal cortex, are highly correlated with treatment response to antidepressant medication. ${ }^{595}$

In general, psychopathology may be associated with changes in this small-world network organization, for instance reduced hierarchy and modularity, loss of frontal hubs, and different connectivity patterns. ${ }^{596-600}$ These changes can lead to dysfunctional connectivity in networks relevant for cognitive functioning, thus underlying aberrant performance in schizophrenia patients in a choice-reaction task, with taskrelated hypo-connectivity and inter-trial interval hyper-connectivity. ${ }^{601}$ Reduced salience network connectivity in bilateral insula and anterior cingulate cortex ${ }^{602}$ and anomalous network connectivity during working memory in schizophrenia patients, ${ }^{603,604}$ and exaggerated positive coherence of activity throughout the brain during a continuous performance task in bipolar patients, ${ }^{605}$ are other examples of these changes.

Synchronization of oscillatory activity, as measured by EEG or magnetoencephalography (MEG) ${ }^{606}$ is an indicator of functional connectivity, and plays an important role in the development of cortical circuits and synaptic plasticity, with late maturation of synchronization being compatible with late myelination of cortico-cortical connections and the late development of GABAergic neurotransmission. ${ }^{607,608}$ Ongoing EEG oscillation phase can possibly account for the rapid waxing and waning of sustained attention and the trial-by-trial variability of reaction times, ${ }^{609}$ and synchronous neural activity, especially in the theta-frequency $(4-8 \mathrm{~Hz})$ and gamma-frequency $(30-100 \mathrm{~Hz})$, plays an important role in memory formation, ${ }^{610}$ attention, ${ }^{611}$ working memory ${ }^{612}$ response speed and accuracy, ${ }^{613}$ and cognition in general. ${ }^{614}$ Disturbance in long distance gamma coherence in bipolar diorder, ${ }^{615,616}$ increased oscillatory activities in response to negative emotional stimuli, ${ }^{617}$ and impaired frontal synchronization of spontaneous magnetoencephalographic 
activity $^{618}$ are examples of, heritable, ${ }^{619,620}$ changes in neocortical synchrony in bipolar disorder, possibly at a cortico-thalamic level, and related to cognitive impairment. ${ }^{621}$ Largely the same abnormalities in oscillations and synchrony, especially in the gamma-band, are seen in schizophrenia patients with regard to, amongst others, cognitive functioning, ${ }^{622-625}$ onset and early progression of psychosis, ${ }^{626,627}$ negative symptoms, ${ }^{628}$ and the pro-psychotic effects of cannabis. ${ }^{629}$ Antipsychotics, interestingly, normalize the increased dynamical complexity in EEG activity in frontal regions in schizophrenia patients. ${ }^{630}$ Dysfunctional thalamus-related networks are hypothesized to underlie the abnormal oscillations and synchrony, at least in schizophrenia patients, but possibly in bipolar patients too (a hypothesis considered here). ${ }^{631,632}$ The thalamus reticular nucleus (TRN) is a GABAergic interface, under glutamatergic control, located between the thalamus and the neocortex, that functions as an integrator, integrating top-down and bottom-up information, such as attention modulation and sensory gating, leading to synchronization of thalamocortical activity by generating gamma oscillations. ${ }^{633,634}$ Impaired cognitive controlrelated gamma cortical oscillatory activity is present at the first psychotic episode in schizophrenia, independent of medication status, ${ }^{635}$ and related to alterations of inhibitory GABA neurons. ${ }^{310,636}$ Lesh and colleagues (2011), reviewing cognitive dysfunctioning in schizophrenia patients, propose a cognitive control deficit model in schizophrenia. ${ }^{637}$ According to this model, the dorsolateral prefrontal cortex (DLPFC), medial frontal cortex, including anterior cingulate cortex, and parietal regions, amongst others, ${ }^{638}$ form a network integrating top-down and bottom-up information associated with a wide range of cognitive processes, representing the ability to maintain context for appropriate behaviour in a given situation in the face of interference. Micro-and macro-circuit dysfunction, for instance altered thalamocortical connectivity and activity of GABAergic interneurons, leads to aberrant synchronization and gamma band responses, which are associated with higher cortical functions such as cognitive control. ${ }^{637}$ This model may be interesting in bipolar disorder too, given the altered connectivity patterns between, for instance, cortical, thalamic and cerebellar regions and the loss of normal inhibitory associations between these areas, resulting in aberrant interregional modulatory influences. ${ }^{605}$ Disordered connectivity may be a target of medication, as illustrated by the atypical behavioural effects of lorazepam with a positive effect on synchronization, via its effects on GABAergic neurotransmission. ${ }^{639}$

\section{Default mode network (DMN)}

The default mode network (DMN), one of the so-called resting-state networks, ${ }^{640}$ first described by Raichle et al. (2001), ${ }^{641}$ consists of several brain regions connected both functionally and structurally, such as precuneus, posterior cingulate cortex (PCC), medial prefrontal cortex (MPFC) and parietal cortex, that are active in the 'resting' brain of an individual that is awake and alert, but not actively involved in an attention demanding or goal-directed activity. ${ }^{641,642}$ Generally, the activity of the 
DMN is attenuated during task performance; the more demanding the task the stronger the deactivation, with persistent DMN activity during simple tasks requiring only minimal attentional resources. ${ }^{643} \mathrm{~A}$ continuous performance task (CPT), for example, has the advantage that patients perform almost as well as controls, thereby avoiding the confounding effects of task complexity and performance deficits on variability of brain network activity, ${ }^{605,644}$ on the one hand, and avoiding the largely uncontrolled resting condition that may induce confounding variation of its own and is, amongst others, influenced by rest period instructions, ${ }^{645}$ on the other hand. Furthermore, resting state studies, according to Fox et al. (2010), may offer a better signal to noise ratio than task-based approaches, given the fact that about $80 \%$ of 'noise', problematic for task-based studies, is actually ongoing spontaneous resting activity, with usually very small $(<5 \%)$ task-related increases in neuronal metabolism. ${ }^{646}$ The DMN is characterised by very low frequency neuronal oscillations $(<0.1$ $\mathrm{Hz}$ ), associated with connectivity of large scale neuronal networks, modulating smaller networks with higher frequencies, ${ }^{647}$ thus providing temporal synchrony between diverse brain regions. ${ }^{648}$ The resting state activity of the brain is functionally and structurally organized as a small-world network with modularity and connected hub regions, ${ }^{649-652}$ with default mode areas characterised by broad-band gamma power suppression during task-related attentive states, ${ }^{653}$ and an impact of the resting-state concentration of GABA in the perigenual anterior cingulate cortex, a tasknegative region, upon stimulus-induced task activity. ${ }^{654}$ The latter, refers to the reststimulus interactions in the brain, with bidirectional interactions and modulation of resting-state activity and stimulus-induced activity in different brain regions, with a central mediating role for GABA. ${ }^{65}$ Thus, the DMN (esp. PCC and MPFC) plays a role in cognitive functioning and emotional processing, with attenuation of this network during goal-directed activity with activation of a task-positive temporally anti-correlated network, reflecting a low frequency toggling between introspective self-referential processes and extrospective attentional orienting processes. ${ }^{656}$ The posterior cingulate cortex (PCC), for example, modulates the dynamic interaction between different networks, whereas this region is more highly integrated with the DMN at low task demands with task-dependent increased connectivity between the (dorsal) PCC and cognitive control network in controlling the efficient allocation of attention. ${ }^{657}$

Cognition in healthy individuals is related to resting-state network topology, ${ }^{658}$ with no significant differences between sexes, ${ }^{659}$ but possibly reduced functional connectivity in older adults, ${ }^{660}$ with a possible role for the default network coupled with the frontoparietal control network in goal-directed cognition, ${ }^{661}$ and a functional role of ongoing 'resting state' activity fluctuations in variability in cognitive functioning. This provides an account for a non-random, coordinated interaction of ongoing and evoked activity, minimizing the amount of prediction error ${ }^{662}$ Furthermore, the default-mode network may be associated, amongst others, with ongoing conscious experience and self-processing operations, ${ }^{663,664}$ state-dependent monitoring of temporality, ${ }^{665}$ working-memory performance, ${ }^{666}$ mind wandering, ${ }^{667}$ and 
spontaneous attentional fluctuations and distractibility, because of interference by insufficient attenuation of its activity, ${ }^{648,668}$ which, in its turn, may play a role in aging and psychopathology. ${ }^{578,669-671}$ Broyd et al. (2009) review default-mode brain dysfunction in mental disorders, mentioning default-mode interference, altered patterns of antagonism between task-positive networks and DMN, and changed patterns of DMN activity and connectivity, as putative mechanisms. ${ }^{656}$ Abnormal resting state functional connectivity in major depression, possibly related to abnormal affect regulation and cognitive deficits, ${ }^{672,673}$ and altered resting state corticolimbic and fronto-temporal connectivity in bipolar disorder ${ }^{674-676}$ and failure of deactivation in mania, ${ }^{677}$ are some recent examples of DMN dysfunction, with differentially affected cingulate regions in bipolar disorder in contrast with more affected temporal lobe regions in schizophrenia patients. ${ }^{644}$ Interestingly, altered resting-state connectivity is seen in subjects at ultra-high risk for psychosis and first-degree relatives of patients with schizophrenia. ${ }^{678,679}$ In schizophrenia, and most likely in bipolar disorder too, altered functional connectivity ${ }^{680,681}$ and failure of sufficient deactivation in the default mode network ${ }^{682}$ is associated with cognitive dysfunctioning in, for example, facial emotion recognition, ${ }^{683}$ target detection, ${ }^{684}$ and working memory ${ }^{685}$ with DMN activity attenuation being dependent on the cognitive processes involved. ${ }^{686}$ The same, inadequate suppression of the DMN during task performance, may underlie the increased variability of reaction time in patients with ADHD. ${ }^{67}$

Finally, medication, for example antipsychotics, may modulate default mode network functioning, ${ }^{493,688}$ increasing regional synchronous neural activity. ${ }^{69}$ Antidepressants, furthermore, possibly restore deactivation of this network, ${ }^{690}$ and a partial agonist of a 7 nicotinic acetylcholine receptors may improve default network function in schizophrenia patients. ${ }^{691}$ Finally, modafinil may modulate default mode network by augmentation of task-induced deactivation of this network leading to faster reaction time and better cognitive performance. ${ }^{692}$ Interestingly, nicotine's cognitive effects may involve suppression of the DMN, with a shift in activity from networks that process internal to those that process external information. ${ }^{693}$

Summarizing, loss or altered functioning of GABAergic interneurons, essential for maintaining resting 'inhibitory tone' and task-related up-regulation of gamma synchrony, ${ }^{694}$ with a central role for disturbed gamma synchrony in schizophrenia ${ }^{695}$ and bipolar disorder, ${ }^{337}$ related to dysfunctions in cognition and salience, is hypothesized to be central in the dysfunction of the default mode network (DMN), that dynamically interacts with other networks, such as the salience network and the central executive network, in regulating (social) cognition and mood. ${ }^{269,696}$ The DMN may thus play a central role in the self-organized, adaptive activity in hierarchical cortical systems in the brain, viewed as an inference or Helmholtz machine, ${ }^{697}$ optimizing brain functioning by minimizing free-energy or prediction error by topdown inhibition of other brain systems. ${ }^{495,698}$ 


\section{Concluding remarks}

In general, cognitive deficits in bipolar disorder are modest, but persistent during euthymia in a significant percentage of patients, with an impact on daily functioning and outcome. As a trait marker and possible intermediary phenotype, cognitive dysfunctioning concerns basically aspecific changes in speed of processing and (sustained) attention, leading to less cognitive efficiency, which expresses itself in impaired performance in 'maintenance plus' tasks requiring increased effort. The overlap between schizophrenia and bipolar disorder concerning cognitive functioning, amongst others, may be modulated by a unifying role of psychosis as an expression of a more neurodevelopmental course of illness, which is in line with a dimensionalspectrum model of psychopathology.

The neurobiology of cognition in bipolar disorder is most likely also aspecific, with various changes on different scales, characterised by 'disconnectivity' in functional and structural networks, 'disbalances' between neurotransmittersystems, and 'dysfunctioning' of GABAergic interneurons, gamma synchrony and default mode network interactions, amongst others. Furthermore, the interplay between (epi-)genetic and environmental factors, against the background of a combination of neurodevelopmental and neurodegenerative processes, contributes to the allostatic load and possible cognitive deficits in bipolar patients, with an important role for medication.

Neuroimaging-genetic paradigms can be used to investigate the role of aberrant default mode network (DMN) functioning, and its underlying neurobiological changes, hypothesized here to be central to the cognitive deficits in bipolar (and schizophrenia) patients. 'Resting state' characteristics of DMN in euthymic bipolar patients, measured by fMRI and/or MEG, during a simple continuous performance task can be compared with functional connectivity patterns in other patient groups, first-degree relatives and healthy controls, testing the possible role of medication, mood, disease characteristics, possible risk genes, and the role of underlying neurobiological mechanisms, amongst others. Dynamic changes in connectivity patterns can then be measured depending task-load, cognitive domain, strategies affecting speed-accuracy trade-off, motivation, and cognitive enhancing therapy.

To illustrate this approach, the effects of candidate genes concerning dopaminergic, glutamatergic and GABAergic neurotransmittersystems, such as GAD1, ${ }^{699}$ DAT $1^{700}$ and COMT, ${ }^{701,702}$ with possible epistatic effects, ${ }^{703,704}$ on default mode network and cognitive functioning could be studied. The study of the possible cognitive enhancing effects of cognitive training ${ }^{705,706}$ and drugs influencing one of these neurotransmittersystems, such as bromocriptine, ${ }^{707}$ modafinil, ${ }^{708}$ positive allosteric modulators of metabotropic glutamate receptors, ${ }^{323,324}$ GABA A receptor subtype selective compounds, ${ }^{709}$ and DHEA, ${ }^{710}$ on default mode functioning is another example of this line of research. 


\section{References}

1. Goodwin FK, Jamison, K.R. Manic-Depressive Illness. Second edition edn. Oxford University Press: Oxford, 2007.

2. Torres IJ, Boudreau, V.G., Yatham, L.N. Neuropsychological functioning in euthymic bipolar disorder: a meta-analysis. Acta Psychiatr Scand 2007; 116 (Suppl 434): 17-26.

3. Bora E, Yucel M, Pantelis C. Cognitive endophenotypes of bipolar disorder: A meta-analysis of neuropsychological deficits in euthymic patients and their first-degree relatives. J Affect Disord 2009; 113: 1-20.

4. Yatham LN, Torres IJ, Malhi GS, Frangou S, Glahn DC, Bearden CE et al. The International Society for Bipolar Disorders-Battery for Assessment of Neurocognition (ISBD-BANC). Bipolar Disord 2010; 12(4): 351-363.

5. Mann-Wrobel MC, Carreno JT, Dickinson D. Meta-analysis of neuropsychological functioning in euthymic bipolar disorder: an update and investigation of moderator variables. Bipolar Disord 2011; 13(4): 334-342.

6. Depp CA, Savla GN, Moore DJ, Palmer BW, Stricker JL, Lebowitz BD et al. Short-term course of neuropsychological abilities in middle-aged and older adults with bipolar disorder. Bipolar Disord 2008; 10(6): 684-690.

7. Szoke A, Trandafir A, Dupont ME, Meary A, Schurhoff F, Leboyer M. Longitudinal studies of cognition in schizophrenia: meta-analysis. Br J Psychiatry 2008; 192: 248-257.

8. Bozikas VP, Andreou C. Longitudinal studies of cognition in first episode psychosis: a systematic review of the literature. Aust N Z J Psychiatry 2011; 45(2): 93-108.

9. Gur RE, Calkins ME, Gur RC, Horan WP, Nuechterlein KH, Seidman LJ et al. The Consortium on the Genetics of Schizophrenia: neurocognitive endophenotypes. Schizophr Bull 2007; 33(1): 49-68.

10. Woolard AA, Kose S, Woodward ND, Verbruggen F, Logan GD, Heckers S. Intact associative learning in patients with schizophrenia: evidence from a Go/NoGo paradigm. Schizophr Res 2010; 122(1-3): 131-135.

11. Birkett P, Sigmundsson T, Sharma T, Toulopoulou T, Griffiths TD, Reveley A et al. Reaction time and sustained attention in schizophrenia and its genetic predisposition. Schizophr Res 2007; 95(1-3): 76-85.

12. Sanchez P, Ojeda N, Pena J, Elizagarate E, Yoller AB, Gutierrez M et al. Predictors of longitudinal changes in schizophrenia: the role of processing speed. J Clin Psychiatry 2009; 70(6): 888-896.

13. Bachman P, Reichenberg A, Rice P, Woolsey M, Chaves O, Martinez D et al. Deconstructing processing speed deficits in schizophrenia: application of a parametric digit symbol coding test. Schizophr Res 2010; 118(1-3): 6-11.

14. Knowles EE, David AS, Reichenberg A. Processing speed deficits in schizophrenia: reexamining the evidence. Am J Psychiatry 2010; 167(7): 828-835.

15. Forbes NF, Carrick LA, McIntosh AM, Lawrie SM. Working memory in schizophrenia: a metaanalysis. Psychol Med 2009; 39(6): 889-905.

16. Gold JM, Hahn B, Zhang WW, Robinson BM, Kappenman ES, Beck VM et al. Reduced capacity but spared precision and maintenance of working memory representations in schizophrenia. Arch Gen Psychiatry 2010; 67(6): 570-577.

17. Hill SK, Griffin GB, Miura TK, Herbener ES, Sweeney JA. Salience of working-memory maintenance and manipulation deficits in schizophrenia. Psychol Med 2010; 40(12): 1979-1986.

18. Carter JD, Bizzell J, Kim C, Bellion C, Carpenter KL, Dichter G et al. Attention deficits in schizophrenia--preliminary evidence of dissociable transient and sustained deficits. Schizophr Res 2010; 122(1-3): 104-112.

19. Hahn B, Robinson BM, Kaiser ST, Harvey AN, Beck VM, Leonard CJ et al. Failure of schizophrenia patients to overcome salient distractors during working memory encoding. Biol Psychiatry 2010; 68(7): 603-609.

20. Le Pelley ME, Schmidt-Hansen M, Harris NJ, Lunter CM, Morris CS. Disentangling the attentional deficit in schizophrenia: pointers from schizotypy. Psychiatry Res 2010; 176(2-3): 143-149. 
21. Chan RC, Li H, Cheung EF, Gong QY. Impaired facial emotion perception in schizophrenia: a metaanalysis. Psychiatry Res 2010; 178(2): 381-390.

22. Kohler CG, Walker JB, Martin EA, Healey KM, Moberg PJ. Facial emotion perception in schizophrenia: a meta-analytic review. Schizophr Bull 2010; 36(5): 1009-1019.

23. Pomarol-Clotet E, Hynes F, Ashwin C, Bullmore ET, McKenna PJ, Laws KR. Facial emotion processing in schizophrenia: a non-specific neuropsychological deficit? Psychol Med 2010; 40(6): 911919.

24. van Rijn S, Aleman A, de Sonneville L, Sprong M, Ziermans T, Schothorst P et al. Misattribution of facial expressions of emotion in adolescents at increased risk of psychosis: the role of inhibitory control. Psychol Med 2011; 41(3): 499-508.

25. Sprong M, Schothorst P, Vos E, Hox J, van Engeland H. Theory of mind in schizophrenia: metaanalysis. Br J Psychiatry 2007; 191: 5-13.

26. Mier D, Sauer C, Lis S, Esslinger C, Wilhelm J, Gallhofer B et al. Neuronal correlates of affective theory of mind in schizophrenia out-patients: evidence for a baseline deficit. Psychol Med 2010; 40(10): 1607-1617.

27. Bora E, Vahip S, Gonul AS, Akdeniz F, Alkan M, Ogut M et al. Evidence for theory of mind deficits in euthymic patients with bipolar disorder. Acta Psychiatr Scand 2005; 112(2): 110-116.

28. Kohler CG, Hoffman LJ, Eastman LB, Healey K, Moberg PJ. Facial emotion perception in depression and bipolar disorder: A quantitative review. Psychiatry Res 2011; 188(3): 303-309.

29. Martino DJ, Strejilevich SA, Fassi G, Marengo E, Igoa A. Theory of mind and facial emotion recognition in euthymic bipolar I and bipolar II disorders. Psychiatry Res 2011; 189(3): 379-384.

30. Bora E, Yucel M, Pantelis C. Theory of mind impairment: a distinct trait-marker for schizophrenia spectrum disorders and bipolar disorder? Acta Psychiatr Scand 2009; 120(4): 253-264.

31. Lahera G, Montes JM, Benito A, Valdivia M, Medina E, Mirapeix I et al. Theory of mind deficit in bipolar disorder: Is it related to aprevious history of psychotic symptoms? Psychiatry Res 2008; 161(3): 309-317.

32. Montag C, Ehrlich A, Neuhaus K, Dziobek I, Heekeren HR, Heinz A et al. Theory of mind impairments in euthymic bipolar patients. J Affect Disord 2010; 123(1-3): 264-269.

33. Wolf F, Brune M, Assion HJ. Theory of mind and neurocognitive functioning in patients with bipolar disorder. Bipolar Disord 2010; 12(6): 657-666.

34. Aleman A, Agrawal N, Morgan KD, David AS. Insight in psychosis and neuropsychological function: meta-analysis. Br J Psychiatry 2006; 189: 204-212.

35. Dias VV, Brissos S, Carita AI. Clinical and neurocognitive correlates of insight in patients with bipolar I disorder in remission. Acta Psychiatr Scand 2008; 117(1): 28-34.

36. Yen CF, Cheng CP, Huang CF, Ko CH, Yen JY, Chang YP et al. Relationship between psychosocial adjustment and executive function in patients with bipolar disorder and schizophrenia in remission: the mediating and moderating effects of insight. Bipolar Disord 2009; 11(2): 190-197.

37. Quee PJ, van der Meer L, Bruggeman R, de Haan L, Krabbendam L, Cahn W et al. Insight in psychosis: relationship with neurocognition, social cognition and clinical symptoms depends on phase of illness. Schizophr Bull 2011; 37(1): 29-37.

38. van der Werf-Eldering MJ, van der Meer L, Burger H, Holthausen EA, Nolen WA, Aleman A. Insight in bipolar disorder: associations with cognitive and emotional processing and illness characteristics. Bipolar Disord 2011; 13(4): 343-354.

39. Gard DE, Fisher M, Garrett C, Genevsky A, Vinogradov S. Motivation and its relationship to neurocognition, social cognition, and functional outcome in schizophrenia. Schizophr Res 2009; 115(1): 74-81.

40. Choi J, Medalia A. Intrinsic motivation and learning in a schizophrenia spectrum sample. Schizophr Res 2010; 118(1-3): 12-19.

41. Martinez-Aran A, Vieta E, Colom F, Torrent C, Reinares M, Goikolea JM et al. Do Cognitive Complaints in Euthymic Bipolar Patients Reflect Objective Cognitive Impairment? Psychother Psychosom 2005; 74(5): 295-302. 
42. Gilbert AM, Olino TM, Houck P, Fagiolini A, Kupfer DJ, Frank E. Self-reported cognitive problems predict employment trajectory in patients with bipolar I disorder. J Affect Disord 2010; 124(3): 324328.

43. Verdoux H, Monello F, Goumilloux R, Cougnard A, Prouteau A. Self-perceived cognitive deficits and occupational outcome in persons with schizophrenia. Psychiatry Res 2010; 178(2): 437-439.

44. Homayoun S, Nadeau-Marcotte, F., Luck, D., Stip, E. Subjective and objective cognitive dysfunction in schizophrenia - is there a link? Frontiers in psychology 2011; July 2011; volume 2: 1-8.

45. van der Werf-Eldering MJ, Burger H, Jabben N, Holthausen EA, Aleman A, Nolen WA. Is the lack of association between cognitive complaints and objective cognitive functioning in patients with bipolar disorder moderated by depressive symptoms? J Affect Disord 2011; 130(1-2): 306-311.

46. Heinz A, Schlagenhauf F. Dopaminergic dysfunction in schizophrenia: salience attribution revisited. Schizophr Bull 2010; 36(3): 472-485.

47. Walter H, Heckers S, Kassubek J, Erk S, Frasch K, Abler B. Further evidence for aberrant prefrontal salience coding in schizophrenia. Frontiers in behavioral neuroscience 2010; 3: 62.

48. Fett AK, Viechtbauer W, Dominguez MD, Penn DL, van Os J, Krabbendam L. The relationship between neurocognition and social cognition with functional outcomes in schizophrenia: A metaanalysis. Neurosci Biobehav Rev 2010.

49. Allott K, Liu P, Proffitt TM, Killackey E. Cognition at illness onset as a predictor of later functional outcome in early psychosis: Systematic review and methodological critique. Schizophr Res 2011; 125(2-3): 221-235.

50. Bowie CR, Depp C, McGrath JA, Wolyniec P, Mausbach BT, Thornquist MH et al. Prediction of real-world functional disability in chronic mental disorders: a comparison of schizophrenia and bipolar disorder. Am J Psychiatry 2010; 167(9): 1116-1124.

51. Biederman J, Petty CR, Wozniak J, Wilens TE, Fried R, Doyle A et al. Impact of executive function deficits in youth with bipolar I disorder: A controlled study. Psychiatry Res 2011.

52. Levy B, Medina AM, Hintz K, Weiss RD. Ecologically valid support for the link between cognitive and psychosocial functioning in bipolar disorder. Psychiatry Res 2011; 185(3): 353-357.

53. Wingo AP, Harvey PD, Baldessarini RJ. Neurocognitive impairment in bipolar disorder patients: functional implications. Bipolar Disord 2009; 11(2): 113-125.

54. Sanchez-Moreno J, Martinez-Aran A, Tabares-Seisdedos R, Torrent C, Vieta E, Ayuso-Mateos JL. Functioning and disability in bipolar disorder: an extensive review. Psychother Psychosom 2009; 78(5): 285-297.

55. Bearden CE, Shih VH, Green MF, Gitlin M, Sokolski KN, Levander E et al. The impact of neurocognitive impairment on occupational recovery of clinically stable patients with bipolar disorder: a prospective study. Bipolar Disord 2011; 13(4): 323-333.

56. Kurtz MM, Jeffrey SB, Rose J. Elementary neurocognitive function, learning potential and everyday life skills in schizophrenia: what is their relationship? Schizophr Res 2010; 116(2-3): 280-288.

57. Dickerson F, Origoni A, Stallings C, Khushalani S, Dickinson D, Medoff D. Occupational status and social adjustment six months after hospitalization early in the course of bipolar disorder: a prospective study. Bipolar Disord 2010; 12(1): 10-20.

58. Burdick KE, Goldberg JF, Harrow M. Neurocognitive dysfunction and psychosocial outcome in patients with bipolar I disorder at 15-year follow-up. Acta Psychiatr Scand 2010; 122(6): 499-506.

59. Martino DJ, Marengo E, Igoa A, Scapola M, Ais ED, Perinot L et al. Neurocognitive and symptomatic predictors of functional outcome in bipolar disorders: A prospective 1 year follow-up study. $J$ Affect Disord 2009; 116(1-2): 37-42.

60. Bonnin CM, Martinez-Aran A, Torrent C, Pacchiarotti I, Rosa AR, Franco C et al. Clinical and neurocognitive predictors of functional outcome in bipolar euthymic patients: a long-term, followup study. J Affect Disord 2010; 121(1-2): 156-160.

61. Torres IJ, DeFreitas CM, DeFreitas VG, Bond DJ, Kunz M, Honer WG et al. Relationship between cognitive functioning and 6-month clinical and functional outcome in patients with first manic episode bipolar I disorder. Psychol Med 2011; 41(5): 971-982. 
62. Gonzalez-Blanch C, Perez-Iglesias R, Pardo-Garcia G, Rodriguez-Sanchez JM, Martinez-Garcia O, Vazquez-Barquero JL et al. Prognostic value of cognitive functioning for global functional recovery in first-episode schizophrenia. Psychol Med 2010; 40(6): 935-944.

63. Tandberg M, Ueland T, Sundet K, Haahr U, Joa I, Johannessen JO et al. Neurocognition and occupational functioning in patients with first-episode psychosis: A 2-year follow-up study. Psychiatry Res 2011; 188(3): 334-342.

64. Depp CA, Mausbach BT, Harvey PD, Bowie CR, Wolyniec PS, Thornquist MH et al. Social competence and observer-rated social functioning in bipolar disorder. Bipolar Disord 2010; 12(8): 843-850.

65. Lin A, Wood SJ, Nelson B, Brewer WJ, Spiliotacopoulos D, Bruxner A et al. Neurocognitive predictors of functional outcome two to 13 years after identification as ultra-high risk for psychosis. Schizophr Res 2011; 132(1): 1-7.

66. Carrion RE, Goldberg TE, McLaughlin D, Auther AM, Correll CU, Cornblatt BA. Impact of neurocognition on social and role functioning in individuals at clinical high risk for psychosis. Am J Psychiatry 2011; 168(8): 806-813.

67. Cullen AE, Dickson H, West SA, Morris RG, Mould GL, Hodgins S et al. Neurocognitive performance in children aged 9-12 years who present putative antecedents of schizophrenia. Schizophr Res 2010; 121(1-3): 15-23.

68. Kremen WS, Vinogradov S, Poole JH, Schaefer CA, Deicken RF, Factor-Litvak P et al. Cognitive decline in schizophrenia from childhood to midlife: a 33-year longitudinal birth cohort study. Schizophr Res 2010; 118(1-3): 1-5.

69. Reichenberg A, Caspi A, Harrington H, Houts R, Keefe RS, Murray RM et al. Static and dynamic cognitive deficits in childhood preceding adult schizophrenia: a 30-year study. Am J Psychiatry 2010; 167(2): 160-169.

70. Woodberry KA, Seidman LJ, Giuliano AJ, Verdi MB, Cook WL, McFarlane WR. Neuropsychological profiles in individuals at clinical high risk for psychosis: relationship to psychosis and intelligence. Schizophr Res 2010; 123(2-3): 188-198.

71. Carrion RE, Goldberg TE, McLaughlin D, Auther AM, Correll CU, Cornblatt BA. Impact of Neurocognition on Social and Role Functioning in Individuals at Clinical High Risk for Psychosis. Am J Psychiatry 2011.

72. Meyer SE, Carlson GA, Wiggs EA, Martinez PE, Ronsaville DS, Klimes-Dougan B et al. A prospective study of the association among impaired executive functioning, childhood attentional problems, and the development of bipolar disorder. Dev Psychopathol 2004; 16(2): 461-476.

73. MacCabe JH, Lambe MP, Cnattingius S, Sham PC, David AS, Reichenberg A et al. Excellent school performance at age 16 and risk of adult bipolar disorder: national cohort study. Br J Psychiatry 2010; 196(2): 109-115.

74. Olvet DM, Stearns WH, McLaughlin D, Auther AM, Correll CU, Cornblatt BA. Comparing clinical and neurocognitive features of the schizophrenia prodrome to the bipolar prodrome. Schizophr Res 2010; 123(1): 59-63.

75. Jabben N, van Os J, Janssen I, Versmissen D, Krabbendam L. Cognitive alterations in groups at risk for psychosis: neutral markers of genetic risk or indicators of social disability? Acta Psychiatr Scand 2007; 116(4): 253-262.

76. Bechard-Evans L, Iyer S, Lepage M, Joober R, Malla A. Investigating cognitive deficits and symptomatology across pre-morbid adjustment patterns in first-episode psychosis. Psychol Med 2010; 40(5): 749-759.

77. Fromann I, Pukrop, R., Brinkmeyer, J., Bechdolf, A., Ruhrmann, S., Berning, J., Decker, P., Riedel, M., Moller, H-J., Wolwer, W., Gaebel, W., Klosterkotter, J., Maier, W., Wagner, M. Neuropsychological profiles in different at-risk states of psychosis: Executive control impairment in the early and additional memory dysfunction in the late - prodromal state. Schizophr Bull 2011; 37(4): 861873.

78. Welham J, Scott J, Williams GM, Najman JM, Bor W, O'Callaghan M et al. The antecedents of nonaffective psychosis in a birth-cohort, with a focus on measures related to cognitive ability, attentional dysfunction and speech problems. Acta Psychiatr Scand 2010; 121: 273-279. 
79. O’Connor M, Harris JM, McIntosh AM, Owens DG, Lawrie SM, Johnstone EC. Specific cognitive deficits in a group at genetic high risk of schizophrenia. Psychol Med 2009; 39(10): 1649-1655.

80. Blanchard MM, Jacobson S, Clarke MC, Connor D, Kelleher I, Garavan H et al. Language, motor and speed of processing deficits in adolescents with subclinical psychotic symptoms. Schizophr Res 2010; 123(1): 71-76.

81. Lindgren M, Manninen M, Laajasalo T, Mustonen U, Kalska H, Suvisaari J et al. The relationship between psychotic-like symptoms and neurocognitive performance in a general adolescent psychiatric sample. Schizophr Res 2010; 123(1): 77-85.

82. Seidman LJ, Giuliano AJ, Meyer EC, Addington J, Cadenhead KS, Cannon TD et al. Neuropsychology of the prodrome to psychosis in the NAPLS consortium: relationship to family history and conversion to psychosis. Arch Gen Psychiatry 2010; 67(6): 578-588.

83. Pflueger MO, Gschwandtner U, Stieglitz RD, Riecher-Rossler A. Neuropsychological deficits in individuals with an at risk mental state for psychosis - working memory as a potential trait marker. Schizophr Res 2007; 97(1-3): 14-24.

84. Bhojraj TS, Diwadkar VA, Sweeney JA, Prasad KM, Eack SM, Montrose DM et al. Longitudinal alterations of executive function in non-psychotic adolescents at familial risk for schizophrenia. Prog Neuropsychopharmacol Biol Psychiatry 2010; 34(3): 469-474.

85. Brotman MA, Guyer AE, Lawson ES, Horsey SE, Rich BA, Dickstein DP et al. Facial emotion labeling deficits in children and adolescents at risk for bipolar disorder. Am J Psychiatry 2008; 165(3): 385-389.

86. Kim HS, Shin NY, Jang JH, Kim E, Shim G, Park HY et al. Social cognition and neurocognition as predictors of conversion to psychosis in individuals at ultra-high risk. Schizophr Res 2011; 130(1-3): $170-175$.

87. Kyte ZA, Carlson GA, Goodyer IM. Clinical and neuropsychological characteristics of child and adolescent bipolar disorder. Psychol Med 2006; 36(9): 1197-1211.

88. Joseph MF, Frazier TW, Youngstrom EA, Soares JC. A quantitative and qualitative review of neurocognitive performance in pediatric bipolar disorder. J Child Adolesc Psychopharmacol 2008; 18(6): 595-605.

89. Pavuluri MN, West A, Hill SK, Jindal K, Sweeney JA. Neurocognitive function in pediatric bipolar disorder: 3-year follow-up shows cognitive development lagging behind healthy youths. J Am Acad Child Adolesc Psychiatry 2009; 48(3): 299-307.

90. Cahill CM, Green MJ, Jairam R, Malhi GS. Do cognitive deficits in juvenile bipolar disorder persist into adulthood? J Nerv Ment Dis 2007; 195(11): 891-896.

91. Hill SK, Reilly JL, Harris MS, Rosen C, Marvin RW, Deleon O et al. A comparison of neuropsychological dysfunction in first-episode psychosis patients with unipolar depression, bipolar disorder, and schizophrenia. Schizophr Res 2009.

92. Barrett SL, Mulholland CC, Cooper SJ, Rushe TM. Patterns of neurocognitive impairment in firstepisode bipolar disorder and schizophrenia. Br J Psychiatry 2009; 195(1): 67-72.

93. Torres IJ, Defreitas VG, Defreitas CM, Kauer-Sant'anna M, Bond DJ, Honer WG et al. Neurocognitive functioning in patients with bipolar I disorder recently recovered from a first manic episode. $J$ Clin Psychiatry 2010; 71(9): 1234-1242.

94. Mesholam-Gately RI, Giuliano AJ, Goff KP, Faraone SV, Seidman LJ. Neurocognition in firstepisode schizophrenia: a meta-analytic review. Neuropsychology 2009; 23(3): 315-336.

95. Galderisi S, Davidson M, Kahn RS, Mucci A, Boter H, Gheorghe MD et al. Correlates of cognitive impairment in first episode schizophrenia: the EUFEST study. Schizophr Res 2009; 115(2-3): 104114.

96. Holmen A, Juuhl-Langseth M, Thormodsen R, Melle I, Rund BR. Neuropsychological profile in early-onset schizophrenia-spectrum disorders: measured with the MATRICS battery. Schizophr Bull 2010; 36(4): 852-859.

97. de Mello Ayres A, Scazufca M, Menezes PR, Nakano EY, Regina AC, Schaufelberger MS et al. Cognitive functioning in subjects with recent-onset psychosis from a low-middle-income environment: multiple-domain deficits and longitudinal evaluation. Psychiatry Res 2010; 179(2): 157-164. 
98. Becker HE, Nieman DH, Wiltink S, Dingemans PM, van de Fliert JR, Velthorst E et al. Neurocognitive functioning before and after the first psychotic episode: does psychosis result in cognitive deterioration? Psychol Med 2010; 40(10): 1599-1606.

99. Gonzalez-Blanch C, Rodriguez-Sanchez JM, Perez-Iglesias R, Pardo-Garcia G, Martinez-Garcia O, Vazquez-Barquero JL et al. First-episode schizophrenia patients neuropsychologically within the normal limits: evidence of deterioration in speed of processing. Schizophr Res 2010; 119(1-3): 18-26.

100. Pantelis C, Wood SJ, Proffitt TM, Testa R, Mahony K, Brewer WJ et al. Attentional set-shifting ability in first-episode and established schizophrenia: Relationship to working memory. Schizophr Res 2009; 112(1-3): 104-113.

101. Rodriguez-Sanchez JM, Perez-Iglesias R, Gonzalez-Blanch C, Pelayo-Teran JM, Mata I, Martinez O et al. 1-year follow-up study of cognitive function in first-episode non-affective psychosis. Schizophr Res 2008; 104(1-3): 165-174.

102. Frangou S, Hadjulis M, Vourdas A. The maudsley early onset schizophrenia study: cognitive function over a 4-year follow-up period. Schizophr Bull 2008; 34(1): 52-59.

103. Braw Y, Bloch Y, Mendelovich S, Ratzoni G, Gal G, Harari H et al. Cognition in young schizophrenia outpatients: comparison of first-episode with multiepisode patients. Schizophr Bull 2008; 34(3): 544-554.

104. Leeson VC, Barnes TR, Harrison M, Matheson E, Harrison I, Mutsatsa SH et al. The relationship between IQ, memory, executive function, and processing speed in recent-onset psychosis: 1-year stability and clinical outcome. Schizophr Bull 2010; 36(2): 400-409.

105. Oie M, Sundet K, Rund BR. Neurocognitive decline in early-onset schizophrenia compared with ADHD and normal controls: evidence from a 13-year follow-up study. Schizophr Bull 2010; 36(3): 557-565.

106. Balanza-Martinez V, Rubio C, Selva-Vera G, Martinez-Aran A, Sanchez-Moreno J, Salazar-Fraile J et al. Neurocognitive endophenotypes (endophenocognitypes) from studies of relatives of bipolar disorder subjects: a systematic review. Neurosci Biobehav Rev 2008; 32(8): 1426-1438.

107. Rybakowski JK. Lithium in neuropsychiatry: A 2010 update. World J Biol Psychiatry 2011.

108. Giakoumaki SG, Roussos P, Rogdaki M, Karli C, Bitsios P, Frangou S. Evidence of disrupted prepulse inhibition in unaffected siblings of bipolar disorder patients. Biol Psychiatry 2007; 62(12): 1418-1422.

109. Schulze KK, Hall MH, McDonald C, Marshall N, Walshe M, Murray RM et al. P50 auditory evoked potential suppression in bipolar disorder patients with psychotic features and their unaffected relatives. Biol Psychiatry 2007; 62(2): 121-128.

110. Hall MH, Schulze K, Sham P, Kalidindi S, McDonald C, Bramon E et al. Further evidence for shared genetic effects between psychotic bipolar disorder and P50 suppression: a combined twin and family study. Am J Med Genet B Neuropsychiatr Genet 2008; 147B(5): 619-627.

111. Brotman MA, Rooney MH, Skup M, Pine DS, Leibenluft E. Increased intrasubject variability in response time in youths with bipolar disorder and at-risk family members. J Am Acad Child Adolesc Psychiatry 2009; 48(6): 628-635.

112. Diwadkar VA, Goradia D, Hosanagar A, Mermon D, Montrose DM, Birmaher B et al. Working memory and attention deficits in adolescent offspring of schizophrenia or bipolar patients: comparing vulnerability markers. Prog Neuropsychopharmacol Biol Psychiatry 2011; 35(5): 1349-1354.

113. Antila M, Partonen T, Kieseppa T, Suvisaari J, Eerola M, Lonnqvist J et al. Cognitive functioning of bipolar I patients and relatives from families with or without schizophrenia or schizoaffective disorder. J Affect Disord 2009; 116(1-2): 70-79.

114. Sitskoorn MM, Aleman A, Ebisch SJ, Appels MC, Kahn RS. Cognitive deficits in relatives of patients with schizophrenia: a meta-analysis. Schizophr Res 2004; 71(2-3): 285-295.

115. Snitz BE, Macdonald AW, 3rd, Carter CS. Cognitive deficits in unaffected first-degree relatives of schizophrenia patients: a meta-analytic review of putative endophenotypes. Schizophr Bull 2006; 32(1): 179-194.

116. de la Serna E, Baeza I, Andres S, Puig O, Sanchez-Guistau V, Romero S et al. Comparison between young siblings and offspring of subjects with schizophrenia: clinical and neuropsychological characteristics. Schizophr Res 2011; 131(1-3): 35-42. 
117. Ivleva EI, Morris DW, Moates AF, Suppes T, Thaker GK, Tamminga CA. Genetics and intermediate phenotypes of the schizophrenia--bipolar disorder boundary. Neurosci Biobehav Rev 2010; 34(6): 897-921.

118. Bediou B, Asri F, Brunelin J, Krolak-Salmon P, D’Amato T, Saoud M et al. Emotion recognition and genetic vulnerability to schizophrenia. Br J Psychiatry 2007; 191: 126-130.

119. Eack SM, Mermon DE, Montrose DM, Miewald J, Gur RE, Gur RC et al. Social cognition deficits among individuals at familial high risk for schizophrenia. Schizophr Bull 2010; 36(6): 1081-1088.

120. Heydebrand G. Cognitive deficits in the families of patients with schizophrenia. Curr Opin Psychiatry 2006; 19(3): 277-281.

121. Bove EA. Cognitive performance and basic symptoms in first-degree relatives of schizophrenic patients. Compr Psychiatry 2008; 49(4): 321-329.

122. Hilti CC, Hilti LM, Heinemann D, Robbins T, Seifritz E, Cattapan-Ludewig K. Impaired performance on the Rapid Visual Information Processing task (RVIP) could be an endophenotype of schizophrenia. Psychiatry Res 2010; 177(1-2): 60-64.

123. Gur RE, Nimgaonkar VL, Almasy L, Calkins ME, Ragland JD, Pogue-Geile MF et al. Neurocognitive endophenotypes in a multiplex multigenerational family study of schizophrenia. Am J Psychiatry 2007; 164(5): 813-819.

124. Calkins ME, Tepper P, Gur RC, Ragland JD, Klei L, Wiener HW et al. Project among AfricanAmericans to explore risks for schizophrenia (PAARTNERS): evidence for impairment and heritability of neurocognitive functioning in families of schizophrenia patients. Am J Psychiatry 2010; 167(4): 459-472.

125. Hill SK, Harris MS, Herbener ES, Pavuluri M, Sweeney JA. Neurocognitive allied phenotypes for schizophrenia and bipolar disorder. Schizophr Bull 2008; 34(4): 743-759.

126. Daban C, Martinez-Aran A, Torrent C, Tabares-Seisdedos R, Balanza-Martinez V, Salazar-Fraile J et al. Specificity of cognitive deficits in bipolar disorder versus schizophrenia. A systematic review. Psychother Psychosom 2006; 75(2): 72-84.

127. Torrent C, Martinez-Aran A, Amann B, Daban C, Tabares-Seisdedos R, Gonzalez-Pinto A et al. Cognitive impairment in schizoaffective disorder: a comparison with non-psychotic bipolar and healthy subjects. Acta Psychiatr Scand 2007; 116(6): 453-460.

128. Stefanopoulou E, Manoharan A, Landau S, Geddes JR, Goodwin G, Frangou S. Cognitive functioning in patients with affective disorders and schizophrenia: a meta-analysis. Int Rev Psychiatry 2009; 21(4): 336-356.

129. Sanchez-Morla EM, Barabash A, Martinez-Vizcaino V, Tabares-Seisdedos R, Balanza-Martinez V, Cabranes-Diaz JA et al. Comparative study of neurocognitive function in euthymic bipolar patients and stabilized schizophrenic patients. Psychiatry Res 2009; 169(3): 220-228.

130. Brambilla P, Cerruti S, Bellani M, Perlini C, Ferro A, Marinelli V et al. Shared impairment in associative learning in schizophrenia and bipolar disorder. Prog Neuropsychopharmacol Biol Psychiatry 2011; 35(4): 1093-1099.

131. Lewandowski KE, Cohen BM, Ongur D. Evolution of neuropsychological dysfunction during the course of schizophrenia and bipolar disorder. Psychol Med 2011; 41(2): 225-241.

132. Murray RM, Sham P, Van Os J, Zanelli J, Cannon M, McDonald C. A developmental model for similarities and dissimilarities between schizophrenia and bipolar disorder. Schizophr Res 2004; 71(2-3): 405-416.

133. Craddock N, O'Donovan MC, Owen MJ. Psychosis genetics: modeling the relationship between schizophrenia, bipolar disorder, and mixed (or "schizoaffective") psychoses. Schizophr Bull 2009; 35(3): 482-490.

134. Gill M, Donohoe G, Corvin A. What have the genomics ever done for the psychoses? Psychol Med 2010; 40(4): 529-540.

135. Wang KS, Liu XF, Aragam N. A genome-wide meta-analysis identifies novel loci associated with schizophrenia and bipolar disorder. Schizophr Res 2010; 124(1-3): 192-199. 
136. Hamshere ML, O’ donovan, M.V., Jones, I.R., Jones, L., Kirov, G., Green, E.K., Moskvina, V., Grozeva, D., Bass, N., McQuillin, A., Gurling, H., St Clair, D., Young, A.H., Ferrier, I.N., Farmer, A., McGuffin, P., Sklar, P., Purcell, S., Holmans, P.A., Owen, M.J., Craddock, N. Polygenic dissection of the bipolar phenotype. British Journal of Psychiatry 2011; 198: 284-288.

137. Robins E, Guze SB. Establishment of diagnostic validity in psychiatric illness: its application to schizophrenia. Am J Psychiatry 1970; 126(7): 983-987.

138. Dibben CR, Rice C, Laws K, McKenna PJ. Is executive impairment associated with schizophrenic syndromes? A meta-analysis. Psychol Med 2009; 39(3): 381-392.

139. Bora E, Yucel M, Pantelis C. Cognitive functioning in schizophrenia, schizoaffective disorder and affective psychoses: meta-analytic study. Br J Psychiatry 2009; 195(6): 475-482.

140. Ventura J, Thames AD, Wood RC, Guzik LH, Hellemann GS. Disorganization and reality distortion in schizophrenia: a meta-analysis of the relationship between positive symptoms and neurocognitive deficits. Schizophr Res 2010; 121(1-3): 1-14.

141. Dominguez Mde G, Viechtbauer W, Simons CJ, van Os J, Krabbendam L. Are psychotic psychopathology and neurocognition orthogonal? A systematic review of their associations. Psychol Bull 2009; 135(1): 157-171.

142. Bora E, Yucel M, Pantelis C. Neurocognitive markers of psychosis in bipolar disorder: A metaanalytic study. J Affect Disord 2010; 127(1-3): 1-9.

143. Weiser M, Reichenberg A, Kravitz E, Lubin G, Shmushkevich M, Glahn DC et al. Subtle cognitive dysfunction in nonaffected siblings of individuals affected by nonpsychotic disorders. Biol Psychiatry 2008; 63(6): 602-608.

144. Reichenberg A, Harvey PD, Bowie CR, Mojtabai R, Rabinowitz J, Heaton RK et al. Neuropsychological function and dysfunction in schizophrenia and psychotic affective disorders. Schizophr Bull 2009; 35(5): 1022-1029.

145. Smith MJ, Barch DM, Csernansky JG. Bridging the gap between schizophrenia and psychotic mood disorders: Relating neurocognitive deficits to psychopathology. Schizophr Res 2009; 107(1): 69-75.

146. Bora E, Yucel M, Pantelis C. Cognitive impairment in affective psychoses: a meta-analysis. Schizophr Bull 2010; 36(1): 112-125.

147. Simonsen C, Sundet K, Vaskinn A, Birkenaes AB, Engh JA, Faerden A et al. Neurocognitive dysfunction in bipolar and schizophrenia spectrum disorders depends on history of psychosis rather than diagnostic group. Schizophr Bull 2011; 37(1): 73-83.

148. Bora E, Yucel M, Pantelis C. Cognitive impairment in schizophrenia and affective psychoses: implications for DSM-V criteria and beyond. Schizophr Bull 2010; 36(1): 36-42.

149. van Os J. 'Salience syndrome' replaces 'schizophrenia' in DSM-V and ICD-11: psychiatry's evidencebased entry into the 21st century? Acta Psychiatr Scand 2009; 120(5): 363-372.

150. van Os J. A salience dysregulation syndrome. Br J Psychiatry 2009; 194(2): 101-103.

151. Krueger RF, Markon KE. A dimensional-spectrum model of psychopathology: progress and opportunities. Arch Gen Psychiatry 2011; 68(1): 10-11.

152. Kessler RC, Ormel J, Petukhova M, McLaughlin KA, Green JG, Russo LJ et al. Development of lifetime comorbidity in the world health organization world mental health surveys. Arch Gen Psychiatry 2011; 68(1): 90-100.

153. Thaker GK. Neurophysiological endophenotypes across bipolar and schizophrenia psychosis. Schizophr Bull 2008; 34(4): 760-773.

154. Roussos P, Giakoumaki SG, Adamaki E, Bitsios P. The influence of schizophrenia-related neuregulin-1 polymorphisms on sensorimotor gating in healthy males. Biol Psychiatry 2011; 69(5): 479-486.

155. Olincy A, Martin L. Diminished suppression of the P50 auditory evoked potential in bipolar disorder subjects with a history of psychosis. Am J Psychiatry 2005; 162(1): 43-49.

156. Sanchez-Morla EM, Garcia-Jimenez MA, Barabash A, Martinez-Vizcaino V, Mena J, Cabranes-Diaz JA et al. P50 sensory gating deficit is a common marker of vulnerability to bipolar disorder and schizophrenia. Acta Psychiatr Scand 2008; 117(4): 313-318.

157. Lijffijt M, Moeller FG, Boutros NN, Steinberg JL, Meier SL, Lane SD et al. Diminished P50, N100 and P200 auditory sensory gating in bipolar I disorder. Psychiatry Res 2009; 167(3): 191-201. 
158. Shaikh M, Hall MH, Schulze K, Dutt A, Walshe M, Williams I et al. Do COMT, BDNF and NRG1 polymorphisms influence P50 sensory gating in psychosis? Psychol Med 2011; 41(2): 263-276.

159. Andersson S, Barder, H.E., Hellvin, T., Lovdahl, H., Malt, U.F. Neuropsychological and electrophysiological indices of neurocognitive dysfunction in bipolar II disorder. Bipolar Disord 2008; 10: 888-899.

160. Bestelmeyer PE, Phillips LH, Crombie C, Benson P, St Clair D. The P300 as a possible endophenotype for schizophrenia and bipolar disorder: Evidence from twin and patient studies. Psychiatry Res 2009; 169(3): 212-219.

161. Fridberg DJ, Hetrick WP, Brenner CA, Shekhar A, Steffen AN, Malloy FW et al. Relationships between auditory event-related potentials and mood state, medication, and comorbid psychiatric illness in patients with bipolar disorder. Bipolar Disord 2009; 11(8): 857-866.

162. Pierson A, Jouvent R, Quintin P, Perez-Diaz F, Leboyer M. Information processing deficits in relatives of manic depressive patients. Psychol Med 2000; 30(3): 545-555.

163. Hall MH, Rijsdijk F, Kalidindi S, Schulze K, Kravariti E, Kane F et al. Genetic overlap between bipolar illness and event-related potentials. Psychol Med 2007; 37(5): 667-678.

164. Hall MH, Schulze K, Rijsdijk F, Kalidindi S, McDonald C, Bramon E et al. Are auditory P300 and duration MMN heritable and putative endophenotypes of psychotic bipolar disorder? A Maudsley Bipolar Twin and Family Study. Psychol Med 2009; 39(8): 1277-1287.

165. Korostenskaja M, Kahkonen S. What do ERPs and ERFs reveal about the effect of antipsychotic treatment on cognition in schizophrenia? Curr Pharm Des 2009; 15(22): 2573-2593.

166. Park EJ, Han SI, Jeon YW. Auditory and visual P300 reflecting cognitive improvement in patients with schizophrenia with quetiapine: a pilot study. Prog Neuropsychopharmacol Biol Psychiatry 2010; 34(4): 674-680.

167. Takei Y, Kumano S, Maki Y, Hattori S, Kawakubo Y, Kasai K et al. Preattentive dysfunction in bipolar disorder: a MEG study using auditory mismatch negativity. Prog Neuropsychopharmacol Biol Psychiatry 2010; 34(6): 903-912.

168. Leitman DI, Sehatpour P, Higgins BA, Foxe JJ, Silipo G, Javitt DC. Sensory deficits and distributed hierarchical dysfunction in schizophrenia. Am J Psychiatry 2010; 167(7): 818-827.

169. Kempton MJ, Geddes JR, Ettinger U, Williams SC, Grasby PM. Meta-analysis, database, and metaregression of 98 structural imaging studies in bipolar disorder. Arch Gen Psychiatry 2008; 65(9): 1017-1032.

170. Emsell L, McDonald C. The structural neuroimaging of bipolar disorder. Int Rev Psychiatry 2009; 21(4): 297-313.

171. Ioannidis JP. Excess significance bias in the literature on brain volume abnormalities. Arch Gen Psychiatry 2011; 68(8): 773-780.

172. Strakowski SM, Delbello MP, Adler CM. The functional neuroanatomy of bipolar disorder: a review of neuroimaging findings. Mol Psychiatry 2005; 10(1): 105-116.

173. Hallahan B, Newell J, Soares JC, Brambilla P, Strakowski SM, Fleck DE et al. Structural magnetic resonance imaging in bipolar disorder: an international collaborative mega-analysis of individual adult patient data. Biol Psychiatry 2011; 69(4): 326-335.

174. Foland-Ross LC, Thompson PM, Sugar CA, Madsen SK, Shen JK, Penfold C et al. Investigation of cortical thickness abnormalities in lithium-free adults with bipolar I disorder using cortical pattern matching. Am J Psychiatry 2011; 168(5): 530-539.

175. Bora E, Fornito A, Yucel M, Pantelis C. Voxelwise meta-analysis of gray matter abnormalities in bipolar disorder. Biol Psychiatry 2010; 67(11): 1097-1105.

176. Lisy ME, Jarvis KB, Delbello MP, Mills NP, Weber WA, Fleck D et al. Progressive neurostructural changes in adolescent and adult patients with bipolar disorder. Bipolar Disord 2011; 13(4): 396-405.

177. Benedetti F, Absinta M, Rocca MA, Radaelli D, Poletti S, Bernasconi A et al. Tract-specific white matter structural disruption in patients with bipolar disorder. Bipolar Disord 2011; 13(4): 414-424.

178. Mahon K, Burdick KE, Szeszko PR. A role for white matter abnormalities in the pathophysiology of bipolar disorder. Neurosci Biobehav Rev 2010; 34(4): 533-554. 
179. McIntosh AM, Moorhead TW, McKirdy J, Hall J, Sussmann JE, Stanfield AC et al. Prefrontal gyral folding and its cognitive correlates in bipolar disorder and schizophrenia. Acta Psychiatr Scand 2009; 119(3): 192-198.

180. Arnone D, Cavanagh J, Gerber D, Lawrie SM, Ebmeier KP, McIntosh AM. Magnetic resonance imaging studies in bipolar disorder and schizophrenia: meta-analysis. Br J Psychiatry 2009; 195(3): 194-201.

181. Rimol LM, Hartberg CB, Nesvag R, Fennema-Notestine C, Hagler DJ, Jr., Pung CJ et al. Cortical thickness and subcortical volumes in schizophrenia and bipolar disorder. Biol Psychiatry 2010; 68(1): 41-50.

182. Ellison-Wright I, Bullmore E. Anatomy of bipolar disorder and schizophrenia: a meta-analysis. Schizophr Res 2010; 117(1): 1-12.

183. Mamah D, wang, L., Csernansky, J.G., Rice, J.P., Smith, M., Barch, D.M. Morphometry of the hippocampus and amygdala in bipolar disorder and schizophrenia. Bipolar Disord 2010; 12: 341-343.

184. de Castro-Manglano P, Mechelli A, Soutullo C, Landecho I, Gimenez-Amaya JM, Ortuno F et al. Structural brain abnormalities in first-episode psychosis: differences between affective psychoses and schizophrenia and relationship to clinical outcome. Bipolar Disord 2011; 13(5-6): 545-555.

185. Hartberg CB, Sundet K, Rimol LM, Haukvik UK, Lange EH, Nesvag R et al. Subcortical brain volumes relate to neurocognition in schizophrenia and bipolar disorder and healthy controls. Prog Neuropsychopharmacol Biol Psychiatry 2011; 35(4): 1122-1130.

186. Fornito A, Malhi GS, Lagopoulos J, Ivanovski B, Wood SJ, Velakoulis D et al. In vivo evidence for early neurodevelopmental anomaly of the anterior cingulate cortex in bipolar disorder. Acta Psychiatr Scand 2007; 116(6): 467-472.

187. Smieskova R, Fusar-Poli P, Allen P, Bendfeldt K, Stieglitz RD, Drewe J et al. Neuroimaging predictors of transition to psychosis--a systematic review and meta-analysis. Neurosci Biobehav Rev 2010; 34(8): 1207-1222.

188. Fusar-Poli P, Borgwardt S, Crescini A, Deste G, Kempton MJ, Lawrie S et al. Neuroanatomy of vulnerability to psychosis: a voxel-based meta-analysis. Neurosci Biobehav Rev 2011; 35(5): 11751185.

189. Mechelli A, Riecher-Rossler A, Meisenzahl EM, Tognin S, Wood SJ, Borgwardt SJ et al. Neuroanatomical abnormalities that predate the onset of psychosis: a multicenter study. Arch Gen Psychiatry 2011; 68(5): 489-495.

190. Adler CM, DelBello MP, Jarvis K, Levine A, Adams J, Strakowski SM. Voxel-based study of structural changes in first-episode patients with bipolar disorder. Biol Psychiatry 2007; 61(6): 776-781.

191. Vita A, De Peri L, Sacchetti E. Gray matter, white matter, brain, and intracranial volumes in firstepisode bipolar disorder: a meta-analysis of magnetic resonance imaging studies. Bipolar Disord 2009; 11(8): 807-814.

192. Rosso IM, Killgore WD, Cintron CM, Gruber SA, Tohen M, Yurgelun-Todd DA. Reduced amygdala volumes in first-episode bipolar disorder and correlation with cerebral white matter. Biol Psychiatry 2007; 61(6): 743-749.

193. Fornito A, Yucel M, Wood SJ, Bechdolf A, Carter S, Adamson C et al. Anterior cingulate cortex abnormalities associated with a first psychotic episode in bipolar disorder. Br J Psychiatry 2009; 194(5): 426-433.

194. de Azevedo-Marques Perico C, Duran FL, Zanetti MV, Santos LC, Murray RM, Scazufca M et al. A population-based morphometric MRI study in patients with first-episode psychotic bipolar disorder: comparison with geographically matched healthy controls and major depressive disorder subjects. Bipolar Disord 2011; 13(1): 28-40.

195. Usher J, Leucht S, Falkai P, Scherk H. Correlation between amygdala volume and age in bipolar disorder - a systematic review and meta-analysis of structural MRI studies. Psychiatry Res 2010; 182(1): 1-8.

196. Ahn MS, Breeze JL, Makris N, Kennedy DN, Hodge SM, Herbert MR et al. Anatomic brain magnetic resonance imaging of the basal ganglia in pediatric bipolar disorder. J Affect Disord 2007; 104(1-3): 147-154. 
197. Geller B, Harms MP, Wang L, Tillman R, DelBello MP, Bolhofner K et al. Effects of age, sex, and independent life events on amygdala and nucleus accumbens volumes in child bipolar I disorder. Biol Psychiatry 2009; 65(5): 432-437.

198. Walterfang M, Wood AG, Barton S, Velakoulis D, Chen J, Reutens DC et al. Corpus callosum size and shape alterations in individuals with bipolar disorder and their first-degree relatives. Prog Neuropsychopharmacol Biol Psychiatry 2009; 33(6): 1050-1057.

199. Takahashi T, Walterfang M, Wood SJ, Kempton MJ, Jogia J, Lorenzetti V et al. Pituitary volume in patients with bipolar disorder and their first-degree relatives. J Affect Disord 2010; 124(3): 256-261.

200. Harms MP, Wang L, Campanella C, Aldridge K, Moffitt AJ, Kuelper J et al. Structural abnormalities in gyri of the prefrontal cortex in individuals with schizophrenia and their unaffected siblings. $\mathrm{Br} \mathrm{J}$ Psychiatry 2010; 196(2): 150-157.

201. Sprooten E, Sussmann JE, Clugston A, Peel A, McKirdy J, Moorhead TW et al. White matter integrity in individuals at high genetic risk of bipolar disorder. Biol Psychiatry 2011; 70(4): 350-356.

202. Cerullo MA, Adler CM, Delbello MP, Strakowski SM. The functional neuroanatomy of bipolar disorder. Int Rev Psychiatry 2009; 21(4): 314-322.

203. Chen CH, Suckling J, Lennox BR, Ooi C, Bullmore ET. A quantitative meta-analysis of fMRI studies in bipolar disorder. Bipolar Disord 2011; 13(1): 1-15.

204. Houenou J, Frommberger J, Carde S, Glasbrenner M, Diener C, Leboyer M et al. Neuroimagingbased markers of bipolar disorder: Evidence from two meta-analyses. J Affect Disord 2011; 132(3): 344-355.

205. Gonul AS, Coburn K, Kula M. Cerebral blood flow, metabolic, receptor, and transporter changes in bipolar disorder: the role of PET and SPECT studies. Int Rev Psychiatry 2009; 21(4): 323-335.

206. Brambilla P, Bellani M, Yeh PH, Soares JC, Tansella M. White matter connectivity in bipolar disorder. Int Rev Psychiatry 2009; 21(4): 380-386.

207. Macritchie KA, Lloyd AJ, Bastin ME, Vasudev K, Gallagher P, Eyre R et al. White matter microstructural abnormalities in euthymic bipolar disorder. Br J Psychiatry 2010; 196(1): 52-58.

208. Benedetti F, Yeh PH, Bellani M, Radaelli D, Nicoletti MA, Poletti S et al. Disruption of white matter integrity in bipolar depression as a possible structural marker of illness. Biol Psychiatry 2011; 69(4): 309-317.

209. Wessa M, Linke J. Emotional processing in bipolar disorder: behavioural and neuroimaging findings. Int Rev Psychiatry 2009; 21(4): 357-367.

210. Kim E, Jung YC, Ku J, Kim JJ, Lee H, Kim SY et al. Reduced activation in the mirror neuron system during a virtual social cognition task in euthymic bipolar disorder. Prog Neuropsychopharmacol Biol Psychiatry 2009; 33(8): 1409-1416.

211. Brooks JO, 3rd, Rosen AC, Hoblyn JC, Woodard SA, Krasnykh O, Ketter TA. Resting prefrontal hypometabolism and paralimbic hypermetabolism related to verbal recall deficits in euthymic older adults with bipolar disorder. Am J Geriatr Psychiatry 2009; 17(12): 1022-1029.

212. Brooks JO, 3rd, Wang PW, Strong C, Sachs N, Hoblyn JC, Fenn R et al. Preliminary evidence of differential relations between prefrontal cortex metabolism and sustained attention in depressed adults with bipolar disorder and healthy controls. Bipolar Disord 2006; 8(3): 248-254.

213. Brooks JO, 3rd, Bearden CE, Hoblyn JC, Woodard SA, Ketter TA. Prefrontal and paralimbic metabolic dysregulation related to sustained attention in euthymic older adults with bipolar disorder. $\mathrm{Bi}$ polar Disord 2010; 12(8): 866-874.

214. Maiza O, Razafimandimby A, Brazo P, Lecardeur L, Delamillieure P, Mazoyer B et al. Functional deficit in the medial prefrontal cortex in patients with chronic schizophrenia, first psychotic episode, and bipolar disorders. Bipolar Disord 2010; 12(4): 450-452.

215. Sussmann JE, Lymer GK, McKirdy J, Moorhead TW, Maniega SM, Job D et al. White matter abnormalities in bipolar disorder and schizophrenia detected using diffusion tensor magnetic resonance imaging. Bipolar Disord 2009; 11(1): 11-18.

216. McIntosh AM, Whalley HC, McKirdy J, Hall J, Sussmann JE, Shankar P et al. Prefrontal function and activation in bipolar disorder and schizophrenia. Am J Psychiatry 2008; 165(3): 378-384. 
217. Hamilton LS, Altshuler LL, Townsend J, Bookheimer SY, Phillips OR, Fischer J et al. Alterations in functional activation in euthymic bipolar disorder and schizophrenia during a working memory task. Hum Brain Mapp 2009.

218. Hall J, Whalley HC, Marwick K, McKirdy J, Sussmann J, Romaniuk L et al. Hippocampal function in schizophrenia and bipolar disorder. Psychol Med 2010; 40(5): 761-770.

219. Bloemen OJ, de Koning MB, Schmitz N, Nieman DH, Becker HE, de Haan L et al. White-matter markers for psychosis in a prospective ultra-high-risk cohort. Psychol Med 2010; 40(8): 1297-1304.

220. Modinos G, Ormel J, Aleman A. Altered activation and functional connectivity of neural systems supporting cognitive control of emotion in psychosis proneness. Schizophr Res 2010; 118(1-3): 8897.

221. Fusar-Poli P, Howes OD, Allen P, Broome M, Valli I, Asselin MC et al. Abnormal frontostriatal interactions in people with prodromal signs of psychosis: a multimodal imaging study. Arch Gen Psychiatry 2010; 67(7): 683-691.

222. Koutsouleris N, Patschurek-Kliche K, Scheuerecker J, Decker P, Bottlender R, Schmitt G et al. Neuroanatomical correlates of executive dysfunction in the at-risk mental state for psychosis. Schizophr Res 2010; 123(2-3): 160-174.

223. Frazier JA, Breeze JL, Papadimitriou G, Kennedy DN, Hodge SM, Moore CM et al. White matter abnormalities in children with and at risk for bipolar disorder. Bipolar Disord 2007; 9(8): 799-809.

224. Chan WY, Yang GL, Chia MY, Lau IY, Sitoh YY, Nowinski WL et al. White matter abnormalities in first-episode schizophrenia: a combined structural MRI and DTI study. Schizophr Res 2010; 119(13): 52-60.

225. Perez-Iglesias R, Tordesillas-Gutierrez D, McGuire PK, Barker GJ, Roiz-Santianez R, Mata I et al. White matter integrity and cognitive impairment in first-episode psychosis. Am J Psychiatry 2010; 167(4): 451-458.

226. Chan WY, Yang GL, Chia MY, Woon PS, Lee J, Keefe R et al. Cortical and subcortical white matter abnormalities in adults with remitted first-episode mania revealed by Tract-Based Spatial Statistics. Bipolar Disord 2010; 12(4): 383-389.

227. James A, Hough M, James S, Burge L, Winmill L, Nijhawan S et al. Structural brain and neuropsychometric changes associated with pediatric bipolar disorder with psychosis. Bipolar Disord 2011; 13(1): 16-27.

228. Pavuluri MN, O'Connor MM, Harral EM, Sweeney JA. An fMRI study of the interface between affective and cognitive neural circuitry in pediatric bipolar disorder. Psychiatry Res 2008; 162(3): 244-255.

229. Pavuluri MN, O’Connor MM, Harral E, Sweeney JA. Affective neural circuitry during facial emotion processing in pediatric bipolar disorder. Biol Psychiatry 2007; 62(2): 158-167.

230. Kalmar JH, Wang F, Chepenik LG, Womer FY, Jones MM, Pittman B et al. Relation between amygdala structure and function in adolescents with bipolar disorder. J Am Acad Child Adolesc Psychiatry 2009; 48(6): 636-642.

231. Dickstein DP, Finger EC, Skup M, Pine DS, Blair JR, Leibenluft E. Altered neural function in pediatric bipolar disorder during reversal learning. Bipolar Disord 2010; 12(7): 707-719.

232. Chaddock CA, Barker GJ, Marshall N, Schulze K, Hall MH, Fern A et al. White matter microstructural impairments and genetic liability to familial bipolar I disorder. Br J Psychiatry 2009; 194(6): 527-534.

233. Drapier D, Surguladze S, Marshall N, Schulze K, Fern A, Hall MH et al. Genetic liability for bipolar disorder is characterized by excess frontal activation in response to a working memory task. Biol Psychiatry 2008; 64(6): 513-520.

234. Allin MP, Marshall N, Schulze K, Walshe M, Hall MH, Picchioni M et al. A functional MRI study of verbal fluency in adults with bipolar disorder and their unaffected relatives. Psychol Med 2010; 40(12): 2025-2035.

235. Surguladze SA, Marshall N, Schulze K, Hall MH, Walshe M, Bramon E et al. Exaggerated neural response to emotional faces in patients with bipolar disorder and their first-degree relatives. Neuroimage 2010. 
236. Thermenos HW, Makris N, Whitfield-Gabrieli S, Brown AB, Giuliano AJ, Lee EH et al. A functional MRI study of working memory in adolescents and young adults at genetic risk for bipolar disorder: preliminary findings. Bipolar Disord 2011; 13(3): 272-286.

237. Mackay CE, Roddick, E., Barrick, T.R., Lloyd, A.J., Roberts, N., Crow, T.J., Young, A.H., Ferrier, I.N. Sex dependence of brain size and shape in bipolar disorder: an exploratory study. Bipolar Disord 2010; $12: 306-311$.

238. Blumberg HP, Krystal JH, Bansal R, Martin A, Dziura J, Durkin K et al. Age, rapid-cycling, and pharmacotherapy effects on ventral prefrontal cortex in bipolar disorder: a cross-sectional study. Biol Psychiatry 2006; 59(7): 611-618.

239. Ekman CJ, Lind J, Ryden E, Ingvar M, Landen M. Manic episodes are associated with grey matter volume reduction - a voxel-based morphometry brain analysis. Acta Psychiatr Scand 2010; 122(6): 507-515.

240. Phillips ML, Travis MJ, Fagiolini A, Kupfer DJ. Medication effects in neuroimaging studies of bipolar disorder. Am J Psychiatry 2008; 165(3): 313-320.

241. Usher J, Menzel P, Schneider-Axmann T, Kemmer C, Reith W, Falkai P et al. Increased right amygdala volume in lithium-treated patients with bipolar I disorder. Acta Psychiatr Scand 2010; 121(2): 119-124.

242. Savitz J, Nugent AC, Bogers W, Liu A, Sills R, Luckenbaugh DA et al. Amygdala volume in depressed patients with bipolar disorder assessed using high resolution 3T MRI: the impact of medication. Neuroimage 2010; 49(4): 2966-2976.

243. Lyoo IK, Dager SR, Kim JE, Yoon SJ, Friedman SD, Dunner DL et al. Lithium-induced gray matter volume increase as a neural correlate of treatment response in bipolar disorder: a longitudinal brain imaging study. Neuropsychopharmacology 2010; 35(8): 1743-1750.

244. Germana C, Kempton MJ, Sarnicola A, Christodoulou T, Haldane M, Hadjulis M et al. The effects of lithium and anticonvulsants on brain structure in bipolar disorder. Acta Psychiatr Scand 2010; 122(6): 481-487.

245. Regenold WT. Lithium and increased hippocampal volume-more tissue or more water? Neuropsychopharmacology 2008; 33(7): 1773-1774; author reply 1775.

246. Jogia J, Haldane M, Cobb A, Kumari V, Frangou S. Pilot investigation of the changes in cortical activation during facial affect recognition with lamotrigine monotherapy in bipolar disorder. $\mathrm{Br} J$ Psychiatry 2008; 192(3): 197-201.

247. Pavuluri MN, Passarotti AM, Harral EM, Sweeney JA. Enhanced prefrontal function with pharmacotherapy on a response inhibition task in adolescent bipolar disorder. J Clin Psychiatry 2010; 71(11): 1526-1534.

248. Moncrieff J, Leo J. A systematic review of the effects of antipsychotic drugs on brain volume. Psychol Med 2010; 40(9): 1409-1422.

249. Ho BC, Andreasen NC, Ziebell S, Pierson R, Magnotta V. Long-term Antipsychotic Treatment and Brain Volumes: A Longitudinal Study of First-Episode Schizophrenia. Arch Gen Psychiatry 2011; 68(2): 128-137.

250. Vernon AC, Natesan S, Modo M, Kapur S. Effect of chronic antipsychotic treatment on brain structure: a serial magnetic resonance imaging study with ex vivo and postmortem confirmation. Biol Psychiatry 2011; 69(10): 936-944.

251. Leung M, Cheung C, Yu K, Yip B, Sham P, Li Q et al. Gray matter in first-episode schizophrenia before and after antipsychotic drug treatment. Anatomical likelihood estimation meta-analyses with sample size weighting. Schizophr Bull 2011; 37(1): 199-211.

252. Navari S, Dazzan P. Do antipsychotic drugs affect brain structure? A systematic and critical review of MRI findings. Psychol Med 2009; 39(11): 1763-1777.

253. Jones LD, Payne ME, Messer DF, Beyer JL, MacFall JR, Krishnan KR et al. Temporal lobe volume in bipolar disorder: relationship with diagnosis and antipsychotic medication use. J Affect Disord 2009; 114(1-3): 50-57.

254. Meisenzahl EM, Scheuerecker J, Zipse M, Ufer S, Wiesmann M, Frodl T et al. Effects of treatment with the atypical neuroleptic quetiapine on working memory function: a functional MRI follow-up investigation. Eur Arch Psychiatry Clin Neurosci 2006; 256(8): 522-531. 
255. Schlagenhauf F, Dinges M, Beck A, Wustenberg T, Friedel E, Dembler T et al. Switching schizophrenia patients from typical neuroleptics to aripiprazole: effects on working memory dependent functional activation. Schizophr Res 2010; 118(1-3): 189-200.

256. Ettinger U, Williams SC, Fannon D, Premkumar P, Kuipers E, Moller HJ et al. Functional magnetic resonance imaging of a parametric working memory task in schizophrenia: relationship with performance and effects of antipsychotic treatment. Psychopharmacology (Berl) 2011; 216(1): 17-27.

257. Keshavan MS, Prasad KM, Pearlson G. Are brain structural abnormalities useful as endophenotypes in schizophrenia? Int Rev Psychiatry 2007; 19(4): 397-406.

258. Prasad KM, Keshavan MS. Structural cerebral variations as useful endophenotypes in schizophrenia: do they help construct "extended endophenotypes"? Schizophr Bull 2008; 34(4): 774-790.

259. McDonald C, Bullmore ET, Sham PC, Chitnis X, Wickham H, Bramon E et al. Association of genetic risks for schizophrenia and bipolar disorder with specific and generic brain structural endophenotypes. Arch Gen Psychiatry 2004; 61(10): 974-984.

260. Pan L, Keener MT, Hassel S, Phillips ML. Functional neuroimaging studies of bipolar disorder: examining the wide clinical spectrum in the search for disease endophenotypes. Int Rev Psychiatry 2009; 21(4): 368-379.

261. Roffman JL, Weiss AP, Goff DC, Rauch SL, Weinberger DR. Neuroimaging-genetic paradigms: a new approach to investigate the pathophysiology and treatment of cognitive deficits in schizophrenia. Harv Rev Psychiatry 2006; 14(2): 78-91.

262. Liu J, Pearlson G, Windemuth A, Ruano G, Perrone-Bizzozero NI, Calhoun V. Combining fMRI and SNP data to investigate connections between brain function and genetics using parallel ICA. Hum Brain Mapp 2009; 30(1): 241-255.

263. Potkin SG, Turner JA, Guffanti G, Lakatos A, Fallon JH, Nguyen DD et al. A genome-wide association study of schizophrenia using brain activation as a quantitative phenotype. Schizophr Bull 2009; 35(1): 96-108.

264. Nicodemus KK, Law AJ, Radulescu E, Luna A, Kolachana B, Vakkalanka R et al. Biological validation of increased schizophrenia risk with NRG1, ERBB4, and AKT1 epistasis via functional neuroimaging in healthy controls. Arch Gen Psychiatry 2010; 67(10): 991-1001.

265. Aarts E, Roelofs A, Franke B, Rijpkema M, Fernandez G, Helmich RC et al. Striatal dopamine mediates the interface between motivational and cognitive control in humans: evidence from genetic imaging. Neuropsychopharmacology 2010; 35(9): 1943-1951.

266. Demirci O, Clark VP, Magnotta VA, Andreasen NC, Lauriello J, Kiehl KA et al. A Review of Challenges in the Use of fMRI for Disease Classification / Characterization and A Projection Pursuit Application from Multi-site fMRI Schizophrenia Study. Brain imaging and behavior 2008; 2(3): 147226.

267. Hahn T, Marquand AF, Ehlis AC, Dresler T, Kittel-Schneider S, Jarczok TA et al. Integrating Neurobiological Markers of Depression. Arch Gen Psychiatry 2010.

268. Haber SN, Rauch SL. Neurocircuitry: a window into the networks underlying neuropsychiatric disease. Neuropsychopharmacology 2010; 35(1): 1-3.

269. Price JL, Drevets WC. Neurocircuitry of mood disorders. Neuropsychopharmacology 2010; 35(1): $192-216$.

270. Krishnan V, Nestler EJ. Linking molecules to mood: new insight into the biology of depression. Am J Psychiatry 2010; 167(11): 1305-1320.

271. Haber SN, Knutson B. The reward circuit: linking primate anatomy and human imaging. Neuropsychopharmacology 2010; 35(1): 4-26.

272. Leh SE, Petrides M, Strafella AP. The neural circuitry of executive functions in healthy subjects and Parkinson's disease. Neuropsychopharmacology 2010; 35(1): 70-85.

273. Hall J, Whalley HC, McKirdy JW, Sprengelmeyer R, Santos IM, Donaldson DI et al. A common neural system mediating two different forms of social judgement. Psychol Med 2010; 40(7): 11831192.

274. Benes FM. Amygdalocortical circuitry in schizophrenia: from circuits to molecules. Neuropsychopharmacology 2010; 35(1): 239-257. 
275. Eisenberg DP, Berman KF. Executive function, neural circuitry, and genetic mechanisms in schizophrenia. Neuropsychopharmacology 2010; 35(1): 258-277.

276. Phillips ML, Ladouceur CD, Drevets WC. A neural model of voluntary and automatic emotion regulation: implications for understanding the pathophysiology and neurodevelopment of bipolar disorder. Mol Psychiatry 2008; 13(9): 829, 833-857.

277. Marchand WR, Yurgelun-Todd D. Striatal structure and function in mood disorders: a comprehensive review. Bipolar Disord 2010; 12(8): 764-785.

278. Sanacora G, Zarate CA, Krystal JH, Manji HK. Targeting the glutamatergic system to develop novel, improved therapeutics for mood disorders. Nat Rev Drug Discov 2008; 7(5): 426-437.

279. Chen G, Henter ID, Manji HK. Presynaptic glutamatergic dysfunction in bipolar disorder. Biol Psychiatry 2010; 67(11): 1007-1009.

280. Castillo M, Kwock L, Courvoisie H, Hooper SR. Proton MR spectroscopy in children with bipolar affective disorder: preliminary observations. Ajnr 2000; 21(5): 832-838.

281. Ongur D, Jensen JE, Prescot AP, Stork C, Lundy M, Cohen BM et al. Abnormal glutamatergic neurotransmission and neuronal-glial interactions in acute mania. Biol Psychiatry 2008; 64(8): 718726.

282. Yuksel C, Ongur D. Magnetic resonance spectroscopy studies of glutamate-related abnormalities in mood disorders. Biol Psychiatry 2010; 68(9): 785-794.

283. Eastwood SL, Harrison PJ. Markers of glutamate synaptic transmission and plasticity are increased in the anterior cingulate cortex in bipolar disorder. Biol Psychiatry 2010; 67(11): 1010-1016.

284. Woo TU, Walsh JP, Benes FM. Density of glutamic acid decarboxylase 67 messenger RNAcontaining neurons that express the N-methyl-D-aspartate receptor subunit NR2A in the anterior cingulate cortex in schizophrenia and bipolar disorder. Arch Gen Psychiatry 2004; 61(7): 649-657.

285. Beneyto M, Kristiansen LV, Oni-Orisan A, McCullumsmith RE, Meador-Woodruff JH. Abnormal glutamate receptor expression in the medial temporal lobe in schizophrenia and mood disorders. Neuropsychopharmacology 2007; 32(9): 1888-1902.

286. Cherlyn SY, Woon PS, Liu JJ, Ong WY, Tsai GC, Sim K. Genetic association studies of glutamate, GABA and related genes in schizophrenia and bipolar disorder: a decade of advance. Neurosci Biobehav Rev 2010; 34(6): 958-977.

287. Fatemi SH, Folsom TD, Thuras PD. Deficits in GABA(B) receptor system in schizophrenia and mood disorders: A postmortem study. Schizophr Res 2011; 128(1-3): 37-43.

288. Woo TU, Shrestha K, Amstrong C, Minns MM, Walsh JP, Benes FM. Differential alterations of kainate receptor subunits in inhibitory interneurons in the anterior cingulate cortex in schizophrenia and bipolar disorder. Schizophr Res 2007; 96(1-3): 46-61.

289. Bielau H, Steiner J, Mawrin C, Trubner K, Brisch R, Meyer-Lotz G et al. Dysregulation of GABAergic neurotransmission in mood disorders: a postmortem study. Ann N Y Acad Sci 2007; 1096: 157169.

290. Sakai T, Oshima A, Nozaki Y, Ida I, Haga C, Akiyama H et al. Changes in density of calciumbinding-protein-immunoreactive GABAergic neurons in prefrontal cortex in schizophrenia and bipolar disorder. Neuropathology 2008; 28(2): 143-150.

291. Kaufman RE, Ostacher MJ, Marks EH, Simon NM, Sachs GS, Jensen JE et al. Brain GABA levels in patients with bipolar disorder. Prog Neuropsychopharmacol Biol Psychiatry 2009; 33(3): 427-434.

292. Cannon DM, Carson RE, Nugent AC, Eckelman WC, Kiesewetter DO, Williams J et al. Reduced muscarinic type 2 receptor binding in subjects with bipolar disorder. Arch Gen Psychiatry 2006; 63(7): 741-747.

293. Cannon DM, Ichise M, Fromm SJ, Nugent AC, Rollis D, Gandhi SK et al. Serotonin transporter binding in bipolar disorder assessed using [11C]DASB and positron emission tomography. Biol Psychiatry 2006; 60(3): 207-217.

294. Chou Y-H, Wang, S-J., Lin, C-L., Mao, W-C., Lee, S-M., Liao, M-H. Decreased brain serotonin transporter binding in the euthymic state of bipolar I but not bipolar II disorder: a SPECT study. Bipolar Disord 2010; 12: 312-318.

295. Cousins DA, Butts K, Young AH. The role of dopamine in bipolar disorder. Bipolar Disord 2009; 11(8): 787-806. 
296. Berk M, Dodd, S., Kauer-Sant'Anna, M., Bourin, M., Kapczinski, F., Norman, T. Dopamine dysregulation syndrome: implications for a dopamine hypothesis of bipolar disorder. Acta Psychiatr Scand 2007; 116 (Suppl 434): 41-49.

297. Yuen EY, Yan Z. Dopamine D4 receptors regulate AMPA receptor trafficking and glutamatergic transmission in GABAergic interneurons of prefrontal cortex. J Neurosci 2009; 29(2): 550-562.

298. Di Giovanni G, Esposito, E., Di Matteo, V. Role of serotonin in central dopamine dysfunction. CNS Neuroscience and Therapeutics 2010; 16: 179-194.

299. Lester DB, Rogers TD, Blaha CD. Acetylcholine-Dopamine Interactions in the Pathophysiology and Treatment of CNS Disorders. CNS Neurosci Ther 2010.

300. Howes OD, Kapur S. The dopamine hypothesis of schizophrenia: version III--the final common pathway. Schizophr Bull 2009; 35(3): 549-562.

301. Sawa A. Cortical development and glutamatergic dysregulation in schizophrenia. Biol Psychiatry 2009; 66(6): 530-532.

302. Choi KH, Zepp ME, Higgs BW, Weickert CS, Webster MJ. Expression profiles of schizophrenia susceptibility genes during human prefrontal cortical development. J Psychiatry Neurosci 2009; 34(6): 450-458.

303. Stone JM, Day F, Tsagaraki H, Valli I, McLean MA, Lythgoe DJ et al. Glutamate dysfunction in people with prodromal symptoms of psychosis: relationship to gray matter volume. Biol Psychiatry 2009; 66(6): 533-539.

304. Volk DW, Eggan SM, Lewis DA. Alterations in Metabotropic Glutamate Receptor 1 \{alpha\} and Regulator of G Protein Signaling 4 in the Prefrontal Cortex in Schizophrenia. Am J Psychiatry 2010; 167(12): 1489-1498.

305. de la Fuente-Sandoval C, Leon-Ortiz P, Favila R, Stephano S, Mamo D, Ramirez-Bermudez J et al. Higher levels of glutamate in the associative-striatum of subjects with prodromal symptoms of schizophrenia and patients with first-episode psychosis. Neuropsychopharmacology 2011; 36(9): 1781-1791.

306. Schultz CC, Nenadic I, Koch K, Wagner G, Roebel M, Schachtzabel C et al. Reduced Cortical Thickness is Associated with the Glutamatergic Regulatory Gene Risk Variant DAOA Arg30Lys in Schizophrenia. Neuropsychopharmacology 2011; 36(8): 1747-1753.

307. Lang UE, Puls I, Muller DJ, Strutz-Seebohm N, Gallinat J. Molecular mechanisms of schizophrenia. Cell Physiol Biochem 2007; 20(6): 687-702.

308. Lisman JE, Coyle JT, Green RW, Javitt DC, Benes FM, Heckers S et al. Circuit-based framework for understanding neurotransmitter and risk gene interactions in schizophrenia. Trends Neurosci 2008; 31(5): 234-242.

309. Fung SJ, Webster MJ, Sivagnanasundaram S, Duncan C, Elashoff M, Weickert CS. Expression of interneuron markers in the dorsolateral prefrontal cortex of the developing human and in schizophrenia. Am J Psychiatry 2010; 167(12): 1479-1488.

310. Gonzalez-Burgos G, Hashimoto T, Lewis DA. Alterations of cortical GABA neurons and network oscillations in schizophrenia. Curr Psychiatry Rep 2010; 12(4): 335-344.

311. Kohl MM, Paulsen O. The roles of GABAB receptors in cortical network activity. Advances in pharmacology (San Diego, Calif 2010; 58: 205-229.

312. Castner SA, Williams GV. Tuning the engine of cognition: a focus on NMDA/D1 receptor interactions in prefrontal cortex. Brain Cogn 2007; 63(2): 94-122.

313. Lewis DA, Moghaddam B. Cognitive dysfunction in schizophrenia: convergence of gammaaminobutyric acid and glutamate alterations. Arch Neurol 2006; 63(10): 1372-1376.

314. Nieoullon A. Dopamine and the regulation of cognition and attention. Prog Neurobiol 2002; 67(1): 53-83.

315. Aarts E, van Holstein M, Cools R. Striatal Dopamine and the Interface between Motivation and Cognition. Front Psychol 2011; 2: 163.

316. Durstewitz D, Seamans JK. The dual-state theory of prefrontal cortex dopamine function with relevance to catechol-o-methyltransferase genotypes and schizophrenia. Biol Psychiatry 2008; 64(9): 739-749. 
317. Cools R, D’Esposito M. Inverted-U-shaped dopamine actions on human working memory and cognitive control. Biol Psychiatry 2011; 69(12): e113-125.

318. Cropley VL, Fujita M, Innis RB, Nathan PJ. Molecular imaging of the dopaminergic system and its association with human cognitive function. Biol Psychiatry 2006; 59(10): 898-907.

319. Amitai N, Markou A. Disruption of performance in the five-choice serial reaction time task induced by administration of $\mathrm{N}$-methyl-D-aspartate receptor antagonists: relevance to cognitive dysfunction in schizophrenia. Biol Psychiatry 2010; 68(1): 5-16.

320. Bustillo JR, Chen H, Gasparovic C, Mullins P, Caprihan A, Qualls C et al. Glutamate as a Marker of Cognitive Function in Schizophrenia: A Proton Spectroscopic Imaging Study at 4 Tesla. Biol Psychiatry 2010.

321. Wylie GR, Clark EA, Butler PD, Javitt DC. Schizophrenia patients show task switching deficits consistent with N-methyl-d-aspartate system dysfunction but not global executive deficits: implications for pathophysiology of executive dysfunction in schizophrenia. Schizophr Bull 2010; 36(3): 585-594.

322. Corlett PR, Honey GD, Krystal JH, Fletcher PC. Glutamatergic model psychoses: prediction error, learning, and inference. Neuropsychopharmacology 2011; 36(1): 294-315.

323. Homayoun H, Moghaddam B. Group 5 metabotropic glutamate receptors: role in modulating cortical activity and relevance to cognition. Eur J Pharmacol 2010; 639(1-3): 33-39.

324. Marek GJ. Metabotropic glutamate2/3 (mGlu2/3) receptors, schizophrenia and cognition. Eur J Pharmacol 2010; 639(1-3): 81-90.

325. Chamberlain SR, Muller U, Blackwell AD, Robbins TW, Sahakian BJ. Noradrenergic modulation of working memory and emotional memory in humans. Psychopharmacology (Berl) 2006; 188(4): 397407.

326. Goto N, Yoshimura R, Kakeda S, Moriya J, Hayashi K, Ikenouchi-Sugita A et al. Associations between plasma levels of 3-methoxy-4-hydroxyphenylglycol (MHPG) and negative symptoms or cognitive impairments in early-stage schizophrenia. Hum Psychopharmacol 2009; 24(8): 639-645.

327. Robbins TW, Roberts AC. Differential regulation of fronto-executive function by the monoamines and acetylcholine. Cereb Cortex 2007; 17 Suppl 1: i151-160.

328. Hasselmo ME, Sarter M. Modes and models of forebrain cholinergic neuromodulation of cognition. Neuropsychopharmacology 2011; 36(1): 52-73.

329. Lewis DA, Cho RY, Carter CS, Eklund K, Forster S, Kelly MA et al. Subunit-selective modulation of GABA type A receptor neurotransmission and cognition in schizophrenia. Am J Psychiatry 2008; 165(12): 1585-1593.

330. Enomoto T, Tse MT, Floresco SB. Reducing prefrontal gamma-aminobutyric Acid activity induces cognitive, behavioral, and dopaminergic abnormalities that resemble schizophrenia. Biol Psychiatry 2011; 69(5): 432-441.

331. Paine TA, Slipp LE, Carlezon WA, Jr. Schizophrenia-Like Attentional Deficits Following Blockade of Prefrontal Cortex GABA(A) Receptors. Neuropsychopharmacology 2011; 36(8): 1703-1713.

332. Pan YJ, Hsieh MH, Liu SK. Visuospatial working memory deficits in remitted patients with bipolar disorder: susceptibility to the effects of GABAergic agonists. Bipolar Disord 2011; 13(4): 365-376.

333. Ogren SO, Eriksson TM, Elvander-Tottie E, D’Addario C, Ekstrom JC, Svenningsson P et al. The role of 5-HT(1A) receptors in learning and memory. Behav Brain Res 2008; 195(1): 54-77.

334. Bosia M, Anselmetti S, Pirovano A, Ermoli E, Marino E, Bramanti P et al. HTTLPR functional polymorphism in schizophrenia: Executive functions vs. sustained attention dissociation. Prog Neuropsychopharmacol Biol Psychiatry 2010; 34: 81-85

335. Madsen K, Erritzoe D, Mortensen EL, Gade A, Madsen J, Baare W et al. Cognitive function is related to fronto-striatal serotonin transporter levels - a brain PET study in young healthy subjects. Psychopharmacology (Berl) 2011; 213(2-3): 573-581.

336. Meltzer HY, Horiguchi M, Massey BW. The role of serotonin in the NMDA receptor antagonist models of psychosis and cognitive impairment. Psychopharmacology (Berl) 2011; 213(2-3): 289-305.

337. Konradi C, Zimmerman EI, Yang CK, Lohmann KM, Gresch P, Pantazopoulos H et al. Hippocampal Interneurons in Bipolar Disorder. Arch Gen Psychiatry 2010. 
338. Konradi C, Yang CK, Zimmerman EI, Lohmann KM, Gresch P, Pantazopoulos H et al. Hippocampal interneurons are abnormal in schizophrenia. Schizophr Res 2011; 131(1-3): 165-173.

339. Benes FM. Neural circuitry models of schizophrenia: is it dopamine, GABA, glutamate, or something else? Biol Psychiatry 2009; 65(12): 1003-1005.

340. Goto Y, Yang CR, Otani S. Functional and dysfunctional synaptic plasticity in prefrontal cortex: roles in psychiatric disorders. Biol Psychiatry 2010; 67(3): 199-207.

341. Eroglu C, Barres BA. Regulation of synaptic connectivity by glia. Nature 2010; 468(7321): 223-231.

342. Deitmer JW, Steinhauser C. Synaptic processes-The role of glial cells. Preface. Brain Res Rev 2010; 63(1-2): 1 .

343. Eulenburg V, Gomeza J. Neurotransmitter transporters expressed in glial cells as regulators of synapse function. Brain Res Rev 2010; 63(1-2): 103-112.

344. Gray LJ, Dean B, Kronsbein HC, Robinson PJ, Scarr E. Region and diagnosis-specific changes in synaptic proteins in schizophrenia and bipolar I disorder. Psychiatry Res 2010; 178(2): 374-380.

345. Khvotchev M. Schizophrenia and synapse: emerging role of presynaptic fusion machinery. Biol Psychiatry 2010; 67(3): 197-198.

346. Mitterauer BJ. Downregulation and upregulation of glial connexins may cause synaptic imbalances responsible for the pathophysiology of bipolar disorder. CNS Neurosci Ther 2011; 17(5): 281-293.

347. Mitterauer BJ. Possible role of glia in cognitive impairment in schizophrenia. CNS Neurosci Ther 2011; 17(5): 333-344.

348. Pantazopoulos H, Woo TU, Lim MP, Lange N, Berretta S. Extracellular matrix-glial abnormalities in the amygdala and entorhinal cortex of subjects diagnosed with schizophrenia. Arch Gen Psychiatry 2010; 67(2): 155-166.

349. Yatham LN, Maj, M. Bipolar disorder. Clinical and neurobiological foundations. Wiley-Blackwell: Chichester, West Sussex, UK, 2010.

350. Schloesser RJ, Huang J, Klein PS, Manji HK. Cellular plasticity cascades in the pathophysiology and treatment of bipolar disorder. Neuropsychopharmacology 2008; 33(1): 110-133.

351. Hu LW, Kawamoto EM, Brietzke E, Scavone C, Lafer B. The role of Wnt signaling and its interaction with diverse mechanisms of cellular apoptosis in the pathophysiology of bipolar disorder. Prog Neuropsychopharmacol Biol Psychiatry 2011; 35(1): 11-17.

352. Sweatt JD. Mitogen-activated protein kinases in synaptic plasticity and memory. Curr Opin Neurobiol 2004; 14(3): 311-317.

353. Yuan P, Zhou R, Wang Y, Li X, Li J, Chen G et al. Altered levels of extracellular signal-regulated kinase signaling proteins in postmortem frontal cortex of individuals with mood disorders and schizophrenia. J Affect Disord 2010; 124(1-2): 164-169.

354. Li X, Liu M, Cai Z, Wang G, Li X. Regulation of glycogen synthase kinase-3 during bipolar mania treatment. Bipolar Disord 2010; 12(7): 741-752.

355. Li X, Jope RS. Is glycogen synthase kinase-3 a central modulator in mood regulation? Neuropsychopharmacology 2010; 35(11): 2143-2154.

356. Li YC, Gao WJ. GSK-3beta activity and hyperdopamine-dependent behaviors. Neurosci Biobehav Rev 2011; 35(3): 645-654.

357. Mamdani F, Alda M, Grof P, Young LT, Rouleau G, Turecki G. Lithium response and genetic variation in the CREB family of genes. Am J Med Genet B Neuropsychiatr Genet 2008; 147B(4): 500504.

358. Clay HB, Sillivan S, Konradi C. Mitochondrial dysfunction and pathology in bipolar disorder and schizophrenia. Int J Dev Neurosci 2010.

359. Andreazza AC, Shao L, Wang JF, Young LT. Mitochondrial complex I activity and oxidative damage to mitochondrial proteins in the prefrontal cortex of patients with bipolar disorder. Arch Gen Psychiatry 2010; 67(4): 360-368.

360. Cataldo AM, McPhie DL, Lange NT, Punzell S, Elmiligy S, Ye NZ et al. Abnormalities in mitochondrial structure in cells from patients with bipolar disorder. The American journal of pathology 2010; 177(2): 575-585. 
361. Regenold WT, Phatak P, Marano CM, Sassan A, Conley RR, Kling MA. Elevated cerebrospinal fluid lactate concentrations in patients with bipolar disorder and schizophrenia: implications for the mitochondrial dysfunction hypothesis. Biol Psychiatry 2009; 65(6): 489-494.

362. Andreazza AC, Kauer-Sant'anna M, Frey BN, Bond DJ, Kapczinski F, Young LT et al. Oxidative stress markers in bipolar disorder: a meta-analysis. J Affect Disord 2008; 111(2-3): 135-144.

363. Yumru M, Savas HA, Kalenderoglu A, Bulut M, Celik H, Erel O. Oxidative imbalance in bipolar disorder subtypes: a comparative study. Prog Neuropsychopharmacol Biol Psychiatry 2009; 33(6): 1070-1074.

364. Gawryluk JW, Wang JF, Andreazza AC, Shao L, Young LT. Decreased levels of glutathione, the major brain antioxidant, in post-mortem prefrontal cortex from patients with psychiatric disorders. Int J Neuropsychopharmacol 2011; 14(1): 123-130.

365. Bitanihirwe BK, Woo TU. Oxidative stress in schizophrenia: An integrated approach. Neurosci Biobehav Rev 2010.

366. Kato T. Molecular neurobiology of bipolar disorder: a disease of 'mood-stabilizing neurons'? Trends Neurosci 2008; 31(10): 495-503.

367. Insel TR, Cuthbert BN. Endophenotypes: bridging genomic complexity and disorder heterogeneity. Biol Psychiatry 2009; 66(11): 988-989.

368. Flint J, Munafo MR. The endophenotype concept in psychiatric genetics. Psychol Med 2007; 37(2): 163-180.

369. Meyer-Lindenberg A. Intermediate or brainless phenotypes for psychiatric research? Psychol Med 2010; 40(7): 1057-1062.

370. Hasler G, Drevets WC, Gould TD, Gottesman, II, Manji HK. Toward constructing an endophenotype strategy for bipolar disorders. Biol Psychiatry 2006; 60(2): 93-105.

371. Ancin I, Santos JL, Teijeira C, Sanchez-Morla EM, Bescos MJ, Argudo I et al. Sustained attention as a potential endophenotype for bipolar disorder. Acta Psychiatr Scand 2010; 122(3): 235-245.

372. Glahn DC, Almasy L, Barguil M, Hare E, Peralta JM, Kent JW, Jr. et al. Neurocognitive endophenotypes for bipolar disorder identified in multiplex multigenerational families. Arch Gen Psychiatry 2010; 67(2): 168-177.

373. Langenecker SA, Saunders EF, Kade AM, Ransom MT, McInnis MG. Intermediate: cognitive phenotypes in bipolar disorder. J Affect Disord 2010; 122(3): 285-293.

374. Benes FM. Searching for unique endophenotypes for schizophrenia and bipolar disorder within neural circuits and their molecular regulatory mechanisms. Schizophr Bull 2007; 33(4): 932-936.

375. O’Donovan MC, Craddock NJ, Owen MJ. Genetics of psychosis; insights from views across the genome. Hum Genet 2009; 126(1): 3-12.

376. Purcell SM, Wray NR, Stone JL, Visscher PM, O'Donovan MC, Sullivan PF et al. Common polygenic variation contributes to risk of schizophrenia and bipolar disorder. Nature 2009.

377. Jaenisch R, Bird A. Epigenetic regulation of gene expression: how the genome integrates intrinsic and environmental signals. Nat Genet 2003; 33 Suppl: 245-254.

378. Meaney MJ, Szyf M. Environmental programming of stress responses through DNA methylation: life at the interface between a dynamic environment and a fixed genome. Dialogues Clin Neurosci 2005; 7(2): 103-123.

379. Dudley KJ, Li X, Kobor MS, Kippin TE, Bredy TW. Epigenetic mechanisms mediating vulnerability and resilience to psychiatric disorders. Neurosci Biobehav Rev 2011; 35(7): 1544-1551.

380. Li E. Chromatin modification and epigenetic reprogramming in mammalian development. Nature reviews 2002; 3(9): 662-673.

381. Pidsley R, Dempster EL, Mill J. Brain weight in males is correlated with DNA methylation at IGF2. Mol Psychiatry 2010; 15(9): 880-881.

382. Borrelli E, Nestler EJ, Allis CD, Sassone-Corsi P. Decoding the epigenetic language of neuronal plasticity. Neuron 2008; 60(6): 961-974.

383. Graff J, Mansuy IM. Epigenetic codes in cognition and behaviour. Behav Brain Res 2008; 192(1): 7087.

384. Day JJ, Sweatt JD. Cognitive neuroepigenetics: A role for epigenetic mechanisms in learning and memory. Neurobiol Learn Mem 2011. 
385. Tsankova N, Renthal W, Kumar A, Nestler EJ. Epigenetic regulation in psychiatric disorders. Nat Rev Neurosci 2007; 8(5): 355-367.

386. Gavin DP, Sharma RP. Histone modifications, DNA methylation, and schizophrenia. Neurosci Biobehav Rev 2010; 34(6): 882-888.

387. Lahiri DK, Maloney B, Zawia NH. The LEARn model: an epigenetic explanation for idiopathic neurobiological diseases. Mol Psychiatry 2009; 14(11): 992-1003.

388. Bale TL, Baram TZ, Brown AS, Goldstein JM, Insel TR, McCarthy MM et al. Early life programming and neurodevelopmental disorders. Biol Psychiatry 2010; 68(4): 314-319.

389. Rutten BP, Mill J. Epigenetic mediation of environmental influences in major psychotic disorders. Schizophr Bull 2009; 35(6): 1045-1056.

390. Pidsley R, Mill J. Epigenetic Studies of Psychosis: Current Findings, Methodological Approaches, and Implications for Postmortem Research. Biol Psychiatry 2010.

391. Abel T, Zukin RS. Epigenetic targets of HDAC inhibition in neurodegenerative and psychiatric disorders. Curr Opin Pharmacol 2008; 8(1): 57-64.

392. Kazantsev AG, Thompson LM. Therapeutic application of histone deacetylase inhibitors for central nervous system disorders. Nat Rev Drug Discov 2008; 7(10): 854-868.

393. Costa E, Chen Y, Dong E, Grayson DR, Kundakovic M, Maloku E et al. GABAergic promoter hypermethylation as a model to study the neurochemistry of schizophrenia vulnerability. Expert Rev Neurother 2009; 9(1): 87-98.

394. Kendler KS. “A gene for...": the nature of gene action in psychiatric disorders. Am J Psychiatry 2005; 162(7): 1243-1252.

395. Keller MC, Miller G. Resolving the paradox of common, harmful, heritable mental disorders: which evolutionary genetic models work best? Behav Brain Sci 2006; 29(4): 385-404; discussion 405-352.

396. Rucker JJ, McGuffin P. Polygenic heterogeneity: a complex model of genetic inheritance in psychiatric disorders. Biol Psychiatry 2010; 68(4): 312-313.

397. Corvin A, Craddock N, Sullivan PF. Genome-wide association studies: a primer. Psychol Med 2010; 40(7): 1063-1077.

398. van Winkel R, Esquivel G, Kenis G, Wichers M, Collip D, Peerbooms O et al. Genome-Wide Findings in Schizophrenia and the Role of Gene-Environment Interplay. CNS Neurosci Ther 2010.

399. Dickson SP, Wang K, Krantz I, Hakonarson H, Goldstein DB. Rare variants create synthetic genome-wide associations. PLoS biology 2010; 8(1): e1000294.

400. Redon R, Ishikawa S, Fitch KR, Feuk L, Perry GH, Andrews TD et al. Global variation in copy number in the human genome. Nature 2006; 444(7118): 444-454.

401. Fortin MP, Rouch I, Dauphinot V, Gedeon C, Genthon S, Bonnefoy M et al. Effects of anticholinergic drugs on verbal episodic memory function in the elderly: a retrospective, cross-sectional study. Drugs Aging 2011; 28(3): 195-204.

402. Bassett AS, Scherer SW, Brzustowicz LM. Copy number variations in schizophrenia: critical review and new perspectives on concepts of genetics and disease. Am J Psychiatry 2010; 167(8): 899-914.

403. Zhang D, Cheng L, Qian Y, Alliey-Rodriguez N, Kelsoe JR, Greenwood T et al. Singleton deletions throughout the genome increase risk of bipolar disorder. Mol Psychiatry 2009; 14(4): 376-380.

404. Grozeva D, Kirov G, Ivanov D, Jones IR, Jones L, Green EK et al. Rare copy number variants: a point of rarity in genetic risk for bipolar disorder and schizophrenia. Arch Gen Psychiatry 2010; 67(4): 318-327.

405. Craddock N, Jones L, Jones IR, Kirov G, Green EK, Grozeva D et al. Strong genetic evidence for a selective influence of GABAA receptors on a component of the bipolar disorder phenotype. Mol Psychiatry 2010; 15(2): 146-153.

406. Breuer R, Hamshere ML, Strohmaier J, Mattheisen M, Degenhardt F, Meier S et al. Independent evidence for the selective influence of GABA(A) receptors on one component of the bipolar disorder phenotype. Mol Psychiatry 2010.

407. Scott LJ, Muglia P, Kong XQ, Guan W, Flickinger M, Upmanyu R et al. Genome-wide association and meta-analysis of bipolar disorder in individuals of European ancestry. Proc Natl Acad Sci U S A 2009; 106(18): 7501-7506. 
408. Smith EN, Bloss CS, Badner JA, Barrett T, Belmonte PL, Berrettini W et al. Genome-wide association study of bipolar disorder in European American and African American individuals. Mol Psychiatry 2009; 14(8): 755-763.

409. Sklar P, Smoller JW, Fan J, Ferreira MA, Perlis RH, Chambert K et al. Whole-genome association study of bipolar disorder. Mol Psychiatry 2008; 13(6): 558-569.

410. Moskvina V, Craddock N, Holmans P, Nikolov I, Pahwa JS, Green E et al. Gene-wide analyses of genome-wide association data sets: evidence for multiple common risk alleles for schizophrenia and bipolar disorder and for overlap in genetic risk. Mol Psychiatry 2009; 14(3): 252-260.

411. Williams HJ, Craddock N, Russo G, Hamshere ML, Moskvina V, Dwyer S et al. Most genome-wide significant susceptibility loci for schizophrenia and bipolar disorder reported to date crosstraditional diagnostic boundaries. Hum Mol Genet 2011; 20(2): 387-391.

412. Voineskos AN, Lerch JP, Felsky D, Tiwari A, Rajji TK, Miranda D et al. The ZNF804A gene: characterization of a novel neural risk mechanism for the major psychoses. Neuropsychopharmacology 2011; 36(9): 1871-1878.

413. Potkin SG, Turner JA, Guffanti G, Lakatos A, Torri F, Keator DB et al. Genome-wide strategies for discovering genetic influences on cognition and cognitive disorders: methodological considerations. Cogn Neuropsychiatry 2009; 14(4-5): 391-418.

414. Tan HY, Callicott JH, Weinberger DR. Prefrontal cognitive systems in schizophrenia: towards human genetic brain mechanisms. Cogn Neuropsychiatry 2009; 14(4-5): 277-298.

415. Bellgrove MA, Mattingley JB. Molecular genetics of attention. Ann N Y Acad Sci 2008; 1129: 200212.

416. Savitz J, Solms M, Ramesar R. The molecular genetics of cognition: dopamine, COMT and BDNF. Genes Brain Behav 2006; 5(4): 311-328.

417. Blanchard MM, Chamberlain SR, Roiser J, Robbins TW, Muller U. Effects of two dopaminemodulating genes (DAT1 9/10 and COMT Val/Met) on n-back working memory performance in healthy volunteers. Psychol Med 2011; 41(3): 611-618.

418. Frank MJ, Fossella JA. Neurogenetics and pharmacology of learning, motivation, and cognition. Neuropsychopharmacology 2011; 36(1): 133-152.

419. Antila M, Tuulio-Henriksson A, Kieseppa T, Soronen P, Palo OM, Paunio T et al. Heritability of cognitive functions in families with bipolar disorder. Am J Med Genet B Neuropsychiatr Genet 2007; 144B(6): 802-808.

420. Martinowich K, Schloesser RJ, Manji HK. Bipolar disorder: from genes to behavior pathways. J Clin Invest 2009; 119(4): 726-736.

421. Carter CJ. Multiple genes and factors associated with bipolar disorder converge on growth factor and stress activated kinase pathways controlling translation initiation: implications for oligodendrocyte viability. Neurochem Int 2007; 50(3): 461-490.

422. Balu DT, Coyle JT. Neuroplasticity signaling pathways linked to the pathophysiology of schizophrenia. Neurosci Biobehav Rev 2010.

423. Beech RD, Lowthert L, Leffert JJ, Mason PN, Taylor MM, Umlauf S et al. Increased peripheral blood expression of electron transport chain genes in bipolar depression. Bipolar Disord 2010; 12(8): 813824.

424. Fullerton JM, Tiwari Y, Agahi G, Heath A, Berk M, Mitchell PB et al. Assessing oxidative pathway genes as risk factors for bipolar disorder. Bipolar Disord 2010; 12(5): 550-556.

425. Giegling I, Genius J, Benninghoff J, Rujescu D. Genetic findings in schizophrenia patients related to alterations in the intracellular Ca-homeostasis. Prog Neuropsychopharmacol Biol Psychiatry 2010; 34(8): 1375-1380.

426. Uemura T, Green M, Corson TW, Perova T, Li PP, Warsh JJ. Bcl-2 SNP rs956572 associates with disrupted intracellular calcium homeostasis in bipolar I disorder. Bipolar Disord 2011; 13(1): 41-51.

427. Zhang P, Xiang N, Chen Y, Sliwerska E, McInnis MG, Burmeister M et al. Family-based association analysis to finemap bipolar linkage peak on chromosome 8q24 using 2,500 genotyped SNPs and 15,000 imputed SNPs. Bipolar Disord 2010; 12(8): 786-792.

428. Arion D, Lewis DA. Altered expression of regulators of the cortical chloride transporters NKCC1 and KCC2 in schizophrenia. Arch Gen Psychiatry 2011; 68(1): 21-31. 
429. Boku S, Nakagawa S, Masuda T, Nishikawa H, Kato A, Toda H et al. Effects of mood stabilizers on adult dentate gyrus-derived neural precursor cells. Prog Neuropsychopharmacol Biol Psychiatry 2011; 35(1): 111-117.

430. Moncrieff J. Questioning the 'neuroprotective' hypothesis: does drug treatment prevent brain damage in early psychosis or schizophrenia? Br J Psychiatry 2011; 198: 85-87.

431. Manji HK, Bowden, C.L., Belmaker, R.H. Bipolar Medications. Mechanisms of Action. American Psychiatric Press, Inc.: Washington, DC, 2000.

432. Bauer M, Grof, P., Muller-Oerlinghausen, B. Lithium in neuropsychiatry. The comprehensive guide. Informa UK ltd: Abingdon, Oxon, 2006.

433. Lieberman JA, Bymaster FP, Meltzer HY, Deutch AY, Duncan GE, Marx CE et al. Antipsychotic drugs: comparison in animal models of efficacy, neurotransmitter regulation, and neuroprotection. Pharmacol Rev 2008; 60(3): 358-403.

434. Fumagalli F, Frasca A, Racagni G, Riva MA. Cognitive effects of second-generation antipsychotics: current insights into neurochemical mechanisms. CNS Drugs 2009; 23(7): 603-614.

435. Artigas F. The prefrontal cortex: a target for antipsychotic drugs. Acta Psychiatr Scand 2010; 121(1): $11-21$.

436. Einat H, Manji HK. Cellular plasticity cascades: genes-to-behavior pathways in animal models of bipolar disorder. Biol Psychiatry 2006; 59(12): 1160-1171.

437. Zarate CA, Jr., Singh J, Manji HK. Cellular plasticity cascades: targets for the development of novel therapeutics for bipolar disorder. Biol Psychiatry 2006; 59(11): 1006-1020.

438. Arnsten AF. Ameliorating prefrontal cortical dysfunction in mental illness: inhibition of phosphotidyl inositol-protein kinase C signaling. Psychopharmacology (Berl) 2009; 202(1-3): 445-455.

439. Silverstone PH, McGrath BM. Lithium and valproate and their possible effects on the myo-inositol second messenger system in healthy volunteers and bipolar patients. Int Rev Psychiatry 2009; 21(4): 414-423.

440. Wada A. Lithium and neuropsychiatric therapeutics: neuroplasticity via glycogen synthase kinase3beta, beta-catenin, and neurotrophin cascades. J Pharmacol Sci 2009; 110(1): 14-28.

441. Aubry JM, Schwald M, Ballmann E, Karege F. Early effects of mood stabilizers on the Akt/GSK3beta signaling pathway and on cell survival and proliferation. Psychopharmacology (Berl) 2009; 205(3): 419-429.

442. Freyberg Z, Ferrando SJ, Javitch JA. Roles of the Akt/GSK-3 and Wnt signaling pathways in schizophrenia and antipsychotic drug action. Am J Psychiatry 2010; 167(4): 388-396.

443. Zhou R, Gray NA, Yuan P, Li X, Chen J, Chen G et al. The anti-apoptotic, glucocorticoid receptor cochaperone protein BAG-1 is a long-term target for the actions of mood stabilizers. J Neurosci 2005; 25(18): 4493-4502.

444. Camins A, Verdaguer E, Junyent F, Yeste-Velasco M, Pelegri C, Vilaplana J et al. Potential mechanisms involved in the prevention of neurodegenerative diseases by lithium. CNS Neurosci Ther 2009; 15(4): 333-344.

445. Omata N, Murata T, Takamatsu S, Maruoka N, Mitsuya H, Yonekura Y et al. Neuroprotective effect of chronic lithium treatment against hypoxia in specific brain regions with upregulation of cAMP response element binding protein and brain-derived neurotrophic factor but not nerve growth factor: comparison with acute lithium treatment. Bipolar Disord 2008; 10(3): 360-368.

446. Machado-Vieira R, Manji HK, Zarate CA, Jr. The role of lithium in the treatment of bipolar disorder: convergent evidence for neurotrophic effects as a unifying hypothesis. Bipolar Disord 2009; 11 Suppl 2: 92-109.

447. Quiroz JA, Machado-Vieira R, Zarate CA, Jr., Manji HK. Novel insights into lithium's mechanism of action: neurotrophic and neuroprotective effects. Neuropsychobiology 2010; 62(1): 50-60.

448. Bachmann RF, Wang Y, Yuan P, Zhou R, Li X, Alesci S et al. Common effects of lithium and valproate on mitochondrial functions: protection against methamphetamine-induced mitochondrial damage. Int J Neuropsychopharmacol 2009; 12(6): 805-822.

449. Maurer IC, Schippel P, Volz HP. Lithium-induced enhancement of mitochondrial oxidative phosphorylation in human brain tissue. Bipolar Disord 2009; 11(5): 515-522. 
450. Lepping P, Delieu J, Mellor R, Williams JH, Hudson PR, Hunter-Lavin C. Antipsychotic medication and oxidative cell stress: a systematic review. J Clin Psychiatry 2010.

451. Padurariu M, Ciobica A, Dobrin I, Stefanescu C. Evaluation of antioxidant enzymes activities and lipid peroxidation in schizophrenic patients treated with typical and atypical antipsychotics. Neurosci Lett 2010; 479(3): 317-320.

452. Wu X, Chen PS, Dallas S, Wilson B, Block ML, Wang CC et al. Histone deacetylase inhibitors upregulate astrocyte GDNF and BDNF gene transcription and protect dopaminergic neurons. Int $J$ Neuropsychopharmacol 2008; 11(8): 1123-1134.

453. Fukuchi M, Nii T, Ishimaru N, Minamino A, Hara D, Takasaki I et al. Valproic acid induces up- or down-regulation of gene expression responsible for the neuronal excitation and inhibition in rat cortical neurons through its epigenetic actions. Neurosci Res 2009; 65(1): 35-43.

454. Yu IT, Park JY, Kim SH, Lee JS, Kim YS, Son H. Valproic acid promotes neuronal differentiation by induction of proneural factors in association with H4 acetylation. Neuropharmacology 2009; 56(2): 473-480.

455. Guidotti A, Auta J, Chen Y, Davis JM, Dong E, Gavin DP et al. Epigenetic GABAergic targets in schizophrenia and bipolar disorder. Neuropharmacology 2010.

456. Leng Y, Liang MH, Ren M, Marinova Z, Leeds P, Chuang DM. Synergistic neuroprotective effects of lithium and valproic acid or other histone deacetylase inhibitors in neurons: roles of glycogen synthase kinase-3 inhibition. J Neurosci 2008; 28(10): 2576-2588.

457. Csoka AB, Szyf M. Epigenetic side-effects of common pharmaceuticals: a potential new field in medicine and pharmacology. Med Hypotheses 2009; 73(5): 770-780.

458. Tomasetti C, Dell'Aversano C, Iasevoli F, Marmo F, de Bartolomeis A. The acute and chronic effects of combined antipsychotic-mood stabilizing treatment on the expression of cortical and striatal postsynaptic density genes. Prog Neuropsychopharmacol Biol Psychiatry 2011; 35(1): 184-197.

459. Rybakowski JK, Suwalska A. Excellent lithium responders have normal cognitive functions and plasma BDNF levels. Int J Neuropsychopharmacol 2010; 13(5): 617-622.

460. Chiu CT, Chuang DM. Molecular actions and therapeutic potential of lithium in preclinical and clinical studies of CNS disorders. Pharmacol Ther 2010; 128(2): 281-304.

461. Suwalska A, Sobieska M, Rybakowski JK. Serum brain-derived neurotrophic factor in euthymic bipolar patients on prophylactic lithium therapy. Neuropsychobiology 2010; 62(4): 229-234.

462. Chang YC, Rapoport SI, Rao JS. Chronic administration of mood stabilizers upregulates BDNF and bcl-2 expression levels in rat frontal cortex. Neurochem Res 2009; 34(3): 536-541.

463. Li N, He X, Zhang Y, Qi X, Li H, Zhu X et al. Brain-derived neurotrophic factor signalling mediates antidepressant effects of lamotrigine. Int J Neuropsychopharmacol 2010: 1-8.

464. Yasuda S, Liang MH, Marinova Z, Yahyavi A, Chuang DM. The mood stabilizers lithium and valproate selectively activate the promoter IV of brain-derived neurotrophic factor in neurons. $\mathrm{Mol}$ Psychiatry 2009; 14(1): 51-59.

465. Ghiglieri V, Sgobio C, Patassini S, Bagetta V, Fejtova A, Giampa C et al. TrkB/BDNF-dependent striatal plasticity and behavior in a genetic model of epilepsy: modulation by valproic acid. Neuropsychopharmacology 2010; 35(7): 1531-1540.

466. Chen CC, Huang TL. Effects of antipsychotics on the serum BDNF levels in schizophrenia. Psychiatry Res 2011; 189(3): 327-330.

467. Pedrini M, Chendo I, Grande I, Lobato MI, Belmonte-de-Abreu PS, Lersch C et al. Serum brainderived neurotrophic factor and clozapine daily dose in patients with schizophrenia: A positive correlation. Neurosci Lett 2011; 491(3): 207-210.

468. Chiba S, Hashimoto R, Hattori S, Yohda M, Lipska B, Weinberger DR et al. Effect of antipsychotic drugs on DISC1 and dysbindin expression in mouse frontal cortex and hippocampus. J Neural Transm 2006; 113(9): 1337-1346.

469. Wang XD, Su YA, Guo CM, Yang Y, Si TM. Chronic antipsychotic drug administration alters the expression of neuregulin 1beta, ErbB2, ErbB3, and ErbB4 in the rat prefrontal cortex and hippocampus. Int J Neuropsychopharmacol 2008; 11(4): 553-561. 
470. Bertolino A, Caforio G, Blasi G, De Candia M, Latorre V, Petruzzella V et al. Interaction of COMT (Val(108/158)Met) genotype and olanzapine treatment on prefrontal cortical function in patients with schizophrenia. Am J Psychiatry 2004; 161(10): 1798-1805.

471. Weickert TW, Goldberg TE, Mishara A, Apud JA, Kolachana BS, Egan MF et al. Catechol-Omethyltransferase val108/158met genotype predicts working memory response to antipsychotic medications. Biol Psychiatry 2004; 56(9): 677-682.

472. Woodward ND, Jayathilake K, Meltzer HY. COMT val108/158met genotype, cognitive function, and cognitive improvement with clozapine in schizophrenia. Schizophr Res 2007.

473. McClay JL, Adkins DE, Aberg K, Bukszar J, Khachane AN, Keefe RS et al. Genome-wide pharmacogenomic study of neurocognition as an indicator of antipsychotic treatment response in schizophrenia. Neuropsychopharmacology 2011; 36(3): 616-626.

474. Goodwin GM, Anderson I, Arango C, Bowden CL, Henry C, Mitchell PB et al. ECNP consensus meeting. Bipolar depression. Nice, March 2007. Eur Neuropsychopharmacol 2008; 18(7): 535-549.

475. Manove E, Levy B. Cognitive impairment in bipolar disorder: an overview. Postgraduate medicine 2010; 122(4): 7-16.

476. Sanches M, Keshavan MS, Brambilla P, Soares JC. Neurodevelopmental basis of bipolar disorder: a critical appraisal. Prog Neuropsychopharmacol Biol Psychiatry 2008; 32(7): 1617-1627.

477. Insel TR. Rethinking schizophrenia. Nature 2010; 468(7321): 187-193.

478. Meunier D, Lambiotte R, Bullmore ET. Modular and hierarchically modular organization of brain networks. Front Neurosci 2010; 4: 200.

479. Zammit S, Wiles, N., Lewis, G. The study of gene-environment interactions in psychiatry : limited gains at a substantial cost? Psychol Med 2010; 40: 711-716.

480. Zammit S, Owen MJ, Lewis G. Misconceptions about gene-environment interactions in psychiatry. Evid Based Ment Health 2010; 13(3): 65-68.

481. Fergusson DM, Horwood LJ, Miller AL, Kennedy MA. Life stress, 5-HTTLPR and mental disorder: findings from a 30-year longitudinal study. Br J Psychiatry 2011; 198: 129-135.

482. van Os J, Rutten BP. Gene-environment-wide interaction studies in psychiatry. Am J Psychiatry 2009; 166(9): 964-966.

483. Thomas D. Gene-environment-wide association studies: emerging approaches. Nature reviews 2010; 11(4): 259-272.

484. Lahey BB, Van Hulle CA, Singh AL, Waldman ID, Rathouz PJ. Higher-order genetic and environmental structure of prevalent forms of child and adolescent psychopathology. Arch Gen Psychiatry 2011; 68(2): 181-189.

485. Kendler KS, Aggen SH, Knudsen GP, Roysamb E, Neale MC, Reichborn-Kjennerud T. The structure of genetic and environmental risk factors for syndromal and subsyndromal common DSM-IV axis I and all axis II disorders. Am J Psychiatry 2011; 168(1): 29-39.

486. Green JG, McLaughlin KA, Berglund PA, Gruber MJ, Sampson NA, Zaslavsky AM et al. Childhood adversities and adult psychiatric disorders in the national comorbidity survey replication I: associations with first onset of DSM-IV disorders. Arch Gen Psychiatry 2010; 67(2): 113-123.

487. McLaughlin KA, Green JG, Gruber MJ, Sampson NA, Zaslavsky AM, Kessler RC. Childhood adversities and adult psychiatric disorders in the national comorbidity survey replication II: associations with persistence of DSM-IV disorders. Arch Gen Psychiatry 2010; 67(2): 124-132.

488. van Os J, Kenis G, Rutten BP. The environment and schizophrenia. Nature 2010; 468(7321): 203212.

489. Lardinois M, Lataster T, Mengelers R, Van Os J, Myin-Germeys I. Childhood trauma and increased stress sensitivity in psychosis. Acta Psychiatr Scand 2011; 123(1): 28-35.

490. Post RM. Kindling and sensitization as models for affective episode recurrence, cyclicity, and tolerance phenomena. Neurosci Biobehav Rev 2007; 31(6): 858-873.

491. Lataster T, Collip D, Lardinois M, van Os J, Myin-Germeys I. Evidence for a familial correlation between increased reactivity to stress and positive psychotic symptoms. Acta Psychiatr Scand 2010; 122(5): 395-404.

492. Arnsten AF. Stress signalling pathways that impair prefrontal cortex structure and function. Nat Rev Neurosci 2009; 10(6): 410-422. 
493. Abbott C, Juarez M, White T, Gollub RL, Pearlson GD, Bustillo J et al. Antipsychotic dose and diminished neural modulation: A multi-site fMRI study. Prog Neuropsychopharmacol Biol Psychiatry 2011; 35(2): 473-482.

494. Conrad CD. A critical review of chronic stress effects on spatial learning and memory. Prog Neuropsychopharmacol Biol Psychiatry 2010; 34(5): 742-755.

495. Friston K. The free-energy principle: a rough guide to the brain? Trends in cognitive sciences 2009; 13(7): 293-301.

496. Aas M, Dazzan P, Fisher HL, Morgan C, Morgan K, Reichenberg A et al. Childhood trauma and cognitive function in first-episode affective and non-affective psychosis. Schizophr Res 2011; 129(1): $12-19$.

497. Geschwind N, Peeters F, Jacobs N, Delespaul P, Derom C, Thiery E et al. Meeting risk with resilience: high daily life reward experience preserves mental health. Acta Psychiatr Scand 2010; 122(2): $129-138$.

498. Hosang GM, Uher R, Keers R, Cohen-Woods S, Craig I, Korszun A et al. Stressful life events and the brain-derived neurotrophic factor gene in bipolar disorder. J Affect Disord 2010; 125(1-3): 345-349.

499. Latalova K, Prasko J, Diveky T, Velartova H. Cognitive impairment in bipolar disorder. Biomed Pap Med Fac Univ Palacky Olomouc Czech Repub 2011; 155(1): 19-26.

500. Feder A, Nestler EJ, Charney DS. Psychobiology and molecular genetics of resilience. Nat Rev Neurosci 2009; 10(6): 446-457.

501. Koenen KC, Moffitt TE, Roberts AL, Martin LT, Kubzansky L, Harrington H et al. Childhood IQ and adult mental disorders: a test of the cognitive reserve hypothesis. Am J Psychiatry 2009; 166(1): 50-57.

502. Juster RP, McEwen BS, Lupien SJ. Allostatic load biomarkers of chronic stress and impact on health and cognition. Neurosci Biobehav Rev 2010; 35(1): 2-16.

503. Kapczinski F, Vieta E, Andreazza AC, Frey BN, Gomes FA, Tramontina J et al. Allostatic load in bipolar disorder: implications for pathophysiology and treatment. Neurosci Biobehav Rev 2008; 32(4): 675-692.

504. Berk M, Kapczinski F, Andreazza AC, Dean OM, Giorlando F, Maes M et al. Pathways underlying neuroprogression in bipolar disorder: Focus on inflammation, oxidative stress and neurotrophic factors. Neurosci Biobehav Rev 2010.

505. Perlis RH, Miyahara S, Marangell LB, Wisniewski SR, Ostacher M, DelBello MP et al. Long-Term implications of early onset in bipolar disorder: data from the first 1000 participants in the systematic treatment enhancement program for bipolar disorder (STEP-BD). Biol Psychiatry 2004; 55(9): 875881.

506. Lopez-Jaramillo C, Lopera-Vasquez J, Gallo A, Ospina-Duque J, Bell V, Torrent C et al. Effects of recurrence on the cognitive performance of patients with bipolar I disorder: implications for relapse prevention and treatment adherence. Bipolar Disord 2010; 12(5): 557-567.

507. Elshahawi HH, Essawi H, Rabie MA, Mansour M, Beshry ZA, Mansour AN. Cognitive functions among euthymic bipolar I patients after a single manic episode versus recurrent episodes. J Affect Disord 2011; 130(1-2): 180-191.

508. Drexhage RC, Knijff EM, Padmos RC, Heul-Nieuwenhuijzen L, Beumer W, Versnel MA et al. The mononuclear phagocyte system and its cytokine inflammatory networks in schizophrenia and bipolar disorder. Expert Rev Neurother 2010; 10(1): 59-76.

509. McAfoose J, Baune BT. Evidence for a cytokine model of cognitive function. Neurosci Biobehav Rev 2009; 33(3): 355-366.

510. Goldstein BI, Kemp DE, Soczynska JK, McIntyre RS. Inflammation and the phenomenology, pathophysiology, comorbidity, and treatment of bipolar disorder: a systematic review of the literature. $J$ Clin Psychiatry 2009; 70(8): 1078-1090.

511. Dickerson FB, Boronow JJ, Stallings C, Origoni AE, Cole S, Leister F et al. The catechol Omethyltransferase Val158Met polymorphism and herpes simplex virus type 1 infection are risk factors for cognitive impairment in bipolar disorder: additive gene-environmental effects in a complex human psychiatric disorder. Bipolar Disord 2006; 8(2): 124-132. 
512. Prasad KM, Eack SM, Goradia D, Pancholi KM, Keshavan MS, Yolken RH et al. Progressive gray matter loss and changes in cognitive functioning associated with exposure to herpes simplex virus 1 in schizophrenia: a longitudinal study. Am J Psychiatry 2011; 168(8): 822-830.

513. Vonk R, van der Schot AC, Kahn RS, Nolen WA, Drexhage HA. Is autoimmune thyroiditis part of the genetic vulnerability (or an endophenotype) for bipolar disorder? Biol Psychiatry 2007; 62(2): $135-140$.

514. Schreurs BG. The effects of cholesterol on learning and memory. Neurosci Biobehav Rev 2010; 34(8): 1366-1379.

515. Krakowski M, Czobor P. Cholesterol and cognition in schizophrenia: A double-blind study of patients randomized to clozapine, olanzapine and haloperidol. Schizophr Res 2011; 130(1-3): 27-33.

516. Friedman JI, Wallenstein S, Moshier E, Parrella M, White L, Bowler S et al. The effects of hypertension and body mass index on cognition in schizophrenia. Am J Psychiatry 2010; 167(10): 1232-1239.

517. Bond DJ, Lang DJ, Noronha MM, Kunz M, Torres IJ, Su W et al. The association of elevated body mass index with reduced brain volumes in first-episode mania. Biol Psychiatry 2011; 70(4): 381-387.

518. Dittmann S, Seemuller F, Grunze HC, Schwarz MJ, Zach J, Fast K et al. The Impact of Homocysteine Levels on Cognition in Euthymic Bipolar Patients: A Cross-Sectional Study. J Clin Psychiatry 2008: e1-e8.

519. Dias VV, Brissos S, Cardoso C, Andreazza AC, Kapczinski F. Serum homocysteine levels and cognitive functioning in euthymic bipolar patients. J Affect Disord 2009; 113(3): 285-290.

520. Vuksan-Cusa B, Jakovljevic M, Sagud M, Mihaljevic Peles A, Marcinko D, Topic R et al. Metabolic syndrome and serum homocysteine in patients with bipolar disorder and schizophrenia treated with second generation antipsychotics. Psychiatry Res 2011; 189(1): 21-25.

521. Sublette ME, Russ MJ, Smith GS. Evidence for a role of the arachidonic acid cascade in affective disorders: a review. Bipolar Disord 2004; 6(2): 95-105.

522. McNamara RK, Jandacek R, Rider T, Tso P, Stanford KE, Hahn CG et al. Deficits in docosahexaenoic acid and associated elevations in the metabolism of arachidonic acid and saturated fatty acids in the postmortem orbitofrontal cortex of patients with bipolar disorder. Psychiatry Res 2008; 160(3): 285-299.

523. Watson S, Thompson JM, Ritchie JC, Nicol Ferrier I, Young AH. Neuropsychological impairment in bipolar disorder: the relationship with glucocorticoid receptor function. Bipolar Disord 2006; 8(1): 85-90.

524. Hunsberger JG, Austin DR, Chen G, Manji HK. Cellular mechanisms underlying affective resiliency: the role of glucocorticoid receptor- and mitochondrially-mediated plasticity. Brain Res 2009; 1293 : 76-84.

525. Ellenbogen MA, Santo JB, Linnen AM, Walker CD, Hodgins S. High cortisol levels in the offspring of parents with bipolar disorder during two weeks of daily sampling. Bipolar Disord 2010; 12(1): 7786.

526. Aas M, Dazzan P, Mondelli V, Toulopoulou T, Reichenberg A, Di Forti M et al. Abnormal cortisol awakening response predicts worse cognitive function in patients with first-episode psychosis. Psychol Med 2011; 41(3): 463-476.

527. Baldini M, Colasanti A, Orsatti A, Airaghi L, Mauri MC, Cappellini MD. Neuropsychological functions and metabolic aspects in subclinical hypothyroidism: the effects of 1-thyroxine. Prog Neuropsychopharmacol Biol Psychiatry 2009; 33(5): 854-859.

528. McIntyre RS, Soczynska JK, Beyer JL, Woldeyohannes HO, Law CW, Miranda A et al. Medical comorbidity in bipolar disorder: re-prioritizing unmet needs. Curr Opin Psychiatry 2007; 20(4): 406-416.

529. Perron BE, Howard MO, Nienhuis JK, Bauer MS, Woodward AT, Kilbourne AM. Prevalence and burden of general medical conditions among adults with bipolar I disorder: results from the National Epidemiologic Survey on Alcohol and Related Conditions. J Clin Psychiatry 2009; 70(10): 1407-1415.

530. Kemp DE, Gao K, Ganocy SJ, Caldes E, Feldman K, Chan PK et al. Medical and substance use comorbidity in bipolar disorder. J Affect Disord 2009; 116(1-2): 64-69. 
531. Roshanaei-Moghaddam B, Katon W. Premature mortality from general medical illnesses among persons with bipolar disorder: a review. Psychiatr Serv 2009; 60(2): 147-156.

532. Fagiolini A, Goracci A. The effects of undertreated chronic medical illnesses in patients with severe mental disorders. J Clin Psychiatry 2009; 70 Suppl 3: 22-29.

533. Kemp DE, Gao, K., Chan, P.K., Ganocy, S.J., Findling, R.L., Calabrese, J.R. Medical comorbidity in bipolar disorder: relationship between illnesses of the endocrine/metabolic system and treatment outcome. Bipolar Disord 2010; 12: 404-413.

534. Callaghan RC, Khizar A. The incidence of cardiovascular morbidity among patients with bipolar disorder: a population-based longitudinal study in Ontario, Canada. J Affect Disord 2010; 122(1-2): $118-123$.

535. Ramsey CM, Leoutsakos JM, Mayer LS, Eaton WW, Lee HB. History of manic and hypomanic episodes and risk of incident cardiovascular disease: 11.5 year follow-up from the Baltimore Epidemiologic Catchment Area Study. J Affect Disord 2010; 125(1-3): 35-41.

536. Newcomer JW. Medical risk in patients with bipolar disorder and schizophrenia. J Clin Psychiatry 2006; 67 (suppl 9): 25-30.

537. Tsai SY, Lee HC, Chen CC, Huang YL. Cognitive impairment in later life in patients with earlyonset bipolar disorder. Bipolar Disord 2007; 9(8): 868-875.

538. Balanza-Martinez V, Selva G, Martinez-Aran A, Prickaerts J, Salazar J, Gonzalez-Pinto A et al. Neurocognition in bipolar disorders--a closer look at comorbidities and medications. Eur J Pharmacol 2010; 626(1): 87-96.

539. Bose M, Olivan B, Laferrere B. Stress and obesity: the role of the hypothalamic-pituitary-adrenal axis in metabolic disease. Current opinion in endocrinology, diabetes, and obesity 2009; 16(5): 340-346.

540. Anagnostis P, Athyros VG, Tziomalos K, Karagiannis A, Mikhailidis DP. Clinical review: The pathogenetic role of cortisol in the metabolic syndrome: a hypothesis. J Clin Endocrinol Metab 2009; 94(8): 2692-2701.

541. Garaulet M, Madrid JA. Chronobiology, genetics and metabolic syndrome. Current opinion in lipidology 2009; 20(2): 127-134.

542. Taylor V, MacQueen, G. Associations between bipolar disorder and metabolic syndrome: A review. J Clin Psychiatry 2006; 67(7): 1034-1041.

543. Fagiolini A, Chengappa KN, Soreca I, Chang J. Bipolar disorder and the metabolic syndrome: causal factors, psychiatric outcomes and economic burden. CNS Drugs 2008; 22(8): 655-669.

544. Torrent C, Amann B, Sanchez-Moreno J, Colom F, Reinares M, Comes M et al. Weight gain in bipolar disorder: pharmacological treatment as a contributing factor. Acta Psychiatr Scand 2008; 118(1): 4-18.

545. Newcomer JW. Comparing the safety and efficacy of atypical antipsychotics in psychiatric patients with comorbid medical illnesses. J Clin Psychiatry 2009; 70 Suppl 3: 30-36.

546. Bhuvaneswar CG, Baldessarini RJ, Harsh VL, Alpert JE. Adverse endocrine and metabolic effects of psychotropic drugs: selective clinical review. CNS Drugs 2009; 23(12): 1003-1021.

547. Gau C-S, Chang, C-J., Tsai, F-J., Chao, P-F., Gau, SS-F. Association between mood stabilizers and hypothyroidism in patients with bipolar disorders: a nested, matched case-control study. Bipolar Disord 2010; 12: 253-263.

548. Mackin P. Cardiac side effects of psychiatric drugs. Hum Psychopharmacol 2008; 23 Suppl 1: 3-14.

549. Flanagan RJ, Dunk L. Haematological toxicity of drugs used in psychiatry. Hum Psychopharmacol 2008; 23 Suppl 1: 27-41.

550. Haddad PM, Dursun SM. Neurological complications of psychiatric drugs: clinical features and management. Hum Psychopharmacol 2008; 23 Suppl 1: 15-26.

551. Vinogradov S, Fisher M, Warm H, Holland C, Kirshner MA, Pollock BG. The cognitive cost of anticholinergic burden: decreased response to cognitive training in schizophrenia. Am J Psychiatry 2009; 166(9): 1055-1062.

552. Wingo AP, Wingo TS, Harvey PD, Baldessarini RJ. Effects of lithium on cognitive performance: a meta-analysis. J Clin Psychiatry 2009.

553. Tsaltas E, Kontis D, Boulougouris V, Papadimitriou GN. Lithium and cognitive enhancement: leave it or take it? Psychopharmacology (Berl) 2009; 202(1-3): 457-476. 
554. Kessing LV, Forman JL, Andersen PK. Does lithium protect against dementia? Bipolar Disord 2010; 12(1): 87-94.

555. Lopez-Jaramillo C, Lopera-Vasquez J, Ospina-Duque J, Garcia J, Gallo A, Cortez V et al. Lithium treatment effects on the neuropsychological functioning of patients with bipolar I disorder. J Clin Psychiatry 2010; 71(8): 1055-1060.

556. Chen PS, Peng GS, Li G, Yang S, Wu X, Wang CC et al. Valproate protects dopaminergic neurons in midbrain neuron/glia cultures by stimulating the release of neurotrophic factors from astrocytes. Mol Psychiatry 2006; 11(12): 1116-1125.

557. Daban C, Martinez-Aran A, Torrent C, Sanchez-Moreno J, Goikolea JM, Benabarre A et al. Cognitive functioning in bipolar patients receiving lamotrigine: preliminary results. J Clin Psychopharmacol 2006; 26(2): 178-181.

558. Pavuluri MN, Passarotti AM, Mohammed T, Carbray JA, Sweeney JA. Enhanced working and verbal memory after lamotrigine treatment in pediatric bipolar disorder. Bipolar Disord 2010; 12(2): 213-220.

559. Adan A, Serra-Grabulosa JM. Effects of caffeine and glucose, alone and combined, on cognitive performance. Hum Psychopharmacol 2010; 25(4): 310-317.

560. Heishman SJ, Kleykamp BA, Singleton EG. Meta-analysis of the acute effects of nicotine and smoking on human performance. Psychopharmacology (Berl) 2010; 210(4): 453-469.

561. Wing VC, Bacher I, Sacco KA, George TP. Neuropsychological performance in patients with schizophrenia and controls as a function of cigarette smoking status. Psychiatry Res 2011; 188(3): 320-326.

562. Sanchez-Moreno J, Martinez-Aran A, Colom F, Scott J, Tabares-Seisdedos R, Sugranyes G et al. Neurocognitive dysfunctions in euthymic bipolar patients with and without prior history of alcohol use. J Clin Psychiatry 2009; 70(8): 1120-1127.

563. Shan C, Lee SY, Chang YH, Wu JY, Chen SL, Chen SH et al. Neuropsychological functions in Han Chinese patients in Taiwan with bipolar II disorder comorbid and not comorbid with alcohol abuse/alcohol dependence disorder. Prog Neuropsychopharmacol Biol Psychiatry 2011; 35(1): 131136.

564. Fernandez-Serrano MJ, Perez-Garcia M, Verdejo-Garcia A. What are the specific vs. generalized effects of drugs of abuse on neuropsychological performance? Neurosci Biobehav Rev 2011; 35(3): 377-406.

565. Iverson GL, Brooks BL, Langenecker SA, Young AH. Identifying a cognitive impairment subgroup in adults with mood disorders. J Affect Disord 2011; 132(3): 360-367.

566. Martinez-Aran A, Vieta E, Colom F, Reinares M, Benabarre A, Gasto C et al. Cognitive dysfunctions in bipolar disorder: evidence of neuropsychological disturbances. Psychother Psychosom 2000; 69(1): $2-18$.

567. Thompson JM, Gallagher P, Hughes JH, Watson S, Gray JM, Ferrier IN et al. Neurocognitive impairment in euthymic patients with bipolar affective disorder. Br J Psychiatry 2005; 186: 32-40.

568. Lesh TA, Niendam, T.A., Minzenberg, M.J., Carter, C.S. Cognitive control deficits in schizophrenia: Mechanisms and meaning. Neuropharmacology 2011; 36: 316-338.

569. Maalouf FT, Klein C, Clark L, Sahakian BJ, Labarbara EJ, Versace A et al. Impaired sustained attention and executive dysfunction: Bipolar disorder versus depression-specific markers of affective disorders. Neuropsychologia 2010.

570. Kumar CT, Christodoulou T, Vyas NS, Kyriakopoulos M, Corrigall R, Reichenberg A et al. Deficits in visual sustained attention differentiate genetic liability and disease expression for Schizophrenia from Bipolar Disorder. Schizophr Res 2010; 124(1-3): 152-160.

571. Chaves OC, Lombardo LE, Bearden CE, Woolsey MD, Martinez DM, Barrett JA et al. Association of clinical symptoms and neurocognitive performance in bipolar disorder: a longitudinal study. Bipolar Disord 2011; 13(1): 118-123.

572. Antila M, Kieseppa T, Partonen T, Lonnqvist J, Tuulio-Henriksson A. The effect of processing speed on cognitive functioning in patients with familial bipolar I disorder and their unaffected relatives. Psychopathology 2011; 44(1): 40-45. 
573. Ueoka Y, Tomotake M, Tanaka T, Kaneda Y, Taniguchi K, Nakataki M et al. Quality of life and cognitive dysfunction in people with schizophrenia. Prog Neuropsychopharmacol Biol Psychiatry 2011; 35(1): 53-59.

574. Bolbecker AR, Hong SL, Kent JS, Forsyth JK, Klaunig MJ, Lazar EK et al. Paced finger-tapping abnormalities in bipolar disorder indicate timing dysfunction. Bipolar Disord 2011; 13(1): 99-110.

575. Bellgrove MA, Hester R, Garavan H. The functional neuroanatomical correlates of response variability: evidence from a response inhibition task. Neuropsychologia 2004; 42(14): 1910-1916.

576. Fleck DE, Shear PK, Strakowski SM. Processing efficiency and sustained attention in bipolar disorder. J Int Neuropsychol Soc 2005; 11(1): 49-57.

577. Strakowski SM, Adler CM, Holland SK, Mills N, DelBello MP. A preliminary FMRI study of sustained attention in euthymic, unmedicated bipolar disorder. Neuropsychopharmacology 2004; 29(9): 1734-1740.

578. Reuter-Lorenz PA, Cappell, K.A. Neurocognitive aging and the compensation hypothesis. Current Directions in Psychological Science 2008; 17: 177-182.

579. Bogacz R, Hu PT, Holmes PJ, Cohen JD. Do humans produce the speed-accuracy trade-off that maximizes reward rate? Quarterly journal of experimental psychology (2006) 2009: 1-29.

580. Leotti LA, Wager TD. Motivational influences on response inhibition measures. J Exp Psychol Hum Percept Perform 2010; 36(2): 430-447.

581. Bogacz R, Wagenmakers EJ, Forstmann BU, Nieuwenhuis S. The neural basis of the speed-accuracy tradeoff. Trends Neurosci 2010; 33(1): 10-16.

582. Bassett DS, Bullmore ET. Human brain networks in health and disease. Current opinion in neurology 2009; 22(4): 340-347.

583. He Y, Evans A. Graph theoretical modeling of brain connectivity. Current opinion in neurology 2010; 23(4): 341-350.

584. Meunier D, Lambiotte R, Fornito A, Ersche KD, Bullmore ET. Hierarchical modularity in human brain functional networks. Frontiers in neuroinformatics 2009; 3: 37.

585. van den Heuvel MP, Stam CJ, Boersma M, Hulshoff Pol HE. Small-world and scale-free organization of voxel-based resting-state functional connectivity in the human brain. Neuroimage 2008; 43(3): 528-539.

586. Bullmore E, Sporns O. Complex brain networks: graph theoretical analysis of structural and functional systems. Nat Rev Neurosci 2009; 10(3): 186-198.

587. Fair DA, Cohen AL, Power JD, Dosenbach NU, Church JA, Miezin FM et al. Functional brain networks develop from a "local to distributed" organization. PLoS computational biology 2009; 5(5): e1000381.

588. Gong G, Rosa-Neto P, Carbonell F, Chen ZJ, He Y, Evans AC. Age- and gender-related differences in the cortical anatomical network. J Neurosci 2009; 29(50): 15684-15693.

589. Smit DJ, Boersma M, van Beijsterveldt CE, Posthuma D, Boomsma DI, Stam CJ et al. Endophenotypes in a dynamically connected brain. Behav Genet 2010; 40(2): 167-177.

590. Stam CJ, Reijneveld JC. Graph theoretical analysis of complex networks in the brain. Nonlinear biomedical physics 2007; 1(1): 3 .

591. Reijneveld JC, Ponten SC, Berendse HW, Stam CJ. The application of graph theoretical analysis to complex networks in the brain. Clin Neurophysiol 2007; 118(11): 2317-2331.

592. van den Heuvel MP, Stam CJ, Kahn RS, Hulshoff Pol HE. Efficiency of functional brain networks and intellectual performance. J Neurosci 2009; 29(23): 7619-7624.

593. Li Y, Liu Y, Li J, Qin W, Li K, Yu C et al. Brain anatomical network and intelligence. PLoS computational biology 2009; 5(5): e1000395.

594. Achard S, Bullmore E. Efficiency and cost of economical brain functional networks. PLoS computational biology 2007; 3(2): e17.

595. Kozel FA, Rao, U., Lu, H., Nakonezny, P.A., Grannemann, B., McGregor, T., Croarkin, P.E., Mapes, K.S., Tamminga, C.A., Trivedi, M.H. Functional connectivity of brain structures correlates with treatment outcome in major depressive disorder. Frontiers in psychiatry 2011; Volume 2(March 2011): 1-7. 
596. Liu Y, Liang M, Zhou Y, He Y, Hao Y, Song M et al. Disrupted small-world networks in schizophrenia. Brain 2008; 131(Pt 4): 945-961.

597. Bassett DS, Bullmore E, Verchinski BA, Mattay VS, Weinberger DR, Meyer-Lindenberg A. Hierarchical organization of human cortical networks in health and schizophrenia. J Neurosci 2008; 28(37): 9239-9248.

598. Rubinov M, Knock SA, Stam CJ, Micheloyannis S, Harris AW, Williams LM et al. Small-world properties of nonlinear brain activity in schizophrenia. Hum Brain Mapp 2009; 30(2): 403-416.

599. Alexander-Bloch AF, Gogtay N, Meunier D, Birn R, Clasen L, Lalonde F et al. Disrupted modularity and local connectivity of brain functional networks in childhood-onset schizophrenia. Frontiers in systems neuroscience 2010; 4: 147.

600. Pettersson-Yeo W, Allen P, Benetti S, McGuire P, Mechelli A. Dysconnectivity in schizophrenia: where are we now? Neurosci Biobehav Rev 2011; 35(5): 1110-1124.

601. Sharma A, Weisbrod M, Kaiser S, Markela-Lerenc J, Bender S. Deficits in fronto-posterior interactions point to inefficient resource allocation in schizophrenia. Acta Psychiatr Scand 2011; 123(2): 125-135.

602. White TP, Joseph V, Francis ST, Liddle PF. Aberrant salience network (bilateral insula and anterior cingulate cortex) connectivity during information processing in schizophrenia. Schizophr Res 2010; 123(2-3): 105-115.

603. Wolf RC, Vasic N, Sambataro F, Hose A, Frasch K, Schmid M et al. Temporally anticorrelated brain networks during working memory performance reveal aberrant prefrontal and hippocampal connectivity in patients with schizophrenia. Prog Neuropsychopharmacol Biol Psychiatry 2009; 33(8): 1464-1473.

604. Meda SA, Stevens MC, Folley BS, Calhoun VD, Pearlson GD. Evidence for anomalous network connectivity during working memory encoding in schizophrenia: an ICA based analysis. PLoS One 2009; 4(11): e7911.

605. Benson BE, Willis MW, Ketter TA, Speer A, Kimbrell TA, George MS et al. Interregional cerebral metabolic associativity during a continuous performance task (Part II) : differential alterations in bipolar and unipolar disorders. Psychiatry Res 2008; 164(1): 30-47.

606. Williams MA, Sachdev PS. Magnetoencephalography in neuropsychiatry: ready for application? Curr Opin Psychiatry 2010.

607. Uhlhaas PJ, Roux F, Rodriguez E, Rotarska-Jagiela A, Singer W. Neural synchrony and the development of cortical networks. Trends in cognitive sciences 2010; 14(2): 72-80.

608. Uhlhaas PJ, Singer W. The development of neural synchrony and large-scale cortical networks during adolescence: relevance for the pathophysiology of schizophrenia and neurodevelopmental hypothesis. Schizophr Bull 2011; 37(3): 514-523.

609. Faber G, van Gool AR, Smid HG, Wiersma D, van den Bosch RJ. [Typical and atypical antipsychotics: Is there a difference in their influence on neurocognition?]. Tijdschrift voor psychiatrie 2011; 53(2): 107-117.

610. Jutras MJ, Buffalo EA. Synchronous neural activity and memory formation. Curr Opin Neurobiol 2010; 20(2): 150-155.

611. Ardid S, Wang XJ, Gomez-Cabrero D, Compte A. Reconciling coherent oscillation with modulation of irregular spiking activity in selective attention: gamma-range synchronization between sensory and executive cortical areas. J Neurosci 2010; 30(8): 2856-2870.

612. Sauseng P, Griesmayr B, Freunberger R, Klimesch W. Control mechanisms in working memory: a possible function of EEG theta oscillations. Neurosci Biobehav Rev 2010; 34(7): 1015-1022.

613. Herrmann CS, Frund I, Lenz D. Human gamma-band activity: a review on cognitive and behavioral correlates and network models. Neurosci Biobehav Rev 2010; 34(7): 981-992.

614. Wang XJ. Neurophysiological and computational principles of cortical rhythms in cognition. Physiological reviews 2010; 90(3): 1195-1268.

615. Ozerdem A, Guntekin B, Saatci E, Tunca Z, Basar E. Disturbance in long distance gamma coherence in bipolar disorder. Prog Neuropsychopharmacol Biol Psychiatry 2010; 34(6): 861-865.

616. Ozerdem A, Guntekin B, Atagun I, Turp B, Basar E. Reduced long distance gamma $(28-48 \mathrm{~Hz})$ coherence in euthymic patients with bipolar disorder. J Affect Disord 2011; 132(3): 325-332. 
617. Lee PS, Chen YS, Hsieh JC, Su TP, Chen LF. Distinct neuronal oscillatory responses between patients with bipolar and unipolar disorders: a magnetoencephalographic study. J Affect Disord 2010; 123(1-3): 270-275.

618. Chen SS, Tu PC, Su TP, Hsieh JC, Lin YC, Chen LF. Impaired frontal synchronization of spontaneous magnetoencephalographic activity in patients with bipolar disorder. Neurosci Lett 2008; 445(2): 174-178.

619. Hall MH, Spencer KM, Schulze K, McDonald C, Kalidindi S, Kravariti E et al. The genetic and environmental influences of event-related gamma oscillations on bipolar disorder. Bipolar Disord 2011; 13(3): 260-271.

620. Donkers FC, Schwikert SR, Evans AM, Cleary KM, Perkins DO, Belger A. Impaired neural synchrony in the theta frequency range in adolescents at familial risk for schizophrenia. Front Psychiatry 2011; 2: 51.

621. Reite M, Teale P, Rojas DC, Reite E, Asherin R, Hernandez O. MEG auditory evoked fields suggest altered structural/functional asymmetry in primary but not secondary auditory cortex in bipolar disorder. Bipolar Disord 2009; 11(4): 371-381.

622. Uhlhaas PJ, Haenschel C, Nikolic D, Singer W. The role of oscillations and synchrony in cortical networks and their putative relevance for the pathophysiology of schizophrenia. Schizophr Bull 2008; 34(5): 927-943.

623. Farzan F, Barr MS, Levinson AJ, Chen R, Wong W, Fitzgerald PB et al. Evidence for gamma inhibition deficits in the dorsolateral prefrontal cortex of patients with schizophrenia. Brain 2010; 133(Pt 5): 1505-1514.

624. Lee SH, Kim DW, Kim EY, Kim S, Im CH. Dysfunctional gamma-band activity during face structural processing in schizophrenia patients. Schizophr Res 2010; 119(1-3): 191-197.

625. Grootens KP, van Veelen NM, Sitskoorn MM, Sabbe BG, Peuskens J, Buitelaar JK et al. Effects on cognitive functioning after olanzapine-ziprasidone crossover in recent-onset schizophrenia. Eur Neuropsychopharmacol 2010; 20(12): 907-912.

626. Woo TU, Spencer K, McCarley RW. Gamma oscillation deficits and the onset and early progression of schizophrenia. Harv Rev Psychiatry 2010; 18(3): 173-189.

627. Anver H, Ward PD, Magony A, Vreugdenhil M. NMDA receptor hypofunction phase couples independent gamma-oscillations in the rat visual cortex. Neuropsychopharmacology 2011; 36(2): 519-528.

628. Zimmermann R, Gschwandtner U, Wilhelm FH, Pflueger MO, Riecher-Rossler A, Fuhr P. EEG spectral power and negative symptoms in at-risk individuals predict transition to psychosis. Schizophr Res 2010; 123(2-3): 208-216.

629. Morrison PD, Nottage J, Stone JM, Bhattacharyya S, Tunstall N, Brenneisen R et al. Disruption of Frontal Theta Coherence by Delta(9)-Tetrahydrocannabinol is Associated with Positive Psychotic Symptoms. Neuropsychopharmacology 2011; 36(4): 827-836.

630. Takahashi T, Cho RY, Mizuno T, Kikuchi M, Murata T, Takahashi K et al. Antipsychotics reverse abnormal EEG complexity in drug-naive schizophrenia: a multiscale entropy analysis. Neuroimage 2010; 51(1): 173-182.

631. Pinault D. Dysfunctional Thalamus-Related Networks in Schizophrenia. Schizophr Bull 2011; 37(2): 238-243.

632. Ferrarelli F, Tononi G. The Thalamic Reticular Nucleus and Schizophrenia. Schizophr Bull 2011.

633. Meyer-Lindenberg A. From maps to mechanisms through neuroimaging of schizophrenia. Nature 2010; 468(7321): 194-202.

634. Uhlhaas PJ, Singer W. Abnormal neural oscillations and synchrony in schizophrenia. Nat Rev Neurosci 2010; 11(2): 100-113.

635. Minzenberg MJ, Firl AJ, Yoon JH, Gomes GC, Reinking C, Carter CS. Gamma Oscillatory Power is Impaired During Cognitive Control Independent of Medication Status in First-Episode Schizophrenia. Neuropsychopharmacology 2010.

636. Rolls ET, Deco G. A computational neuroscience approach to schizophrenia and its onset. Neurosci Biobehav Rev 2011; 35(8): 1644-1653. 
637. Lesh TA, Niendam TA, Minzenberg MJ, Carter CS. Cognitive control deficits in schizophrenia: mechanisms and meaning. Neuropsychopharmacology 2011; 36(1): 316-338.

638. Cole MW, Schneider W. The cognitive control network: Integrated cortical regions with dissociable functions. Neuroimage 2007; 37(1): 343-360.

639. Giersch A, Boucart M, Elliott M, Vidailhet P. Atypical behavioural effects of lorazepam: clues to the design of novel therapies? Pharmacol Ther 2010; 126(1): 94-108.

640. Doucet G, Naveau M, Petit L, Delcroix N, Zago L, Crivello F et al. Brain activity at rest: A multiscale hierarchical functional organization. Journal of neurophysiology 2011.

641. Raichle ME, MacLeod AM, Snyder AZ, Powers WJ, Gusnard DA, Shulman GL. A default mode of brain function. Proc Natl Acad Sci U S A 2001; 98(2): 676-682.

642. Greicius MD, Supekar K, Menon V, Dougherty RF. Resting-state functional connectivity reflects structural connectivity in the default mode network. Cereb Cortex 2009; 19(1): 72-78.

643. Greicius MD, Krasnow B, Reiss AL, Menon V. Functional connectivity in the resting brain: a network analysis of the default mode hypothesis. Proc Natl Acad Sci U S A 2003; 100(1): 253-258.

644. Calhoun VD, Maciejewski PK, Pearlson GD, Kiehl KA. Temporal lobe and "default" hemodynamic brain modes discriminate between schizophrenia and bipolar disorder. Hum Brain Mapp 2008; 29(11): 1265-1275.

645. Benjamin C, Lieberman, D.A., Chang, M., Ofen, N., Whitfield-Gabrieli, S., Gabrieli, J.D.E., Gaab, N. The influence of rest period instructions on the default mode network. Frontiers in human neuroscience 2010; 4(december 2010; doi: 10.3389/fnhum.2010.00218): 1-9.

646. Fox MD, Greicius M. Clinical applications of resting state functional connectivity. Frontiers in systems neuroscience 2011; 4: 19.

647. Buzsaki G, Draguhn A. Neuronal oscillations in cortical networks. Science 2004; 304(5679): $1926-$ 1929.

648. Sonuga-Barke EJ, Castellanos FX. Spontaneous attentional fluctuations in impaired states and pathological conditions: a neurobiological hypothesis. Neurosci Biobehav Rev 2007; 31(7): 977-986.

649. Wang J, Zuo X, He Y. Graph-based network analysis of resting-state functional MRI. Frontiers in systems neuroscience 2010; 4: 16.

650. Ferrarini L, Veer IM, Baerends E, van Tol MJ, Renken RJ, van der Wee NJ et al. Hierarchical functional modularity in the resting-state human brain. Hum Brain Mapp 2009; 30(7): 2220-2231.

651. Uddin LQ, Supekar K, Menon V. Typical and atypical development of functional human brain networks: insights from resting-state FMRI. Frontiers in systems neuroscience 2010; 4: 21.

652. Honey CJ, Sporns O, Cammoun L, Gigandet X, Thiran JP, Meuli R et al. Predicting human restingstate functional connectivity from structural connectivity. Proc Natl Acad Sci U S A 2009; 106(6): 2035-2040.

653. Jerbi K, Vidal JR, Ossandon T, Dalal SS, Jung J, Hoffmann D et al. Exploring the electrophysiological correlates of the default-mode network with intracerebral EEG. Frontiers in systems neuroscience 2010; 4: 27.

654. Northoff G, Walter M, Schulte RF, Beck J, Dydak U, Henning A et al. GABA concentrations in the human anterior cingulate cortex predict negative BOLD responses in fMRI. Nat Neurosci 2007; 10(12): 1515-1517.

655. Northoff G, Qin, P., Nakao, T. Rest-stimulus interaction in the brain: a review. Trends in Neurosciences 2010; 33: 277-284.

656. Broyd SJ, Demanuele C, Debener S, Helps SK, James CJ, Sonuga-Barke EJ. Default-mode brain dysfunction in mental disorders: a systematic review. Neurosci Biobehav Rev 2009; 33(3): 279-296.

657. Leech R, Kamourieh S, Beckmann CF, Sharp DJ. Fractionating the default mode network: distinct contributions of the ventral and dorsal posterior cingulate cortex to cognitive control. J Neurosci 2011; 31(9): 3217-3224.

658. Douw L, Schoonheim MM, Landi D, van der Meer ML, Geurts JJ, Reijneveld JC et al. Cognition is related to resting-state small-world network topology: an magnetoencephalographic study. Neuroscience 2011. 
659. Weissman-Fogel I, Moayedi M, Taylor KS, Pope G, Davis KD. Cognitive and default-mode resting state networks: do male and female brains "rest" differently? Hum Brain Mapp 2010; 31(11): 17131726.

660. Grady CL, Protzner AB, Kovacevic N, Strother SC, Afshin-Pour B, Wojtowicz M et al. A multivariate analysis of age-related differences in default mode and task-positive networks across multiple cognitive domains. Cereb Cortex 2010; 20(6): 1432-1447.

661. Spreng RN, Stevens WD, Chamberlain JP, Gilmore AW, Schacter DL. Default network activity, coupled with the frontoparietal control network, supports goal-directed cognition. Neuroimage 2010; 53(1): 303-317.

662. Sadaghiani S, Hesselmann G, Friston KJ, Kleinschmidt A. The relation of ongoing brain activity, evoked neural responses, and cognition. Frontiers in systems neuroscience 2010; 4: 20.

663. Stawarczyk D, Majerus S, Maquet P, D’Argembeau A. Neural correlates of ongoing conscious experience: both task-unrelatedness and stimulus-independence are related to default network activity. PLoS One 2011; 6(2): e16997.

664. Fingelkurts AA. Persistent operational synchrony within brain default-mode network and selfprocessing operations in healthy subjects. Brain Cogn 2011; 75(2): 79-90.

665. Lloyd D. Neural correlates of temporality: Default mode variability and temporal awareness. Conscious Cogn 2011.

666. Esposito F, Aragri A, Latorre V, Popolizio T, Scarabino T, Cirillo S et al. Does the default-mode functional connectivity of the brain correlate with working-memory performances? Archives italiennes de biologie 2009; 147(1-2): 11-20.

667. Christoff K, Gordon AM, Smallwood J, Smith R, Schooler JW. Experience sampling during fMRI reveals default network and executive system contributions to mind wandering. Proc Natl Acad Sci US A 2009; 106(21): 8719-8724.

668. Weissman DH, Roberts KC, Visscher KM, Woldorff MG. The neural bases of momentary lapses in attention. Nat Neurosci 2006; 9(7): 971-978.

669. Fassbender C, Zhang H, Buzy WM, Cortes CR, Mizuiri D, Beckett L et al. A lack of default network suppression is linked to increased distractibility in ADHD. Brain Res 2009; 1273: 114-128.

670. Northoff G, Qin P. How can the brain's resting state activity generate hallucinations? A 'resting state hypothesis' of auditory verbal hallucinations. Schizophr Res 2011; 127(1-3): 202-214.

671. Jang JH, Jung WH, Choi JS, Choi CH, Kang DH, Shin NY et al. Reduced prefrontal functional connectivity in the default mode network is related to greater psychopathology in subjects with high genetic loading for schizophrenia. Schizophr Res 2011; 127(1-3): 58-65.

672. Veer IM, Beckmann CF, van Tol MJ, Ferrarini L, Milles J, Veltman DJ et al. Whole brain restingstate analysis reveals decreased functional connectivity in major depression. Frontiers in systems neuroscience 2010; 4.

673. Northoff G, Wiebking C, Feinberg T, Panksepp J. The 'resting-state hypothesis' of major depressive disorder-a translational subcortical-cortical framework for a system disorder. Neurosci Biobehav Rev 2011; 35(9): 1929-1945.

674. Anand A, Li Y, Wang Y, Lowe MJ, Dzemidzic M. Resting state corticolimbic connectivity abnormalities in unmedicated bipolar disorder and unipolar depression. Psychiatry Res 2009; 171(3): 189198.

675. Dickstein DP, Gorrostieta C, Ombao H, Goldberg LD, Brazel AC, Gable CJ et al. Fronto-temporal spontaneous resting state functional connectivity in pediatric bipolar disorder. Biol Psychiatry 2010; 68(9): 839-846.

676. Chai XJ, Whitfield-Gabrieli S, Shinn AK, Gabrieli JD, Nieto Castanon A, McCarthy JM et al. Abnormal medial prefrontal cortex resting-state connectivity in bipolar disorder and schizophrenia. Neuropsychopharmacology 2011; 36(10): 2009-2017.

677. Pomarol-Clotet E, Moro N, Sarro S, Goikolea JM, Vieta E, Amann B et al. Failure of de-activation in the medial frontal cortex in mania: evidence for default mode network dysfunction in the disorder. World J Biol Psychiatry 2011.

678. Shim G, Oh JS, Jung WH, Jang JH, Choi CH, Kim E et al. Altered resting-state connectivity in subjects at ultra-high risk for psychosis: an fMRI study. Behav Brain Funct 2010; 6: 58. 
679. Whitfield-Gabrieli S, Thermenos HW, Milanovic S, Tsuang MT, Faraone SV, McCarley RW et al. Hyperactivity and hyperconnectivity of the default network in schizophrenia and in first-degree relatives of persons with schizophrenia. Proc Natl Acad Sci U S A 2009; 106(4): 1279-1284.

680. Skudlarski P, Jagannathan K, Anderson K, Stevens MC, Calhoun VD, Skudlarska BA et al. Brain connectivity is not only lower but different in schizophrenia: a combined anatomical and functional approach. Biol Psychiatry 2010; 68(1): 61-69.

681. Woodward ND, Rogers B, Heckers S. Functional resting-state networks are differentially affected in schizophrenia. Schizophr Res 2011; 130(1-3): 86-93.

682. Pomarol-Clotet E, Salvador R, Sarro S, Gomar J, Vila F, Martinez A et al. Failure to deactivate in the prefrontal cortex in schizophrenia: dysfunction of the default mode network? Psychol Med 2008; 38(8): 1185-1193.

683. Salgado-Pineda P, Fakra E, Delaveau P, McKenna PJ, Pomarol-Clotet E, Blin O. Correlated structural and functional brain abnormalities in the default mode network in schizophrenia patients. Schizophr Res 2011; 125(2-3): 101-109.

684. Hasenkamp W, James GA, Boshoven W, Duncan E. Altered engagement of attention and default networks during target detection in schizophrenia. Schizophr Res 2011; 125(2-3): 169-173.

685. Kim DI, Manoach DS, Mathalon DH, Turner JA, Mannell M, Brown GG et al. Dysregulation of working memory and default-mode networks in schizophrenia using independent component analysis, an fBIRN and MCIC study. Hum Brain Mapp 2009; 30(11): 3795-3811.

686. Schneider FC, Royer A, Grosselin A, Pellet J, Barral FG, Laurent B et al. Modulation of the default mode network is task-dependant in chronic schizophrenia patients. Schizophr Res 2011; 125(2-3): 110-117.

687. Kuntsi J, Wood AC, Rijsdijk F, Johnson KA, Andreou P, Albrecht B et al. Separation of cognitive impairments in attention-deficit/hyperactivity disorder into 2 familial factors. Arch Gen Psychiatry 2010; 67(11): 1159-1167.

688. Sambataro F, Blasi G, Fazio L, Caforio G, Taurisano P, Romano R et al. Treatment with olanzapine is associated with modulation of the default mode network in patients with Schizophrenia. Neuropsychopharmacology 2010; 35(4): 904-912.

689. Lui S, Li T, Deng W, Jiang L, Wu Q, Tang H et al. Short-term effects of antipsychotic treatment on cerebral function in drug-naive first-episode schizophrenia revealed by "resting state" functional magnetic resonance imaging. Arch Gen Psychiatry 2010; 67(8): 783-792.

690. Delaveau P, Jabourian M, Lemogne C, Guionnet S, Bergouignan L, Fossati P. Brain effects of antidepressants in major depression: A meta-analysis of emotional processing studies. J Affect Disord 2011; 130(1-2): 66-74.

691. Tregellas JR, Tanabe J, Rojas DC, Shatti S, Olincy A, Johnson L et al. Effects of an Alpha 7-Nicotinic Agonist on Default Network Activity in Schizophrenia. Biol Psychiatry 2010.

692. Minzenberg MJ, Yoon JH, Carter CS. Modafinil modulation of the default mode network. Psychopharmacology (Berl) 2011; 215(1): 23-31.

693. Tanabe J, Nyberg E, Martin LF, Martin J, Cordes D, Kronberg E et al. Nicotine effects on default mode network during resting state. Psychopharmacology (Berl) 2011; 216(2): 287-295.

694. Sohal VS, Zhang F, Yizhar O, Deisseroth K. Parvalbumin neurons and gamma rhythms enhance cortical circuit performance. Nature 2009; 459(7247): 698-702.

695. Gandal MJ, Edgar JC, Klook K, Siegel SJ. Gamma synchrony: Towards a translational biomarker for the treatment-resistant symptoms of schizophrenia. Neuropharmacology 2011.

696. Allen M, Williams, G. Conciousness, plasticity, and connectomics: the role of intersubjectivity in human cognition. Frontiers in psychology 2011; 2(February 2011): 1-16.

697. Dayan P, Hinton GE, Neal RM, Zemel RS. The Helmholtz machine. Neural Comput 1995; 7(5): 889904.

698. Carhart-Harris RL, Friston KJ. The default-mode, ego-functions and free-energy: a neurobiological account of Freudian ideas. Brain 2010; 133(Pt 4): 1265-1283.

699. Marenco S, Savostyanova AA, van der Veen JW, Geramita M, Stern A, Barnett AS et al. Genetic modulation of GABA levels in the anterior cingulate cortex by GAD1 and COMT. Neuropsychopharmacology 2010; 35(8): 1708-1717. 
700. Brown AB, Biederman J, Valera E, Makris N, Doyle A, Whitfield-Gabrieli S et al. Relationship of DAT1 and adult ADHD to task-positive and task-negative working memory networks. Psychiatry Res 2011; 193(1): 7-16.

701. Pomarol-Clotet E, Fatjo-Vilas M, McKenna PJ, Monte GC, Sarro S, Ortiz-Gil J et al. COMT Val158Met polymorphism in relation to activation and de-activation in the prefrontal cortex: A study in patients with schizophrenia and healthy subjects. Neuroimage 2010; 53(3): 899-907.

702. Liu B, Song M, Li J, Liu Y, Li K, Yu C et al. Prefrontal-related functional connectivities within the default network are modulated by COMT val158met in healthy young adults. J Neurosci 2010; 30(1): 64-69.

703. Tan HY, Chen Q, Sust S, Buckholtz JW, Meyers JD, Egan MF et al. Epistasis between catechol-Omethyltransferase and type II metabotropic glutamate receptor 3 genes on working memory brain function. Proc Natl Acad Sci U S A 2007; 104(30): 12536-12541.

704. Prata DP, Mechelli A, Fu CH, Picchioni M, Toulopoulou T, Bramon E et al. Epistasis between the DAT 3' UTR VNTR and the COMT Val158Met SNP on cortical function in healthy subjects and patients with schizophrenia. Proc Natl Acad Sci U S A 2009; 106(32): 13600-13605.

705. Schlosser R, Koch K, Wagner G, Schultz C, Robel M, Schachtzabel C et al. Intensive practice of a cognitive task is associated with enhanced functional integration in schizophrenia. Psychol Med 2009; 39(11): 1809-1819.

706. Haut KM, Lim KO, MacDonald A, 3rd. Prefrontal cortical changes following cognitive training in patients with chronic schizophrenia: effects of practice, generalization, and specificity. Neuropsychopharmacology 2010; 35(9): 1850-1859.

707. Wallace DL, Vytlacil JJ, Nomura EM, Gibbs SE, D’Esposito M. The dopamine agonist bromocriptine differentially affects fronto-striatal functional connectivity during working memory. Front Hum Neurosci 2011; 5: 32.

708. Young JW, Geyer MA. Action of modafinil--increased motivation via the dopamine transporter inhibition and D1 receptors? Biol Psychiatry 2010; 67(8): 784-787.

709. Vinkers CH, Mirza NR, Olivier B, Kahn RS. The inhibitory GABA system as a therapeutic target for cognitive symptoms in schizophrenia: investigational agents in the pipeline. Expert Opin Investig Drugs 2010; 19(10): 1217-1233.

710. Ritsner MS, Gibel A, Ratner Y, Tsinovoy G, Strous RD. Improvement of sustained attention and visual and movement skills, but not clinical symptoms, after dehydroepiandrosterone augmentation in schizophrenia: a randomized, double-blind, placebo-controlled, crossover trial. J Clin Psychopharmacol 2006; 26(5): 495-499. 



\section{Samenvatting}

De bipolaire stoornis wordt, uiteraard, gekenmerkt door stemmingswisselingen, maar lijkt in toenemende mate ook te karakteriseren door wisselende cognitieve verschijnselen. Deze treden niet alleen op tijdens een stemmingsepisode, maar kunnen bij een aanzienlijk deel van de patiënten persisteren tijdens de euthyme fase van hun ziekte.

Dit proefschrift beschrijft een aantal onderzoeken gericht op mogelijke determinanten van deze wisselende cognitieve functiestoornissen en het beloop ervan in de tijd.

In het inleidende Hoofdstuk 1 wordt de literatuur over de relatie tussen de bipolaire stoornis en het optreden van cognitieve symptomen kort besproken. Het belang van deze symptomen voor ziektebeloop- en uitkomst, en het optreden tijdens stemmingsepisoden (depressie en (hypo-)manie) en tijdens euthyme periodes passeren de revue. Daarnaast lijken cognitieve problemen bij eerstegraads familieleden van bipolaire patiënten voor te komen, wijzend op de mogelijkheid dat cognitieve stoornissen een uiting zijn van de genetische kwetsbaarheid voor de ziekte ("endofenotype"). Tenslotte komt de overlap met schizofrenie aan de orde, waarbij de hypothese is dat er alleen kwantitatieve en geen kwalitatieve verschillen zijn in cognitieve stoornissen bij beide aandoeningen.

Hoofdstuk 2 beschrijft een meta-analyse van de literatuur naar cognitief functioneren bij patiënten met schizofrenie en bipolaire stoornis. In het algemeen presteren patiënten met een bipolaire stoornis beter op cognitieve taken dan schizofrenie patiënten, waarbij sprake is van heterogeniteit en kleine verschillen. Er zijn echter geen duidelijke kwalitatieve verschillen in cognitief functioneren tussen de beide groepen patiënten.

Een tweede meta-analyse wordt beschreven in Hoofdstuk 3, waarin is gekeken naar de literatuur met betrekking tot cognitieve functiestoornissen bij euthyme bipolaire patiënten en hun eerstegraads familieleden. Bipolaire patiënten laten relatief grote cognitieve defecten zien op het gebied van werkgeheugen, snelheid van informatieverwerking en verbaal geheugen. Familieleden hebben duidelijk minder ernstige cognitieve functiestoornissen, die met name op het gebied van de executieve functies aanwezig zijn. Dit onderzoek geeft slechts beperkte aanwijzingen voor het bestaan van cognitieve stoornissen als endofenotype. 
De overlap met schizofrenie en het cognitief functioneren in familieleden wordt verder onderzocht in Hoofdstuk 4, waarin de rol van psychotische symptomen centraal staat. Familieleden bleken op cognitieve taken even goed te presteren als gezonde controleproefpersonen, hetgeen tegen de endofenotype-hypothese pleit. Familieleden van bipolaire patiënten met een psychose in de voorgeschiedenis bleken beter te presteren, waarbij in de groep familieleden een verband werd gevonden tussen de aanwezigheid van subklinische psychotische symptomen en beter cognitief functioneren. Bij bipolaire patiënten werd een soortgelijk verband gevonden tussen psychose en cognitief functioneren. Een consistente bevinding bij patiënten met schizofrenie is dat er geen negatieve associatie bestaat tussen positieve symptomen van psychose en neurocognitieve stoornissen; de bevindingen bij bipolaire patiënten en hun familieleden passen hierbij. Dit gegeven vormt een anwijzing voor de overlappende kwetsbaarheid voor schizofrenie en de bipolaire stoornis.

Hoofdstuk 5 beschrijft een longitudinaal, 2 jaar durend onderzoek naar het beloop en de determinanten van het cognitief functioneren in een cohort van 76 patienten met een bipolaire (spectrum)stoornis, die elke 2 maande neuropsychologisch werden getest. Op baseline presteren bipolaire patiënten op alle cognitieve taken slechter dan gezonde controleproefpersonen, waarbij de verschillen echter over het algemeen klein zijn. Met name de volgehouden aandacht lijkt gestoord te zijn bij patiënten met een bipolaire stoornis. Gedurende de 2 jaar van het onderzoek blijkt het cognitief functioneren sterk te varieren, gepaard gaande met subjectieve cognitieve klachten en beperkingen in het dagelijks leven. De volgehouden aandacht en snelheid van motorische reacties laten de minste variatie in de loop der tijd zien. Biografische variabelen, als leeftijd, geslacht en opleiding, hadden slechts een kleine voorspellende waarde op het beloop van het cognitief functioneren, evenals ziektekenmerken (aantal episodes; ziekteduur etc.), symptomen (depressie, manie, psychose) en schildklierfunctie. Medicatie bleek eveneens weinig tot geen effect te hebben op cognitief functioneren bij bipolaire patiënten met uitzondering van een negatief effect van atypische antipsychotica op snelheid van motoriek en informatieverwerking.

Gezien bovenstaande, variatie in cognitief functioneren die (bijna) niet verklaard kan worden door klinische variabelen, werd in Hoofdstuk 6 en 7 de mogelijke rol van genetische factoren nader onderzocht.

Hoofdstuk 6 beschrijft de invloed van het CACNA1C rs1006737 risico allel op cognitief functioneren van bipolaire patiënten. Dit gen(-polymorfisme) is het best onderzocht en het sterkst geassocieerd met het risico op een bipolaire stoornis; het speelt mogelijk een rol bij de membraanstabiliteit van neuronen via effecten op de calciumkanalen. Er blijkt een associatie te bestaan tussen dit risico allel en slechter cognitief functioneren in patiënten met een bipolaire stoornis; een dergelijk verband werd niet gevonden in een groep familieleden en gezonde controlepersonen.

Het mogelijk nadelige effect van antipsychotica op de cognitieve prestaties van bipolaire patiënten werd nader onderzocht in Hoofdstuk 7, waarin werd gekeken naar de eventueel modererende invloed van het COMT gen. Dit gen speelt een rol bij 
de regulatie van de (prefrontale) dopaminerge neurotransmissie; een belangrijk aangrijpingspunt van antipsychotica. Het COMTVal ${ }^{108 / 158}$ Met rs 4680 genotype bleek te interacteren met gebruik van antipsychotica, in die zin dat een toename van het Val allel, leidend tot verminderde beschikbaarheid van dopamine, gepaard ging met een toename van het negatieve effect van deze middelen op cognitief functioneren.

In Hoofdstuk 8, tenslotte, wordt een samenvatting gegeven van de voornaamste bevindingen van dit proefschrift. In de Discussie komen de rol van psychose en neurobiologische verklaringsmodellen van cognitief functioneren aan de orde. Gezien de overlap in cognitief (dis-)functioneren bij patiënten met schizofrenie en een bipolaire stoornis lijkt er een centrale rol weggelegd voor psychose als "epifenomeen" van een ernstigere vorm van de bipolaire stoornis, gepaard gaande met meer vroege neurobiologische veranderingen in het brein en (ernstigere) cognitieve stoornissen, analoog aan de veranderingen die bij schizofrenie worden gezien. Psychose wordt dan opgevat als een dimensioneel concept, waarbij naast positieve symptomen, onder andere negatieve en cognitieve symptoomdimensies worden onderscheiden volgens het zogenaamde "salience dysregulation syndrome".

Een netwerkmodel, onder andere gekenmerkt door een disbalans tussen subcorticale hyperactiviteit en verminderde prefrontale modulatie van hersengebieden betrokken bij de adaptieve regulatie van emoties en cognitie, wordt beschreven. Centraal in dit model staat verlies van GABA-erge interneuronen, essentieel voor inhibitoire regulatie en synchronisatie van breinactiviteit, die een belangrijke rol spelen bij cognitieve processen en de veronderstelde disfunctie van zogenaamde "default" neuronale netwerken. Deze netwerken hebben in interactie met andere neuronale netwerken een regulerende en modulerende rol bij emotionele en cognitieve adaptieve processen.

Concluderend lijkt bij de bipolaire stoornis in een aanzienlijk deel van de patiënten sprake te zijn van, matig ernstige, persisterende cognitieve functiestoornissen, die varieren in de tijd, effect hebben op het beloop van de ziekte, kwantitatief verschillen van cognitieve stoornissen bij schizofrenie, en slechts zeer ten dele verklaard kunnen worden door klinische variabelen. Deze aspecifieke cognitieve functiestoornissen zijn mogelijk ernstiger bij psychotische bipolaire patiënten, gepaard gaande met vroege, eveneens aspecifieke neurobiologische afwijkingen in het brein. Disconnectiviteit, disbalans en verlies van GABA-erge interneuronen spelen onder andere een rol bij deze afwijkingen in neurale netwerken, die ontstaan door (epi-)genetische interacties met omgevingsfactoren als, bijvoorbeeld, stress en medicatie. 



\section{Tegen wil-en dankwoord}

"Een proefschrift schrijf je niet alleen", zo wil het cliché. In dit geval echter wel; ik heb talloze zondagochtenden in grote eenzaamheid en afzondering doorgebracht in het azM om dit boekje te voltooien. Tijdens het schrijven riep een zin vaak een tegenzin op, waardoor ik regelmatig de zinnen heb moeten verzetten. Mede hierdoor heeft een en ander een zekere vertraging opgelopen, waarbij het langzaam tot expressie komen van genen ook een belangrijke rol heeft gespeeld.

Opgelucht wil ik dan ook een aantal mensen bedanken die direct of indirect hebben bijgedragen aan de afronding van dit proefschrift. Op de eerste plaats bedank ik Nienke Jabben, zonder wie dit proefschrift en het onderzoek waarop het gebaseerd is zeker niet tot stand zouden zijn gekomen. Zij was de drijvende kracht achter het onderzoek en heeft de data verzameld door alle patiënten en familieleden neuropsychologisch te onderzoeken. Haar inzet, humor en relativeringsvermogen waardeer ik zeer, evenals haar klinische blik en gezond verstand; eigenschappen die vaak node worden gemist in de wetenschap en in de psychiatrie in het bijzonder. Daarnaast bedank ik mijn promotor, Jim van Os, en copromotor, Lydia Krabbendam, die, zij het op enige afstand, vanuit hun ivoren torens heel verstandige dingen hebben gezegd en me, zonodig, hebben aangemoedigd. Lydia heeft aan de wieg gestaan van dit proefschrift en de boel op stapel gezet; helaas vertrok ze voortijdig naar het verre Amsterdam. Jim bestiert als 3-sterren kok al jarenlang met veel succes een wetenschappelijk bedrijf. Ik ben hem erkentelijk dat ik een kijkje in de keuken heb mogen nemen en mijn eigen menu heb kunnen samen stellen; mijn voorkeur gaat echter uit naar eten en niet naar koken. Een bijzonder woord van dank gaat uit naar Marjan Drukker, die me heeft behoedt voor een statistische misser van formaat, en Ruud van Winkel die me attendeerde op CACNA1C. Claudia Simons, tenslotte, heeft het stokje van Nienke overgenomen en me kordaat en snel van repliek gediend met betrekking tot de genartikelen, waarvoor dank. De vaak enthousiaste deelnemers aan dit onderzoek wil ik uiteraard ook graag bedanken voor hun inzet om, in 2 jaar tijd, 12 keer de gang naar het azM te maken om (langdurig) neuropsychologisch onderzoek te ondergaan; een uitzonderlijke prestatie waarvoor hartelijk dank.

De beoordelingscommissie wil ik graag hartelijk danken voor hun positieve oordeel.

Mijn paranimfen Jan en Franz dank ik hartelijk voor hun inspanningen, steun en vriendschap. 
Tenslotte wil ik allen bedanken die vrijwillig of onvrijwillig hebben meegeleefd en mee- geleden; met name voor hun geduld en, af en toe pijnlijke, belangstelling ben ik ze erkentelijk. Dank aan collega- psychiaters, verpleegkundigen, secretaresses (met name Jolien en Elsa), arts-assistenten, familieleden en, last but not least, het thuisfront. Camiel, Wayan en Tarzan dank voor jullie Oosterse berusting, ongeveinsde desinteresse en geduld. Petra bedankt voor je niet aflatende intensieve thuiszorg en "dwingende" stimulans om op te schieten; het is volbracht. 


\section{Curriculum Vitae}

Baer Arts werd geboren op 25 oktober 1960 te Helmond. In 1979 behaalde hij het VWO diploma aan het Fivelcollege te Delfzijl. In Groningen studeerde hij psychologie van 1979 tot 1986 en geneeskunde van 1982 tot 1988. Na de opleiding tot psychiater in Maastricht, werkt hij sinds 1998 als psychiater in het academisch ziekenhuis Maastricht. 